Pacific Northwest National Laboratory

Operated by Battelle for the U.S. Department of Energy

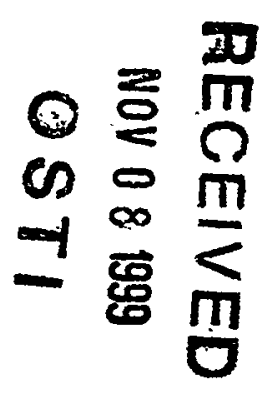

\section{Property Data for Simulated Americium/Curium Glasses}

\author{
J. D. Vienna \\ M. J. Schweiger \\ B.J. Riley \\ D. E. Smith \\ Pacific Northreest National Laboratory, Ricbland, Washington 99352 \\ D. K. Peeler \\ I. A. Reamer \\ Savannab River Technology Center, Aiken, South Carolina 29808
}

October 1999

Prepared for the U.S. Department of Energy under Contract DE-AC06-76RLO 1830 


\title{
DISCLAIMER
}

This report was prepared as an account of work sponsored by an agency of the United States Government. Neither the United States Government nor any agency thereof, nor Battelle Memorial Institute, nor any of their employees, makes any warranty, expressed or implied, or assumes any legal liability or responsibility for the accuracy, completeness, or usefulness of any information, apparatus, product, or process disclosed, or represents that its use would not infringe privately owned rights. Reference herein to any specific commercial product, process, or service by trade name, trademark, manufacturer, or - otherwise does not necessarily constitute or imply its endorsement, recommendation, or favoring by the United States Government or any agency thereof, or Battelle Memorial Institute. The views and opinions of authors expressed herein do not necessarily state or reflect those of the United States Government or any agency thereof.

\section{PACIFIC NORTHWEST NATIONAL LABORATORY \\ ' operated by \\ BATTELLE MEMORIAL INSTITUTE \\ for the \\ UNITED STATES DEPARTMENT OF ENERGY \\ under Contract DE-ACO6-76RLO 1830}

\author{
Printed in the United States of America \\ Available to DOE and DOE contractors from the \\ Office of Scientific and Technical Information, P.O. Box 62, Oak Ridge, TN 37831; \\ prices available from (615) 576-8401.
}

Available to the public from the National Technical Information Service, U.S. Department of Commerce, 5285 Port Royal Rd., Springfield, VA 22161

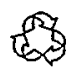
This document was printed on recycled paper. 


\section{DISCLAIMER}

Portions of this document may be illegible in electronic image products. Images are produced from the best available original document. 


\title{
Property Data for Simulated Americium/Curium Glasses
}

\author{
J.D. Vienna \\ B.J. Riley \\ M. J. Schweiger \\ D. E. Smith \\ Pacific Nortbrest National Laboratory, Ricbland, Washington 99352 \\ D. K. Peeler \\ I. A. Reamer \\ †Savannab River Technology Center, Aiken, South Carolina 29808
}

October 1999

Prepared for the U.S. Department of Energy under Contract DE-AC06-76RLO 1830

Pacific Northwest National Laboratory

Richland, Washington 99352 
. 


\section{Summary}

We studied the properties of mixed lanthanide-alumino-borosilicate glasses. Fifty-five glasses were designed to augment a previous, Phase I, study by systematically varying the composition of $\mathrm{Ln}_{2} \mathrm{O}_{3}$ and the concentrations of $\mathrm{Ln}_{2} \mathrm{O}_{3}, \mathrm{SiO}_{2}, \mathrm{~B}_{2} \mathrm{O}_{3}, \mathrm{Al}_{2} \mathrm{O}_{3}$, and $\mathrm{SrO}$ in glass. These glasses were designed and fabricated at the Savannah River Technology Center and tested at the Pacific Northwest National Laboratory. The properties measured include the hightemperature viscosity $(\eta)$ as a function of temperature $(T)$ and the liquidus temperature $\left(T_{L}\right)$ of Phase II test glasses.

The $\mathrm{T}_{\mathrm{L}}$ of the 55 Phase II glasses were between $1153^{\circ} \mathrm{C}(\mathrm{AC} 2-52)$ and $1405^{\circ} \mathrm{C}$ (AC204). Only two glasses had $T_{L} S$ above the $1350^{\circ} \mathrm{C}$ limit, $A C 2-04$ and $A C 2-18$. Two crystal types, rare earth silicates (RESs) and aluminum oxide $\left(\mathrm{Al}_{2} \mathrm{O}_{3}\right)$, were identified as the primary crystalline phases in the Phase II glasses using a combination of X-ray diffraction (XRD), scanning electron microscopy (SEM) with energy dispersive spectroscopy (EDS), and optical microscopy (OM). This differs from Phase I glasses in which RES and aluminosilicate (AlS) crystals were found and $\mathrm{Al}_{2} \mathrm{O}_{3}$ was not. These data are summarized in Table S.1. Appendix A (Glass Property Measurements) contains the detailed explanation of $T_{L}$ measurements for each glass, including $T_{L}$ measurement data, $O M$ and SEM micrographs, and analyses results from $\mathrm{XRD}$ and EDS.

RES was the primary phase in 47 of the 55 glasses; however, we observed four distinct morphologies of the RES when identifying these crystals: needle-like (thin and straight), hairlike (thin and wavy), plate-like, and rectangular cap. Crystals with each of the different morphologies were analyzed using SEM/EDS. EDS data showed $\mathrm{Si}, \mathrm{La}, \mathrm{Nd}$, and $\mathrm{O}$ as major components and $\mathrm{Ce}, \mathrm{Pr}, \mathrm{Sm}, \mathrm{Gd}$, and $\mathrm{Er}$ as minor components in the crystals. $\mathrm{Al}$ is present as a minor component in some crystals, but not in others. Chemically, the RES crystals are the same regardless of morphology. Samples analyzed by XRD matched the crystal structure of neodymium germanium borate silicate $\left(\mathrm{Nd}_{3} \mathrm{BGe}_{1.08} \mathrm{Si}_{0.92} \mathrm{O}_{10}\right)$. In this crystal structure, Ge could be replaced by $\mathrm{Si}$ and $\mathrm{Nd}$ could be replaced by rare earth elements to form $\mathrm{RE}_{3} \mathrm{BSi}_{2} \mathrm{O}_{10}$, the crystal type that is probably present in these samples. Generally, the glasses within the RES primary phase field showed massive crystallinity (i.e., $>30 \mathrm{vol} \%$ RES) after a $24 \mathrm{~h}$ heat treatment at temperatures between $3^{\circ} \mathrm{C}$ and $30^{\circ} \mathrm{C}$ below $\mathrm{T}_{\mathrm{L}}$. As RES crystals are difficult to redissolve once crystallized, this observation should be considered when planning for off-normal operating scenarios.

Aluminum oxide crystals were found as the primary phase in eight glasses. Two distinct $\mathrm{Al}_{2} \mathrm{O}_{3}$ crystals formed concurrently, a plate-like crystal and a garnet shaped crystal. SEM/EDS identified both crystal types with high aluminum and oxygen and did not make any differentiation as to chemical composition. The structures of these crystals were not determinable by XRD; therefore, it is not understood whether there is more than one $\mathrm{Al}_{2} \mathrm{O}_{3}$ crystal structure.

The $\eta$ - $\mathrm{T}$ relationship was measured for Phase II glasses using a high-temperature spindle viscometer. Generally, the data did not conform to the standard $\eta-T$ relationship as found in most silicate glasses (described by the Vogel-Tamman-Fulcher model). The viscosity values at 
$1350^{\circ} \mathrm{C}\left(\eta_{1350}\right)$ for Phase II glasses were estimated by a linear interpolation of $\ln \left[\eta_{1350}\right]$ vs $1 / \mathrm{T}$ for either 1) the entire data set for glasses displaying nearly linear $\ln [\eta]-1 / T$ behavior or 2) the data points taken on either side of $1350^{\circ} \mathrm{C}$ for glasses displaying non-linear $\ln [\eta]-1 / \mathrm{T}$ behavior and the data was available.

The $\eta_{1350}$ values of Phase II test glasses range from 0.57 Pa.s for AC2-03 to 2.21 Pa.s for AC2-07, both exterior vertex glasses. All Phase II glasses passed the $0.3 \mathrm{~Pa} \cdot \mathrm{s}$ to $2.4 \mathrm{~Pa} \cdot \mathrm{s}$ limit on $\eta_{1350}$. The $\eta_{1350}$ values are listed in Table $S .1$ for these glasses. A roughly linear relationship between $\mathrm{Ln}_{2} \mathrm{O}_{3}$ concentration in glass and the $\ln \left[\eta_{1350}\right]$ value was shown for Phase II glasses consistent with that found with Phase I glasses.

Table S.1. $T_{L}\left({ }^{\circ} \mathrm{C}\right)$, Primary Crystalline Phase, and $\eta_{1350}(\mathrm{~Pa} \cdot \mathrm{s})$ for Test Glasses

\begin{tabular}{|c|c|c|c|c|c|c|}
\hline Glass & $\mathrm{T}_{\mathrm{L}}$ & Phase & $\eta_{1350}$ & Glass & $\mathrm{T}_{\mathrm{L}}$ Phase & $\eta_{1350}$ \\
\hline AC2-01 & 1308 & RES & 1.44 & $\mathrm{AC} 2-29$ & $1300 \mathrm{RES}$ & 0.66 \\
\hline $\mathrm{AC} 2-02$ & 1257 & $\mathrm{Al}_{2} \mathrm{O}_{3}$ & 0.81 & $A C 2-30$ & 1227 RES & 1.35 \\
\hline $\mathrm{AC} 2-03$ & 1313 & RES & 0.57 & AC2-31 & 1305 RES & 1.49 \\
\hline AC2-04 & 1405 & RES & (1) & AC2-32 & 1264 RES & 1.18 \\
\hline $\mathrm{AC} 2-05$ & 1241 & RES & 2.20 & AC2-33 & 1271 RES & 1.17 \\
\hline $\mathrm{AC} 2-06$ & 1309 & RES & 0.70 & AC2-34 & 1232 RES & 1.44 \\
\hline AC2-07 & 1209 & RES & 2.21 & $\mathrm{AC} 2-35$ & 1289 RES & 1.08 \\
\hline AC2-08 & 1242 & RES & 1.70 & $\mathrm{AC} 2-36$ & 1294 RES & 1.03 \\
\hline AC2-09 & 1323 & RES & 0.79 & AC2-37 & 1305 RES & 0.96 \\
\hline$A C 2-10$ & 1255 & RES & 1.29 & AC2-38 & 1308 RES & 0.95 \\
\hline $\mathrm{AC} 2-11$ & 1292 & $\mathrm{Al}_{2} \mathrm{O}_{3}$ & 0.96 & AC2-39 & 1318 RES & 0.91 \\
\hline AC2-12 & 1333 & RES & 1.42 & AC $2-40$ & 1325 RES & 0.91 \\
\hline $\mathrm{AC} 2-13$ & 1181 & RES & 1.86 & AC2-41 & 1324 RES & 0.87 \\
\hline AC2-14 & 1250 & $\mathrm{Al}_{2} \mathrm{O}_{3}$ & 0.89 & AC2-42 & 1180 RES & 1.75 \\
\hline$A C 2-15$ & 1279 & RES & 1.33 & $\mathrm{AC} 2-43$ & 1227 RES & 1.32 \\
\hline $\mathrm{AC} 2-16$ & 1298 & $\mathrm{Al}_{2} \mathrm{O}_{3}$ & 1.09 & AC2-44 & 1305 RES & 0.94 \\
\hline $\mathrm{AC} 2-17$ & 1273 & RES & 1.14 & AC2-45 & 1259 RES & 1.10 \\
\hline AC2-18 & 1366 & RES & (1) & $\mathrm{AC} 2-46$ & 1333 RES & 0.80 \\
\hline $\mathrm{AC} 2-19$ & 1249 & RES & 1.39 & AC2-47 & 1272 RES & 1.17 \\
\hline $\mathrm{AC} 2-20$ & 1343 & RES & (1) & AC2-48 & 1181 RES & 1.73 \\
\hline AC2-21 & 1242 & $\mathrm{Al}_{2} \mathrm{O}_{3}$ & 0.86 & AC2-49 & $1220 \mathrm{RES}$ & 1.46 \\
\hline AC2-22 & 1284 & RES & 1.34 & AC2-50 & 1272 RES & 1.12 \\
\hline AC2-23 & 1282 & $\mathrm{Al}_{2} \mathrm{O}_{3}$ & 1.00 & $\mathrm{AC} 2-51$ & 1305 RES & 0.95 \\
\hline AC2-24 & 1319 & RES & 0.61 & AC2-52 & 1153 RES & 2.17 \\
\hline $\mathrm{AC} 2-25$ & 1305 & $\mathrm{Al}_{2} \mathrm{O}_{3}$ & 1.18 & AC2-53 & 1192 RES & 1.76 \\
\hline $\mathrm{AC} 2-26$ & 1208 & RES & 2.17 & AC2-54 & $1326 \mathrm{RES}$ & 0.86 \\
\hline AC2-27 & 1242 & RES & 1.93 & $A C 2-55$ & 1255 RES & 1.14 \\
\hline $\mathrm{AC} 2-28$ & 1260 & $\mathrm{Al}_{2} \mathrm{O}_{3}$ & 0.86 & & & \\
\hline
\end{tabular}




\section{Glossary}

$\begin{array}{ll}\eta & \text { viscosity } \\ \rho & \text { density }\end{array}$

$\begin{array}{ll}\text { AlS } & \text { aluminosilicate } \\ \text { DNFSB } & \text { Defense Nuclear Facility Safety Board } \\ \text { EDS } & \text { energy dispersive spectroscopy } \\ \text { MPPF } & \text { Multi-Purpose Processing Facility } \\ \text { NBS } & \text { National Bureau of Standards } \\ \text { NIST } & \text { National Institute for Standards and Technolog } \\ \text { OM } & \text { optical microscopy } \\ \text { ORNL } & \text { Oak Ridge National Laboratory } \\ \text { Pa.s } & \text { pascal seconds } \\ \text { PNNL } & \text { Pacific Northwest National Laboratory } \\ \text { QA } & \text { quality assurance } \\ \text { RES } & \text { rare-earth silicate } \\ \text { SEM } & \text { scanning electron microscopy } \\ \text { SRM } & \text { Standard Reference Material } \\ \text { SRS } & \text { Savannah River Site } \\ \text { SRTC } & \text { Savannah River Technology Center } \\ \text { T } & \text { temperature } \\ T_{A} & \text { lowest temperature at which samples did not form crystals } \\ T_{C} & \text { highest temperature at which samples did form crystals } \\ T_{L} & \text { liquidus temperature } \\ \text { VTF } & \text { Vogel-Tamman-Fulcher (model) } \\ \text { XRD } & \text { X-ray diffraction }\end{array}$

ZAF corrections for atomic number, absorption, and fluorescence effects 


\section{Acknowledgments}

Pacific Northwest National Laboratory is operated for the U.S. Department of Energy by Battelle under Contract DE-AC06-76RLO 1830.

The authors wish to acknowledge the guidance and funding for this multi-institutional task by the Department of Energy's Environmental Management Program. Funding to perform this task was provided by a subcontract from Savannah River Technical Center and we would like to thank this institution for their selection of this team to do this challenging and demanding task.

The following individuals from Pacific Northwest National Laboratory were key in helping complete the task:

Wayne C. Cosby - for his tireless efforts, late nights, and long weekends to make this document a well written report.

Orie Barnes - for his expertise as a Quality Assurance representative and ensuring quality work is passed on to the client.

Loni M. Peurrung - for her helpful support as line manager and for her thoughtful review of this document.

Stacey A. Hartley - for the mathematical calculations she did to define the measured viscosity data.

James E. Coleman and James S. Young - who worked very hard providing scanning electron microscopy data, sometimes under very demanding conditions.

Jarrod V. Crum - who helped us with sample heat treatments, XRD analyses, and furnace profiling and who volunteered for weekend sample changes.

Renee L. Russell - for her help in preparation of glass for $T_{L}$ measurement.

Harry D. Smith - for review of all the calculations performed for this study.

Virginia A. Rhoades - who supported us as secretary and records custodian.

Pavel Hrma, Hong Li, and Greg Piepel - for their helpful comments and suggestions on this document. 


\section{Contents}

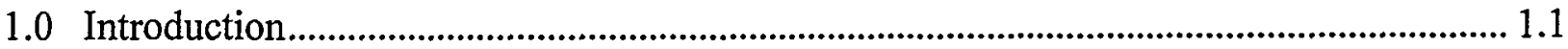

1.1 Americium/Curium Project................................................................................. 1.1

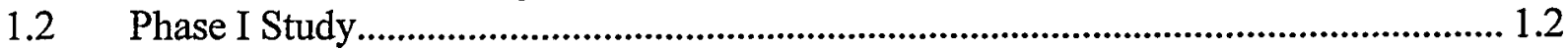

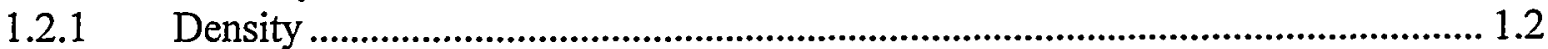

1.2.2 Liquidus Temperature ....................................................................................... 1.3

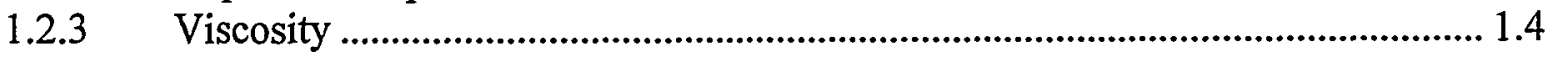

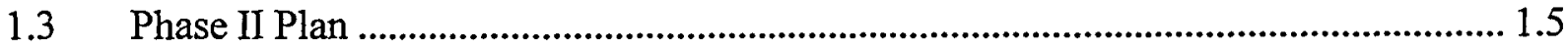

2.0 Experimental Procedures ............................................................................................... 2.1

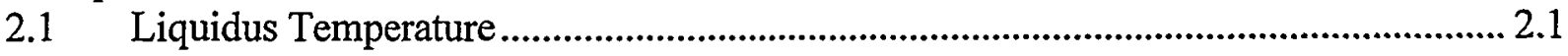

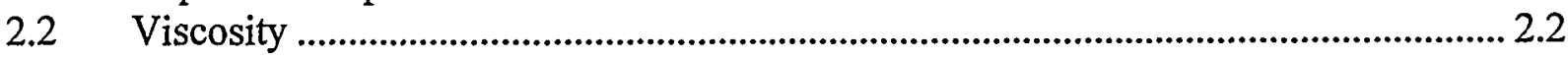

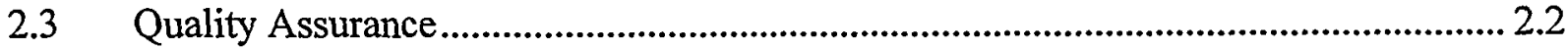

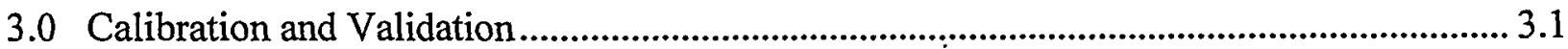

$3.1 \quad$ Liquidus Temperature .......................................................................................... 3.1

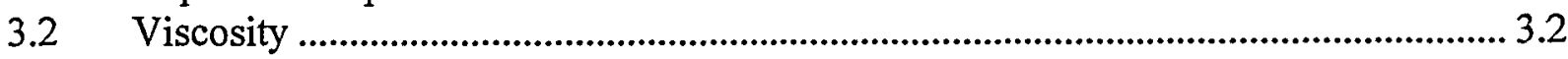

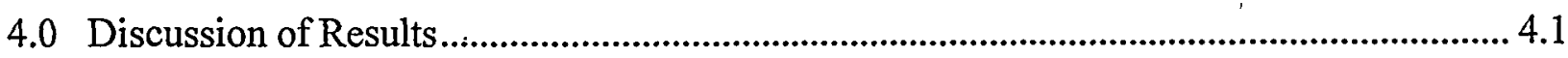

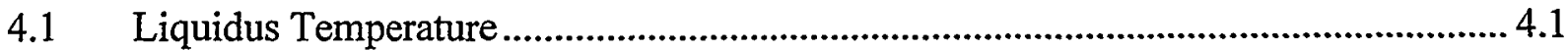

4.1.1 Rare Earth Silicate Crystals ............................................................................. 4.2

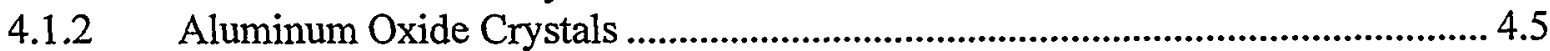

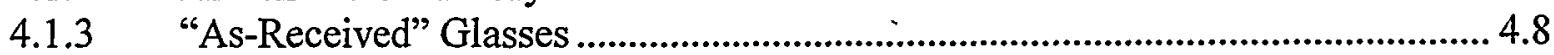

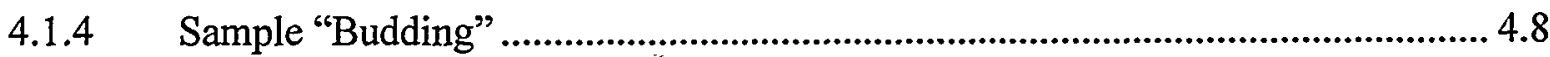

4.1.5 Quantitative Analysis of RES Crystals by SEM................................................. 4.11

4.1.6 Glass Composition Effects............................................................................ 4.13

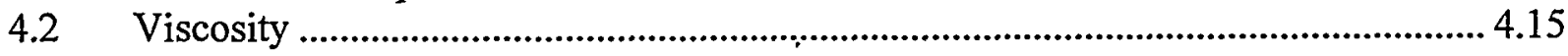

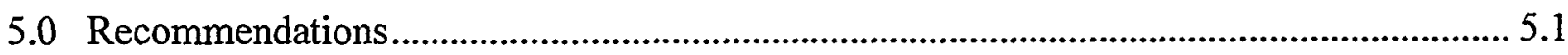

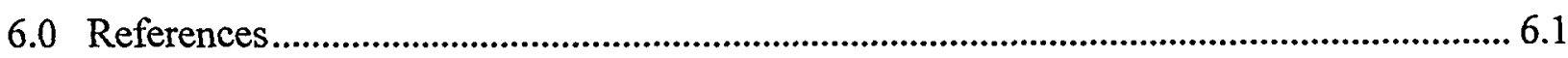




\section{Figures}

Figure 1.1. Schematic of the Vitrification Process Steps............................................................ 1.2

Figure 1.2. Specific Volume as a Function of $\mathrm{Ln}_{2} \mathrm{O}_{3}$ Concentration for Phase I Glasses ........... 1.3

Figure 1.3. $\mathrm{T}_{\mathrm{L}}$ as a Function of $\mathrm{Ln}_{2} \mathrm{O}_{3}$ Concentration for Phase I Glasses ................................. 1.4

Figure 1.4. $\mathrm{Ln}\left(\eta_{1350}\right)$ as a Function of $\mathrm{Ln}_{2} \mathrm{O}_{3}$ Concentration for Phase I Glasses ..................... 1.5

Figure 1.5. Ternary Projection of Phase $\mathrm{I}$ and II Glasses in $\mathrm{SiO}_{2}-\mathrm{Al}_{2} \mathrm{O}_{3}-\mathrm{B}_{2} \mathrm{O}_{3}$ Space............. 1.6

Figure 3.1. Comparison of Measured (Val-02) and Certified $\eta$ for SRM 710a Glass as a

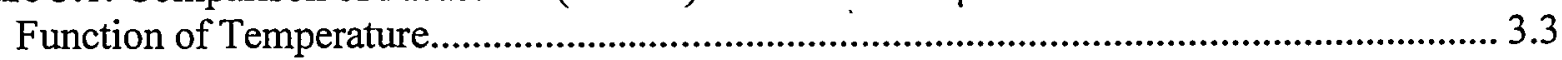

Figure 4.1. Example of Needle-Like RES Crystal Phase ................................................................. 4.3

Figure 4.2. AC1-31, Plate-Like RES Crystals ............................................................................... 4.3

Figure 4.3. AC2-44 $\left(1302^{\circ} \mathrm{C}\right)$ Plate-Like RES Crystals .............................................................. 4.4

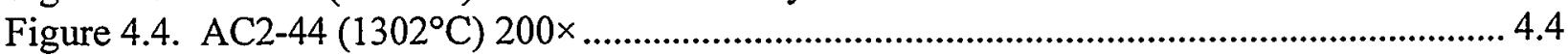

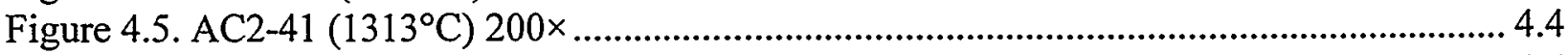

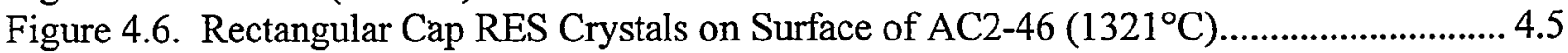

Figure 4.7. Aluminum Oxide Crystals ......................................................................................... 4.6

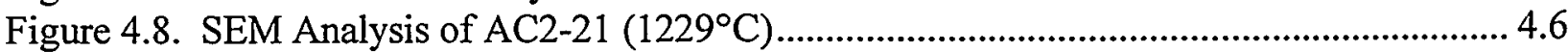

Figure 4.9. $\mathrm{AC2}-14\left(1232^{\circ}\right)$, Garnet Shaped $\mathrm{Al}_{2} \mathrm{O}_{3}$ Crystal ................................................... 4.7

Figure 4.10. Scan of Crystal in Figure 4.9 ……….................................................................... 4.7

Figure 4.11. Photograph of Buds on Crucible Edges...................................................................... 4.8

Figure 4.12. AC2-16 $\left(1297^{\circ} \mathrm{C}\right)$ Buds on Crucible Wing of Platinum Fold ................................. 4.9

Figure 4.13. Magnification of Figure 4.12 ...................................................................................... 4.9

Figure 4.14. AC2-29 $\left(1299^{\circ} \mathrm{C}\right)$, Small Buds on Wing of Crucible............................................. 4.10

Figure 4.15. AC2-29 $\left(1299^{\circ} \mathrm{C}\right)$ after Crucible Wing is Polished (note: platinum wall

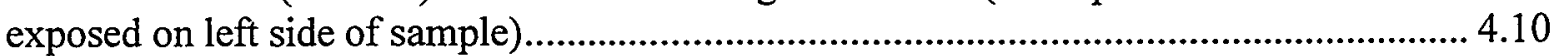

Figure 4.16. AC2-29 $\left(1299^{\circ} \mathrm{C}\right)$, Outer Surface of Bud .............................................................. 4.10

Figure 4.17. EDS Scan of Light Gray Crystals in Figure 4.16 .................................................. 4.11

Figure 4.18. EDS Scan of Black Crystals in Figure 4.16 .......................................................... 4.11

Figure 4.19. $\mathrm{T}_{\mathrm{L}}$ as a Function of $\mathrm{Ln}_{2} \mathrm{O}_{3}$ Concentration in Phase I and II Glasses (S-Alumino-

Silicate Crystals in Phase I Glasses, *-RES Crystals in Phase I Glasses, +-RES Crystals in

Phase II glasses, and $\mathrm{A}-\mathrm{Al}_{2} \mathrm{O}_{3}$ Crystals in Phase II Glasses) .............................................. 4.14

Figure 4.20. Composition Projection of Phase I and II Glasses in a $\mathrm{SiO}_{2}-\mathrm{Al}_{2} \mathrm{O}_{3}-\mathrm{Ln}_{2} \mathrm{O}_{3}$ Space with Primary Crystalline Phases Noted as Symbols: S-Alumino-Silicate, +-RES,

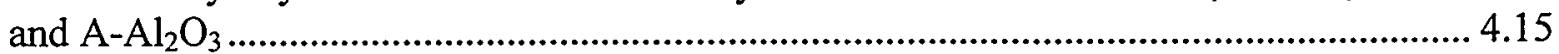

Figure 4.21. Comparison of $\ln [\eta]-1 / \mathrm{T}$ Behavior of (a) AC2-14 and (b) Val-01 ........................16

Figure 4.22. Effect of $\operatorname{Ln}_{2} \mathrm{O}_{3}$ Concentration on $\ln \left[\eta_{1350}\right]$ for Phase II Glasses (symbol numbers represent glass numbers)

Figure 4.23. Effect of $\mathrm{Ln}_{2} \mathrm{O}_{3}$ Concentration on $\ln \left[\eta_{1350}\right]$ for Phase I and II Glasses (symbols represent: A-Phase I glasses, B-Linear Phase II glasses, and N- Nonlinear Phase II glasses) 


\section{Tables}

Table 1.1. Phase II Glass Compositions in Mass Fractions of Oxide Components....................... 1.7

Table 3.1. $\mathrm{T}_{\mathrm{L}}$ Validation Data....................................................................................................... 3.1

Table 3.2. Viscosity-Temperature Data for Validation Glasses .................................................. 3.2

Table 4.1. $\mathrm{T}_{\mathrm{L}}$ and Primary Crystalline Phase for $55 \mathrm{Am} / \mathrm{Cm}$ Phase II Glasses ............................ 4.1

Table 4.2. Quantitative Analysis of Crystals in Glass ................................................................ 4.12

Table 4.3. Quantitative Analysis of Glass Matrix Compared to Target Composition.... 4.13

Table 4.4. Summary of Phase II Viscosity Data .............................................................................. 4.16 


\subsection{Introduction}

\subsection{Americium/Curium Project}

Approximately 11,000 liters (3,600 gallons) of solution containing isotopes of Am and $\mathrm{Cm}$ are stored in Tank 17.1 in the Savannah River Site's (SRS) F-Canyon. These isotopes were recovered during plutonium-242 production campaigns in the mid and late 1970s. The continued storage of these isotopes was identified as an item of primary concern in the Defense Nuclear Facility Safety Board's (DNFSB) Recommendation 94-1. The process selected to treat the contents of this tank includes

- pretreating the tank contents in existing canyon vessels to separate actinides and lanthanides from other impurities (primarily iron, aluminum, and sodium)

- vitrifying the actinide/lanthanide fraction of the tank contents in the Multi-Purpose Processing Facility (MPPF) in the F-Canyon

- shipping the actinide containing glass to Oak Ridge National Laboratory (ORNL) for storage and separation of actinides from glass

- irradiating the separated $\mathrm{Cm}$ to form heavy elements such as $\mathrm{Cf}$ for civilian and militar applications.

The proposed process is described in detail by Fellinger et al. (1998a and 1998b) and Marra et al. (to be published 1999). A schematic of the vitrification step is displayed in Figure 1.1. In the vitrification process, the feed from pretreatment is transferred to a reaction vessel. Actinide and lanthanide oxalates are precipitated from solution and washed. Oxalate precipitate is then transferred to a Pt/Rh induction melter, which is preloaded with fritted glass-making additives. The mixture is dried and heated to approximately $1450^{\circ} \mathrm{C}$ to produce a molten glass. The glass is then poured through a drain tube into a stainless steel can.

A lanthanide-alumino-borosilicate glass has been developed specifically for this process (Fellinger et al. 1998a and 1998b): The 25SrABS glass frit (33.68 mass\% $\mathrm{SiO}_{2}, 25.00 \mathrm{La}_{2} \mathrm{O}_{3}$, $24.87 \mathrm{Al}_{2} \mathrm{O}_{3}, 13.54 \mathrm{~B}_{2} \mathrm{O}_{3}$, and 2.91 SrO), when combined with 20 to 50 mass percent lanthanide/actinide $\left(\mathrm{Ln}_{2} \mathrm{O}_{3}\right)^{2}$ oxides, produces a glass with adequate properties for this process. It was shown that properties critical to the success of the proposed process, including viscosity $(\eta)$ and liquidus temperature $\left(T_{L}\right)$, vary with glass composition (Fellinger et al. 1998a and 1998b). Property limits were set to ensure adequate processability of the melter feed (Martin 1999 and Peeler and Edwards 1999). These limits include $\mathrm{T}_{\mathrm{L}} \leq 1350^{\circ} \mathrm{C}$ and $0.3 \mathrm{~Pa} \cdot \mathrm{s} \leq \eta$ at $1350^{\circ} \mathrm{C}\left(\eta_{1350}\right) \leq 2.4 \mathrm{~Pa} \cdot \mathrm{s}$. Therefore, we studied the impact of total $\mathrm{Ln}_{2} \mathrm{O}_{3}$ concentration and composition on the properties of the proposed glass.

\footnotetext{
${ }^{a}$ In this study, $\mathrm{Ln}_{2} \mathrm{O}_{3}$ represents the total concentration of three valent lanthanide oxides. Which simulates the total concentration of three valent lanthanide and actinide oxides in the radioactive glass?
} 


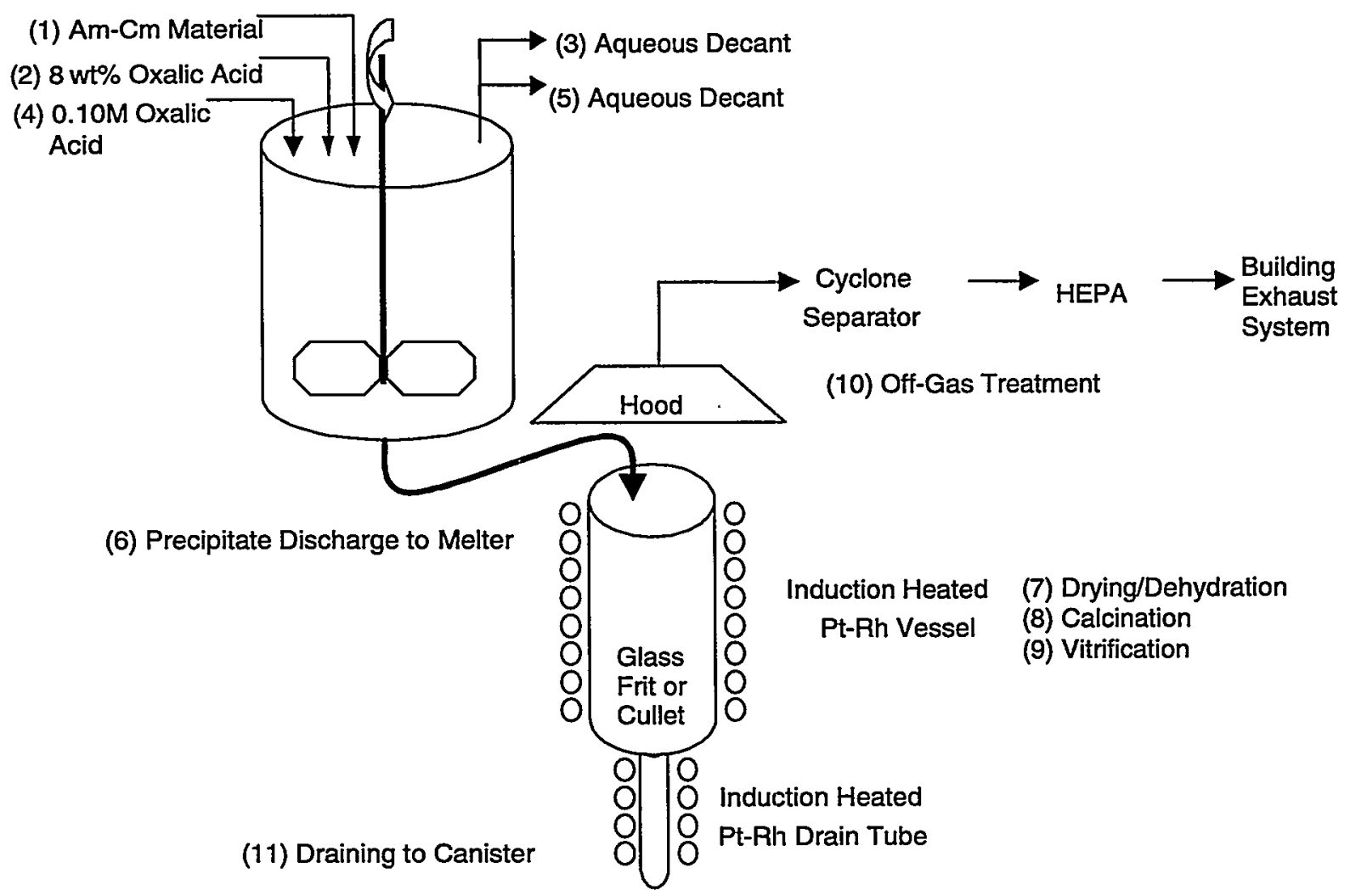

Figure 1.1. Schematic of the Vitrification Process Steps

\subsection{Phase I Study}

In the first phase of this study, the concentration of $\mathrm{Ln}_{2} \mathrm{O}_{3}$ in glass was systematically varied between 38 and 54 mass percent along with its composition (Peeler 1998 and Peeler and Edwards 1999). Thirty-one glasses were fabricated and characterized in a joint Savannah River Technology Center (SRTC) and Pacific Northwest National Laboratory (PNNL) effort. The results of this study are described in detail by Peeler and colleagues (Peeler et al. 1999 and Peeler et al., to be published, 2000). It was found that the variation in properties, such as density ( $\rho$ ), $T_{L}$, and $\eta$, could be described to first order by the variation in $\mathrm{Ln}_{2} \mathrm{O}_{3}$ concentration in glass.

\subsubsection{Density}

The $\rho$ of Phase I glasses, measured by gas pycnometry, ranged from $3.435 \mathrm{~g} / \mathrm{cm}^{3}$ to 4.103 $\mathrm{g} / \mathrm{cm}^{3}$, corresponding to specific volumes $(v)$ of $0.291 \mathrm{~cm}^{3} / \mathrm{g}$ and $0.244 \mathrm{~cm}^{3} / \mathrm{g}$. A linear decrease in $v$ with $\mathrm{Ln}_{2} \mathrm{O}_{3}$ is shown in Figure 1.2. The trend suggests a partial specific $v$ from $\mathrm{Ln}_{2} \mathrm{O}_{3}$ of $0.1023 \mathrm{~cm}^{3} / \mathrm{g}^{2}$ with a $\mathrm{Ln}_{2} \mathrm{O}_{3}$ free-glass partial specific $v$ of $0.4091 \mathrm{~cm}^{3} / \mathrm{g}^{2}$. These values extrapolate to effective $\rho s$ for $\mathrm{Ln}_{2} \mathrm{O}_{3}$ and $\mathrm{Ln}_{2} \mathrm{O}_{3}$ free glass of $9.775 \mathrm{~g} / \mathrm{cm}^{3}$ and $2.444 \mathrm{~g} / \mathrm{cm}^{3}$, respectively. The $v$ of $\mathrm{SrO}-\mathrm{Al}_{2} \mathrm{O}_{3}-\mathrm{B}_{2} \mathrm{O}_{3}-\mathrm{SiO}_{2}$ glasses can be expected to fall reasonably close to $0.41 \mathrm{~cm}^{3} / \mathrm{g}$. The $\rho$ of lanthanide oxide minerals range from $6.51 \mathrm{~g} / \mathrm{cm}^{3}$ for $\mathrm{La}_{2} \mathrm{O}_{3}$ to $9.42 \mathrm{~g} / \mathrm{cm}^{3}$ for $\mathrm{Lu}_{2} \mathrm{O}_{3}\left(v=0.106 \mathrm{~cm}^{3} / \mathrm{g}\right.$ to $\left.0.154 \mathrm{~cm}^{3} / \mathrm{g}\right)$. This suggests that the local density of $\mathrm{Ln}_{2} \mathrm{O}_{3}$ in this 
glass is similar to that in the oxide minerals. Furthermore, the similarity in densities between the end members suggest a low heat of mixing.

\subsubsection{Liquidus Temperature}

Two primary crystalline phases were found to precipitate from Phase I glasses, an aluminosilicate (AlS) with $\mathrm{T}_{\mathrm{L}}$ values ranging from $1164^{\circ} \mathrm{C}$ to $1255^{\circ} \mathrm{C}$ and a rare-earth silicate (RES) with $\mathrm{T}_{\mathrm{L}}$ values ranging from $1163^{\circ} \mathrm{C}$ to $1298^{\circ} \mathrm{C}$. For $\mathrm{Ln}_{2} \mathrm{O}_{3}$ concentrations less than 43 mass percent, AlS was found to be the primary phase; glasses with higher $\mathrm{Ln}_{2} \mathrm{O}_{3}$ concentrations were in the RES primary phase field. A weak correlation, based on low $\mathrm{R}^{2}$ values, was found between $\mathrm{T}_{\mathrm{L}}$ and $\mathrm{Ln}_{2} \mathrm{O}_{3}$ concentrations for Phase I glasses in both primary phase fields as shown in Figure 1.3. A minimum in $T_{L}$ is found at approximately 44 mass percent $\mathrm{Ln}_{2} \mathrm{O}_{3}$, with increasing $\mathrm{T}_{\mathrm{L}}$ at both higher and lower $\mathrm{Ln}_{2} \mathrm{O}_{3}$ concentrations.

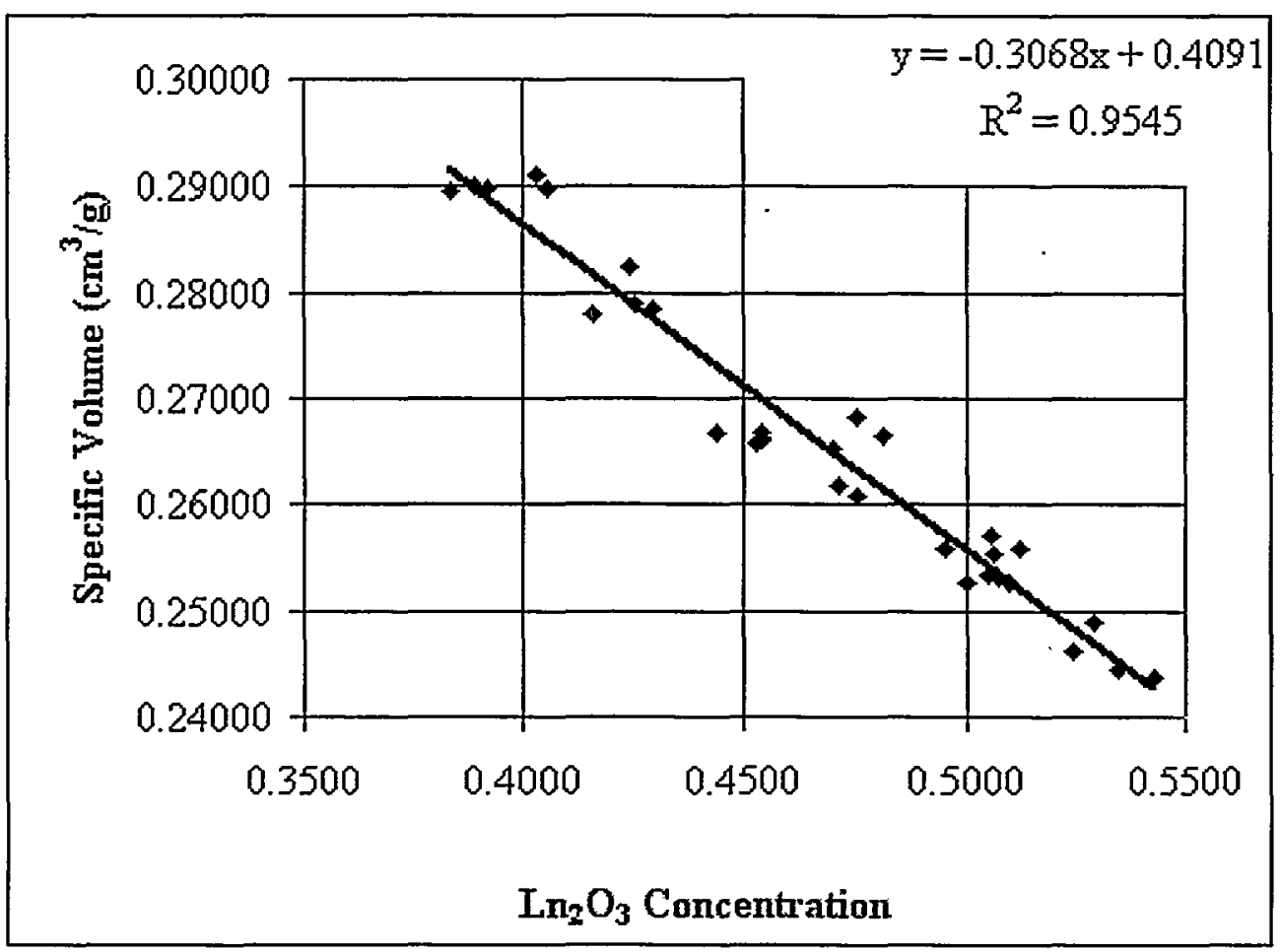

Figure 1.2. Specific Volume as a Function of $\mathrm{Ln}_{2} \mathrm{O}_{3}$ Concentration (in mass fraction) for Phase I Glasses 


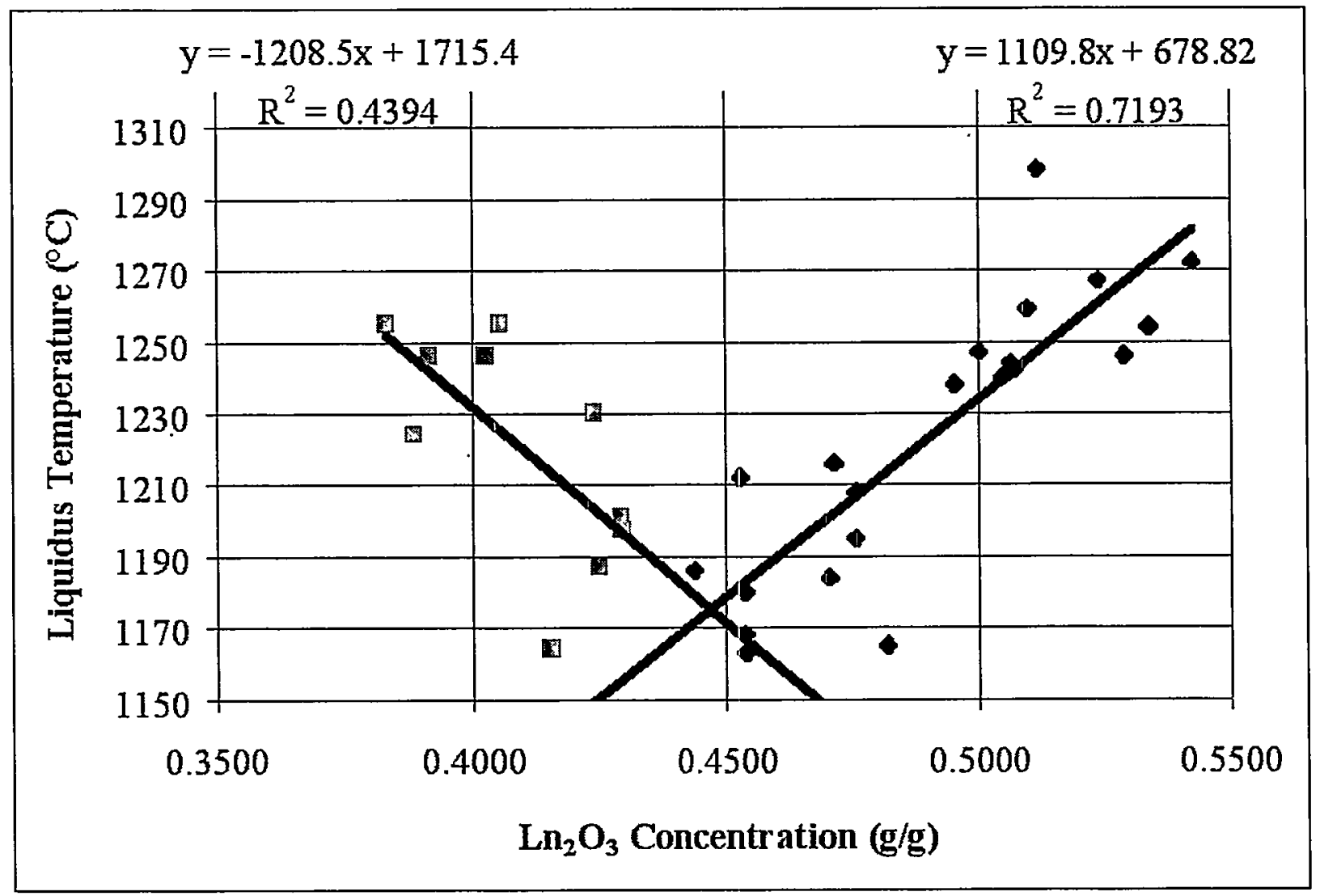

Figure 1.3. $\mathrm{T}_{\mathrm{L}}$ as a Function of $\mathrm{Ln}_{2} \mathrm{O}_{3}$ Concentration for Phase I Glasses

\subsubsection{Viscosity}

The $\eta \mathrm{s}$ of Phase I glasses were measured as functions of temperature (T). The $\eta-T$ data were then fitted to a Vogel-Tamman-Fulcher (VTF) model:

$$
\ln \eta=A+\frac{B}{T-T_{0}}
$$

where $A, B$, and $T_{0}$ are temperature independent coefficients. Equation (1) was then used to calculate a $\eta$ at $1350^{\circ} \mathrm{C}$, which was considered the nominal melter operating temperature during the Phase I study. The $\eta_{1350}$ values ranged from 1.24 pascal seconds $(\mathrm{Pa} \cdot \mathrm{s})$ to $4.01 \mathrm{~Pa} \cdot \mathrm{s}$. The effect of $\mathrm{Ln}_{2} \mathrm{O}_{3}$ concentration on $\ln \left[\eta_{1350}\right]$ is shown in Figure 1.4. The $\ln \left[\eta_{1350}(\mathrm{~Pa} \cdot \mathrm{s})\right]$ is decreased by 7.28 per mass fraction of $\mathrm{Ln}_{2} \mathrm{O}_{3}$ to the glass. For a glass with $\eta_{1350}=2.5 \mathrm{~Pa} \cdot \mathrm{s}$, adding one mass percent $\mathrm{Ln}_{2} \mathrm{O}_{3}$ will reduce the $\eta_{1350}$ by $0.2 \mathrm{~Pa} \cdot \mathrm{s}$ to $2.3 \mathrm{~Pa} \cdot \mathrm{s}$. 


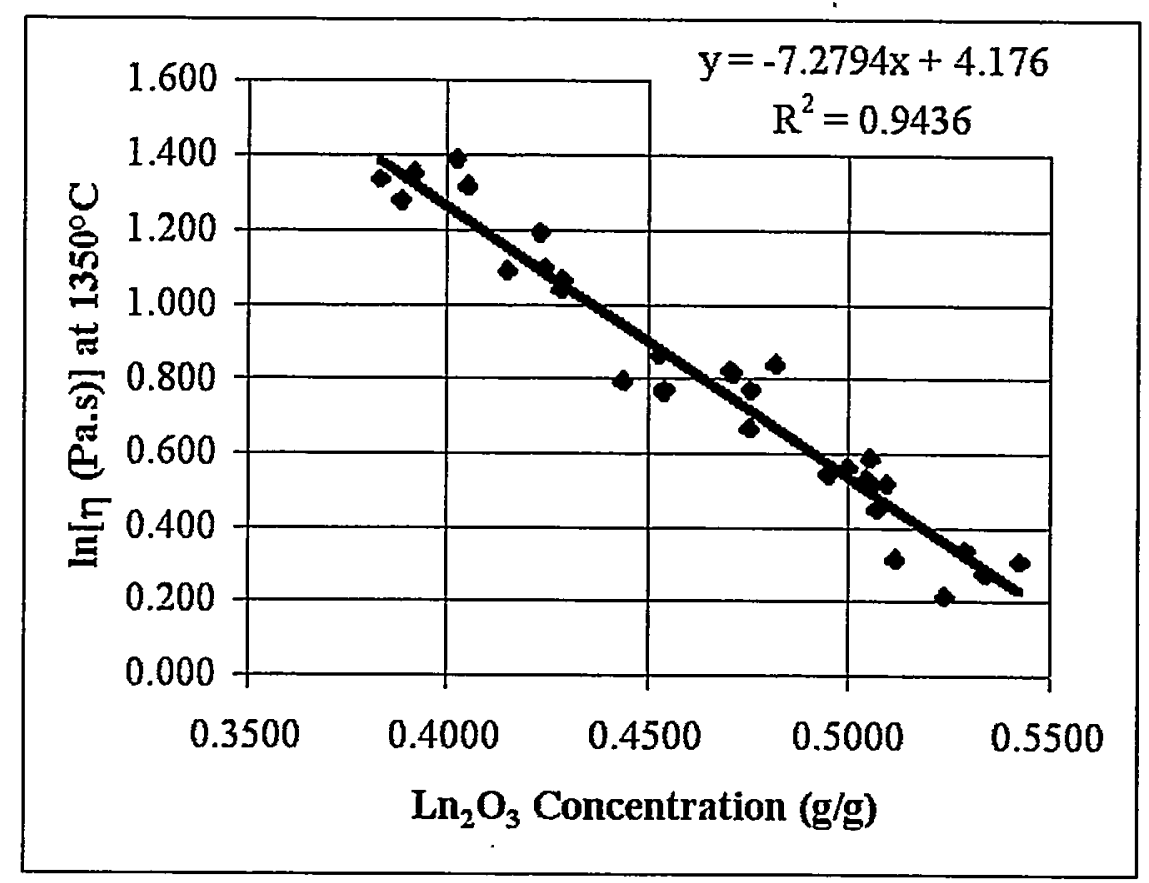

Figure 1.4. $\mathrm{Ln}\left(\eta_{1350}\right)$ as a Function of $\mathrm{Ln}_{2} \mathrm{O}_{3}$ Concentration for Phase I Glasses

\subsection{Phase II Plan}

Phase II was designed to systematically vary the composition of $\mathrm{Ln}_{2} \mathrm{O}_{3}$ and the concentrations of $\mathrm{Ln}_{2} \mathrm{O}_{3}, \mathrm{SiO}_{2}, \mathrm{Al}_{2} \mathrm{O}_{3}, \mathrm{~B}_{2} \mathrm{O}_{3}$, and $\mathrm{SrO}$ in glass (Peeler and Edwards 1999). Fifty five glasses were fabricated and characterized in a joint SRTC and PNNL effort. Table 1.1 lists these glass compositions. The concentration of $\mathrm{Ln}_{2} \mathrm{O}_{3}$ varied between 48.9 and 64.1 mass percent. The ratios of $\mathrm{SiO}_{2}, \mathrm{Al}_{2} \mathrm{O}_{3}, \mathrm{~B}_{2} \mathrm{O}_{3}$, and $\mathrm{SrO}$ remained constant and equal to those in the Phase I study in 27 of the 55 glasses, at $46.7,34.5,18.8$, and 0.39 mass percent, respectively. The ratios of these components varied systematically in the remaining 28 glass compositions. Figure 1.5 shows the normalized projections of the 55 glass compositions in $\mathrm{SiO}_{2}-\mathrm{Al}_{2} \mathrm{O}_{3}-\mathrm{B}_{2} \mathrm{O}_{3}$ space. The center point of the ring contains the 27 Phase II and 32 Phase I glasses with constant ratios of frit components. The data points on the near circle surrounding the center point contain the additional 28 glass compositions. The ratios of $\mathrm{SiO}_{2}, \mathrm{Al}_{2} \mathrm{O}_{3}, \mathrm{~B}_{2} \mathrm{O}_{3}$, and $\mathrm{SrO}$ fall into categories of low $(\mathrm{L})$ and high $(\mathrm{H})$ for each component and a central or middle $(\mathrm{M})$ for those ratios consistent with Phase I glasses. In the discussion of glass properties, the $\mathrm{L}, \mathrm{M}$, and $\mathrm{H}$ will be used to describe the relative concentrations of these components in glass rather than the absolute concentrations. See Peeler and Edwards (1999) for further detail on test matrix design. 


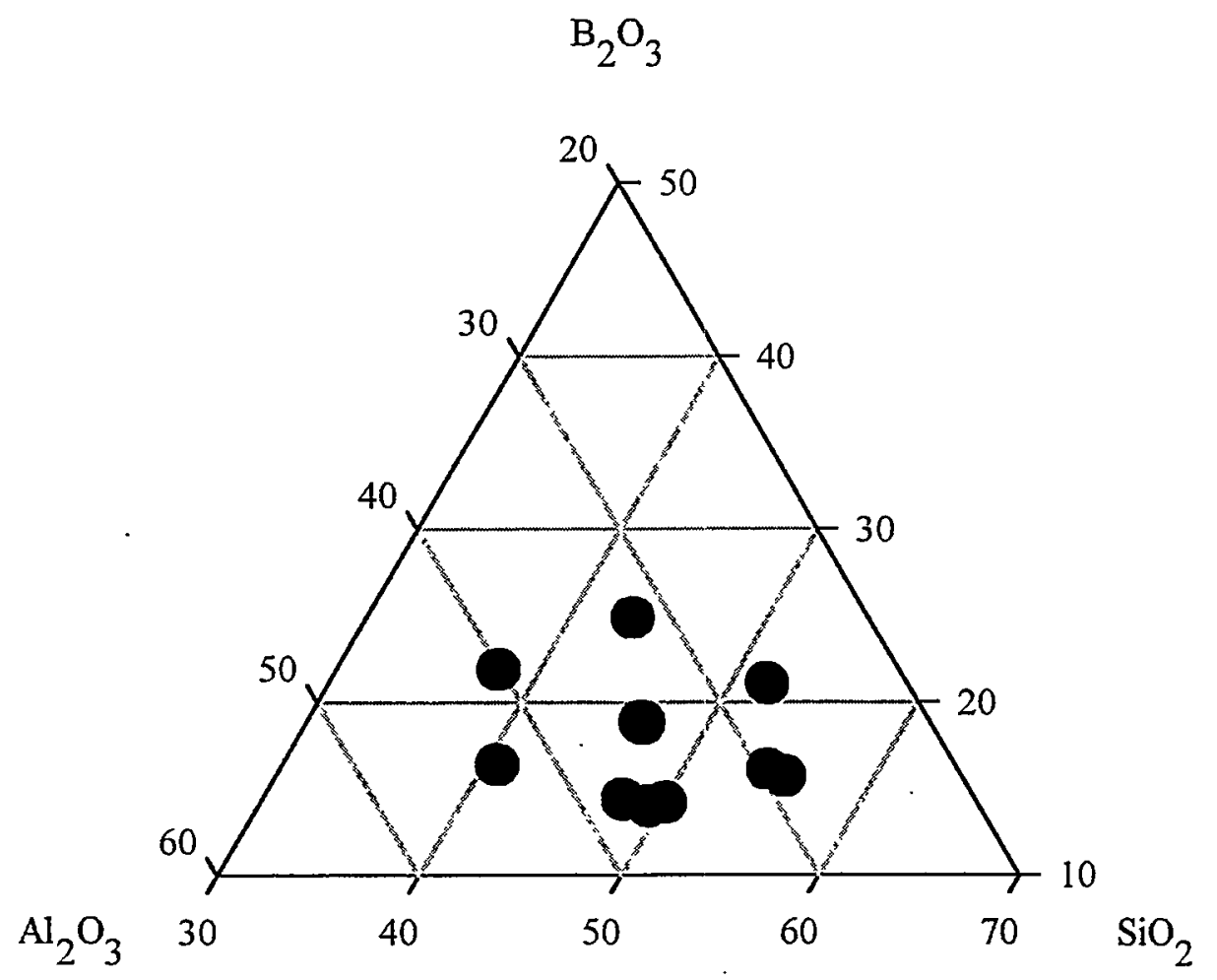

Figure 1.5. Ternary Projection of Phase I and II Glasses in $\mathrm{SiO}_{2}-\mathrm{Al}_{2} \mathrm{O}_{3}-\mathrm{B}_{2} \mathrm{O}_{3}$ Space

The results of $T_{L}$ and $\eta$ testing on Phase II glasses are described in this report. Section 2.0 describes the experimental procedures, Section 3.0 describes how test calibration and validation were performed, Section 4.0 discusses results, and Section 5.0 gives recommendations for the use of these data and further studies. Appendix A shows the measurement results by glass. 
Table 1.1. Phase II Glass Compositions in Mass Fractions of Oxide Components

\begin{tabular}{|c|c|c|c|c|c|c|c|c|c|c|c|c|c|c|}
\hline ID & $\mathrm{La}_{2} \mathrm{O}_{3}$ & $\mathrm{Ce}_{2} \mathrm{O}_{3}$ & $\mathrm{Pr}_{2} \mathrm{O}_{3}$ & $\mathrm{Nd}_{2} \mathrm{O}_{3}$ & $\mathrm{Sm}_{2} \mathrm{O}_{3}$ & $\mathrm{Eu}_{2} \mathrm{O}_{3}$ & $\mathrm{Gd}_{2} \mathrm{O}_{3}$ & $\mathrm{Er}_{2} \mathrm{O}_{3}$ & $\mathrm{Al}_{2} \mathrm{O}_{3}$ & $\mathrm{~B}_{2} \mathrm{O}_{3}$ & $\mathrm{SiO}_{2}$ & $\mathrm{SrO}$ & inor ${ }^{(a)}$ & $\mathrm{Ln}_{2} \mathrm{O}_{3}$ \\
\hline $\mathrm{AC} 2-01$ & 0.2300 & 0.0840 & 0.0730 & 0.0840 & 0.0200 & 0.0050 & 0.0110 & 0.0760 & 0.1190 & 0.0650 & 0.2190 & 0.0140 & $N$ & 0.5830 \\
\hline $\mathrm{AC} 2-02$ & 0.2300 & 0.0840 & 0.0730 & 0.0920 & 0.0200 & 0.0050 & 0.0280 & 0.0300 & 0.1700 & 0.0930 & 0.1610 & 0.0140 & $\mathrm{~N}$ & 0.5620 \\
\hline $\mathrm{AC} 2-03$ & 0.2300 & 0.0840 & 0.0290 & 0.1900 & 0.0200 & 0.0130 & 0.0110 & 0.0300 & 0.1190 & 0.0930 & 0.1610 & 0.0200 & $\mathrm{~N}$ & 0.6070 \\
\hline AC2-04 & 0.2300 & 0.0340 & 0.0730 & 0.1850 & 0.0500 & 0.0050 & & 0.0300 & 0.1190 & & 0.1610 & 0.0200 & $\mathrm{~N}$ & \\
\hline $\mathrm{AC} 2-05$ & 0.2300 & 0.0340 & 0.0290 & 0.1020 & 0.0500 & 0.0130 & 0.0280 & 0.0300 & 0.1700 & 0.0650 & 0.2290 & 0.0200 & $\mathrm{~N}$ & 0.5160 \\
\hline $\mathrm{AC} 2-06$ & 0.2300 & 0.0340 & 0.0290 & 0.1780 & 0.0500 & 0.0050 & 0.0110 & 0.0760 & 0.1190 & 0.0930 & 0.1610 & 0.0140 & $\mathrm{~N}$ & 0.6130 \\
\hline C2-07 & 0.2300 & 0.0340 & 0.0290 & 0.1090 & & 0.0130 & & 0.0760 & 0.1700 & & 0.2290 & 0.0140 & $N$ & 0.5220 \\
\hline 08 & 0.1840 & 0.0840 & 0.0730 & 0.0840 & 0.0500 & 0.0130 & 0.0 & 0.0300 & 0.1700 & 0.0650 & 0.2160 & 0.0200 & $N$ & 0.5290 \\
\hline $\mathrm{AC} 2-09$ & 0.1840 & 0.0840 & 0.0730 & 0.1330 & 0.0500 & 0.0130 & 0.0280 & 0.0760 & 0.1190 & 0.0650 & 0.1610 & 0.0140 & $\mathrm{~N}$ & 410 \\
\hline$A C 2-10$ & 0.1840 & 0.0840 & 0.0290 & 0.0840 & 0.0500 & 0.0050 & 0.0280 & 0.0760 & 0.1190 & 0.0930 & 0.2280 & 0.0200 & $N$ & 0.5400 \\
\hline $\mathrm{AC} 2-11$ & 0.1840 & 0.0840 & 0.0290 & 0.1970 & 0.0500 & 0.0050 & 0.0110 & 0.0300 & 0.1700 & 0.0650 & 0.1610 & 0.0140 & $\mathrm{~N}$ & 0.5900 \\
\hline $\mathrm{C} 2-12$ & 0.1840 & 0.0340 & 0.0730 & 0.2070 & 0.0200 & 0.0050 & 0.0110 & 0.0330 & 0.1190 & 0.0650 & 0.2290 & 0.0200 & $N$ & 0.5670 \\
\hline$C 2-13$ & 0.1840 & 0.0340 & 0.0730 & 0.1070 & 0.0500 & 0.0050 & 0.0110 & 0.0300 & 0.1700 & & 0.2290 & 0.0140 & $N$ & 0.4940 \\
\hline$C 2-14$ & 0.1840 & 0.0340 & 0.0730 & 0.1450 & 0.0200 & 0.0130 & 0.0110 & 0.0760 & 0.1700 & 0.0930 & 0.1610 & 0.0200 & $\mathrm{~N}$ & \\
\hline$C 2-15$ & 0.1840 & 0.0340 & 0.0290 & 0.2070 & 0.0200 & 0.0130 & 0.0280 & 0.0300 & 0.1190 & 0.0930 & 0.2290 & 0.0140 & $\mathrm{~N}$ & 0.5450 \\
\hline$C 2-16$ & 0.1840 & 0.0350 & 0.0290 & 0.2070 & 0.0200 & 0.0050 & 0.0280 & 0.0760 & 0.1700 & 0.0650 & 0.1610 & 0.0200 & $N$ & 0.5840 \\
\hline $\mathrm{C} 2-17$ & 0.2064 & 0.0580 & 0.0504 & 0.1361 & 0.0347 & 0.0090 & 0.0194 & 0.0524 & 0.1439 & 0.0787 & 0.1941 & 0.0170 & $\mathrm{~N}$ & 0.5664 \\
\hline $\mathrm{AC} 2-18^{\circ}$ & 0.1700 & 0.0970 & 0.0220 & 0.2420 & 0.0580 & 0.0150 & 0.0080 & 0.0230 & 0.1190 & 0.0650 & 0.1610 & 0.0200 & $N$ & 0.6350 \\
\hline$A C 2-19$ & 0.2400 & 0.0970 & 0.0250 & 0.0630 & 0.0150 & 0.0030 & 0.0080 & 0.0880 & 0.1190 & 0.0930 & 0.2290 & 0.0200 & $N$ & 0.5390 \\
\hline $\mathrm{AC} 2-20$ & 0.2400 & 0.0970 & 0.0850 & 0.1340 & 0.0150 & 0.0150 & 0.0320 & 0.0230 & 0.1190 & 0.0650 & 0.1610 & 0.0140 & $N$ & 0.6410 \\
\hline $\mathrm{AC} 2-21$ & 0.2400 & 0.0970 & 0.0220 & 0.0810 & 0.0580 & 0.0030 & 0.0320 & 0.0230 & 0.1700 & 0.0930 & 0.1610 & 0.0200 & $N$ & 0.5560 \\
\hline $\mathrm{AC} 2-22$ & 0.2400 & 0.0250 & 0.0830 & 0.0630 & 0.0580 & 0.0150 & 0.0320 & 0.0230 & 0.1190 & 0.0930 & 0.2290 & 0.0200 & $N$ & 0.5390 \\
\hline $\mathrm{AC} 2-23$ & 0.2400 & 0.0250 & 0.0850 & 0.1850 & 0.0150 & 0.0030 & 0.0080 & 0.0230 & 0.1700 & 0.0650 & 0.1610 & 0.0200 & $N$ & 0.5840 \\
\hline $\mathrm{AC} 2-24$ & 0.2400 & 0.0250 & 0.0220 & 0.2420 & 0.0150 & 0.0030 & 0.0320 & 0.0340 & 0.1190 & 0.0930 & 0.1610 & 0.0140 & $\mathrm{~N}$ & 0.6130 \\
\hline
\end{tabular}




\begin{tabular}{|c|c|c|c|c|c|c|c|c|c|c|c|c|c|c|}
\hline & & & & & & & & & & & & & & \\
\hline & & & & & & & & & & & & 0.0200 & $\mathrm{~N}$ & \\
\hline & & & & & & & & & & & & & & \\
\hline & & & & & & & & & & & & & & \\
\hline & & 0970 & & 0.0630 & & 0.01 & 0.0320 & & & & & 0.0200 & & נס \\
\hline $2-29$ & & & & 780. & & & 0.0 & & & & & & & \\
\hline & & & & & & & & & & & & & & \\
\hline & & & & & & & & & & & & & & \\
\hline & & & & & & & & & & & & & & \\
\hline & 8 & & & 394 & & & 83 & & & & & & & \\
\hline & 8 & 573 & & 27 & & 0 & 0187 & & & & & 66 & & \\
\hline $2-35$ & & & & & & & & & & & & & & 579 \\
\hline & & & & & & & & & & & & & & 8 \\
\hline & & & & & & 089 & 201 & & & & & & & 9 \\
\hline & & & & & & & & & & & & & & 0 \\
\hline & & & & & & & & & & & & & & 0 \\
\hline & & & & & & & & & & & & & & .616 \\
\hline & 022 & & & & & 097 & & & & & & & & 624 \\
\hline & 194 & & & 062 & & 062 & & & & & & & & \\
\hline & & & & & & & & & & & & & & .52 \\
\hline & & & & & & & & & & & & & & 639 \\
\hline & 1988 & & & & & & & & & & & & & .564 \\
\hline & 2050 & & & & & & & & & & & & & 601 \\
\hline & & & & & & & & & & & & & & .56 \\
\hline & & & & & & & & & & & & & $N$ & \\
\hline & 2146 & 493 & & 228 & & 072 & & & & 853 & & 183 & $\mathrm{~N}$ & .526 \\
\hline & 3 & & & 394 & & & 0.0 & & & & & 0.0169 & $Y$ & .564 \\
\hline & 2050 & 626 & 7 & 1559 & & 0.0091 & 0 & 0.0568 & 0.1318 & & 0 & 0.0154 & $Y$ & 0.601 \\
\hline
\end{tabular}




\begin{tabular}{|c|c|c|c|c|c|c|c|c|c|c|c|c|c|c|}
\hline ID & $\mathrm{La}_{2} \mathrm{O}_{3}$ & $\mathrm{Ce}_{2} \mathrm{O}_{3}$ & $\mathrm{Pr}_{2} \mathrm{O}_{3}$ & $\mathrm{Nd}_{2} \mathrm{O}_{3}$ & $\mathrm{Sm}_{2} \mathrm{O}_{3}$ & $\mathrm{Eu}_{2} \mathrm{O}_{3}$ & $\mathrm{Gd}_{2} \mathrm{O}_{3}$ & $\mathrm{Er}_{2} \mathrm{O}_{3}$ & $\mathrm{Al}_{2} \mathrm{O}_{3}$ & $\mathrm{~B}_{2} \mathrm{O}_{3}$ & $\mathrm{SiO}_{2}$ & $\mathrm{SrO}$ & minor $^{(a)}$ & $\mathrm{Ln}_{2} \mathrm{O}_{3}$ \\
\hline $\mathrm{AC} 2-52$ & 0.2194 & 0.0426 & 0.0372 & 0.1062 & 0.0252 & 0.0062 & 0.0140 & 0.0387 & 0.1691 & 0.0921 & 0.2290 & 0.0198 & $\mathrm{Y}$ & 0.4895 \\
\hline AC2-53 & 0.2146 & 0.0493 & 0.0431 & 0.1228 & 0.0291 & 0.0072 & 0.0161 & 0.0447 & 0.1567 & 0.0853 & 0.2122 & 0.0183 & $Y$ & 0.5269 \\
\hline $\mathrm{AC} 2-54$ & 0.2002 & 0.0693 & 0.0605 & 0.1725 & 0.0409 & 0.0101 & 0.0227 & 0.0628 & 0.1194 & 0.0650 & 0.1617 & 0.0140 & $\mathrm{Y}$ & 0.6390 \\
\hline AC2-55 & 0.2100 & 0.1120 & 0.0489 & 0.0835 & 0.0331 & 0.0082 & 0.0183 & 0.0508 & 0.1444 & 0.0786 & 0.1955 & 0.0169 & $\mathrm{~N}$ & 0.5648 \\
\hline
\end{tabular}

(a) N-Indicates no minor component addition, $\mathrm{Y}$ - Indicates that the glass has been spiked with a mixture of minor components (0.01 mass \% $\mathrm{Fe}_{2} \mathrm{O}_{3}, 0.005 \mathrm{NiO}, 0.005 \mathrm{Cr}_{2} \mathrm{O}_{3}, 0.005 \mathrm{CaO}, 0.005 \mathrm{Na}_{2} \mathrm{O}, 0.005 \mathrm{~K}_{2} \mathrm{O}$, and $0.05 \mathrm{mass} \% \mathrm{MnO}$ ) 


\subsection{Experimental Procedures}

\subsection{Liquidus Temperature}

$\mathrm{T}_{\mathrm{L}}$ was measured following Method B of PNNL technical procedure GDL-LQT, "Standard Test Methods for Determining the $T_{L}$ of Waste Glasses and Simulated Waste Glasses," latest revision. A run order was not used for determining $T_{L}$ for individual samples due to time constraints, but samples were grouped together in furnaces operating at a specific temperature. The final measurements used to determine $T_{L}$ were confined to one of three validated furnaces to prevent differences of temperature profiles between furnaces from biasing results. In many cases, additional heat treatments in alternate furnaces are reported (See Appendix A); however, these measurements were not used in final $\mathrm{T}_{\mathrm{L}}$ determination.

As glass samples were received from SRTC, they were logged and analyzed by optical microscopy (OM) for crystalline material or inhomogeneities. Approximately $300 \mathrm{~g}$ of each glass was split out to measure $\eta$ (See Section 2.2). The remaining glass was for $T_{L}$ testing. The $\mathrm{T}_{\mathrm{L}}$ test samples were crushed in a tungsten carbide milling chamber, sieved to capture 4.0 to 0.5 $\mathrm{mm}$ grains, ultrasonically washed for 2 minutes in ethanol, and dried at $90^{\circ} \mathrm{C}$ following the technical procedure. Each glass sample had its own platinum crucible (approximately $1.27 \mathrm{~cm}^{3}$ ) and lid, which were cleaned between heat treatments. Samples were heat treated for $24 \pm 2 \mathrm{~h}$ in calibrated and temperature-profiled furnaces.

Each glass was initially tested with three to nine preliminary heat treatments, which narrowed the temperature range in which $T_{L}$ would be determined and reported. The first heat treatments were at roughly $1200^{\circ} \mathrm{C}$, and new samples were heat treated at progressively higher (or lower) temperatures in roughly $20^{\circ} \mathrm{C}$ to $50^{\circ} \mathrm{C}$ intervals until the heat-treated glass sample appeared crystal free by low magnification $O M$. Based on these results, the temperature difference between the lowest temperature at which samples did not form crystals $\left(T_{A}\right)$ and the highest temperature at which samples did form crystals $\left(\mathrm{T}_{\mathrm{C}}\right)$ was narrowed by additional heat treatments. Data were then collected on the samples tested near the temperature region of $T_{L}$. Some of the samples that were used for XRD and scanning electron microscopy (SEM) cam from the initial heat treatments because the samples near $T_{L}$ did not have sufficient crystalnumber density and crystal size for useful microstructural analysis. Care was taken to ensure that the crystals analyzed matched those found at $T_{L}$.

Three Del Tech ${ }^{\mathrm{TM}}$ furnaces were used for final $\mathrm{T}_{\mathrm{L}}$ determination. The furnaces were profiled for temperature differences in the hot zone where samples were heat treated using certified thermocouples.and calibrated thermocouple readouts. The method was validated by heat treating SRM-773 $T_{L}$ Glass from the National Institute of Standards and Technology (NIST) at the beginning, middle, and end of the test period.

Crystals were identified by OM (at magnifications as high as 500x), X-ray diffraction (XRD), and SEM, accompanied by energy dispersive spectroscopy (EDS), to characterize the chemical composition of analyzed samples. XRD and SEM/EDS were used for phase 
identification of those crystals observed by OM. Familiar phases observed by OM were not repeatedly characterized with XRD or SEM.

\subsection{Viscosity}

Glass $\eta$ s were measured as functions of $T$ using a spindle viscometer. The measurements were obtained in accordance with the procedure ASTM C 965, "Standard Practice for Measuring Viscosity of Glass Above the Softening Point," using PNNL procedure GDL-VIS, Rev. 1, "Standard Viscosity Measurement for Vitrified Nuclear Waste." The $\eta$ data were evaluated and fit to either single or multiple Arrhenius functions:

$$
\ln \eta=\mathrm{E}+\mathrm{F} / \mathrm{T}
$$

where $\mathrm{E}$ and $\mathrm{F}$ are $\mathrm{T}$-independent coefficients. Many $\ln \eta-1 / \mathrm{T}$ curves showed nonlinear behavior, which is rare in silicate glasses and was not observed in the Phase I study. Therefore, great care was taken in the analyses of $\eta-T$ data for each glass. Any $\eta$ data points obtained at temperatures, below the measured $T_{L}$ were not considered in the calculation due to the potential impact of crystals on $\eta$. To obtain the most data possible on these glasses, data were collected at $\eta \mathrm{s}$ below the limit for the viscometer's current setup. Viscosity values below $0.549 \mathrm{~Pa} \cdot \mathrm{s}, \ln [\eta(\mathrm{Pa} \cdot \mathrm{s})]=-$ 0.600 , are listed for information only and were not used in any calculations. Finally, the $\ln \eta-1 / T$ curve was evaluated for linear trends. In many cases, a single line accurately described the ln $\eta$ $1 / \mathrm{T}$ behavior (the glass behaved in an Arrhenian fashion), and in other glasses (nonlinear), it did not. For the nonlinear glasses, the $\eta_{1350}$ was interpolated from the measured data at $T$ closest to and on either side of $1350^{\circ} \mathrm{C}$ with Equation (2). In some cases, there were insufficient data to interpolate the $\eta_{1350}$; in these cases, the value was obtained by extrapolation of the available data or was not estimated at all if less than two data points were available. The exact steps used to determine the $\eta-T$ function and $\eta_{1350}$ are described in Section Appendix A for each glass.

\subsection{Quality Assurance}

All data were collected and reported under the PNNL Spent Nuclear Fuel Quality Assurance (QA) Program, SNF-70-001. The SNF QA Program is an NQA-1-based program that also conforms to the requirements of DOE/RW-0333P, Quality Assurance Requirements and Description. Quality assurance oversight within PNNL was provided by a Quality Engineer matrixed to this work from the independent Process Quality Department. Additional surveillance was provided by the SRTC QA staff as documented in Surveillance Report 99-SUR11-020. 


\subsection{Calibration and Validation}

\subsection{Liquidus Temperature}

The three Del Tech ${ }^{\mathrm{tm}}$ furnaces were checked initially, in the middle of the testing period (see note below for Furnace \#8), and at the end of the testing period using Standard Reference Material number 773 (SRM-773) glass to validate the accuracy of the furnaces, thermocouples, and thermocouple readouts used for $\mathrm{T}_{L}$ measurement. SRM-773 glass has a reported $\mathrm{T}_{L}$ of $988^{\circ} \mathrm{C} \pm 3^{\circ} \mathrm{C}$ for Method A, the trough-type platinum container test, and $991^{\circ} \mathrm{C} \pm 5^{\circ} \mathrm{C}$ Method $\mathrm{B}$, the perforated platinum plate test (NBS 1980). A different method was used than what is described in the SRM-773 certificate. All of the validation test measurements are summarized in Table 3.1.

Table 3.1. $T_{L}$ Validation Data

\begin{tabular}{|c|c|c|c|c|}
\hline Furnace & IN & $\mathrm{T}\left({ }^{\circ} \mathrm{C}\right)$ & Observations & \\
\hline 3 & $3: 00 p m$ 5/3 & 988 & 3:00pm 5/4 crystals & \\
\hline 3 & 3:00pm 5/4 & 993 & $2: 55 \mathrm{pm} \cdot 5 / 5$ no crystals & \\
\hline 3 & 3:00pm5/5 & 990 & $2: 55 p m$ 5/6 no crystals & \\
\hline 3 & 3:00pm 5/6 & 986 & 2:55pm $5 / 7$ crystals & $\mathrm{T}_{\mathrm{L}}=989^{\circ} \mathrm{C}$ \\
\hline 3 & 11:58am $6 / 7$ & 986 & $10: 52$ am $6 / 8$ crystals & $T_{L}=988^{\circ} \mathrm{C}$ \\
\hline 3 & $3: 45 p m$ 8/23 & 990 & 2:00pm 8/24 no crystals & \\
\hline 3 & $3: 45 p m$ 5/25 & 985 & $3: 25 \mathrm{pm} 8 / 26$ few crystals & $T_{L}=987^{\circ} \mathrm{C}$ \\
\hline 8 & 3:00pm 6/11 & 993 & 2:20pm 6/12 no crystals & \\
\hline 8 & 5:00pm 6/15 & 990 & $3: 20 \mathrm{pm} 6 / 16$ no crystals & \\
\hline 8 & 5:00pm 6/16 & 986 & 3:00pm $6 / 17$ few crystals & \\
\hline 8 & 5:00pm 6/17 & 982 & 3:00pm $6 / 18$ crystals & $T_{L}=988^{\circ} \mathrm{C}$ \\
\hline 8 & 11:03am 8/4 & 992 & $1: 14 \mathrm{pm} 8 / 5$ no crystals & \\
\hline 8 & 2:00pm 8/9 & 989 & 3:30pm 8/10 no crystals & \\
\hline 8 & $4: 15 p m$ 8/10 & 984 & $4: 00 p m$ 8/11 few crystals & \\
\hline 8 & 4:30pm 8/12 & 980 & 5:00pm $8 / 13$ crystals & $\mathrm{T}_{L}=986^{\circ} \mathrm{C}$ \\
\hline 12 & 3:00pm 4/13 & 1001 & 1:00pm 4/14 no crystals & \\
\hline 12 & 3:00pm 4/14 & 991 & 3:00pm 4/15 no crystals & \\
\hline 12 & 3:00pm 4/20 & 982 & 3:00pm 4/21 crystals & \\
\hline 12 & 3:00pm 4/21 & 988 & 3:00pm 4/22 crystals & $\mathrm{T}_{\mathrm{L}}=990^{\circ} \mathrm{C}$ \\
\hline 12 & 2:45pm 7/9 & 987 & $1: 00 p m$ 7/10 crystals & \\
\hline 12 & 5:15pm 7/18 & 992 & 3:15pm $7 / 19$ no crystals & $\mathrm{T}_{\mathrm{L}}=989^{\circ} \mathrm{C}$ \\
\hline 12 & 12:00pm 8/4 & 994 & $1: 14 \mathrm{pm} 8 / 5$ no crystals & \\
\hline 12 & 2:00pm 8/9 & 992 & 3:30pm 8/10 no crystals & \\
\hline 12 & $4: 15 p m$ 8/10 & 988 & 4:00pm 8/11 no crystals & \\
\hline 12 & 4:30pm 8/12 & 984 & $5: 00 p m 8 / 13$ one crystal & \\
\hline 12 & 4:30pm 8/17 & 980 & $5: 00$ pm $8 / 18$ crystals & $T_{L}=985^{\circ} \mathrm{C}$ \\
\hline
\end{tabular}


To summarize the validation tests in each furnace with SRM-773 glass, Furnace \#3 had a $\mathrm{T}_{\mathrm{L}}$ of $989^{\circ} \mathrm{C}$ (beginning), $988^{\circ} \mathrm{C}$ (mid), and $987^{\circ} \mathrm{C}$ (final), Furnace $\# 8$ had $\mathrm{T}_{\mathrm{L}}$ of $988^{\circ} \mathrm{C}$ (beginning) and $986^{\circ} \mathrm{C}$ (final), and Furnace $\# 12$ had a $\mathrm{T}_{\mathrm{L}}$ of $990^{\circ} \mathrm{C}$ (beginning), $989^{\circ} \mathrm{C}$ (mid), and $985^{\circ} \mathrm{C}$ (final). Furnace \#8 was used mainly for preliminary tests; therefore, only two validation tests were performed during its six weeks of use for final $T_{L}$ measurements.

The gradual decline in $T_{L}$ temperatures for the validation tests (e.g., Furnace \#3, $\mathrm{T}_{\mathrm{L}}=989^{\circ} \mathrm{C}$ in May 1999 and by late August $1999, \mathrm{~T}_{\mathrm{L}}=987^{\circ} \mathrm{C}$ ) could be attributed to the evaporation of rhodium from the "Type $S$ " thermocouple wire used in the thermocouples for temperature measurements. Phase II testing was at much higher temperatures than Phase I, and the constant use of the furnaces at these high temperatures is known to slowly degrade the thermocouples, causing the electrical signal from the wire to drop slightly in voltage output, which would cause the measured temperature to decline.

\subsection{Viscosity}

To validate the glass $\eta$ data, the $\eta$ of a standard glass was repeatedly measured. Each measured $\eta$-T relationship of the SRM for high-temperature $\eta$ (SRM-710a) (NIST 1991) was referred to as a run. Samples of this glass were tested at the beginning (Val-01) and end of this study (Val-03) and twice during the study (Val-01a and Val-02) for a total of four runs. The $\eta-T$ data from these runs are listed in Table 3.2.

Table 3.2. Viscosity-Temperature Data for Validation Glasses

\begin{tabular}{cccccccc}
\hline \multicolumn{2}{c}{ Val-01 } & \multicolumn{2}{c}{ Val-01a } & \multicolumn{2}{c}{ Val-02 } & \multicolumn{2}{c}{ Val-03 } \\
\hline $\mathrm{T}\left({ }^{\circ} \mathrm{C}\right)$ & $\eta(\mathrm{Pa} \cdot \mathrm{s})$ & $\mathrm{T}\left({ }^{\circ} \mathrm{C}\right)$ & $\eta(\mathrm{Pa} \cdot \mathrm{s})$ & $\mathrm{T}\left({ }^{\circ} \mathrm{C}\right)$ & $\eta(\mathrm{Pa} \cdot \mathrm{s})$ & $\mathrm{T}\left({ }^{\circ} \mathrm{C}\right)$ & $\eta(\mathrm{Pa} \cdot \mathrm{s})$ \\
1136 & 227.405 & 1135 & 248.029 & 1137 & 256.169 & 1137 & 235.003 \\
1185 & 122.914 & 1184 & 133.711 & 1186 & 137.310 & 1186 & 126.375 \\
1234 & 70.454 & 1233 & 76.683 & 1235 & 78.898 & 1235 & 72.807 \\
1283 & 43.182 & 1282 & 47.495 & 1284 & 47.553 & 1284 & 44.115 \\
1332 & 28.157 & 1283 & 46.737 & 1333 & 30.447 & 1333 & 28.404 \\
1382 & 17.915 & 1283 & 46.737 & 1382 & 19.153 & 1382 & 17.946 \\
1431 & 12.346 & 1331 & 29.313 & 1431 & 13.152 & 1431 & 12.411 \\
1480 & 8.381 & 1381 & 19.308 & 1480 & 8.736 & 1480 & 8.413 \\
1529 & 6.254 & 1430 & 13.442 & 1529 & 6.576 & 1529 & 6.576 \\
1530 & 6.197 & 1479 & 9.219 & & & 1529 & 6.302 \\
& & 1529 & 6.616 & & & & \\
\hline
\end{tabular}

The $\eta$-T data from each run were fitted to the VTF model (Equation 1), and the withinrun data variability was estimated using the uncertainties associated with these fits. The between-run variability was estimated by pooling $\eta$ data from similar temperatures (within $1^{\circ} \mathrm{C}$ ). To estimate the correct degrees of freedom, a method called the "Satterwaithe" procedure was employed for each model (Neter et al. 1990). This procedure pools the estimates and their 
degrees of freedom to provide an estimate such that the uncertainties can be combined. The estimate of total variance is the combination of the between-run and within-run variances.

Once the total estimates of uncertainty were estimated, $95 \%$ confidence intervals were constructed to compare the measured PNNL glasses to the NIST standards (function of $\eta$ ). An asymptotic t-distribution is appropriate for estimating the intervals, using the degrees of freedom derived from the Satterwaithe procedure and the combined estimate of within-run and betweenrun uncertainty from the variance-covariance matrix and the between-run variability. The measured $\eta$ interval corresponded with that reported by the National Bureau of Standards (NBS) for three of the four validation runs over the entire measured-temperature range. However, the measured $\eta$ was slightly higher than the certified values in one of the validation runs (Val-02) at temperatures below $1282^{\circ} \mathrm{C}$. Figure 3.1 compares the $\ln [\eta]-T$ curves for the measured values from run Val-02 (dotted lines) with those reported with the SRM-710a certificate (solid lines) with associated uncertainties. The uncertainty associated with this run (Val-02) was also significantly higher than in the other three runs, giving unusually broad error bands.

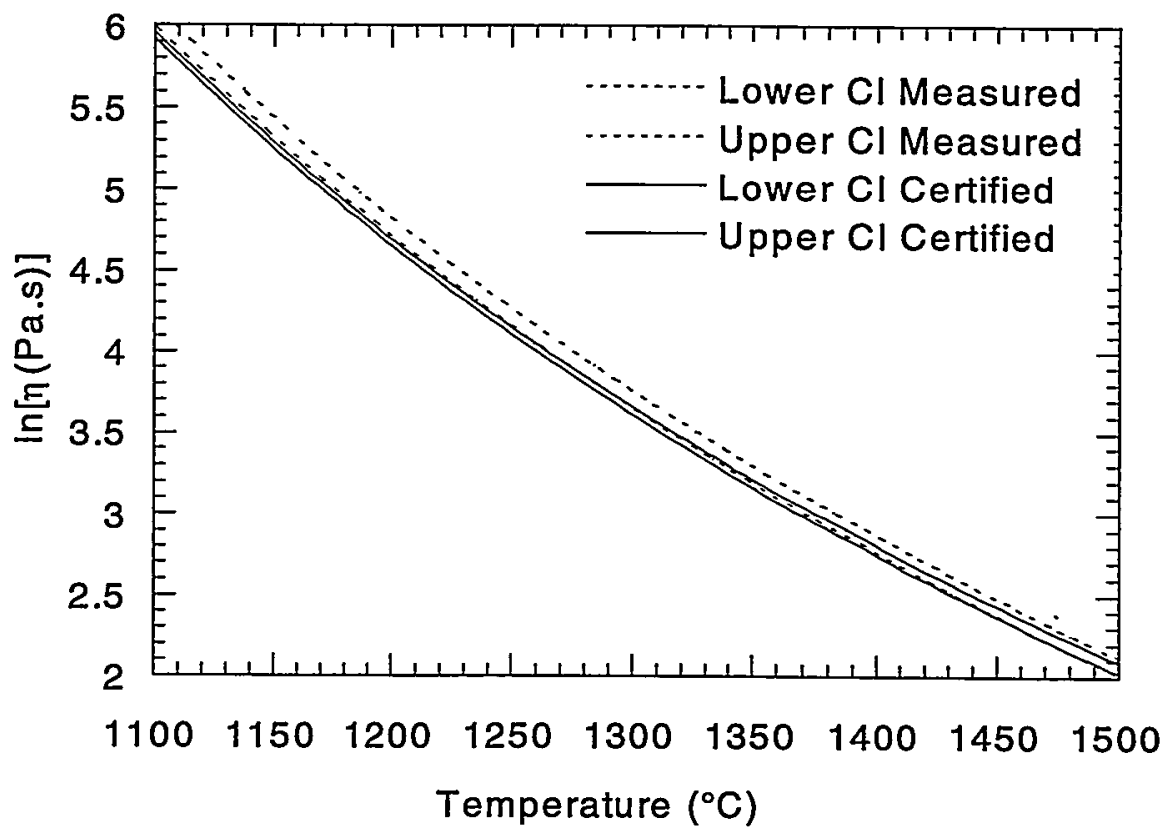

Figure 3.1. Comparison of Measured (Val-02) and Certified $\eta$ for SRM 710a Glass as a Function of Temperature

As the uncertainty of any $\eta$-temperature data point is a combination of the within-run and between-run uncertainties, it is difficult to accurately estimate the uncertainties at any measured point for Phase $\Pi$ test glasses. The within-run uncertainty is estimated using a fit of the VFT data (an estimate of the variability seen that cannot be explained by the model), while the between-run uncertainty is calculated separately. 


\subsection{Discussion of Results}

Detailed results for each glass are described in Appendix A. These descriptions include a discussion of each measurement performed to identify the $\eta-T$ behavior, $T_{L}$, and primary crystalline phase of each glass. The results of the study as a whole are discussed in the following sections. General trends in $T_{L}$ data are given in Section 4.1, and $\eta-T$ data are summarized in Section 4.2.

\subsection{Liquidus Temperature}

The $\mathrm{T}_{\mathrm{L}}$ of the 55 Phase II glasses were between $1153^{\circ} \mathrm{C}(\mathrm{AC2}-52)$ and $1405^{\circ} \mathrm{C}(\mathrm{AC2}-$ 04). Only two glasses had $T_{L} s$ above the $1350^{\circ} \mathrm{C}$ limit, $A C 2-04$ and $A C 2-18$. Two crystal types, rare earth silicates (RESs) and aluminum oxide $\left(\mathrm{Al}_{2} \mathrm{O}_{3}\right)$, were identified as the primary crystalline phases in the Phase II glasses using a combination of XRD, SEM/EDS, and OM. This differs from Phase I glasses in which aluminosilicate crystals were found and $\mathrm{Al}_{2} \mathrm{O}_{3}$ was not. These data are summarized in Table $S .1$. The primary crystalline phase, $T_{L}, T_{A}$, and $T_{C}$ are summarized in Table 4.1 along with notations regarding primary crystalline phase and budding, described in Section 4.1.4. Appendix A (Glass Property Measurements) contains the detailed explanation of $T_{L}$ measurements for each glass, including $T_{L}$ measurement data, OM and SEM micrographs, and analyses results from XRD and EDS.

Table 4.1. $T_{L}$ and Primary Crystalline Phase for $55 \mathrm{Am} / \mathrm{Cm}$ Phase II Glasses

\begin{tabular}{|c|c|c|c|c|c|c|c|c|c|c|}
\hline Glass ID & $\mathrm{T}_{\mathrm{C}}\left({ }^{\circ} \mathrm{C}\right)$ & $\mathrm{T}_{\mathrm{A}}\left({ }^{\circ} \mathrm{C}\right)$ & $\mathrm{T}_{\mathrm{L}}\left({ }^{\circ} \mathrm{C}\right)$ & Phase & buds & Glass ID & $\mathrm{T}_{\mathrm{C}}\left({ }^{\circ} \mathrm{C}\right)$ & $\mathrm{T}_{\mathrm{A}}\left({ }^{\circ} \mathrm{C}\right)$ & $\mathrm{T}_{\mathrm{L}}\left({ }^{\circ} \mathrm{C}\right)$ & Phase buds \\
\hline AC2-01 & 1306 & 1315 & 1308 & RES & & AC2-29 & 1296 & 1306 & 1300 & RES yes \\
\hline AC2-02 & 1252 & 1262 & 1257 & $\mathrm{Al}_{2} \mathrm{O}_{3}$ & & AC2-30 & 1225 & 1236 & 1227 & RES \\
\hline AC2-03 & 1312 & 1315 & 1313 & RES & yes & AC2-31 & 1301 & 1306 & 1305 & RES \\
\hline AC2-04 & 1401 & 1409 & 1405 & RES & & AC2-32 & 1260 & 1265 & 1264 & RES yes \\
\hline $\mathrm{AC} 2-05$ & 1240 & 1241 & 1241 & RES & & AC2-33 & 1265 & 1274 & 1271 & RES yes \\
\hline AC2-06 & 1306 & 1314 & 1309 & RES & yes & AC2-34 & 1225 & 1235 & 1232 & RES \\
\hline AC2-07 & 1204 & 1213 & 1209 & RES & & AC2-35 & 1284 & 1289 & 1289 & RES \\
\hline $\mathrm{AC} 2-08$ & 1241 & 1252 & 1242 & RES & & AC2-36 & 1289 & 1295 & 1294 & RES yes \\
\hline AC2-09 & 1320 & 1327 & 1323 & RES & yes & AC2-37 & 1302 & 1307 & 1305 & RES \\
\hline AC2-10 & 1252 & 1261 & 1255 & RES & & AC2-38 & 1306 & 1312 & 1308 & RES \\
\hline AC2-11 & 1289 & 1295 & 1292 & $\mathrm{Al}_{2} \mathrm{O}_{3}$ & yes & AC2-39 & 1314 & 1321 & 1318 & RES \\
\hline $\mathrm{AC} 2-12$ & 1328 & 1335 & 1333 & RES & & AC2-40 & 1321 & 1328 & 1325 & RES yes \\
\hline AC2-13 & 1179 & 1185 & 1181 & RES & yes & AC2-41 & 1320 & 1327 & 1324 & RES yes \\
\hline AC2-14 & 1246 & 1252 & 1250 & $\mathrm{Al}_{2} \mathrm{O}_{3}$ & & AC2-42 & 1179 & 1191 & 1180 & RES \\
\hline AC2-15 & 1275 & 1283 & 1279 & RES & & AC2-43 & 1225 & 1236 & 1227 & RES \\
\hline AC2-16 & 1295 & 1299 & 1298 & $\mathrm{Al}_{2} \mathrm{O}_{3}$ & yes & $A C 2-44$ & 1302 & 1307 & 1305 & RES yes \\
\hline AC2-17 & 1265 & 1275 & 1273 & RES & & AC2-45 & 1255 & 1260 & 1259 & RES \\
\hline $\mathrm{AC} 2-18$ & 1364 & 1374 & 1366 & RES & & AC2-46 & 1328 & 1335 & 1333 & RES yes \\
\hline AC2-19 & 1242 & 1252 & 1249 & RES & & AC2-47 & 1265 & 1274 & 1272 & RES yes \\
\hline $\mathrm{AC} 2-20$ & 1336 & 1349 & 1343 & RES & yes & $\mathrm{AC} 2-48$ & 1179 & 1185 & 1181 & RES \\
\hline
\end{tabular}




\begin{tabular}{llllllllll}
\hline Glass ID & $\mathrm{T}_{\mathrm{C}}\left({ }^{\circ} \mathrm{C}\right)$ & $\mathrm{T}_{\mathrm{A}}\left({ }^{\circ} \mathrm{C}\right)$ & $\mathrm{T}_{\mathrm{L}}\left({ }^{\circ} \mathrm{C}\right)$ & $\mathrm{Phase}$ buds & Glass $\mathrm{ID}$ & $\mathrm{T}_{\mathrm{C}}\left({ }^{\circ} \mathrm{C}\right)$ & $\mathrm{T}_{\mathrm{A}}\left({ }^{\circ} \mathrm{C}\right)$ & $\mathrm{T}_{\mathrm{L}}\left({ }^{\circ} \mathrm{C}\right)$ & Phase buds \\
\hline $\mathrm{AC} 2-21$ & 1240 & 1249 & 1242 & $\mathrm{Al}_{2} \mathrm{O}_{3}$ & $\mathrm{AC} 2-49$ & 1219 & 1226 & 1220 & RES \\
$\mathrm{AC} 2-22$ & 1283 & 1287 & 1284 & $\mathrm{RES}$ & $\mathrm{AC} 2-50$ & 1265 & 1274 & 1272 & RES yes \\
$\mathrm{AC} 2-23$ & 1278 & 1284 & 1282 & $\mathrm{Al}_{2} \mathrm{O}_{3}$ yes & $\mathrm{AC} 2-51$ & 1300 & 1307 & 1305 & $\mathrm{RES}$ \\
$\mathrm{AC} 2-24$ & 1313 & 1321 & 1319 & $\mathrm{RES}$ & $\mathrm{AC} 2-52$ & 1150 & 1158 & 1153 & $\mathrm{RES}$ \\
$\mathrm{AC} 2-25$ & 1299 & 1314 & 1305 & $\mathrm{Al}_{2} \mathrm{O}_{3}$ & $\mathrm{AC} 2-53$ & 1191 & 1197 & 1192 & $\mathrm{RES}$ \\
$\mathrm{AC} 2-26$ & 1204 & 1210 & 1208 & $\mathrm{RES}$ & $\mathrm{AC} 2-54$ & 1321 & 1328 & 1326 & $\mathrm{RES}$ yes \\
$\mathrm{AC} 2-27$ & 1241 & 1242 & 1242 & $\mathrm{RES}$ & $\mathrm{AC} 2-55$ & 1249 & 1257 & 1255 & $\mathrm{RES}$ yes \\
$\mathrm{AC} 2-28$ & 1249 & 1264 & 1260 & $\mathrm{Al}_{2} \mathrm{O}_{3}$ & & & & & \\
\hline
\end{tabular}

\subsubsection{Rare Earth Silicate Crystals}

RES was the primary phase in 47 of the 55 glasses; however, we observed four distinct morphologies of the RES when identifying these crystals: needle-like (thin and straight), hairlike (thin and wavy), plate-like, and rectangular cap. Each crystal shape was analyzed using SEM. EDS coupled to SEM showed $\mathrm{Si}, \mathrm{La}, \mathrm{Nd}$, and $\mathrm{O}$ as major components and $\mathrm{Ce}, \mathrm{Pr}, \mathrm{Sm}$, $\mathrm{Gd}$, and $\mathrm{Er}$ as minor components in the crystals. $\mathrm{Al}$ is present as a minor component in some crystals, but not in others. Chemically, the RES crystals are the same regardless of morphology. Samples analyzed by XRD matched the crystal structure of neodymium germanium borate silicate $\left(\mathrm{Nd}_{3} \mathrm{BGe}_{1.08} \mathrm{Si}_{0.92} \mathrm{O}_{10}\right)$. In this crystal structure, Ge could be replaced by $\mathrm{Si}$ and $\mathrm{Nd}$ could be replaced by rare earth elements to form $\mathrm{RE}_{3} \mathrm{BSi}_{2} \mathrm{O}_{10}$, the crystal type that is probably present in these samples. Generally, the glasses within the RES primary phase field showed massive crystallinity (i.e., $>30 \mathrm{vol} \% \mathrm{RES}$ ) after a $24 \mathrm{~h}$ heat treatment at temperatures between $3^{\circ} \mathrm{C}$ and $30^{\circ} \mathrm{C}$ below $T_{L}$. As RES crystals are difficult to redissolve once crystallized, this observation should be considered when planning for off-normal operating scenarios.

The RES crystals observed as needle-shaped crystals were found individually and clustered at a focal point with the needles pointing out in all directions, both found in Figure 4.1. The size of the crystals had a wide range in length from $<0.1 \mathrm{~mm}$ to $>1.0 \mathrm{~mm}$, and were approximately $1 \mu \mathrm{m}$ to $>10 \mu \mathrm{m}$ thick.

Associated with the needle crystals are hair-like crystals, found within or near the needle clusters (Figure 4.2a). These crystals are very thin $(<0.5 \mu \mathrm{m})$ and long $(>100 \mu \mathrm{m})$ and curved like an eyebrow. Occasionally they are observed in a coil. These crystals may be straight also, but they are so thin that they are difficult to observe by OM. However, they are very distinct when they curve or coil. SEM/EDS scans indicated a similar chemical composition for both needle and hair-like RES crystals.

Plate-like, RES crystals (Figure $4.2 \mathrm{~b}$ and Figure 4.3 ) were found in many of the samples. Unlike the plate-like RES in Phase I, some of the plate-like crystals in Phase II developed unusual structures at the narrow end of the rectangular or lathe shaped crystal (Figure 4.4 and Figure 4.5). SEM/EDS analysis found no change in chemical composition of the crystals even with the unique shapes. 


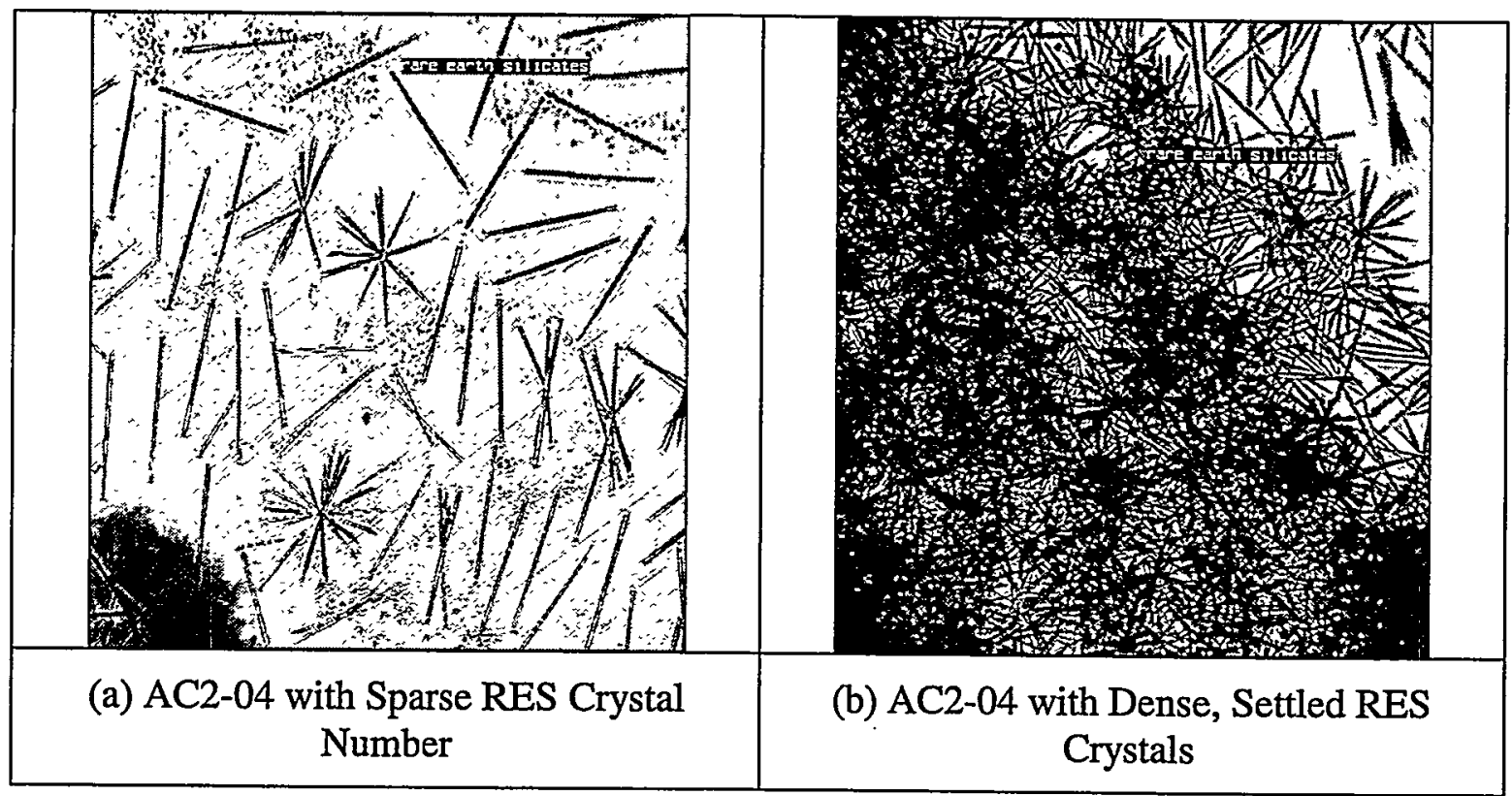

Figure 4.1. Examples of Needle-Like RES Crystals

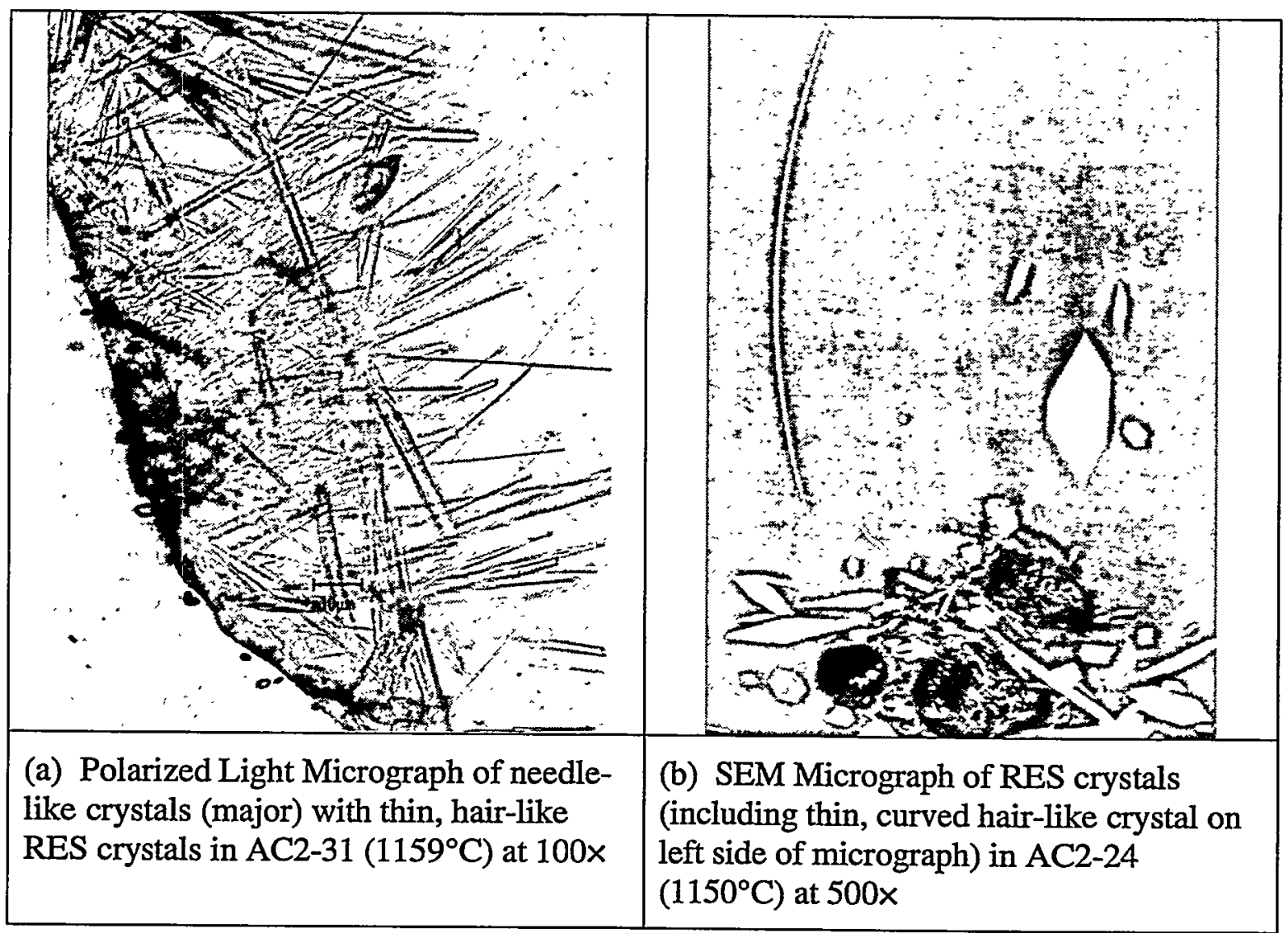

Figure 4.2. Examples of Needle-Like, Hair-Like, and Plate-Like RES Crystals 


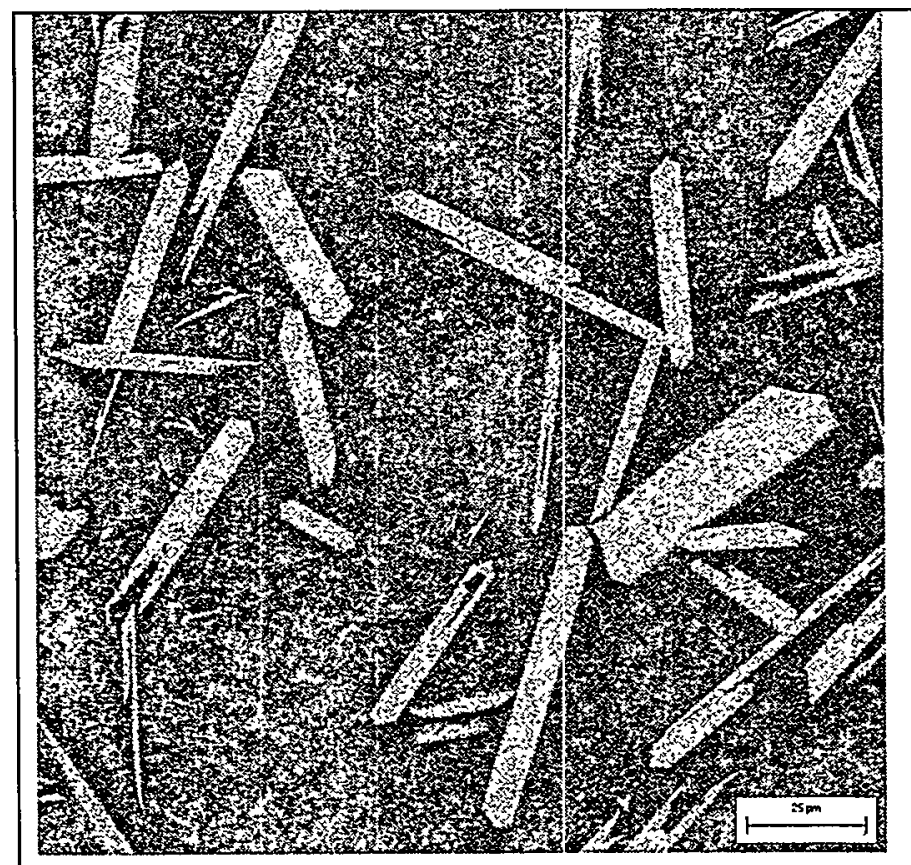

Figure 4.3. SEM Micrograph of Plate-Like RES Crystals in $\mathrm{AC} 2-44\left(1302^{\circ} \mathrm{C}\right)$

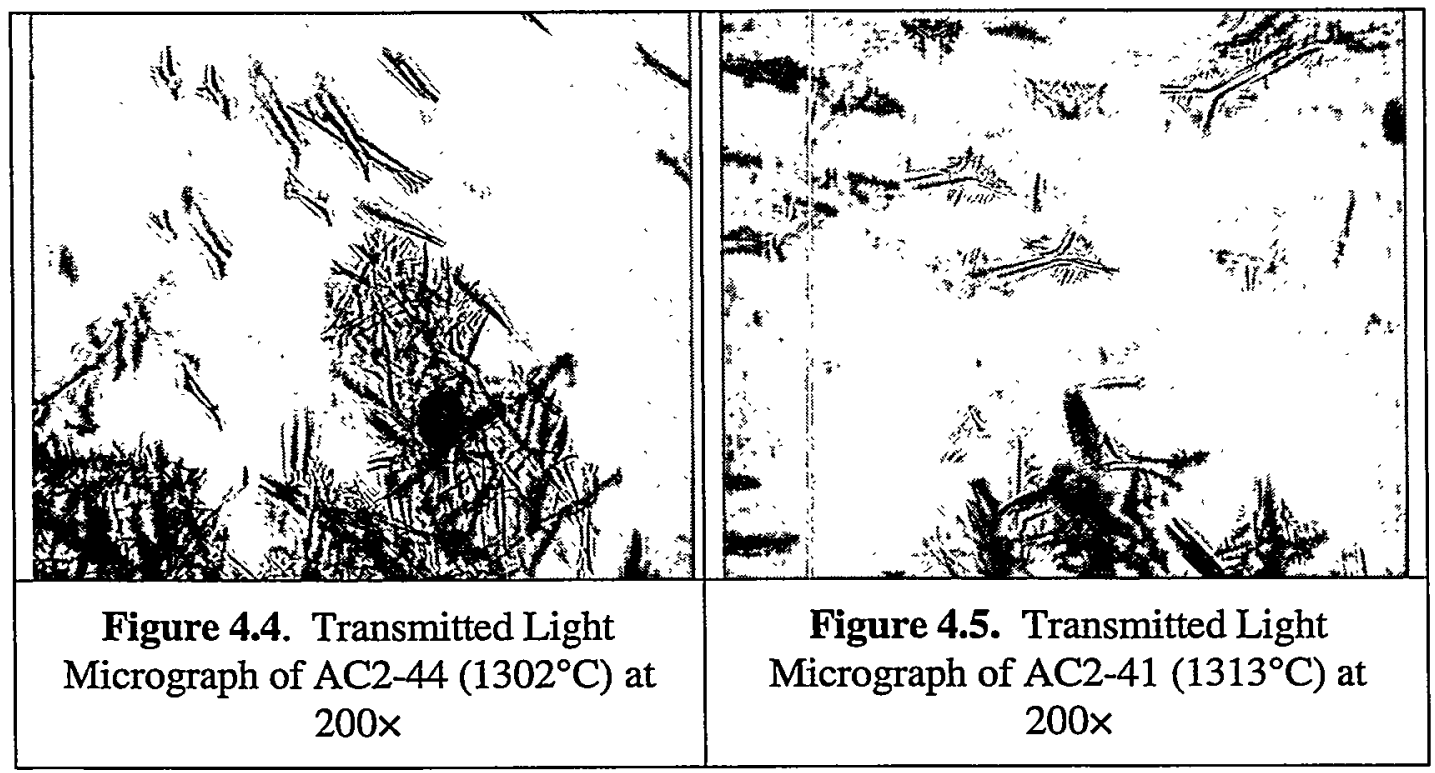

Another unique crystal shape, observed only in the Phase II study, is the rectangular cap (Figure 4.6) found in seven samples: AC2-09 $\left(1314^{\circ} \mathrm{C}\right), \mathrm{AC} 2-29\left(1288^{\circ} \mathrm{C}\right), \mathrm{AC} 2-40\left(1321^{\circ} \mathrm{C}\right)$, $\mathrm{AC} 2-41\left(1321^{\circ} \mathrm{C}\right), \mathrm{AC} 2-44\left(1321^{\circ} \mathrm{C}\right), \mathrm{AC} 2-46\left(1321^{\circ} \mathrm{C}\right)$, and $\mathrm{AC} 2-54\left(1321^{\circ} \mathrm{C}\right)$. This RES crystal shape is found in samples with dense crystal numbers, crystals settling on the bottom, and 
the top smooth glass surface. The rectangular cap crystals are found floating on the surface in the middle of the sample, not near other crystal types. Many samples were thin-sectioned in an attempt to analyze this odd-shaped crystal type, but the rectangular cap was never found below the surface. AC2-46 was sent as a bulk sample, and the surface was analyzed by SEM/EDS. The EDS scan on these crystals had a similar profile to that of RES crystals with other shapes.

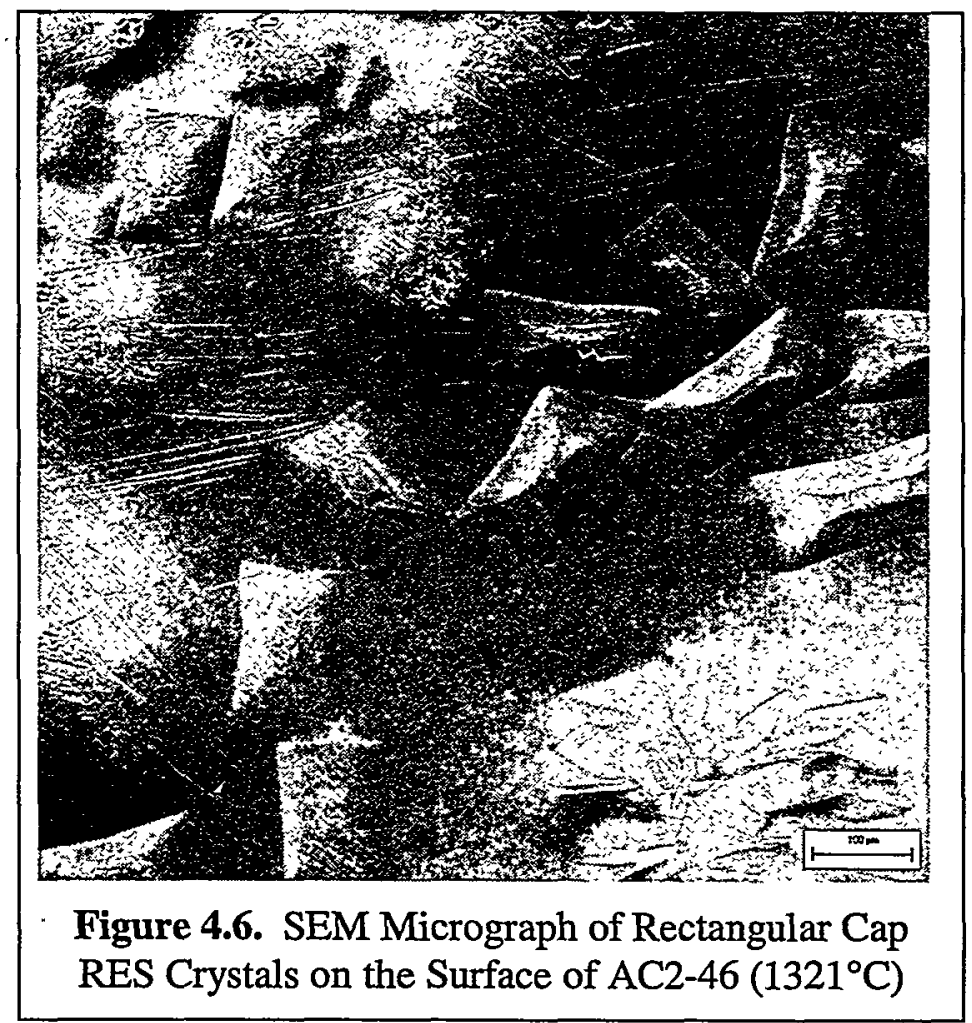

\subsubsection{Aluminum Oxide Crystals}

Aluminum oxide was identified as the primary phase in 8 Phase $I$ glasses (see Table 4.1). Two distinct $\mathrm{Al}_{2} \mathrm{O}_{3}$ crystal morphologies formed in the same melt, a plate-like crystal (Figure 4.7a) and a garnet shaped crystal (Figure 4.7b). SEM/EDS identified high aluminum and oxygen concentrations in both crystal types (Figure 4.8, along with Figure 4.9 and Figure 4.10). No chemical difference between the two differently shaped crystals could be detected. Many samples of glasses crystallizing $\mathrm{Al}_{2} \mathrm{O}_{3}$ were analyzed by $\mathrm{XRD}$, with no conclusive results. Therefore, the structure(s) of the $\mathrm{Al}_{2} \mathrm{O}_{3}$ crystals was not identified.

In glasses with $\mathrm{Al}_{2} \mathrm{O}_{3}$ as the primary phase, RES formed as a secondary phase at $30^{\circ} \mathrm{C}$ to $40^{\circ} \mathrm{C}$ below $T_{L}$. In samples that were 50 to $100^{\circ} \mathrm{C}<\mathrm{T}_{\mathrm{L}}$, RES crystals would be very high (in both size and number density of crystals), and $\mathrm{Al}_{2} \mathrm{O}_{3}$ crystals would not be found. The $\mathrm{Al}_{2} \mathrm{O}_{3}$ crystal was never found in samples where RES was the primary phase, except when budding was observed (see Section 4.1.4 for a description of budding and Appendix A for further details) where $\mathrm{Al}_{2} \mathrm{O}_{3}$ crystals were detected by SEM/EDS in the buds. 


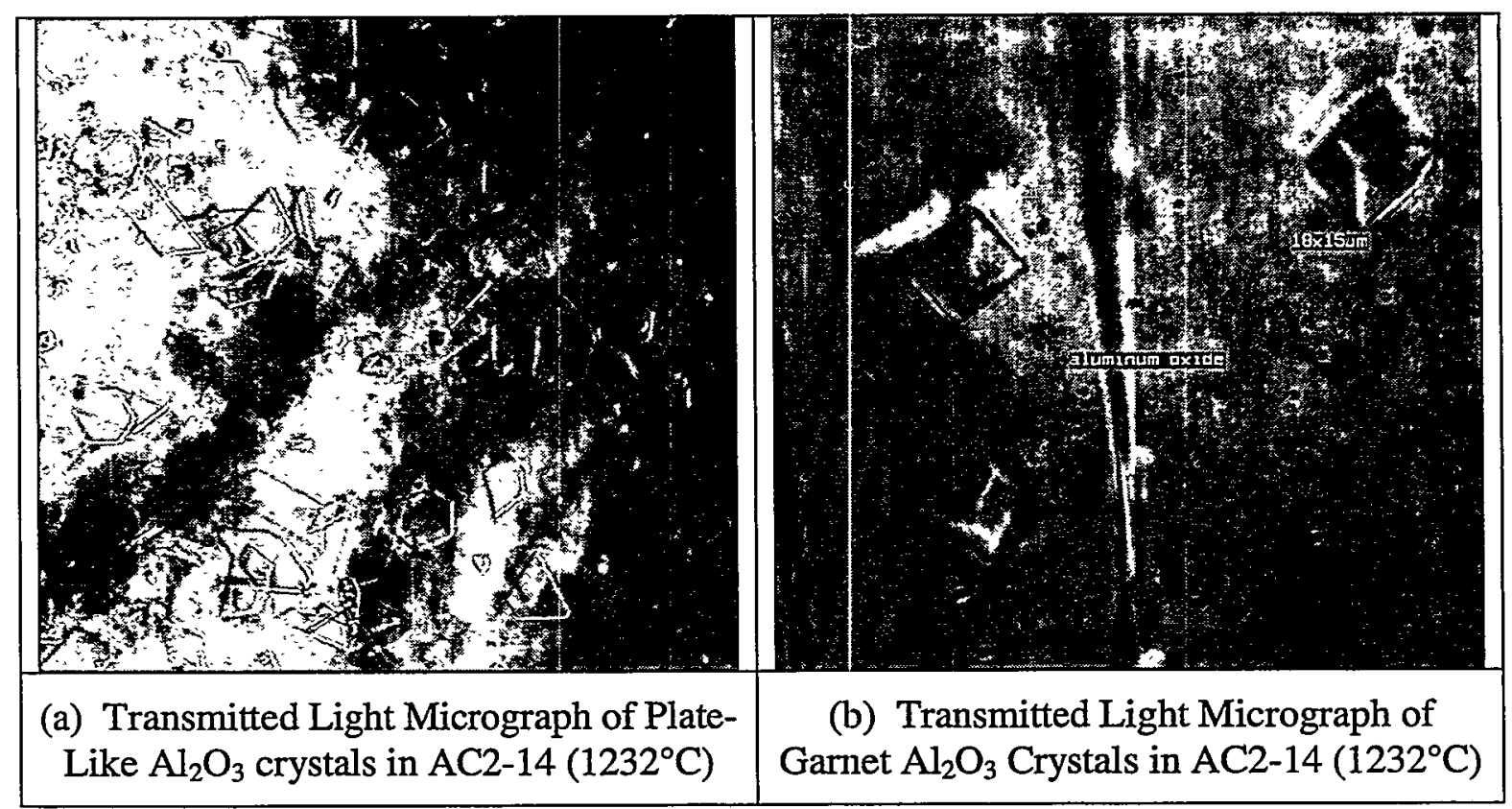

Figure 4.7. Aluminum Oxide Crystals

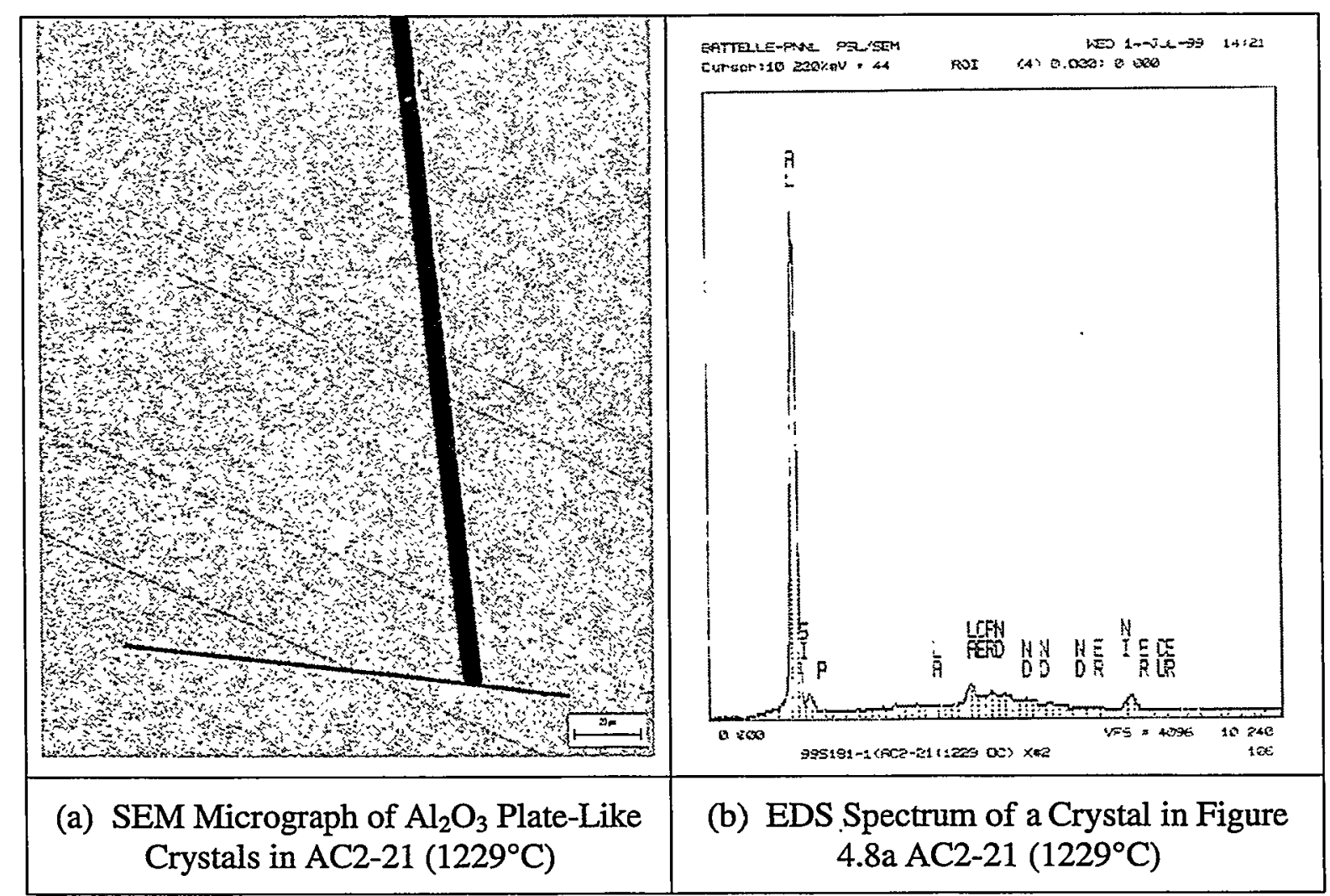

Figure 4.8. SEM Analysis of $\mathrm{AC} 2-21\left(1229^{\circ} \mathrm{C}\right)$ 


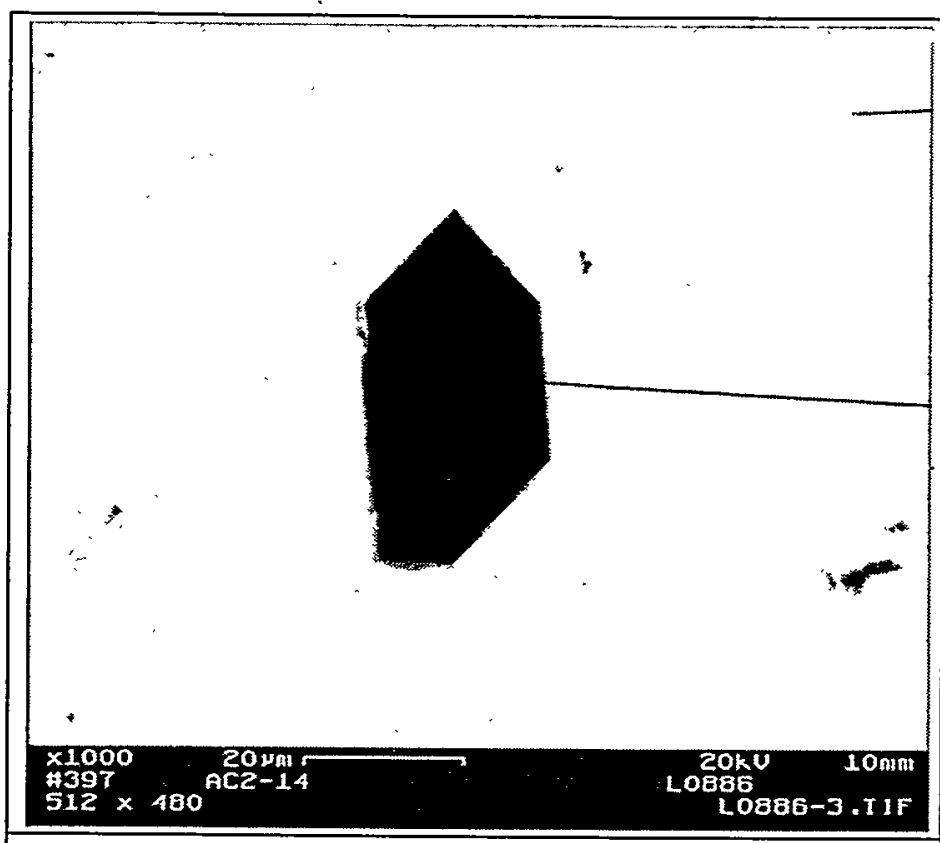

Figure 4.9. SEM Micrograph of a Garnet Shaped $\mathrm{Al}_{2} \mathrm{O}_{3}$ Crystal in $\mathrm{AC} 2-14\left(1232^{\circ}\right)$,

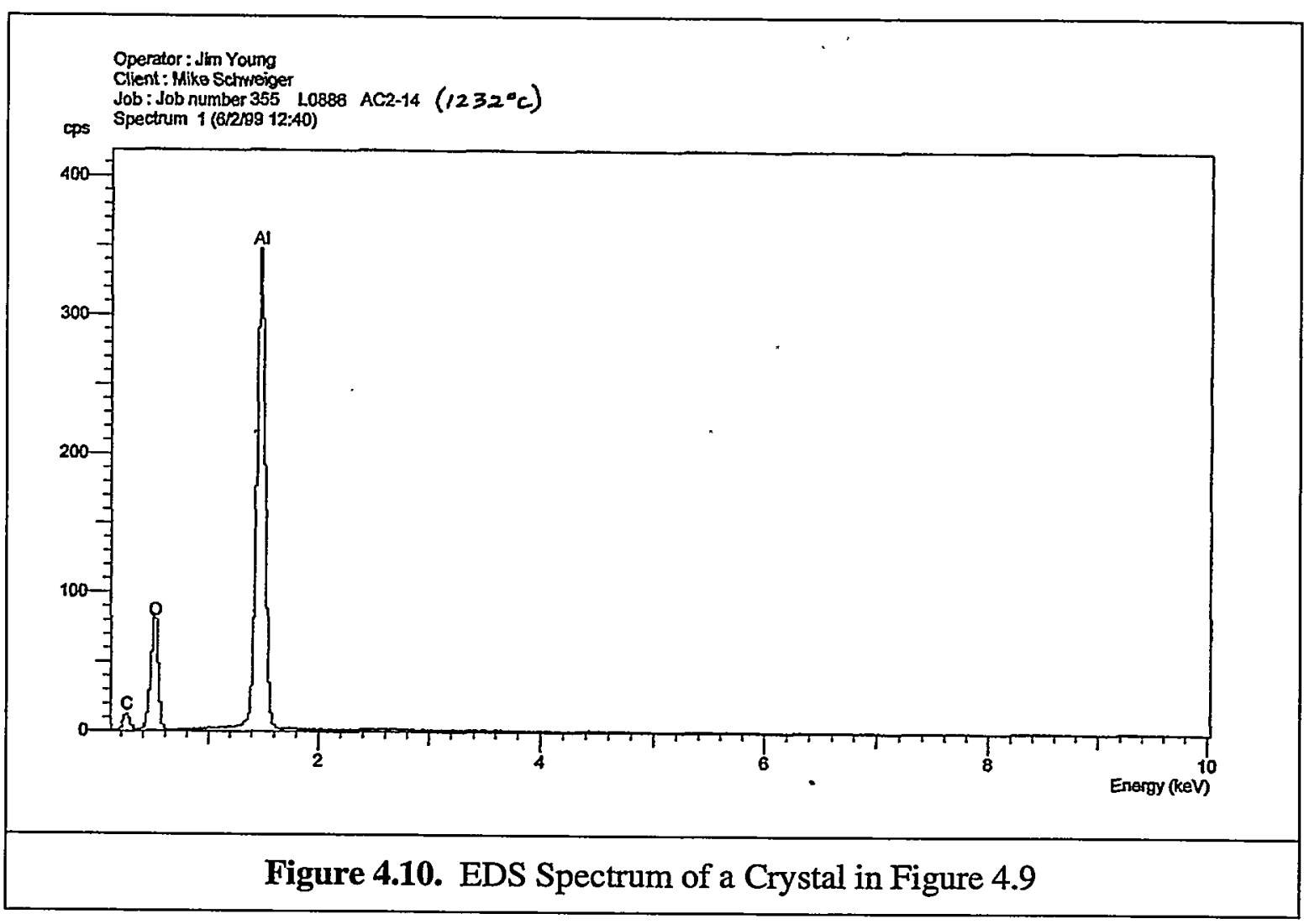




\subsection{3 “As-Received" Glasses}

"As-Received" glasses were analyzed by OM to determine if crystalline or immiscible liquid phases existed. Three glasses, AC2-04, -18, and -19, were found to have RES crystals present in streaks as minor inclusions. The crystals appear very similar to those found in AC204 (see Figure 4.1). The crystal fraction is not determined, but was estimated to be well less than 1 percent. Only a few scattered crystals were found in AC2-19. All other samples appeared to be free of crystals based on OM analyses.

\subsubsection{Sample "Budding"}

Some of the heat-treated samples displayed a phenomenon coined "budding." In these samples, nodes or buds would form at the folds of the box crucible as shown in Figure 4.11. This phenomenon was thought to be caused when a portion of the melt was pulled by capillary force to the top of the $\mathrm{Pt}$ folds and exposed to the open atmosphere. This phenomenon was not consistent. In other words, no pattern for the behavior was determined. If budding occurred, it would happen once, sometimes twice, in the series of heat treatments for the glass, usually at one of the highest temperatures runs, but not consistently at the highest heat-treatment temperature. This phenomenon was also observed in some glasses during Phase I testing, but only with a few samples. Forty percent of the Phase II glasses experienced budding in some heat-treated samples (see Table 4.1 and the "Comments" section of the Heat-Treatment Summary for Determination of $T_{L}$ for each glass in Appendix A).

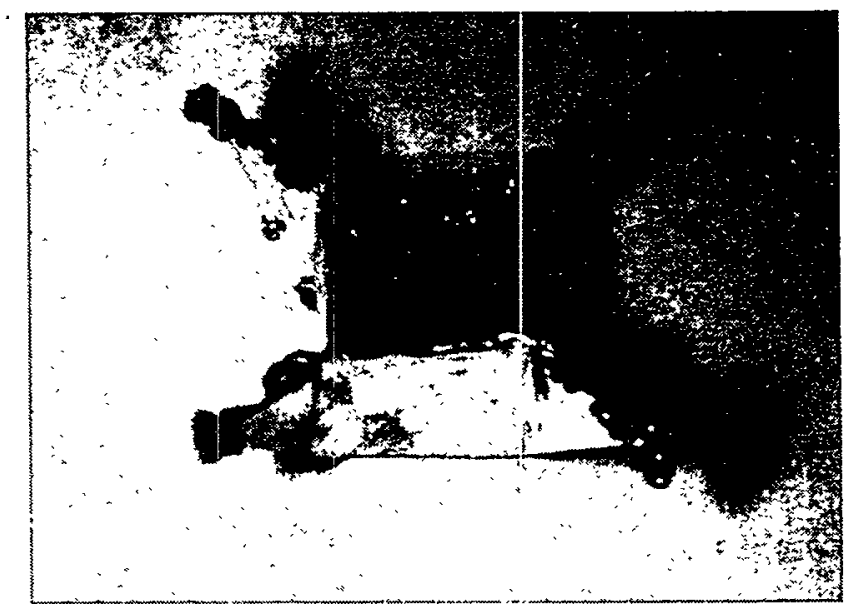

Figure 4.11. Photograph of Buds on Crucible Edges

Buds that formed on heat-treated crucible walls were dull, opaque, and rough, having lost the appearance of the smooth, highly reflective glass surface. AC2-16, heat treated at $1297^{\circ} \mathrm{C}$, had buds form on the crucible folds. Figure 4.12 is an SEM micrograph of the wing of the platinum box crucible of this sample. The platinum wall of the fold can be seen as a smooth metallic section at the base of the picture. The buds were found on the top of the platinum folds 
and appear as undulating mounds. Figure 4.13 is a magnified area of Figure 4.12 and shows the crystals densely packed on the surface of the bud.

Glass AC2-29 heat treated at $1299^{\circ} \mathrm{C}$ also formed small buds. This sample was examined by SEM (Figure 4.14), polished with 600-grit polishing paper, and re-examined (Figure 4.15). SEM micrographs show densely packed crystals at the surface of the bud (see magnified area of bud surface-Figure 4.16), but within 50 microns of the surface, the crystal number density diminishes. The surface layer contains both RES (light gray crystal phase justified in Figure 4.17) and $\mathrm{Al}_{2} \mathrm{O}_{3}$ crystals (black phase justified in Figure 4.18), but below this dense crystal layer, $\mathrm{Al}_{2} \mathrm{O}_{3}$ crystals did not exist. RES crystals observed in the remaining cross section of the polished sample were estimated at 3 to 5 volume percent by visual inspection.

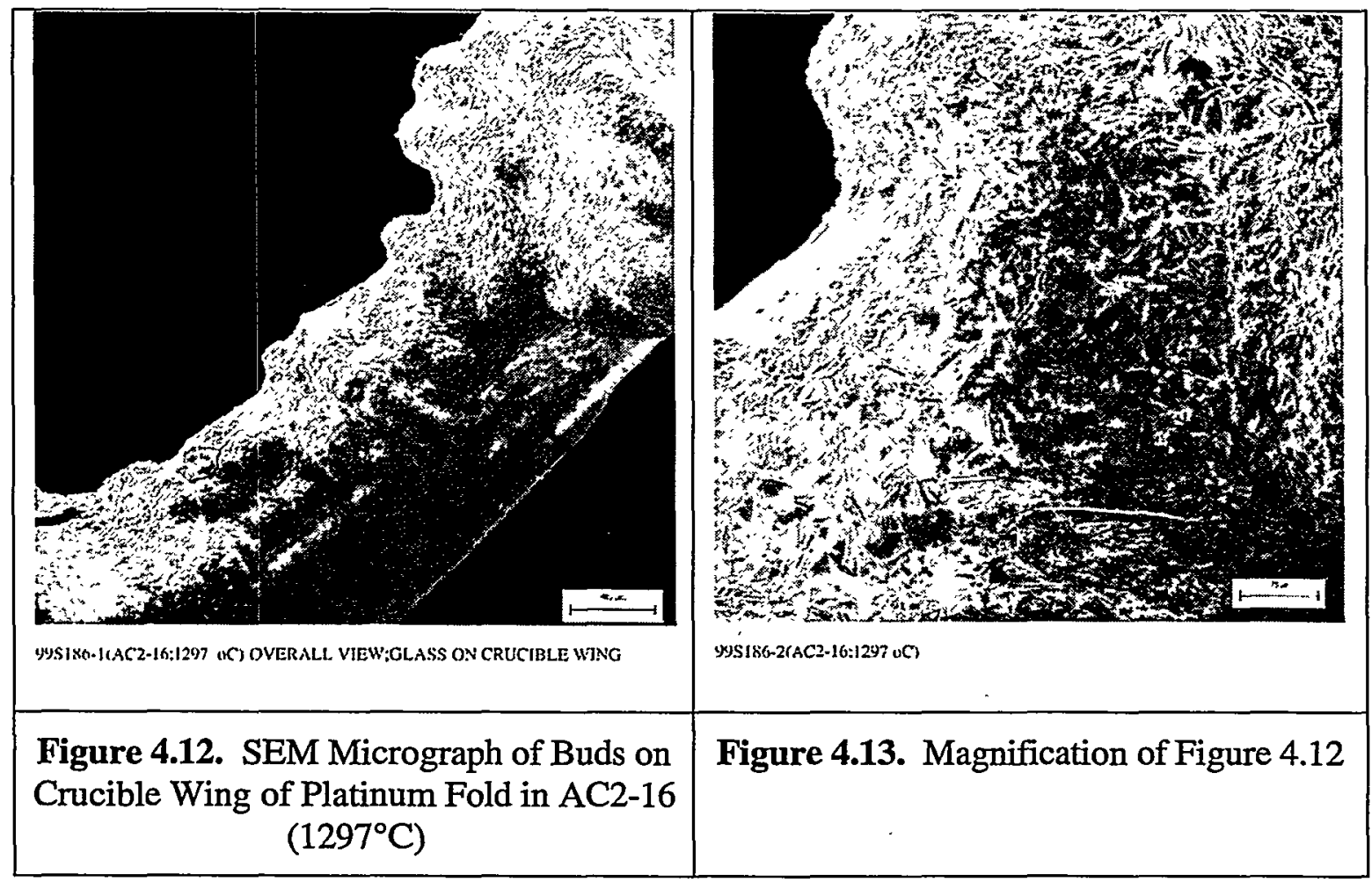

Budding was not found to affect $T_{L}$ measurement. Several samples were tested in crucibles where the wings were folded in tightly, and a platinum lid covered the entire top of the crucible during sample heat treatment. No differences existed between these samples and those heat treated at the same temperatures that produced buds. Budding is a localized effect that does not appear to change conditions in the bulk glass. 

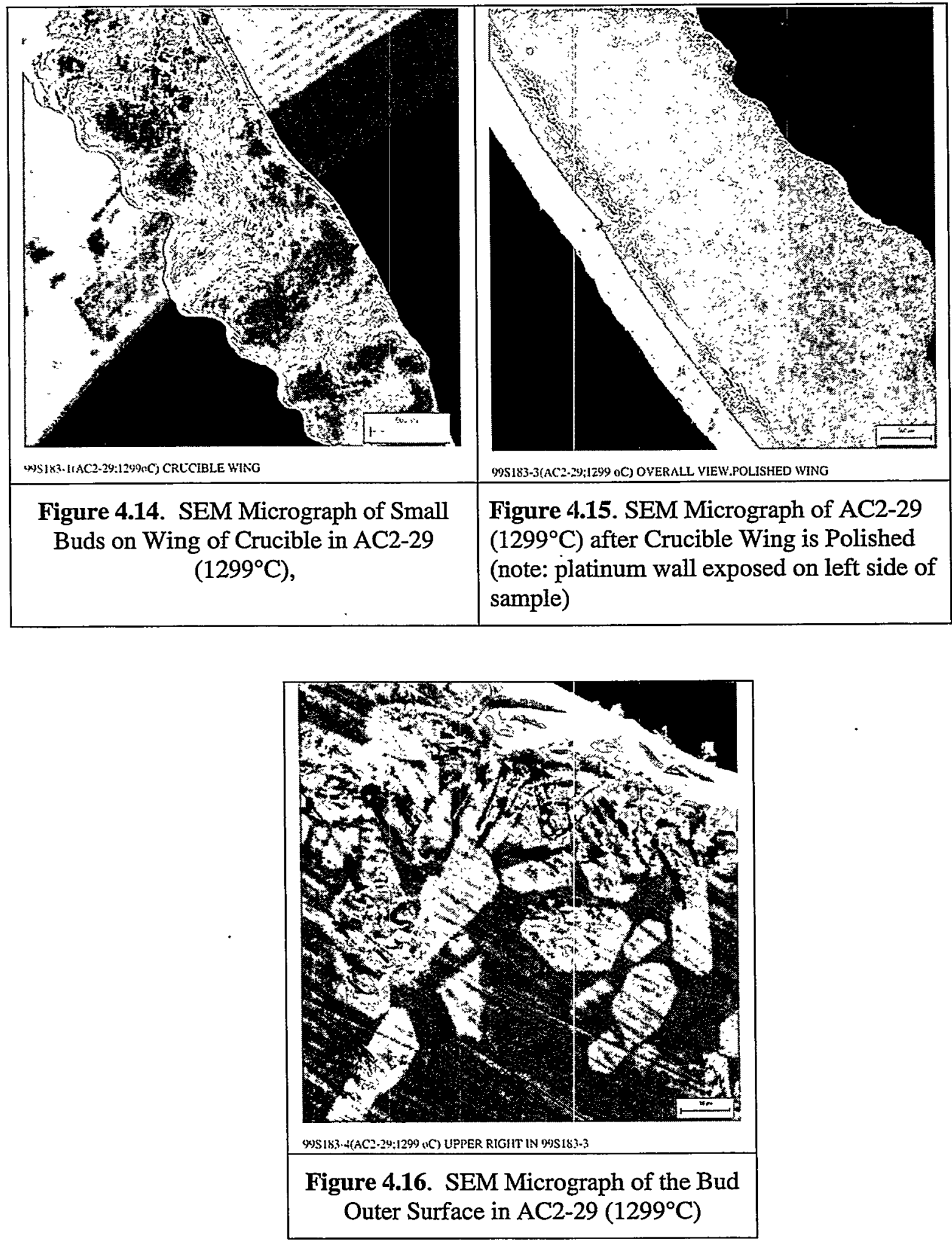


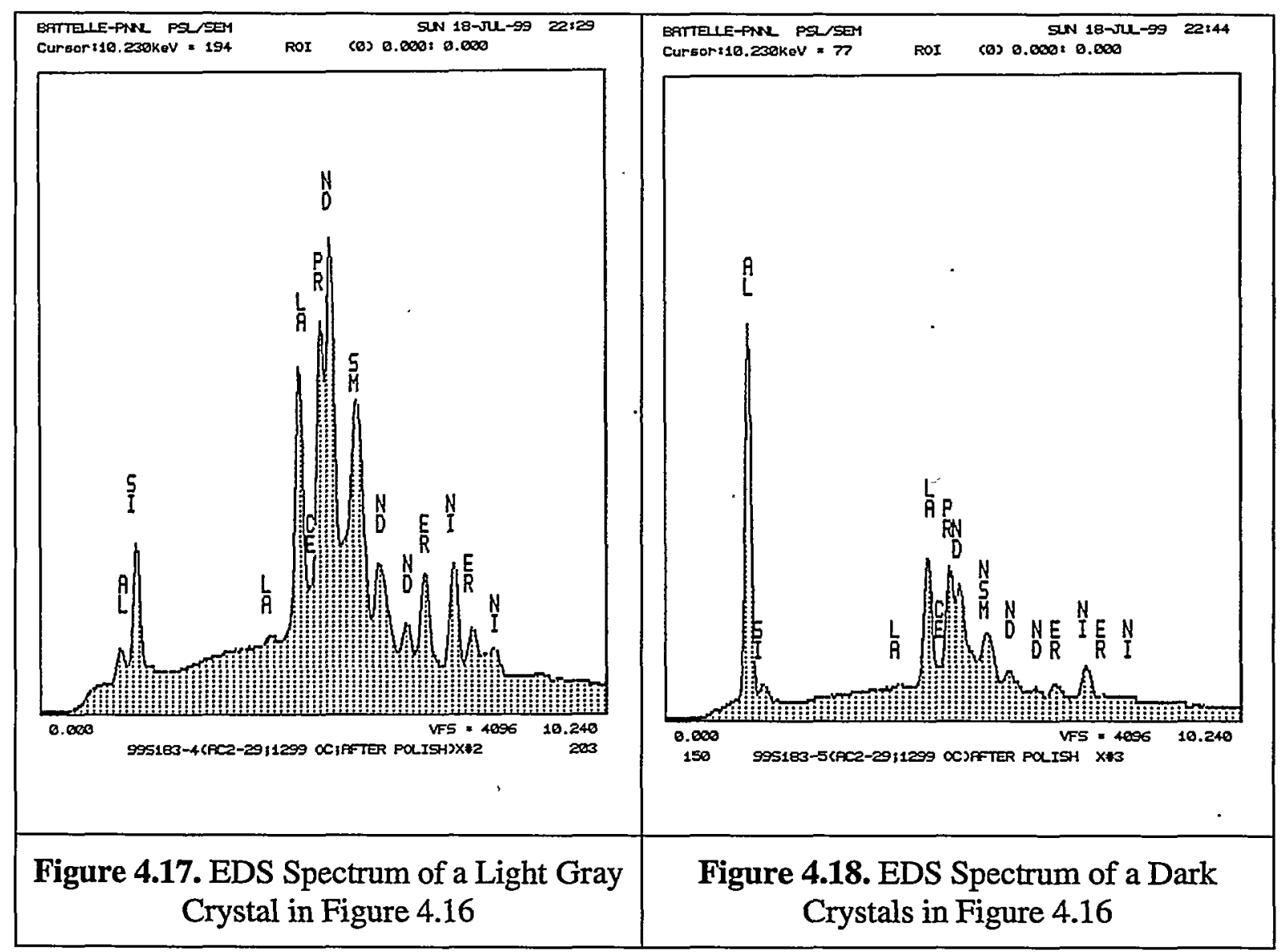

\subsubsection{Quantitative Analysis of RES Crystals by SEM}

Quantitative SEM/EDS analyses ${ }^{\mathrm{b}}$ were performed to determine if differences in chemical composition occurred in the RES crystals. Glasses AC2-04 heat-treated at $1398^{\circ} \mathrm{C}$ and AC2-05 heat treated at $1223^{\circ} \mathrm{C}$ were chosen for the analysis since there was a large difference in $T_{L}$ values, $1405^{\circ} \mathrm{C}$ for $\mathrm{AC2}-04$ and $1241^{\circ} \mathrm{C}$ for $\mathrm{AC2}-05$. In addition, the bulk chemical composition was quite different between the two glasses. Therefore, we expect a difference in the chemical composition of the RES crystals formed in the two glasses. The RES crystals in the two glass samples were different sizes. The RES crystals found in AC2-04 were 5 to 10 times longer than those found in AC2-05, though they were both needle-shaped crystals.

${ }^{b}$ Analysis was performed on an elemental basis using $\mathrm{Al}_{2} \mathrm{O}_{3}, \mathrm{SiO}_{2}$ (quartz), $\mathrm{LaB}_{6}, \mathrm{CeO}_{2}, \mathrm{PrF}_{3}$, $\mathrm{NdF}_{3}, \mathrm{GdF}_{3}$, and $\mathrm{ErF}_{3}$ as instrument calibration standards for their representative elements. To correct for X-ray absorbency and fluorescence, a mathematical iteration (quantitative ZAF correction method) was applied. The comparison between SEM glass-matrix composition analysis and the normalized target composition (mole percent) had an error margin of less than \pm 10 percent for all major elements. 
The analyzed crystal compositions are listed in Table 4.2, and glass compositions are listed in Table 4.3. On a mole-percent basis, Si was the major element in the RES crystal structure (40.5\% in AC2-04 and between 43.6 to $46.4 \%$ for AC2-05). The Si concentration in glass appears to influence the RES crystal composition. As Si increased in the glass composition from 30.6 mole percent in AC2-04 glass to 37.6 mole percent in AC2-05 glass, so did its concentration in the crystal structure (again 40.5 to about 45 mole percent). Lanthanum, the element with the second highest concentration in both the crystal structure and glass, also increased from 23.65 mole percent in AC2-04 to about 26 mole percent in AC2-05. This is not intuitive since the concentration of $\mathrm{La}$ in the glass decreases from 18.2 mole percent in $\mathrm{AC} 2-04$ to 14.3 mole percent in AC2-05 (measured by EDS) and from 16.1 mole percent to 13.9 mole percent (target composition) for AC2-04 and AC2-05, respectively. Similarly, Ce concentration in the RES crystal increased while its concentration in the base glass decreased. Praseodymium and $\mathrm{Nd}$ followed the expected pattern of increasing in concentration in the crystal with higher concentration in the base glass. The most notable difference is in the concentration of $\mathrm{Al}$ in the two crystals. This evidence, however, does not suggest a different crystal type as Al is only a minor element in both spectra, and the total rare earth concentration in both crystals is similar.

Table 4.2. Quantitative Analysis of Crystals in Glass (in mole percent metals normalized to100)

\begin{tabular}{lcccc}
\hline & \multicolumn{2}{c}{ AC2-04 } & \multicolumn{2}{c}{ AC2-05 } \\
\hline & Spectrum 1 & Spectrum 2 & Spectrum 1 & Spectrum 2 \\
$\mathrm{Al}$ & 2.19 & 2.63 & 0.42 & 0.22 \\
$\mathrm{Si}$ & 40.41 & 40.62 & 43.67 & 46.37 \\
$\mathrm{La}$ & 23.72 & 23.63 & 26.50 & 25.14 \\
$\mathrm{Ce}$ & 2.54 & 2.69 & 3.50 & 3.35 \\
$\mathrm{Pr}$ & 6.20 & 6.75 & 3.26 & 3.15 \\
$\mathrm{Nd}$ & 20.99 & 21.25 & 12.11 & 11.43 \\
$\mathrm{Sm}$ & not analyzed & not analyzed & 5.07 & 4.87 \\
$\mathrm{Gd}$ & 1.50 & 0.67 & 2.84 & 2.77 \\
$\mathrm{Er}$ & 2.44 & 1.78 & 2.63 & 2.70 \\
\hline Total & 100.00 & 100.00 & 100.00 & 100.00 \\
\hline
\end{tabular}


Table 4.3. Quantitative Analysis of Glass Matrix Compared to Target Composition (in mole percent metals normalized to 100 )

\begin{tabular}{|c|c|c|c|c|}
\hline & \multicolumn{2}{|c|}{ AC2-04 } & \multicolumn{2}{|c|}{ AC2-05 } \\
\hline & & Normalized & & Normalized \\
\hline & SEM Analysis & Target Comp & SEM Analysis & Target Comp \\
\hline $\mathrm{Al}$ & 27.76 & 26.64 & 33.21 & 32.90 \\
\hline $\mathrm{Si}$ & 33.56 & 30.58 & 39.84 & 37.60 \\
\hline $\mathrm{La}$ & 18.23 & 16.11 & 14.28 & 13.93 \\
\hline $\mathrm{Ce}$ & 2.62 & 2.25 & 1.93 & 1.95 \\
\hline $\operatorname{Pr}$ & 4.03 & 5.05 & 1.34 & 1.74 \\
\hline $\mathrm{Nd}$ & 11.64 & 12.55 & 4.85 & 5.98 \\
\hline $\mathrm{Sm}$ & not analyzed & 3.27 & 2.07 & 2.83 \\
\hline Gd & 0.74 & 1.76 & 1.07 & 1.52 \\
\hline $\mathrm{Er}$ & 1.42 & 1.79 & 1.41 & 1.55 \\
\hline Total & 100.00 & 100.00 & 100.00 & 100.00 \\
\hline
\end{tabular}

\subsubsection{Glass Composition Effects}

A linear relationship between $\mathrm{Ln}_{2} \mathrm{O}_{3}$ concentration in glass with $\mathrm{T}_{\mathrm{L}}$ and with a primaryphase boundary was shown for Phase I glasses in Section 1.2.2. The effect of $\mathrm{Ln}_{2} \mathrm{O}_{3}$ concentration on $T_{L}$ of Phase $I$ and II glasses is shown in Figure 4.19. This comparison shows a reasonably close match in $\mathrm{Ln}_{2} \mathrm{O}_{3}$ effect on $\mathrm{T}_{\mathrm{L}}$ for Phase $\mathrm{I}$ and Phase II glasses, despite the fact that $\mathrm{SiO}_{2}, \mathrm{Al}_{2} \mathrm{O}_{3}, \mathrm{~B}_{2} \mathrm{O}_{3}$, and $\mathrm{SrO}$ concentrations varied independently in Phase II glasses and not in Phase I glasses. There is a clear primary-phase boundary between alumino-silicate and RES fields. However, the glass compositions in the $\mathrm{Al}_{2} \mathrm{O}_{3}$ primary phase field are intermixed with those in the RES primary phase field. Further examination of compositions was required to separate the two primary-phase fields. Figure 4.20 shows a composition projection of Phase and II glasses in a $\mathrm{SiO}_{2}-\mathrm{Al}_{2} \mathrm{O}_{3}-\mathrm{Ln}_{2} \mathrm{O}_{3}$ space with primary crystalline phases noted as symbols. A clear distinction between the $\mathrm{RES}$ and $\mathrm{Al}_{2} \mathrm{O}_{3}$ primary-phase fields can be seen by the $\mathrm{Al}_{2} \mathrm{O}_{3} / \mathrm{SiO}_{2}$ ratio. All glasses with a ratio above 1 are in the $\mathrm{Al}_{2} \mathrm{O}_{3}$ primary phase field. 


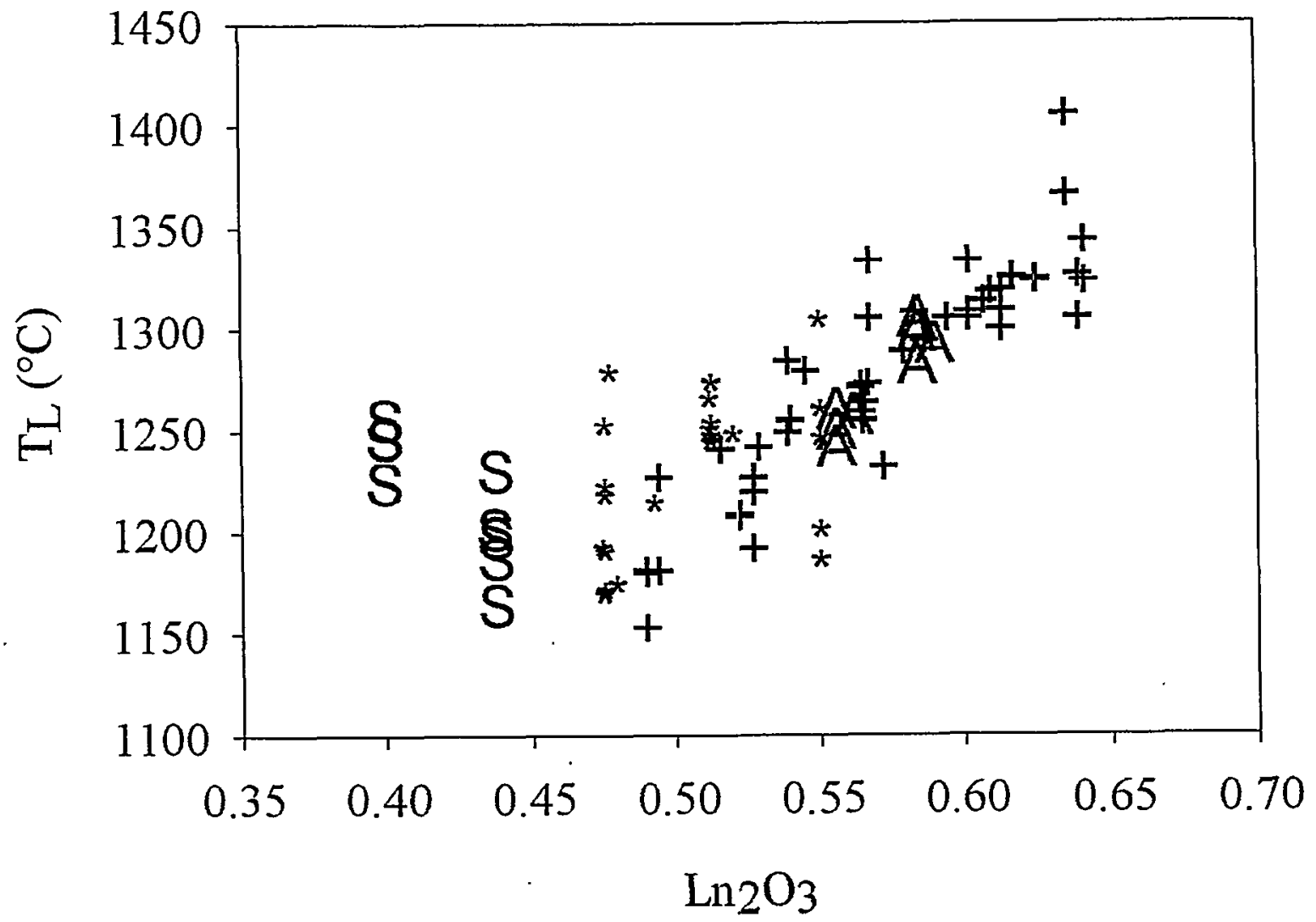

Figure 4.19. $\mathrm{T}_{\mathrm{L}}$ as a Function of $\mathrm{Ln}_{2} \mathrm{O}_{3}$ Concentration (in mass fraction) in Phase $\mathrm{I}$ and $\mathrm{I}$ Glasses (S-Alumino-Silicate Crystals in Phase I Glasses, *-RES Crystals in Phase I Glasses, +RES Crystals in Phase II glasses, and $\mathrm{A}-\mathrm{Al}_{2} \mathrm{O}_{3}$ Crystals in Phase II Glasses) 


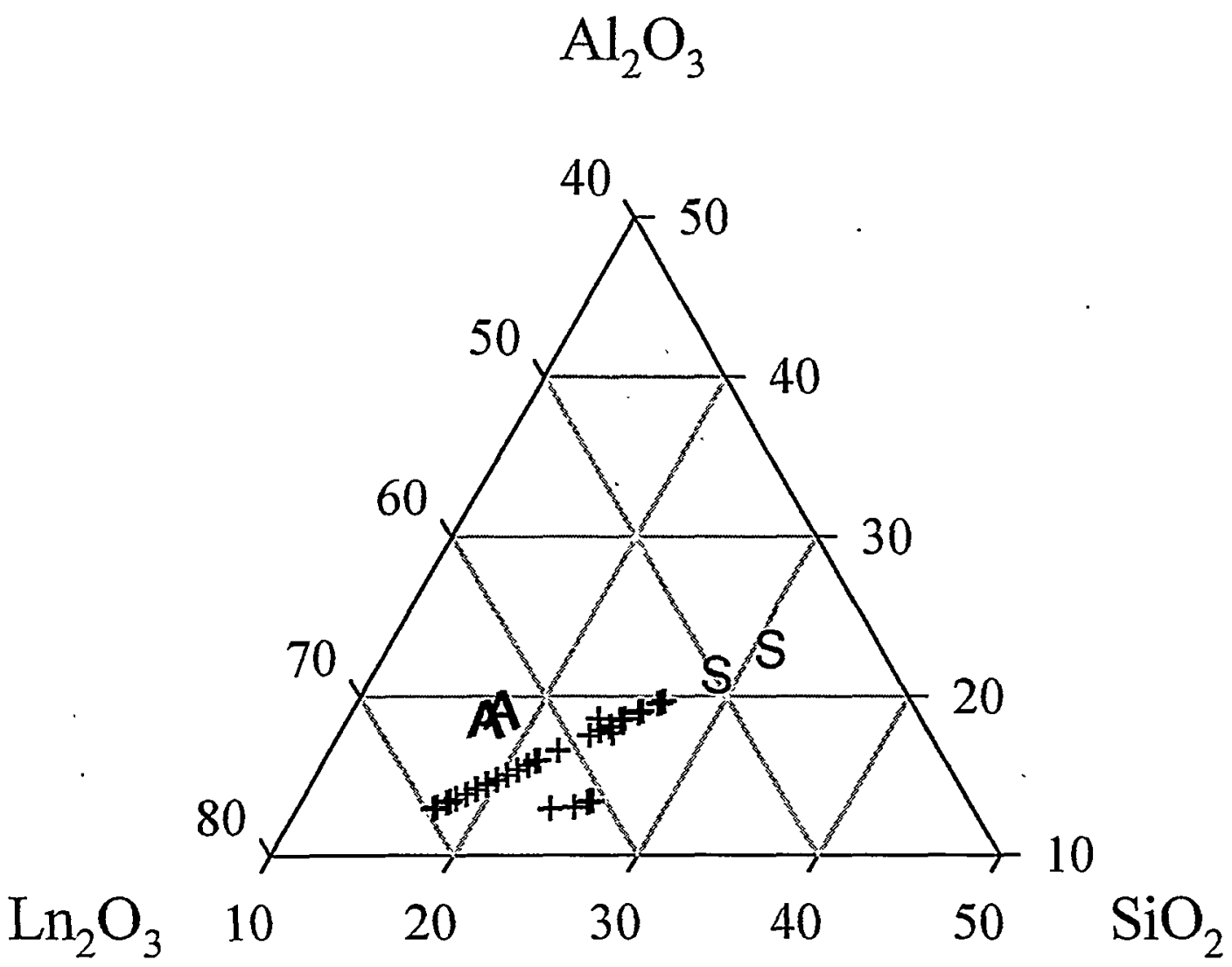

Figure 4.20. Composition Projection of Phase $\mathrm{I}$ and II Glasses in a $\mathrm{SiO}_{2}-\mathrm{Al}_{2} \mathrm{O}_{3}-\mathrm{Ln}_{2} \mathrm{O}_{3}$ Space with Primary Crystalline Phases Noted as Symbols: S-Alumino-Silicate, +-RES, and $\mathrm{A}-\mathrm{Al}_{2} \mathrm{O}_{3}$

\subsection{Viscosity}

The $\eta$ - T relationship was measured for Phase II glasses using a high-temperature spindle viscometer. Generally, the data did not conform to the standard $\eta$-T relationship as described by the VTF model (Equation 1). Figure 4.21 compares the $\ln [\eta]-1 / T$ behavior of a "typical" silicate glass with that of AC2-14. The $\ln [\eta]$ of AC2-14 is nearly piecewise linear with variation in $1 / \mathrm{T}$. For Val-01, the variation of $\ln [\eta]$ with $1 / \mathrm{T}$ is nearly linear with a positive curvature, which is typical of silicate glasses. 


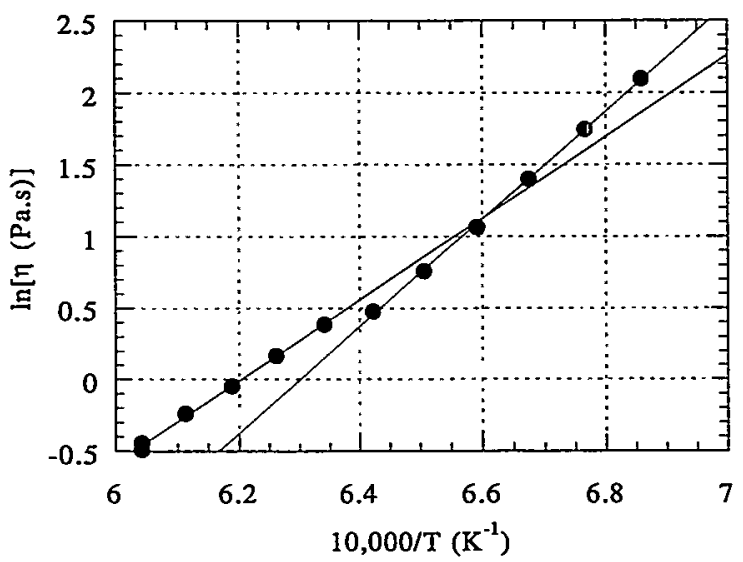

(a)

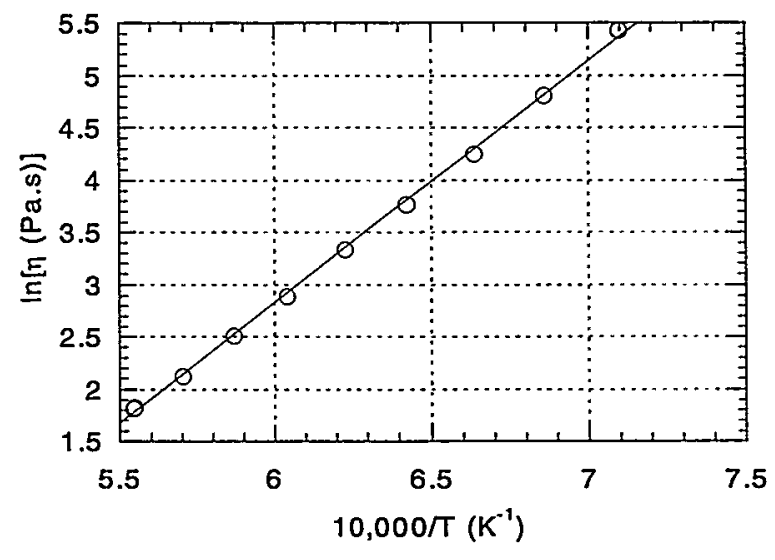

(b)

Figure 4.21. Comparison of $\ln [\eta]-1 / T$ Behavior of (a) AC2-14 and (b) Val-01

For glasses with linear $\ln \left[\eta_{1350}\right]-1 / T$ relationship the $\eta_{1350}$ value of Phase II glasses was estimated by a linear interpolation of $\ln \left[\eta_{1350}\right]$ vs $1 / T$ for the entire data set. For the nonlinear glasses, the $\eta_{1350}$ was interpolated from the measured data at $T$ closest to and on either side of $1350^{\circ} \mathrm{C}$ with Equation (2). In some cases, there was insufficient data to interpolate the $\eta_{1350}$, in these cases the value was obtained by extrapolation of the available data or wasn't estimated at all if less than two data points were available. The exact steps used to determine the $\eta-T$ function and $\eta_{1350}$ are described in Section Appendix A for each glass. This was in contrast to the VTF model (Equation 1), which was used to estimate $\eta_{1350}$ values for glasses in the Phase I study. Table 4.4 summarizes the linear $\eta-T$ parameters ( $E$ and $F$ in Equation 2), $\eta_{1350}$, and the method used to derive these values for the Phase II glasses.

Table 4.4. Summary of Phase II Viscosity Data

\begin{tabular}{lrrrl}
\hline Glass ID & \multicolumn{1}{c}{$\mathrm{E}$} & $\mathrm{F}(\mathrm{K})$ & $\eta_{1350}(\mathrm{~Pa} \cdot \mathrm{s})$ & Comments/Method \\
\hline AC2-01 & -17.449 & 28,908 & 1.44 & linear \\
AC2-02 & -20.390 & 32,760 & 0.81 & nonlinear \\
AC2-03 & -19.528 & 30,769 & 0.57 & two data points \\
AC2-04 & & & & fewer than two data points \\
AC2-05 & -15.642 & 26,669 & 2.20 & nonlinear \\
AC2-06 & -9.177 & 14,314 & 0.70 & two data points \\
AC2-07 & -19.963 & 33,688 & 2.21 & nonlinear \\
AC2-08 & -12.177 & 20,627 & 1.70 & nonlinear \\
AC2-09 & -18.999 & 30,452 & 0.79 & linear \\
AC2-10 & -8.973 & 14,981 & 1.29 & nonlinear \\
AC2-11 & -15.613 & 25,279 & 0.96 & nonlinear \\
AC2-12 & -4.052 & 7,147 & 1.42 & nonlinear \\
AC2-13 & -13.098 & 22,267 & 1.86 & nonlinear \\
AC2-14 & -15.750 & 25,380 & 0.89 & nonlinear \\
\hline
\end{tabular}




\begin{tabular}{lrrrl}
\hline Glass $\mathrm{D}$ & \multicolumn{1}{c}{$\mathrm{E}$} & $\mathrm{F}(\mathrm{K})$ & $\eta_{1350}(\mathrm{~Pa} \cdot \mathrm{s})$ & Comments/Method \\
\hline AC2-15 & -15.571 & 25,731 & 1.33 & linear \\
AC2-16 & -17.671 & 28,821 & 1.09 & nonlinear \\
AC2-17 & -15.154 & 24,804 & 1.14 & linear \\
AC2-18 & & & & fewer than two data points \\
AC2-19 & -14.837 & 24,619 & 1.39 & linear \\
AC2-20 & & & & fewer than two data points \\
AC2-21 & -14.596 & 23,443 & 0.86 & linear \\
AC2-22 & -15.045 & 24,893 & 1.34 & linear \\
AC2-23 & -14.288 & 23,182 & 1.00 & linear \\
AC2-24 & -19.831 & 31,376 & 0.61 & two data points \\
AC2-25 & -15.537 & 25,492 & 1.18 & two data points \\
AC2-26 & -19.470 & 32,858 & 2.17 & nonlinear \\
AC2-27 & -13.273 & 22,608 & 1.93 & nonlinear \\
AC2-28 & -18.947 & 30,512 & 0.86 & nonlinear \\
AC2-29 & -16.871 & 26,717 & 0.66 & linear \\
AC2-30 & -9.360 & 15,680 & 1.35 & nonlinear \\
AC2-31 & -7.207 & 12,340 & 1.49 & nonlinear \\
AC2-32 & -19.993 & 32,717 & 1.18 & nonlinear \\
AC2-33 & -14.740 & 24,182 & 1.17 & linear \\
AC2-34 & -11.883 & 19,877 & 1.44 & nonlinear \\
AC2-35 & -15.684 & 25,573 & 1.08 & two data points \\
AC2-36 & -15.187 & 24,702 & 1.03 & linear \\
AC2-37 & -17.594 & 28,495 & 0.96 & linear \\
AC2-38 & -16.272 & 26,319 & 0.95 & linear \\
AC2-39 & -16.986 & 27,416 & 0.91 & linear \\
AC2-40 & -18.659 & 30,139 & 0.91 & two data points \\
AC2-41 & -17.554 & 28,261 & 0.87 & linear \\
AC2-42 & -11.555 & 19,663 & 1.75 & nonlinear \\
AC2-43 & -8.382 & 14,049 & 1.32 & nonlinear \\
AC2-44 & -15.956 & 25,803 & 0.94 & linear \\
AC2-45 & -14.669 & 23,967 & 1.10 & linear \\
AC2-46 & -16.753 & 26,832 & 0.80 & linear \\
AC2-47 & -14.938 & 24,506 & 1.17 & linear \\
AC2-48 & -11.809 & 20,058 & 1.73 & nonlinear \\
AC2-49 & -10.729 & 18,031 & 1.46 & nonlinear \\
AC2-50 & -14.338 & 23,449 & 1.12 & linear \\
AC2-51 & -16.473 & 26,651 & 0.95 & linear \\
AC2-52 & -18.357 & 31,054 & 2.17 & nonlinear \\
AC2-53 & -10.844 & 18,520 & 1.76 & nonlinear \\
\hline
\end{tabular}




\begin{tabular}{lcccl}
\hline Glass ID & $\mathrm{E}$ & $\mathrm{F}(\mathrm{K})$ & $\eta_{1350}(\mathrm{~Pa} \cdot \mathrm{s})$ & Comments/Method \\
\hline AC2-54 & -17.617 & 28,349 & 0.86 & linear \\
$\mathrm{AC} 2-55$ & -15.600 & 25,530 & 1.14 & nonlinear \\
\hline
\end{tabular}

The $\eta_{1350}$ values of Phase II test glasses range from 0.57 Pa-s for AC2-03 to 2.21 Pa.s for AC2-07, both exterior vertex glasses. All Phase II glasses passed the $0.3 \mathrm{~Pa} \cdot \mathrm{s}$ to $2.4 \mathrm{~Pa} \cdot \mathrm{s}$ constrain on $\eta_{1350}$ established by Martin (1999). However, the odd $\eta$ - $T$ behavior of these glasses warrants further study.

A linear relationship between the $\mathrm{Ln}_{2} \mathrm{O}_{3}$ concentration in glass and the $\ln \left[\eta_{1350}\right]$ value was shown for Phase I glasses in Section 1.2.3. The effect of $\mathrm{Ln}_{2} \mathrm{O}_{3}$ concentration on $\ln \left[\eta_{1350}\right]$ of Phase II glasses is shown in Figure 4.22. This relationship is compared to that for Phase glasses in Figure 4.23. This comparison shows a reasonably close match in the $\mathrm{Ln}_{2} \mathrm{O}_{3}$ effect on $\ln \left[\eta_{1350}\right]$ for Phase I and Phase II glasses, despite the fact that $\mathrm{SiO}_{2}, \mathrm{Al}_{2} \mathrm{O}_{3}, \mathrm{~B}_{2} \mathrm{O}_{3}$, and $\mathrm{SrO}$ concentrations varied independently in Phase II glasses and not in Phase I glasses. Specifically, the $\mathrm{Ln}_{2} \mathrm{O}_{3}$ partial specific $\ln \left[\eta_{1350}\right]$ for Phase I and Phase II glasses are -3.1 and -3.0 , respectively. Generally, some of the Phase I glasses and some of the nonlinear Phase II glasses fell off of the linear trend. 


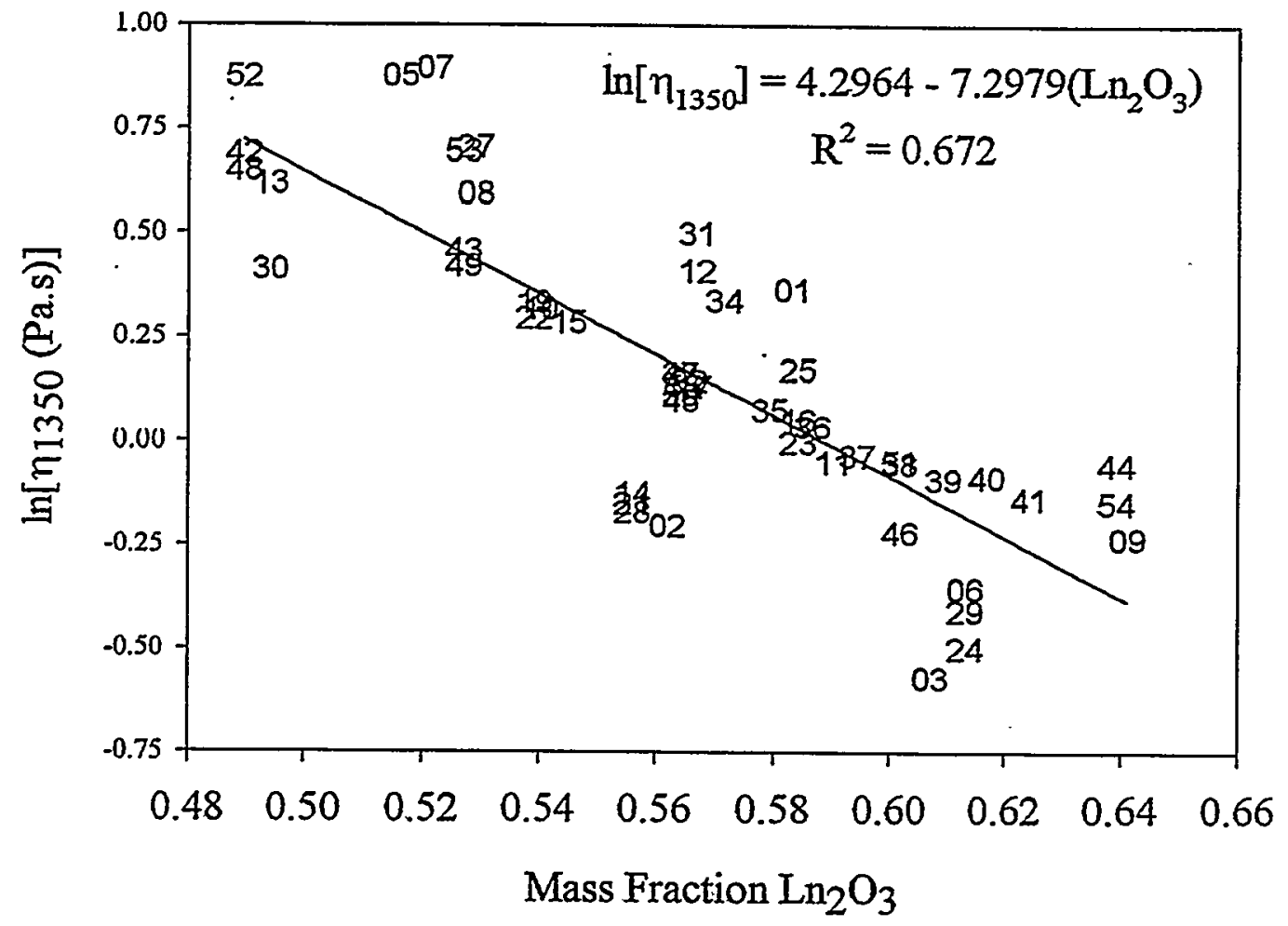

Figure 4.22. Effect of $\mathrm{Ln}_{2} \mathrm{O}_{3}$ Concentration on $\operatorname{In}\left[\eta_{1350}\right]$ for Phase II Glasses (symbol numbers represent glass numbers) 


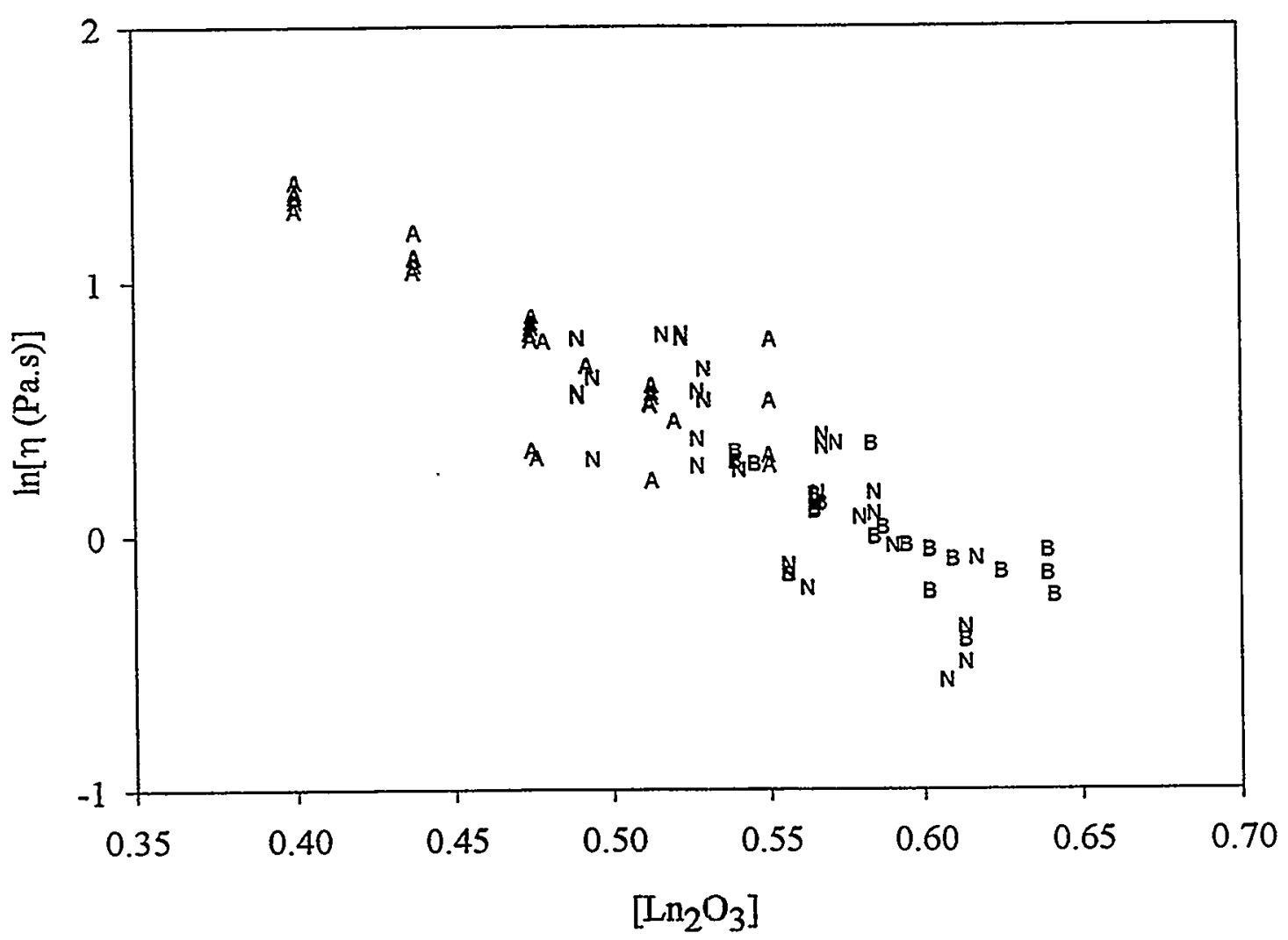

Figure 4.23. Effect of $\mathrm{Ln}_{2} \mathrm{O}_{3}$ Concentration (in mass fraction) on $\ln \left[\eta_{1350}\right]$ for Phase I and II Glasses (symbols represent: A-Phase I glasses, B-Linear Phase II glasses, and N-Nonlinear Phase II glasses) 


\subsection{Recommendations}

Based on the glass-property measurement results from Phase I and Phase II glasses, we recommend the following in considering in plant operation and planning for future testing.

1. Based on the following information,

- the glass property criteria set by Martin (1999) and Peeler and Edwards (1999)

- the favorable measured $\eta_{1350}$ and $T_{L}$ values

- the assumption that all other property restrictions are met by a majority of Phase I glasses,

we recommend that the $\mathrm{Am} / \mathrm{Cm}$ process proceed to design and implementation using the composition regions studied in Phases I and II. In other words, no critical glass-property flaws were identified in this study, and only two glasses failed to meet the $\mathrm{T}_{L}<1350^{\circ} \mathrm{C}$ criteria.

2. The anomalous $\eta-T$ behavior is indicative of glass structural changes occurring at high temperatures. These changes may be due to medium ( 5 to $50 \AA$ ) range-order reconfigurations in the melt or may be due to nano-crystal (e.g., crystal nuclei) formation. In either case, these changes could have a pronounced impact on melter operation and the current scientific understanding of rare earth-alumino-borosilicate melts. We recommend further study aimed at identifying the cause for the anomalous $\eta-T$ behavior and its impact on properties critical to plant operation.

3. The composition region studied in Phase II is generally more fragile than that studied in Phase I. In other words, Phase II glasses showed a higher tendency to grossly crystallize at temperatures slightly below $T_{L}$ than Phase I glasses. Since massive crystallization in the melter could be detrimental to plant operation, we recommend that studies be performed to understand gross crystallization observed in many Phase II glasses. These studies should focus on determining the composition regions most susceptible to and the conditions ( $T-t)$ that allow massive crystallization.

4. The crystalline phases formed under the $T_{L}$ of Phase $I$ and Phase II glasses are highly refractory minerals, alumino-silicates, RESs, and aluminum oxide. If a large fraction of these crystalline phases were to form in the melter, it would be difficult to redissolve the crystals and return to a homogeneous melt. We recommend that plans be made to mitigate such an event if it were to occur during off-normal operations. This planning should include study of 1) methods for redissolving the crystals, 2) characterization of the properties of a crystallized melt body, and 3) methods for disposition of a full melter body and melter replacement.

5. The rare earth-alumino-borosilicate melts have been shown to compositionally segregate at standard plant-operating temperatures into a higher and lower density melt. It is recommended that the process of conversion of the frit and simulated oxalate feed be studied. These studies should continue to develop an understanding of the conversion chemistry, the 
phenomena responsible for melt segregation, and mitigation strategies to ensure that melt segregation does not occur or is controllable in plant operation. 


\subsection{References}

Fellinger, A. P., M. A. Baich, B. J. Hardy, G. T. Jannik, T. M. Jones, J. E. Marra, C. B. Miller, D. H. Miller, D. K. Peeler, T. K. Synder, M. E. Stone, and D. C. Witt. 1998a. "Americium Curium Vitrification Process Development (U)," Materials Research Society, Symposium on the Scientific Basis for Nuclear Waste Management XXII.

Fellinger, A. P., M. A. Baich, B. J. Hardy, G. T. Jannik, T. M. Jones, J. E. Marra, C. B. Miller, D. H. Miller, D. K. Peeler, T. K. Synder, M. E. Stone, and D. C. Witt. 1998b. AmericiumCurium Vitrification Process Development, WSRC-MS-98-00864, Westinghouse Savannah River Company, Aiken, South Carolina.

Marra, J. E., M. A. Baich, A. P. Fellinger, B. J. Hardy, G. T. Jannik, T. M. Jones, C. B. Miller, D. H. Miller, D. K. Peeler, T. K. Synder, M. E. Stone, and D. C. Witt. "A Batch Process for Vitrification of Americium/Curium Solution (U)," to be published in the ACS proceedings (1999).

Martin, W. H. 1999. Am-Cm Strontium Alumium Borosilicate (SrABS) Glass Bariability Study \#2 - TTR\#99-NMSS/SE-003. NMS-ERS-990007, Westinghouse Savannah River Company, Aiken, South Carolina.

NBS. 1980. Certificate, Standard Reference Material 773, Soda-Lime-Silica Glass for GradientFurnace Liquidus Temperature. National Bureau of Standards, Washington, D.C.

NIST. 1991. Certificate, Standard Reference Material 710a, Soda-Lime-Silica Glass. National Institute of Standards and Technology, Gaithersburg, MD

Neter, J., W. Wasserman, and M. H. Kutner. 1990. Applied Linear Statistical Models. $3^{\text {rd }}$ Ed. Irwin Publishing, Homewood, IL

Peeler, D. K. 1998. Am-Cm: SrABS Glass Variability Study, Technical Task and QA Plan, WSRC-RP-98-01144, Rev. 0, Westinghouse Savannah River Company, Aiken, South Carolina.

Peeler, D. K., and T. B. Edwards. 1999. Phase $2 \mathrm{Am} / \mathrm{Cm}$ Glass Variability Study, Technical Task and QA Plan. WSRC-RP-99-00272, Rev. 0, Westinghouse Savannah River Company, Aiken, South Carolina.

Peeler, D. K., T. B. Edwards, I. A. Reamer, J. D. Vienna, D. E. Smith, M. J. Schweiger, B. J. Riley, and J. V. Crum. 1999. Composition/Property Relationships for the Phase $1 \mathrm{Am} / \mathrm{Cm}$ Glass Variability Study ( $U$, WSRC-TR-99-00055, Westinghouse Savannah River Company, Aiken, South Carolina.

Peeler, D. K., T. B. Edwards, I. A. Reamer. J. D. Vienna, D. E. Smith, M. J. Schweiger, B. J. Riley, and J. V. Crum, "Composition/Property Relationships for the Phase $1 \mathrm{Am} / \mathrm{Cm}$ Glass Variability Study," to be published (2000) in the Proceedings of the International Symposium on 
Waste Management Technologies in Ceramic and Nuclear Industries, Ceramic Transaction series. 


\section{Appendix A}

Glass Property Measurements 


\section{Contents}

1.0 AC2-01

2.0 AC2-02

3.0 AC2-03

4.0 AC2-04

5.0 AC2-05

6.0 AC2-06

7.0 AC2-07

8.0 AC2-08

9.0 AC2-09

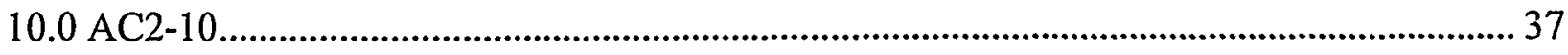

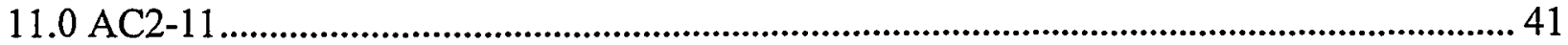

12.0 AC2-12

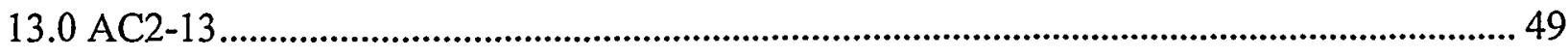

14.0 AC2-14

15.0 AC2-15

16.0 AC2-16

17.0 AC2-17

18.0 AC2-18

19.0 AC2-19

20.0 AC2-20

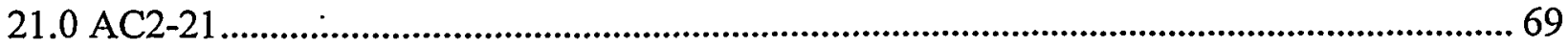

22.0 AC2-22

23.0 AC2-23

24.0 AC2-24

25.0 AC2-25

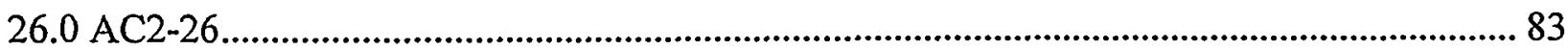

27.0 AC2-27

28.0 AC2-28

29.0 AC2-29

30.0 AC2-30

31.0 AC2-31

32.0 AC2-32

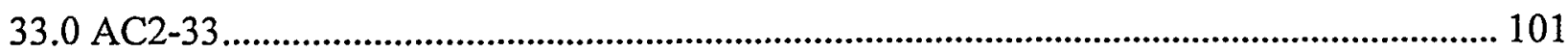

34.0 AC2-34

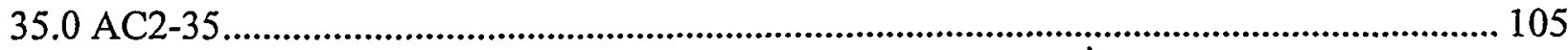

36.0 AC2-36

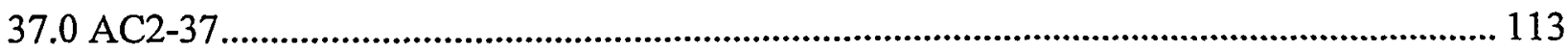

38.0 AC2-38

39.0 AC2-39

40.0 AC2-40

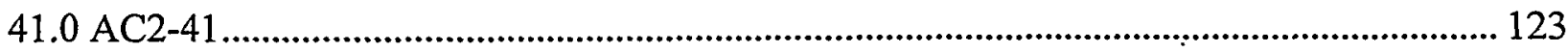

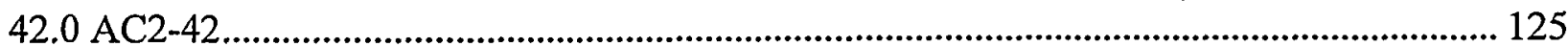

43.0 AC2-43

44.0 AC2-44 


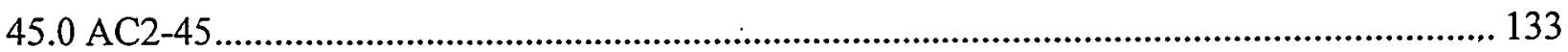

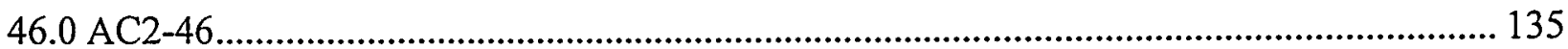

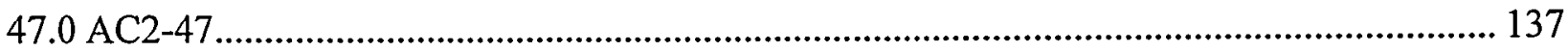

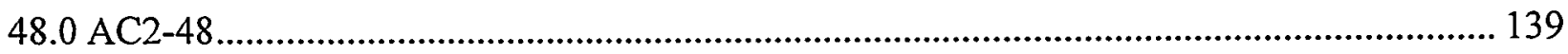

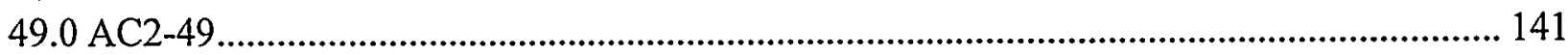

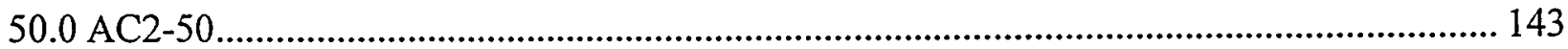

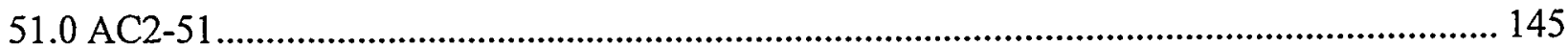

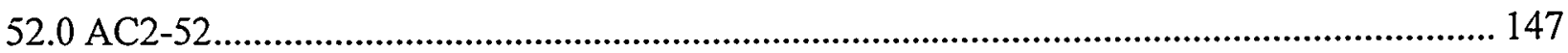

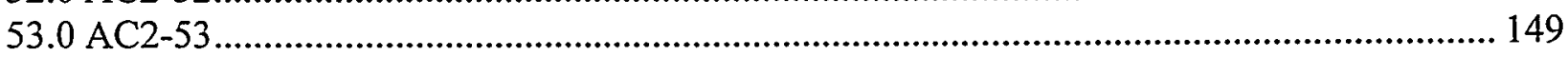

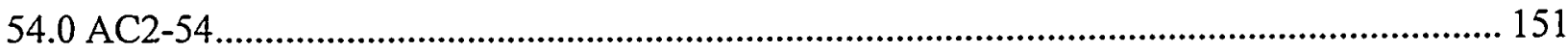

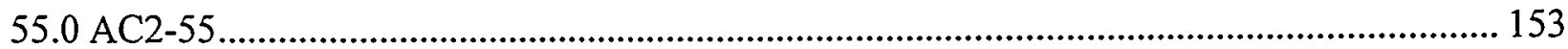




\section{Appendix A \\ Glass Property Measurements}

\subsection{AC2-01}

Glass AC2-01 is an extreme vertex on the inner level of glass compositions. This glass targets 58.3 mass percent $\mathrm{Ln}_{2} \mathrm{O}_{3}$. The ratio of $\mathrm{SiO}_{2}$ to other frit components is higher in this glass than in the baseline frit. In other words, the relative concentrations of $\mathrm{SiO}_{2}, \mathrm{Al}_{2} \mathrm{O}_{3}, \mathrm{~B}_{2} \mathrm{O}_{3}$, and $\mathrm{SrO}$ are high, low, low, and low, respectively in comparison to the standard frit composition.

\section{$1.1 \quad$ Liquidus Temperature}

In the final $\mathrm{T}_{\mathrm{L}}$ measurements, four heat treatments were performed in Furnace \#12 between $1296^{\circ} \mathrm{C}$ and $1315^{\circ} \mathrm{C}$ (see Table 1.1). Heat treatments at $1296^{\circ} \mathrm{C}$ and $1301^{\circ} \mathrm{C}$ had a thin crystal layer on the surface with crystals precipitating to a thick layer of settled crystals on the crucible bottom; all crystals were rare earth silicates (RES). At $1306^{\circ} \mathrm{C}$, only a few crystal clusters remained on the bottom of the sample after heat treatment, and at $1315^{\circ} \mathrm{C}$, the heattreated sample appeared to be crystal free by OM. The $T_{L}$ was estimated to be $1308^{\circ} \mathrm{C}$ with RES as the primary phase. Both XRD (Figure 1.1) and SEM (Figure 1.2) analyses were performed on a sample heat treated at $1296^{\circ} \mathrm{C}$. An EDS spectrum of the glass matrix is shown in Figure 1.3. The EDS spectrum in Figure 1.4 shows the relative concentration of components in the RES crystal.

Eight preliminary heat treatments were performed between $1153^{\circ} \mathrm{C}$ and $1343^{\circ} \mathrm{C}$ at approximately $50^{\circ} \mathrm{C}$ intervals. Abundant crystals were observed at $1248^{\circ} \mathrm{C}$ and $1296^{\circ} \mathrm{C}$, which matches the observations in the final heat treatments. Samples at $1319^{\circ} \mathrm{C}$ and $1343^{\circ} \mathrm{C}$ appeared to be crystal free by OM. A sample, heat treated in Furnace $\# 3$ at $1313^{\circ} \mathrm{C}$, appeared to be free of crystals when examined by $\mathrm{OM}$.

Table 1.1. Heat-Treatment Summary for Determination of $T_{L}$ for AC2-01

\begin{tabular}{cccccllc}
\hline Crucible & Furnace & Time/Date IN & $\mathrm{T}\left({ }^{\circ} \mathrm{C}\right)$ & Time/Date OUT & Observations & Comments \\
\hline $\mathrm{L}$ & 8 & $2: 00 \mathrm{pm} \mathrm{04/20}$ & 1198 & $1: 00 \mathrm{pm} \mathrm{04/21}$ & Crystals & Preliminary \\
1 & 3 & $3: 00 \mathrm{pm} \mathrm{06/18}$ & 1313 & $1: 30 \mathrm{pm} \mathrm{06/19}$ & No crystals & different furnace \\
1 & 12 & $2: 00 \mathrm{pm} \mathrm{06/23}$ & 1306 & $3: 00 \mathrm{pm} \mathrm{06/24}$ & Few clusters & $\mathrm{T}_{\mathrm{C}}$ \\
1 & 12 & $3: 00 \mathrm{pm} \mathrm{06/25}$ & 1296 & $1: 20 \mathrm{pm} \mathrm{06/26}$ & Crystals & XRD/SEM \\
1 & 12 & $8: 52 \mathrm{am} \mathrm{07/06}$ & 1301 & $10: 50 \mathrm{am} \mathrm{07/07}$ & Crystals & \\
1 & 12 & $4: 05 \mathrm{pm} \mathrm{07/17}$ & 1315 & $3: 22 \mathrm{pm} \mathrm{07/18}$ & No crystals & $\mathrm{T}_{\mathrm{A}}$ \\
\hline
\end{tabular}



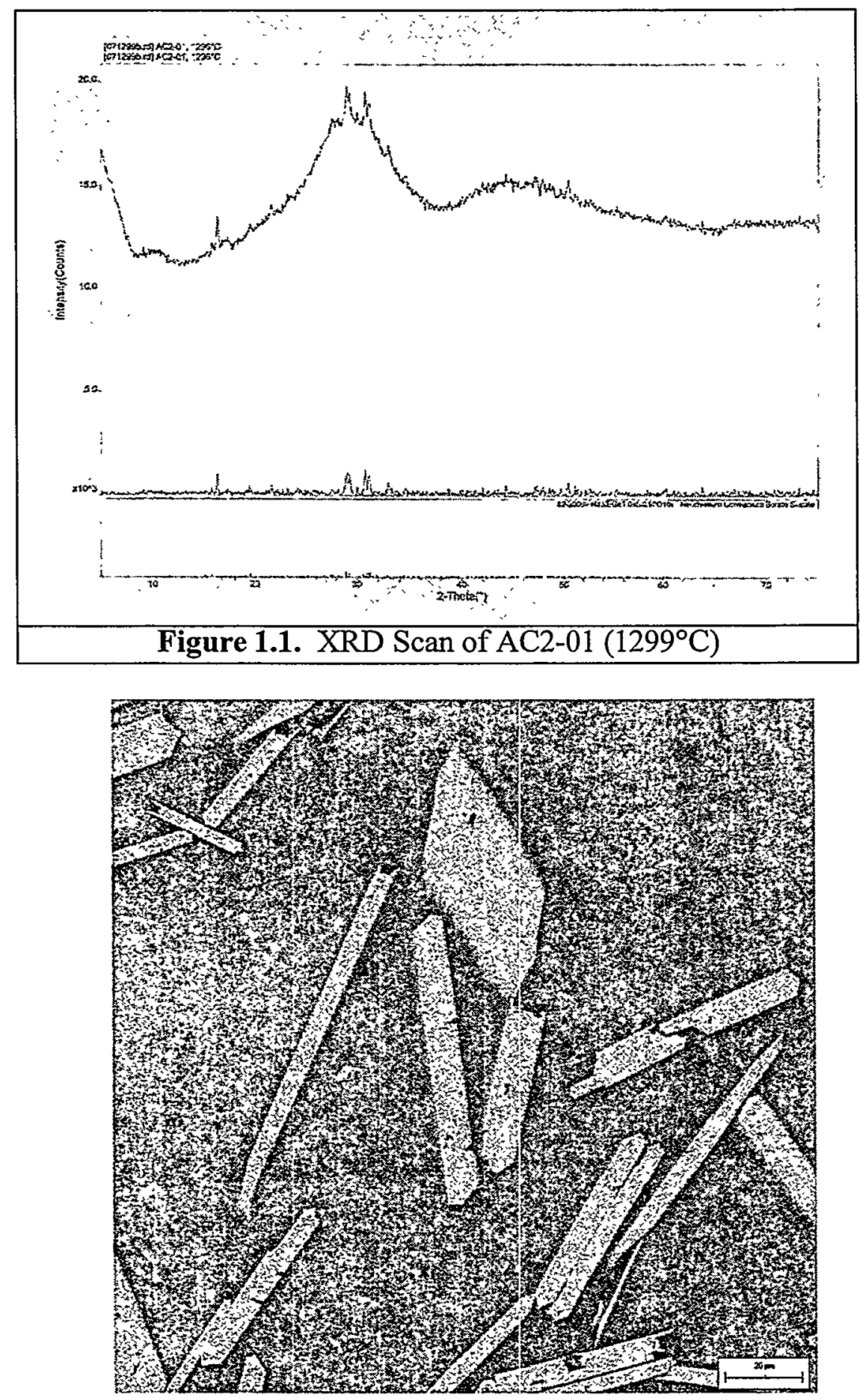

Figure 1.2. SEM Micrograph of $\mathrm{AC} 2-01\left(1296^{\circ} \mathrm{C}\right)$ at $500 \times$ 


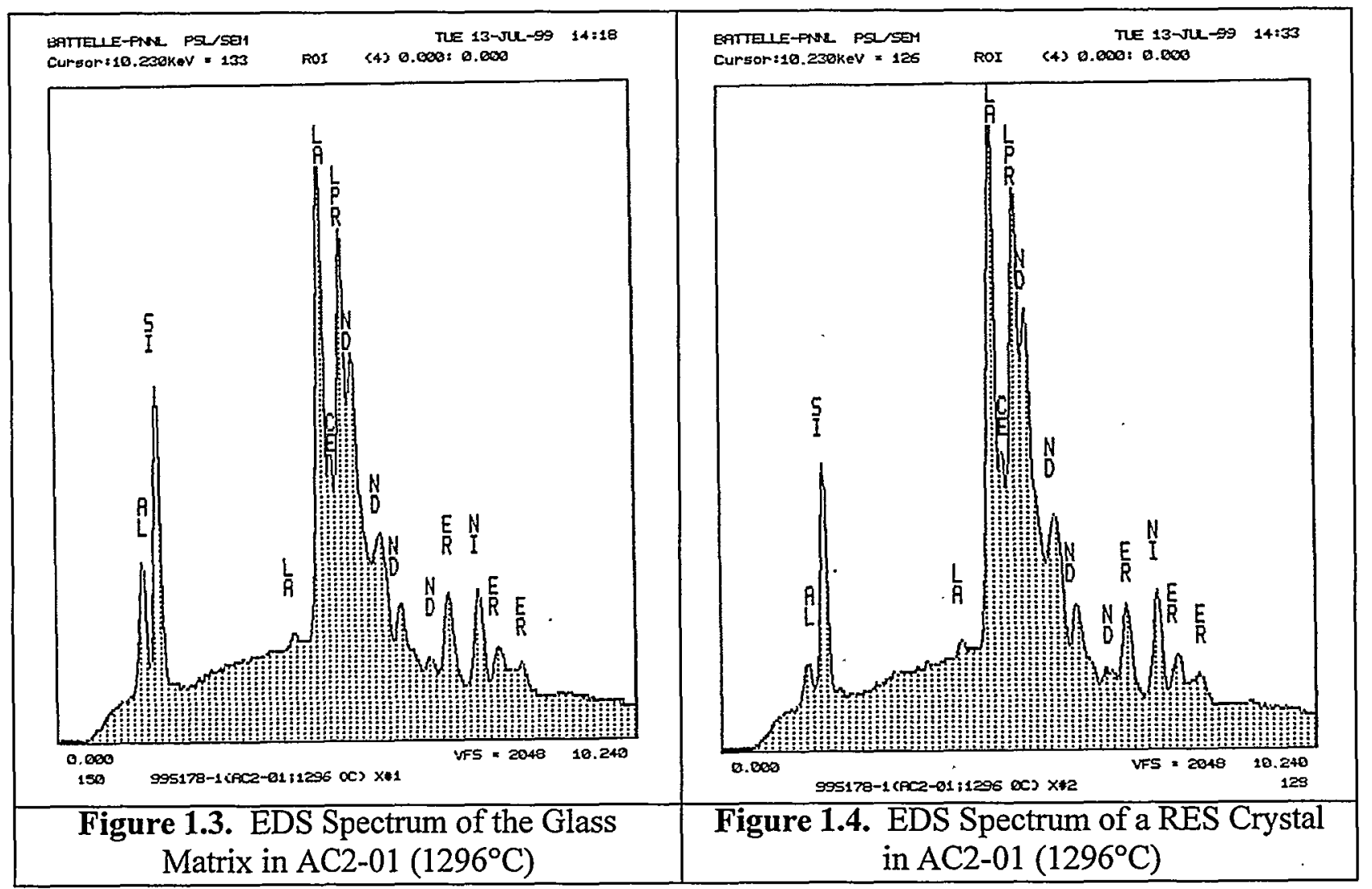

\subsection{Viscosity}

Table 1.2 lists the measured $\eta-T$ values for AC2-01 in chronological order. These data are shown on an Arrhenius plot $(\ln \eta$ vs. $1 / \mathrm{T})$ in Figure 1.5. With a $T_{L}$ of $1308^{\circ} \mathrm{C}$, all the data in Table 1.2 are valid for calculations. Equation (2) was fitted to the data to yield $\mathrm{E}$ and $\mathrm{F}$ values of -17.449 and $28908 \mathrm{~K}$, respectively. This fit, which accurately reflects the data, was then used to calculate a $\eta_{1350}$ value of $1.44 \mathrm{~Pa} \cdot \mathrm{s}$.

Table 1.2. Viscosity-Temperature Data for $\mathrm{AC} 2-01$

\begin{tabular}{cccc}
\hline $\mathrm{T}\left({ }^{\circ} \mathrm{C}\right)$ & $\eta(\mathrm{Pa} \cdot \mathrm{s})$ & $10000 / \mathrm{T}\left(\mathrm{K}^{-1}\right)$ & $\ln [\eta(\mathrm{Pa} \cdot \mathrm{s})]$ \\
\hline 1383 & 1.017 & $6.039^{\circ}$ & 0.017 \\
1404 & 0.827 & 5.963 & -0.190 \\
1424 & 0.643 & 5.893 & -0.441 \\
1384 & 1.004 & 6.035 & 0.004 \\
1364 & 1.228 & 6.109 & 0.206 \\
1344 & 1.515 & 6.184 & 0.415 \\
1384 & 1.004 & 6.035 & 0.004 \\
\hline
\end{tabular}




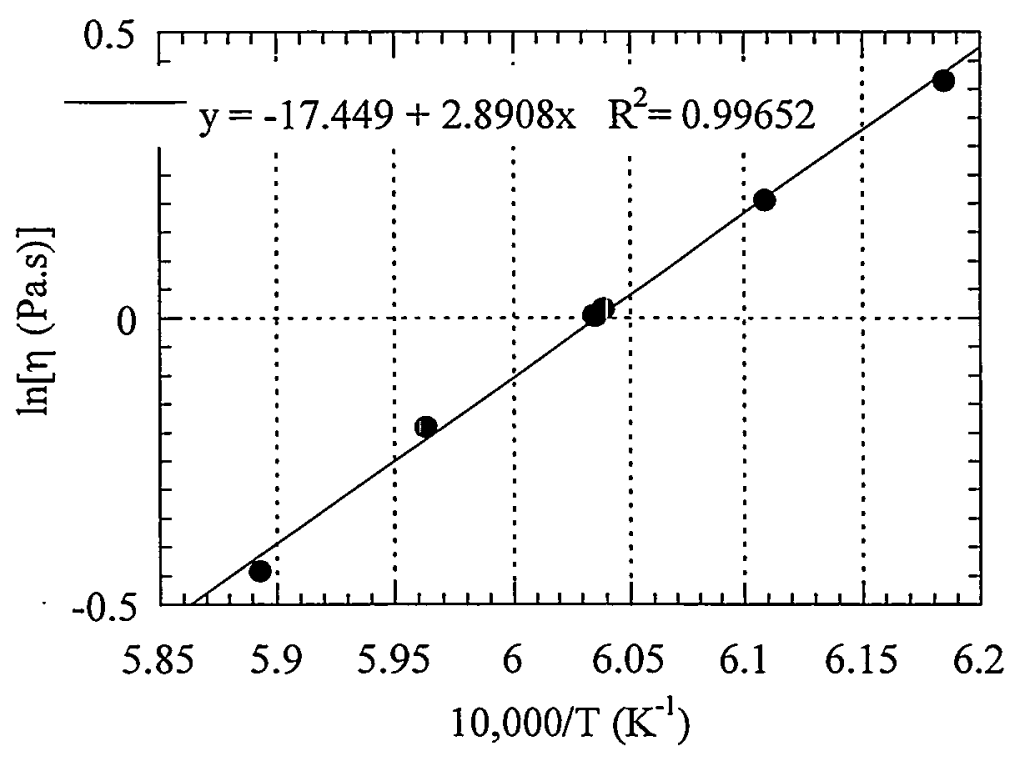

Figure 1.5. Measured ln Viscosity vs. 10000/T for AC2-01 


\section{$2.0 \quad$ AC2-02}

Glass $\mathrm{AC} 2-02$ is an extreme vertex on the inner level of glass compositions. This glass targets 56.2 mass percent $\mathrm{Ln}_{2} \mathrm{O}_{3}$. The ratios of $\mathrm{Al}_{2} \mathrm{O}_{3}$ and $\mathrm{B}_{2} \mathrm{O}_{3}$ to other frit components are higher in this glass than in the baseline frit. In other words, the relative concentrations of $\mathrm{SiO}_{2}$, $\mathrm{Al}_{2} \mathrm{O}_{3}, \mathrm{~B}_{2} \mathrm{O}_{3}$, and $\mathrm{SrO}$ are low, high, high, and low, respectively, in comparison to the standard frit composition.

\subsection{Liquidus Temperature}

The final $\mathrm{T}_{\mathrm{L}}$ measurements were performed in Furnace $\# 3$ between $1232^{\circ} \mathrm{C}$ and $1271^{\circ} \mathrm{C}$ with seven heat treatments (see Table 2.1). Aluminum oxide was the only crystalline phase observed in this temperature range. Aluminum oxide was abundant in the $1232^{\circ} \mathrm{C}$ and $1237^{\circ} \mathrm{C}$ samples checked by OM with both plate-like and garnet-shaped crystals; both crystal types were transparent to visible light. SEM was used to analyze the sample at $1232^{\circ} \mathrm{C}$ (Figure 2.1 and Figure 2.2), but when several measurements were performed on the same sample with $\mathrm{XRD}$, including a 48-h scan, no distinct peaks characterized the crystalline phase (Figure 2.3).

Aluminum oxide crystal number density diminished in the three samples between $1243^{\circ} \mathrm{C}$ and $1252^{\circ} \mathrm{C}$, with only a few crystals observed at $1252^{\circ} \mathrm{C}$. The $\mathrm{T}_{\mathrm{L}}$ was estimated to be $1257^{\circ} \mathrm{C}$ with aluminum oxide as the primary phase. The RES phase was observed concurrently with the $\mathrm{Al}_{2} \mathrm{O}_{3}$ phase at $<1232^{\circ} \mathrm{C}$. A 48 -h XRD scan was obtained on the heat-treated sample at $1198^{\circ} \mathrm{C}$ with both phases matching peaks observed in the scan along with $\mathrm{SiO}_{2}$ phase.

Six preliminary heat treatments were performed between $1153^{\circ} \mathrm{C}$ and $1248^{\circ} \mathrm{C}$ at approximately $50^{\circ} \mathrm{C}$ intervals. Abundant crystals were observed at $1232^{\circ} \mathrm{C}$, which matches the observations in the final heat treatments. The sample at $1248^{\circ} \mathrm{C}$ appeared to be crystal free by $\mathrm{OM}$. One measurement was performed in Furnace $\# 12$ at $1259^{\circ} \mathrm{C}$, which contained only a few crystals.

Table 2.1. Heat-Treatment Summary for Determination of $\mathrm{T}_{L}$ for AC2-02

\begin{tabular}{ccccccc}
\hline Crucible & Furnace & Time/Date IN & T $\left({ }^{\circ} \mathrm{C}\right)$ & Time/Date OUT & Observations & Comments \\
\hline $\mathrm{P}$ & 8 & $2: 00 \mathrm{pm} \mathrm{04/20}$ & 1198 & $1: 00 \mathrm{pm} \mathrm{04/21}$ & Surface crystals & Preliminary/XRD \\
2 & 3 & $2: 30 \mathrm{pm} \mathrm{05/18}$ & 1246 & $2: 40 \mathrm{pm} \mathrm{05/19}$ & Few crystals & \\
2 & 3 & $3: 20 \mathrm{pm} \mathrm{05/20}$ & 1232 & $3: 35 \mathrm{pm} \mathrm{05/21}$ & Crystals on surface & \\
2 & 3 & $3: 45 \mathrm{pm} \mathrm{05/25}$ & 1237 & $1: 45 \mathrm{pm} \mathrm{05/26}$ & Crystals on surface & \\
2 & 3 & $4: 30 \mathrm{pm} \mathrm{06/09}$ & 1243 & $3: 00 \mathrm{pm} \mathrm{06/10}$ & Few small crystals & \\
2 & 3 & $4: 30 \mathrm{pm} \mathrm{06/10}$ & 1252 & $2: 30 \mathrm{pm} \mathrm{06/11}$ & Few bulk crystals & $\mathrm{T}_{\mathrm{C}}$ \\
2 & 12 & $2: 17 \mathrm{pm} \mathrm{06/20}$ & 1259 & $1: 00 \mathrm{pm} \mathrm{06/21}$ & Few crystals & different furnace \\
2 & 3 & $3: 20 \mathrm{pm} \mathrm{07/27}$ & 1262 & $2: 25 \mathrm{pm} \mathrm{07/28}$ & No crystals & $\mathrm{T}_{\mathrm{A}}$, Buds \\
2 & 3 & $4: 40 \mathrm{pm} \mathrm{07/28}$ & 1271 & $3: 40 \mathrm{pm} \mathrm{07/29}$ & No crystals & Buds \\
\hline
\end{tabular}




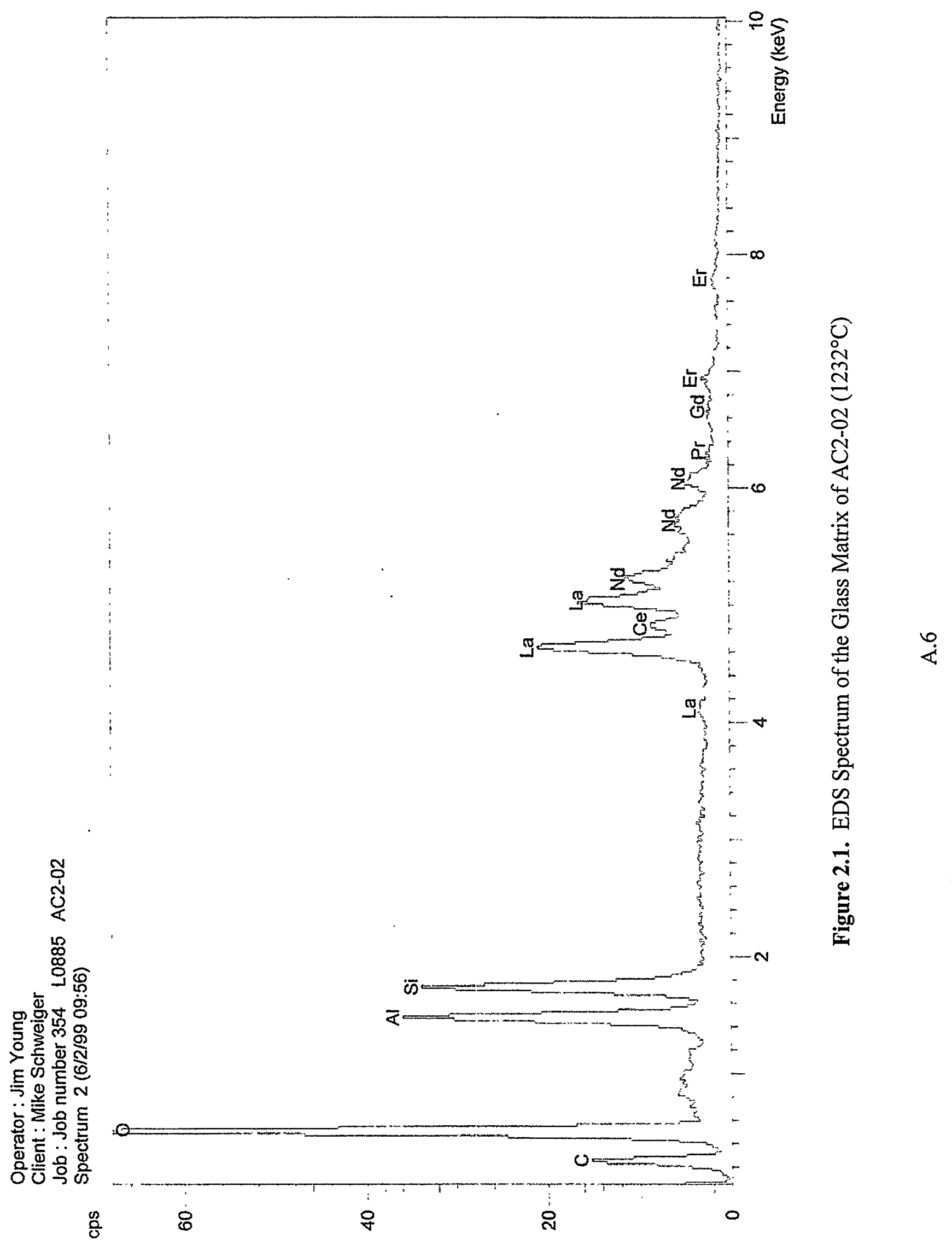




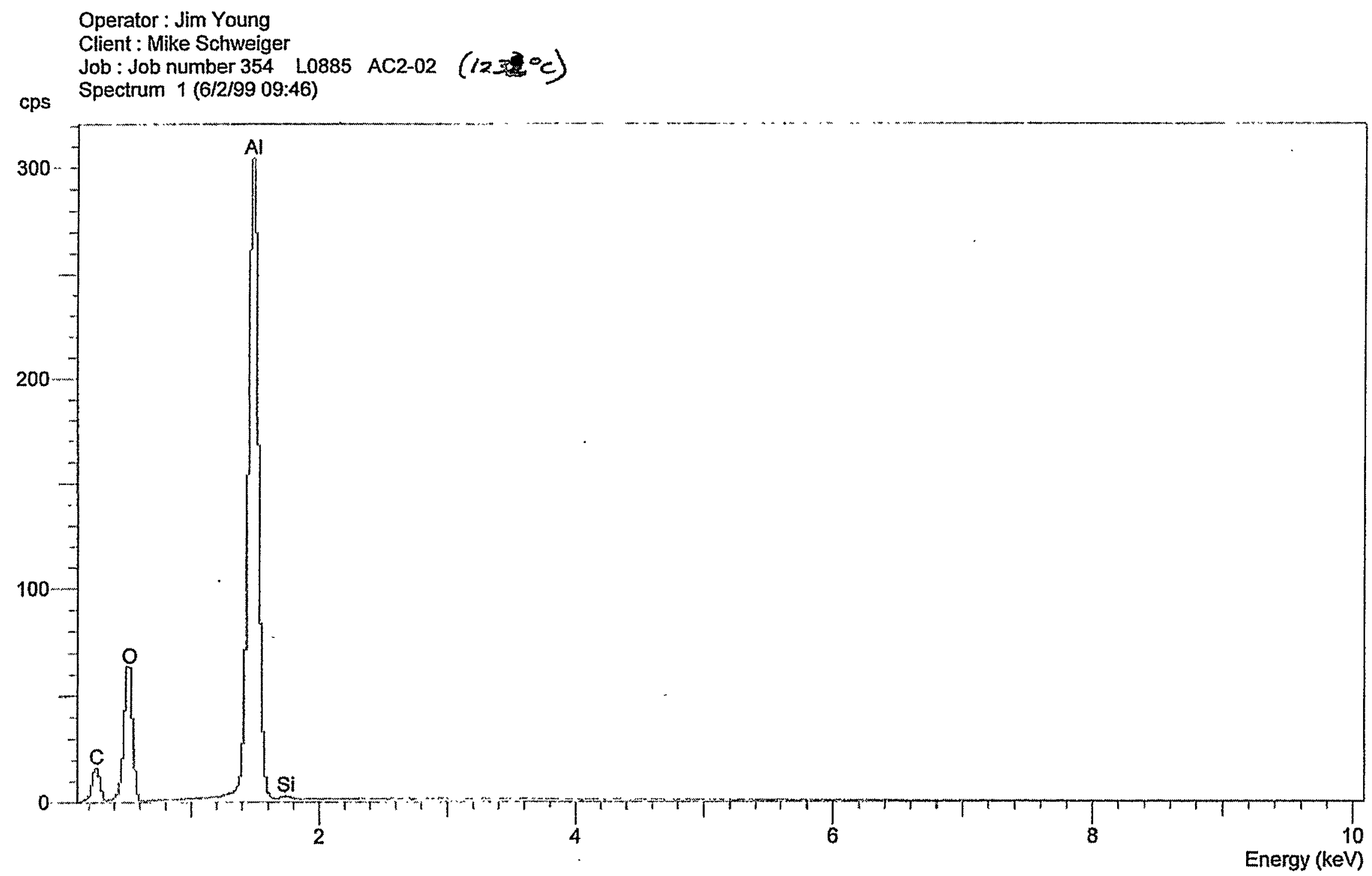

Figure 2.2. EDS Spectrum of an $\mathrm{Al}_{2} \mathrm{O}_{3}$ Crystal in $\mathrm{AC} 2-02\left(1232^{\circ} \mathrm{C}\right)$

A.7 


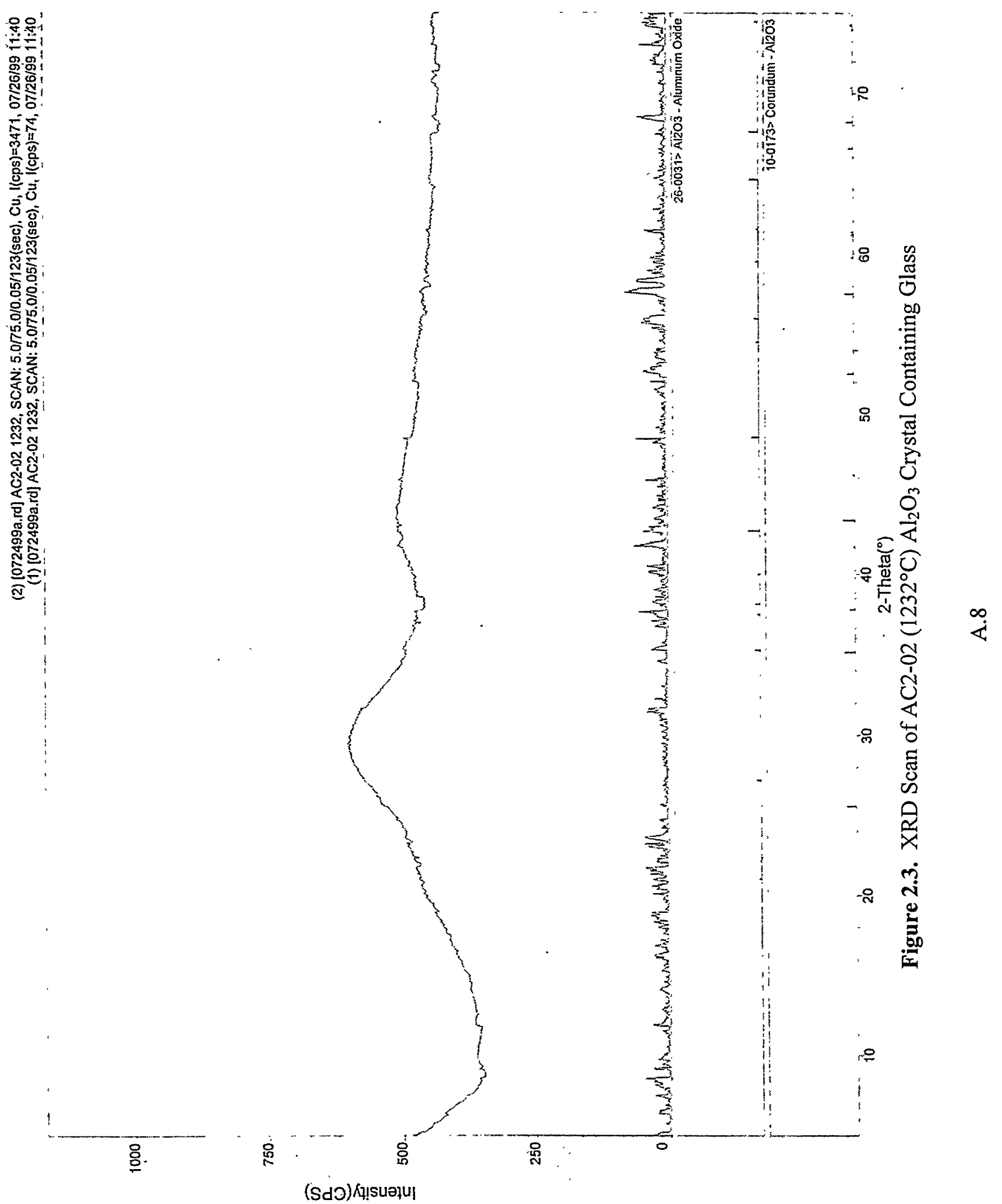




\subsection{Viscosity}

Table 2.2 lists the measured $\eta-T$ values for AC2-02 in chronological order. These data are shown on an Arrhenius plot ( $\ln \eta$ vs. 1/T) in Figure 2.4. Six data points from Table 2.2 were excluded from calculations. Two of these points, at $1383^{\circ} \mathrm{C}$ and $1384^{\circ} \mathrm{C}$, had measured $\eta$ values below the instrument's range while four data points, at $1187^{\circ} \mathrm{C}, 1206^{\circ} \mathrm{C}, 1226^{\circ} \mathrm{C}$, and $1246^{\circ} \mathrm{C}$, were taken at Ts below $\mathrm{T}_{\mathrm{L}}$. The excluded data are plotted as open circles and listed in strikethrough font. Equation (2) was fitted to the remaining data, plotted as filled circles, to yield $\mathrm{E}$ and $\mathrm{F}$ values of -15.245 and $24410 \mathrm{~K}$, respectively. The data appear to be nonlinear. Therefore, a $\eta_{1350}$ value of $0.81 \mathrm{~Pa} \cdot \mathrm{s}$ was obtained by interpolation between the data points at $1345^{\circ} \mathrm{C}$ and $1364^{\circ} \mathrm{C}$ using Equation (2).

Table 2.2. Viscosity-Temperature Data for $\mathrm{AC2}-02$

\begin{tabular}{cccc}
\hline $\mathrm{T}\left({ }^{\circ} \mathrm{C}\right)$ & $\eta(\mathrm{Pa} \cdot \mathrm{s})$ & $10000 / \mathrm{T}\left(\mathrm{K}^{-1}\right)$ & $\ln [\eta(\mathrm{Pa} \cdot \mathrm{s})]$ \\
\hline 1383 & 0.532 & 6.039 & -0.631 \\
1364 & 0.685 & 6.109 & -0.378 \\
1345 & 0.867 & 6.180 & -0.143 \\
1325 & 1.056 & 6.258 & 0.054 \\
1306 & 1.306 & 6.333 & 0.267 \\
1285 & 1.476 & 6.418 & 0.390 \\
1266 & 1.818 & 6.498 & 0.598 \\
1246 & 2.437 & 6.583 & 0.891 \\
1226 & 3.352 & 6.671 & 1.210 \\
1206 & 4.690 & 6.761 & 1.545 \\
1187 & 6.979 & 6.849 & 1.943 \\
1384 & 0.513 & 6.035 & -0.668 \\
\hline
\end{tabular}




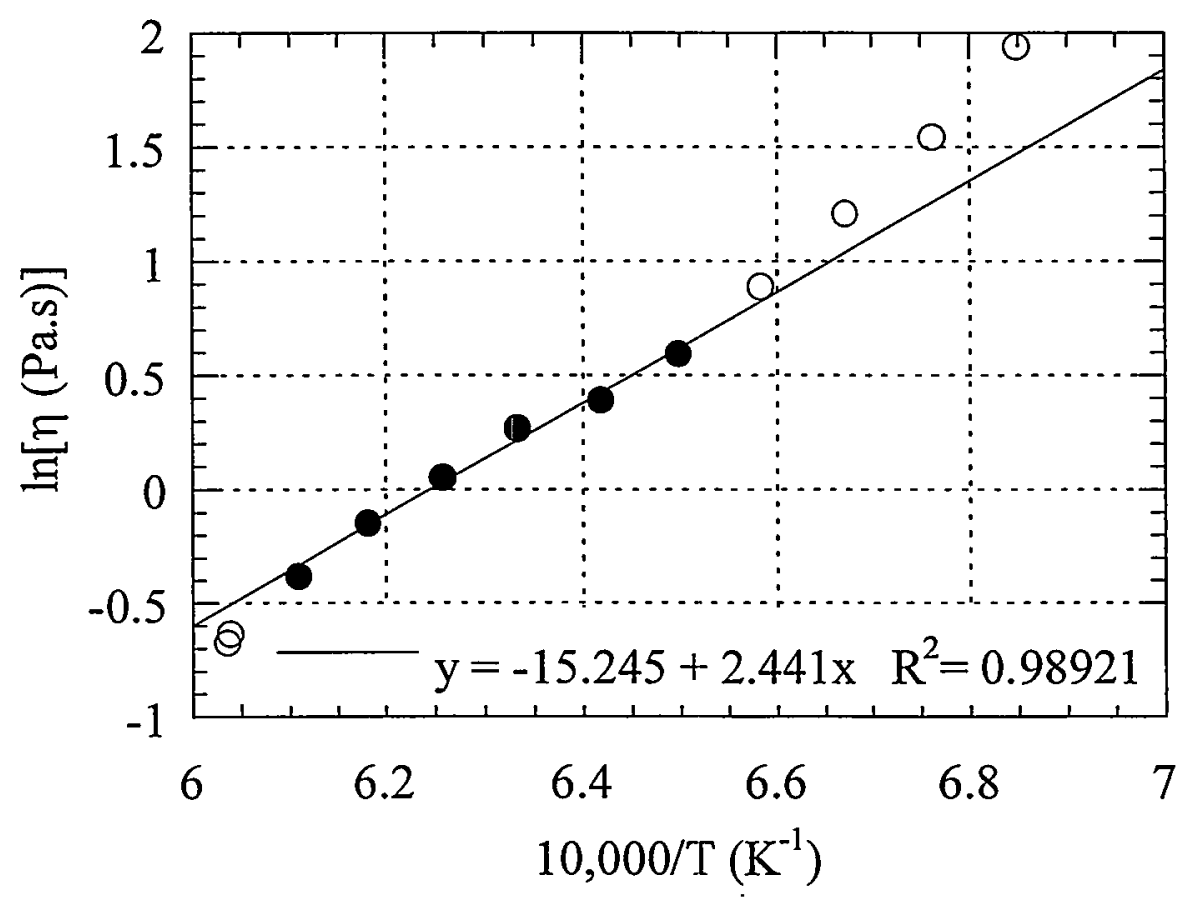

Figure 2.4. Measured ln Viscosity vs. 10000/T for AC2-02 


\section{$3.0 \cdot \mathrm{AC} 2-03$}

Glass $\mathrm{AC} 2-03$ is an extreme vertex on inner level of glass compositions. This glass targets 60.7 mass percent $\mathrm{Ln}_{2} \mathrm{O}_{3}$. The ratios of $\mathrm{B}_{2} \mathrm{O}_{3}$ and $\mathrm{SrO}$ to other frit components are higher in this glass than in the baseline frit. In other words, the relative concentrations of $\mathrm{SiO}_{2}, \mathrm{Al}_{2} \mathrm{O}_{3}$, $\mathrm{B}_{2} \mathrm{O}_{3}$, and $\mathrm{SrO}$ are low, low, high, and high, respectively, in comparison to the standard frit composition.

\subsection{Liquidus Temperature}

Table 3.1 summarizes the final heat treatments performed on this glass. The $T_{L}$ of this glass was estimated at $1313^{\circ} \mathrm{C}$ using Furnace \#12 since only one small crystal remained during the $1312^{\circ} \mathrm{C}$ heat treatment, and the sample heat treated at $1315^{\circ} \mathrm{C}$ appeared to be crystal free by OM. RES crystals formed in samples of this glass heat treated at temperatures below $T_{L}$. These crystals were identified by the characteristic morphology of the crystal as seen in Figure 3.1 and by an XRD scan of a sample heat treated at $1198^{\circ} \mathrm{C}$ shown in Figure 3.2.

During the $1306^{\circ} \mathrm{C}$ heat treatment of $\mathrm{AC} 2-03$, small nodules or buds of glass formed at the upper edge of the Pt/Rh box folds. Figure 4.11 (body of report) shows an example of these buds. The buds are thought to be formed by capillary forces drawing glass to the top of the $\mathrm{Pt} / \mathrm{Rh}$ foil folds. Further analysis of these buds was performed and is reported in Section 4.1.4 of this report.

Eight preliminary heat treatments were performed between $1153^{\circ} \mathrm{C}$ and $1343^{\circ} \mathrm{C}$ at approximately $50^{\circ} \mathrm{C}$ intervals. Abundant crystals were observed at $1248^{\circ} \mathrm{C}$ and $1296^{\circ} \mathrm{C}$, which matches the observations in the final heat treatments. The sample at $1343^{\circ} \mathrm{C}$ appeared to be crystal free by OM.

Table 3.1. Heat-Treatment Summary for Determination of $T_{L}$ for AC2-03

\begin{tabular}{ccccccc}
\hline Crucible & Furnace & Time/Date IN & $\mathrm{T}\left({ }^{\circ} \mathrm{C}\right)$ & Time/Date OUT & Observations & Comments \\
\hline $\mathrm{A}$ & 8 & $2: 00 \mathrm{pm} \mathrm{04/20}$ & 1198 & $1: 00 \mathrm{pm} \mathrm{04/21}$ & Crystals & Preliminary/XRD \\
3 & 12 & $3: 40 \mathrm{pm} \mathrm{06/21}$ & 1312 & $3: 30 \mathrm{pm} \mathrm{06/22}$ & One small crystal & $\mathrm{T}_{\mathrm{C}}$ \\
3 & 12 & $2: 00 \mathrm{pm} \mathrm{06/23}$ & 1306 & $3: 00 \mathrm{pm} \mathrm{06/24}$ & Few prisms & Buds \\
3 & 12 & $4: 05 \mathrm{pm} \mathrm{07/16}$ & 1315 & $3: 22 \mathrm{pm} \mathrm{07/17}$ & No crystals & $\mathrm{T}_{\mathrm{A}}$, Buds \\
\hline
\end{tabular}




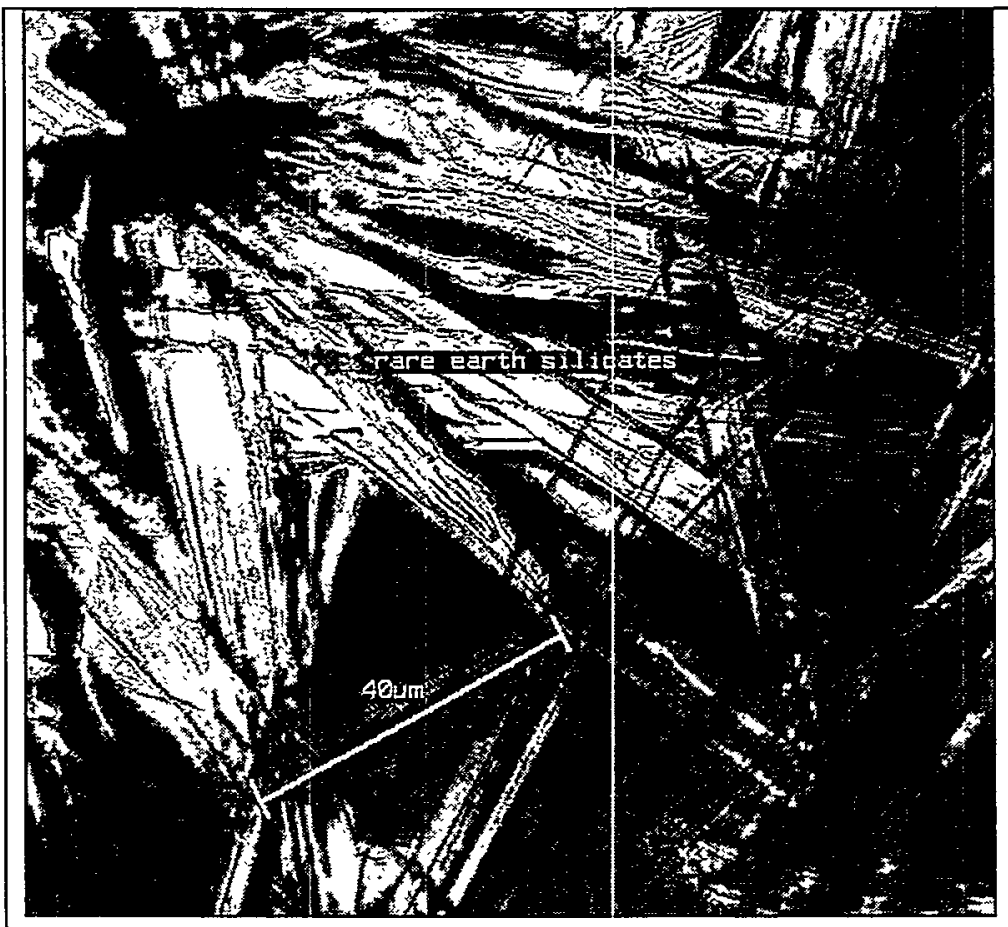

Figure 3.1. Optical Micrograph of RES Crystals in AC2$03\left(1296^{\circ} \mathrm{C}\right)$ at $100 \times$

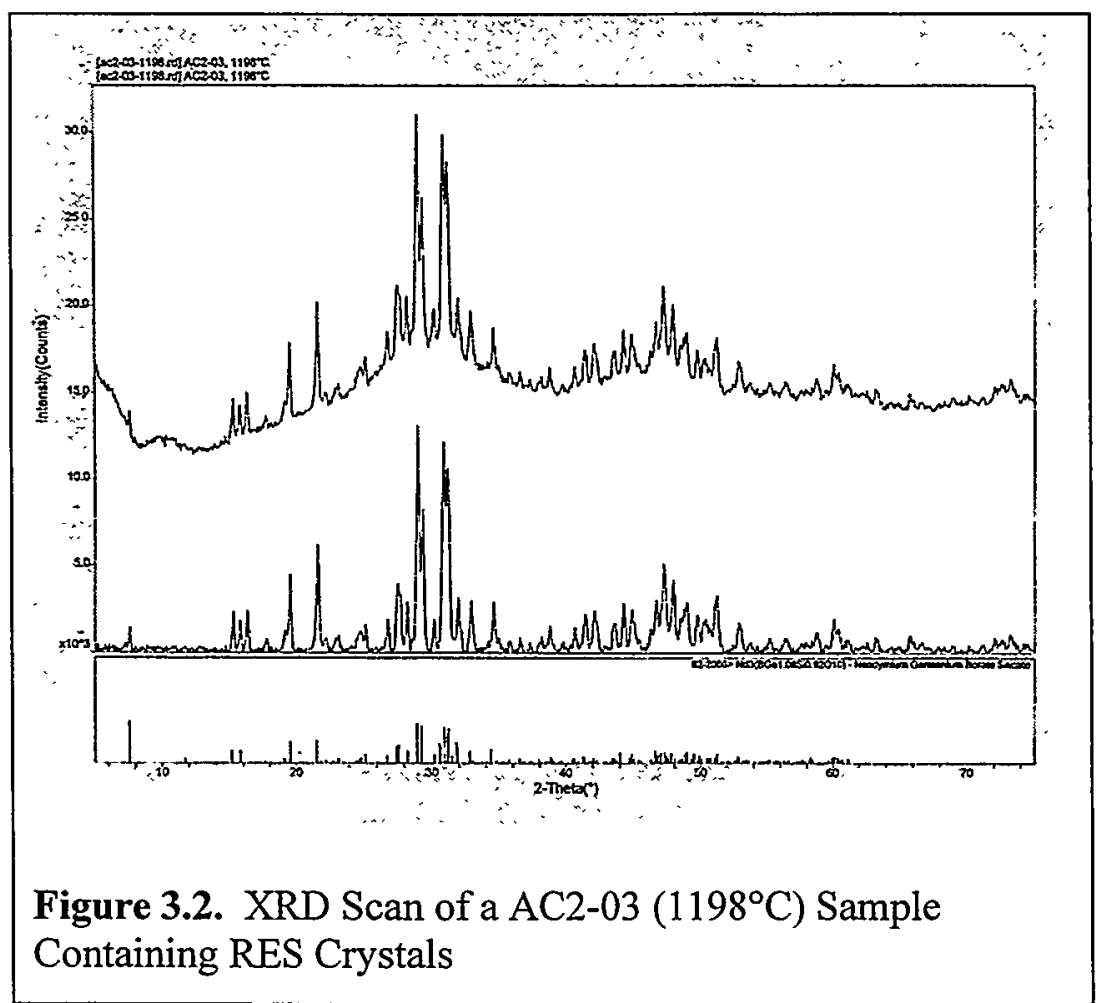




\subsection{Viscosity}

Table 3.2 lists the measured $\eta-\mathrm{T}$ values for $\mathrm{AC} 2-03$ in chronological order. These data are shown on an Arrhenius plot ( $\ln \eta$ vs. 1/T) in Figure 3.3. Four data points from Table 3.2 were excluded from calculations. These points, two at $1384^{\circ} \mathrm{C}$ and one at $1364^{\circ} \mathrm{C}$, had measured $\eta$ values below the instrument's range while a datum, at $1305^{\circ} \mathrm{C}$, was at a $\mathrm{T}$ below $\mathrm{T}_{\mathrm{L}}$. The excluded data are plotted as open circles and listed in strike-through font. Equation (2) was fitted to the remaining two data, plotted as filled circles, to yield $\mathrm{E}$ and $\mathrm{F}$ values of -19.528 and $30769 \mathrm{~K}$, respectively. This fit, based on only two valid data points, was then used to calculate a $\eta_{1350}$ value of $0.57 \mathrm{~Pa} \cdot \mathrm{s}$.

Table 3.2. Viscosity-Temperature Data for $\mathrm{AC} 2-03$

\begin{tabular}{cccc}
\hline $\mathrm{T}\left({ }^{\circ} \mathrm{C}\right)$ & $\eta(\mathrm{Pa} \cdot \mathrm{s})$ & $10000 / \mathrm{T}\left(\mathrm{K}^{-1}\right)$ & $\ln [\eta(\mathrm{Pa} \cdot \mathrm{s})]$ \\
\hline 1384 & 0.355 & 6.035 & -1.04 \\
1364 & 0.456 & 6.109 & -0.78 \\
1344 & 0.609 & 6.184 & -0.50 \\
1324 & 0.774 & 6.262 & -0.26 \\
1305 & 0.964 & 6.337 & -0.04 \\
1384 & 0.335 & 6.035 & 1.09 \\
\hline
\end{tabular}

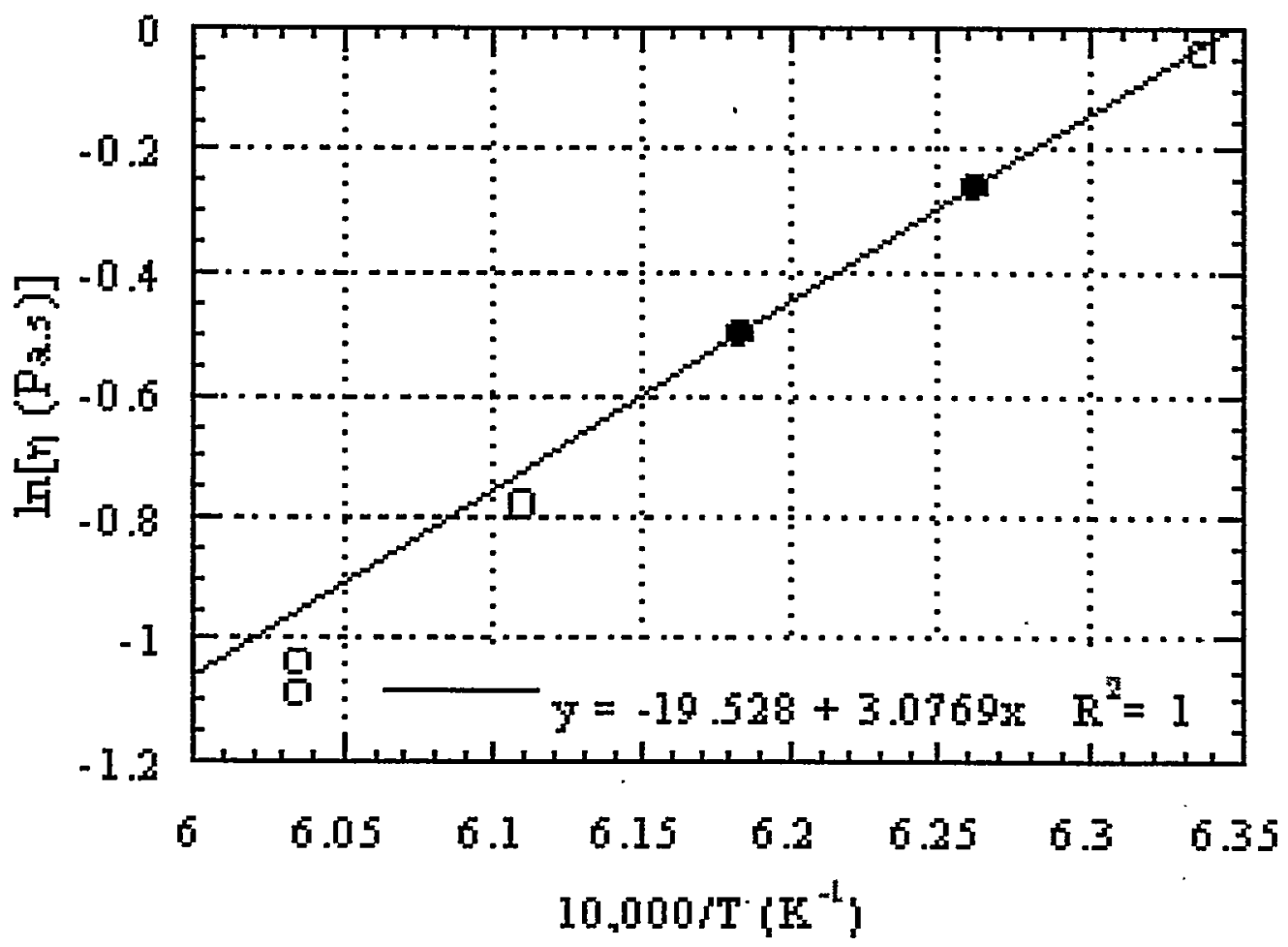

Figure 3.3. Measured ln Viscosity vs. $10000 / \mathrm{T}$ for $\mathrm{AC} 2-03$ 
A. 14 


\subsection{AC2-04}

Glass AC2-04 is an extreme vertex on inner level of glass compositions. This glass targets 63.5 mass percent $\mathrm{Ln}_{2} \mathrm{O}_{3}$. The ratio of $\mathrm{SrO}$ to other frit components is higher in this glass than in the baseline frit. In other words, the relative concentrations of $\mathrm{SiO}_{2}, \mathrm{Al}_{2} \mathrm{O}_{3}, \mathrm{~B}_{2} \mathrm{O}_{3}$, and $\mathrm{SrO}$ are same, same, same, and high, respectively, in comparison to the standard frit composition.

\subsection{Liquidus Temperature}

The "as-received" glass had thin, hair-like crystals observed by OM. The glass was not remelted before testing, but every effort was performed to use representative samples for $T_{L}$ measurements. Nine preliminary tests starting at $1451^{\circ} \mathrm{C}$ down to $1268^{\circ} \mathrm{C}$ indicated the $\mathrm{T}_{\mathrm{L}}$ to be approximately $1400^{\circ} \mathrm{C}$. Subsequent tests between $1401^{\circ} \mathrm{C}$ and $1344^{\circ} \mathrm{C}$ produced no crystals. Another glass sample was requested from Savannah River Technology Center (SRTC), and in three measurements between $1380^{\circ} \mathrm{C}$ and $1409^{\circ} \mathrm{C}$, the $\mathrm{T}_{\mathrm{L}}$ was estimated to be at $1405^{\circ} \mathrm{C}$ with the primary phase as RESs, as seen in Table 4.1.

A few needle-like crystals, probably RESs, were observed by OM on the melt surfaces of the sample heat treated at $1409^{\circ} \mathrm{C}$ and the preliminary sample heat treated at $1451^{\circ} \mathrm{C}$. Because of the high testing temperatures of this sample (the only glass with $T_{L}>1405^{\circ} \mathrm{C}$ ), volatilization of glass components was evident and caused surface crystals to form. These crystals were easily distinguished from those formed just below $T_{L}$. The crystals formed at temperatures just below $T_{L}$ were observed below the glass surface and on the crucible bottom.

Nine preliminary heat treatments were performed between $1268^{\circ} \mathrm{C}$ and $1451^{\circ} \mathrm{C}$ at approximately $50^{\circ} \mathrm{C}$ intervals. Abundant crystals were observed at $1344^{\circ} \mathrm{C}$ and $1387^{\circ} \mathrm{C}$, which matches the observations in the final heat treatments. Unusually long needle-like crystals (4 to $5 \mathrm{~mm}$ length) were observed at $1398^{\circ} \mathrm{C}$ and characterized by SEM as RESs (Figure 4.1 and Figure 4.2).

Table 4.1. Heat-Treatment Summary for Determination of $\mathrm{T}_{\mathrm{L}}$ for AC2-04

\begin{tabular}{ccccccc}
\hline Crucible & Furnace & Date/Time IN & T $\left({ }^{\circ} \mathrm{C}\right)$ & Date/Time OUT & Observations & Comments \\
\hline 4 & 8 & $9: 25 \mathrm{am} \mathrm{06/30}$ & 1401 & $9: 25 \mathrm{am} \mathrm{07/01}$ & Few crystals & $\mathrm{T}_{\mathrm{C}}$ \\
4 & 8 & $3: 50 \mathrm{pm} \mathrm{07/26}$ & 1390 & $3: 00 \mathrm{pm} \mathrm{07/27}$ & RES on bottom & \\
4 & 8 & $3: 20 \mathrm{pm} \mathrm{07/27}$ & 1380 & $1: 12 \mathrm{pm} \mathrm{07/28}$ & Crystals throughout & \\
4 & 8 & $3: 07 \mathrm{pm} \mathrm{07/28}$ & 1409 & $1: 12 \mathrm{pm} \mathrm{07/29}$ & Only one crystal caused by volatility & $\mathrm{T}_{\mathrm{A}}$ \\
\hline
\end{tabular}




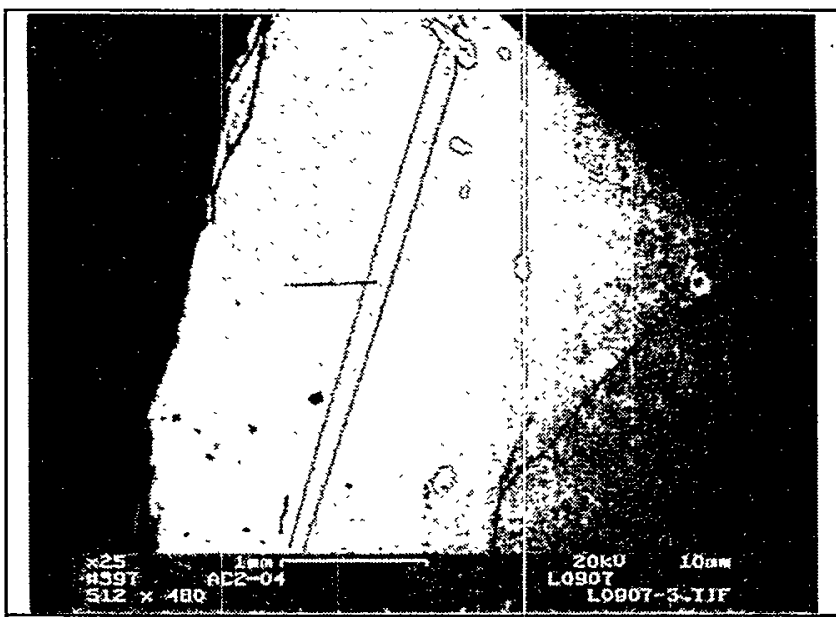

Figure 4.1. SEM Micrograph of AC2-04 $\left(1398^{\circ} \mathrm{C}\right)$

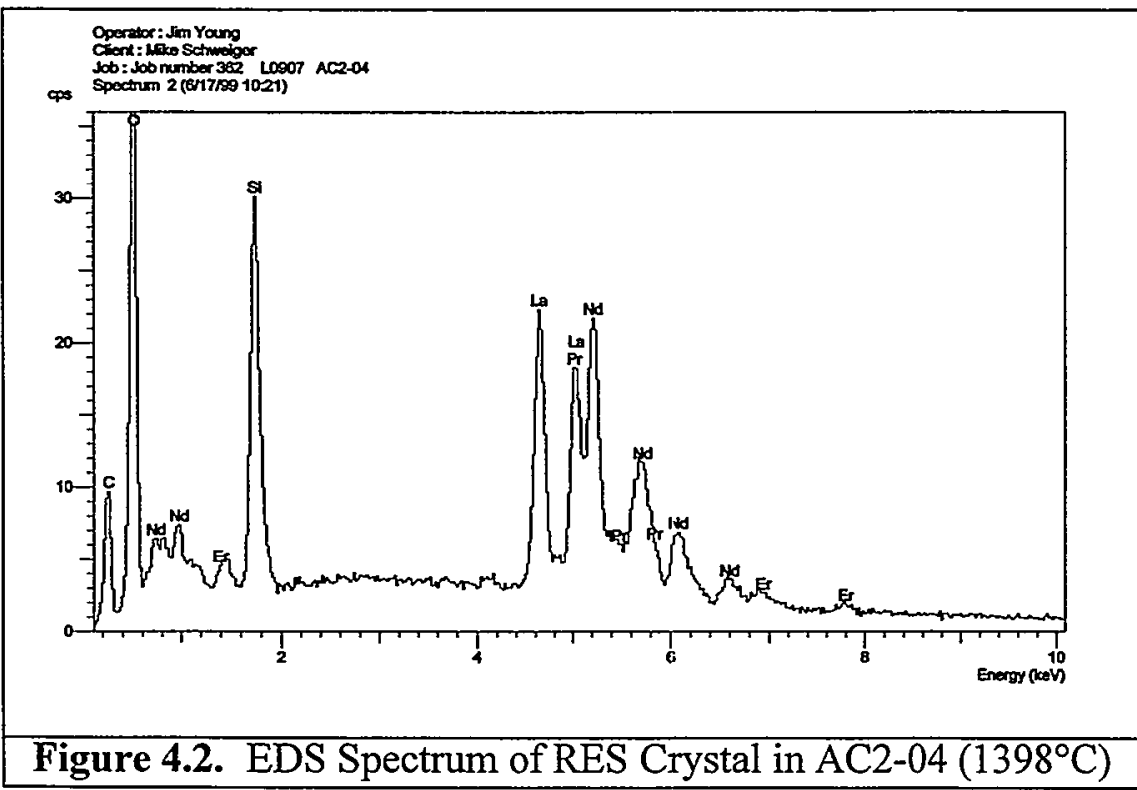

\subsection{Viscosity}

Table 4.2 lists the measured $\eta-T$ values for AC2-04 in chronological order. These data are shown on an Arrhenius plot $(\ln \eta$ vs. 1/T) in Figure 4.3. All four data points from Table 4.2 were excluded from calculations. All but one of these points, at $1384^{\circ} \mathrm{C}$, had measured $\eta$ values below the instrument's range while all data points were taken at Ts below $\mathrm{T}_{\mathrm{L}}$. The excluded data are plotted as open circles and listed in strike-through font. With no valid data for calculations, Equation (2) was not fitted for this glass. 
Table 4.2. Viscosity-Temperature Data for $\mathrm{AC2}-04$

\begin{tabular}{cccc}
\hline $\mathrm{T}\left({ }^{\circ} \mathrm{C}\right)$ & $\eta(\mathrm{Pa} \cdot \mathrm{s})$ & $10000 / \mathrm{T}\left(\mathrm{K}^{-1}\right)$ & $\ln [\eta(\mathrm{Pa} \cdot \mathrm{s})]$ \\
\hline 1384 & 0.585 & 6.035 & -0.536 \\
1404 & 0.380 & 5.963 & -0.967 \\
1384 & 0.496 & 6.035 & -0.700 \\
1404 & 0.484 & 5.963 & -0.727 \\
\hline
\end{tabular}

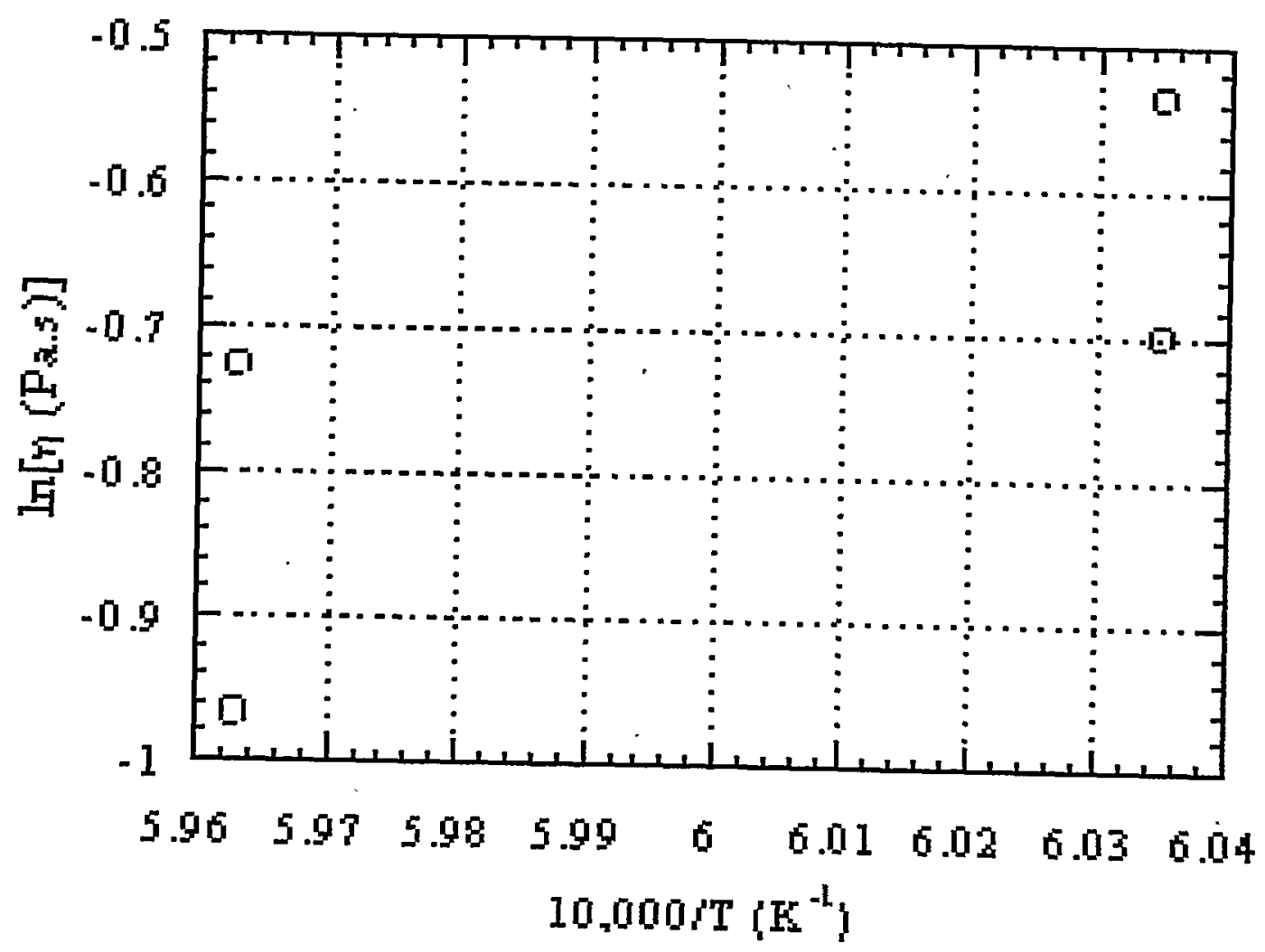

Figure 4.3. Measured ln Viscosity vs. 10000/T for AC2-04 
A. 18 


\section{$5.0 \quad$ AC2-05}

Glass AC2-05 is an extreme vertex on the inner level of glass compositions. This glass targets 51.6 mass percent $\mathrm{Ln}_{2} \mathrm{O}_{3}$. The ratios of $\mathrm{SiO}_{2}, \mathrm{Al}_{2} \mathrm{O}_{3}$, and $\mathrm{SrO}$ to other frit components are higher in this glass than in the baseline frit. In other words, the relative concentrations of $\mathrm{SiO}_{2}$, $\mathrm{Al}_{2} \mathrm{O}_{3}, \mathrm{~B}_{2} \mathrm{O}_{3}$, and $\mathrm{SrO}$ are high, high, low, and high, respectively, in comparison to the standard frit composition.

\subsection{Liquidus Temperature}

Table 5.1 summarizes the final heat treatments performed on this glass. The $T_{L}$ of this glass was estimated at $1241^{\circ} \mathrm{C}$ since one sample appeared to be crystal free after a heat treatment at $1241^{\circ} \mathrm{C}$, and a second sample contained only a few small crystals after a heat treatment at $1240^{\circ} \mathrm{C}$. RES crystals formed in samples of this glass heat treated at temperatures below $T_{L}$. These crystals were identified as RESs by SEM (Figure 5.1 and Figure 5.2) and by the characteristic morphology seen in Figure 5.3. See Section 4.1.5 in this report for a comparison of the EDS spectra of the crystals in a $1223^{\circ} \mathrm{C}$ heat-treated sample with that of the glass/matrix. The crystal appears to be composed of $\mathrm{Ln}_{2} \mathrm{O}_{3}$ and $\mathrm{SiO}_{2}$; the ratio of $\mathrm{Ln}_{2} \mathrm{O}_{3}$ to $\mathrm{SiO}_{2}$ appears to be higher in the crystal than in the glass.

Six preliminary heat treatments were performed between $1153^{\circ} \mathrm{C}$ and $1248^{\circ} \mathrm{C}$ at approximately $50^{\circ} \mathrm{C}$ intervals. Abundant crystals were observed at $1223^{\circ} \mathrm{C}$ and $1233^{\circ} \mathrm{C}$, which matches observations from final heat treatments. The sample at $1240^{\circ} \mathrm{C}$ appeared to be crystal free by OM.

Table 5.1. Heat-Treatment Summary for Determination of $T_{L}$ for $A C 2-05$

\begin{tabular}{ccccccc}
\hline Crucible & Furnace & Time/Date IN & $\mathrm{T}\left({ }^{\circ} \mathrm{C}\right)$ & Time/Date OUT & Observations & Comments \\
\hline $\mathrm{C}$ & 8 & $2: 45 \mathrm{pm} \mathrm{04/23}$ & 1223 & $4: 53 \mathrm{pm} \mathrm{04/24}$ & Long crystals & Preliminary, SEM \\
5 & 3 & $4: 00 \mathrm{pm} \mathrm{05/28}$ & 1241 & $2: 00 \mathrm{pm} \mathrm{05/29}$ & No crystals & $\mathrm{T}_{\mathrm{A}}$ \\
5 & 3 & $4: 00 \mathrm{pm} \mathrm{06/01}$ & 1233 & $2: 30 \mathrm{pm} \mathrm{06/02}$ & Very few crystals & \\
5 & 3 & $3: 30 \mathrm{pm} \mathrm{06/02}$ & 1240 & $2: 30 \mathrm{pm} \mathrm{06/03}$ & Few small crystals & $\mathrm{T}_{\mathrm{C}}$ \\
5 & 3 & $1: 45 \mathrm{pm} \mathrm{06/23}$ & 1251 & $2: 00 \mathrm{pm} \mathrm{06/24}$ & No crystals & \\
\hline
\end{tabular}




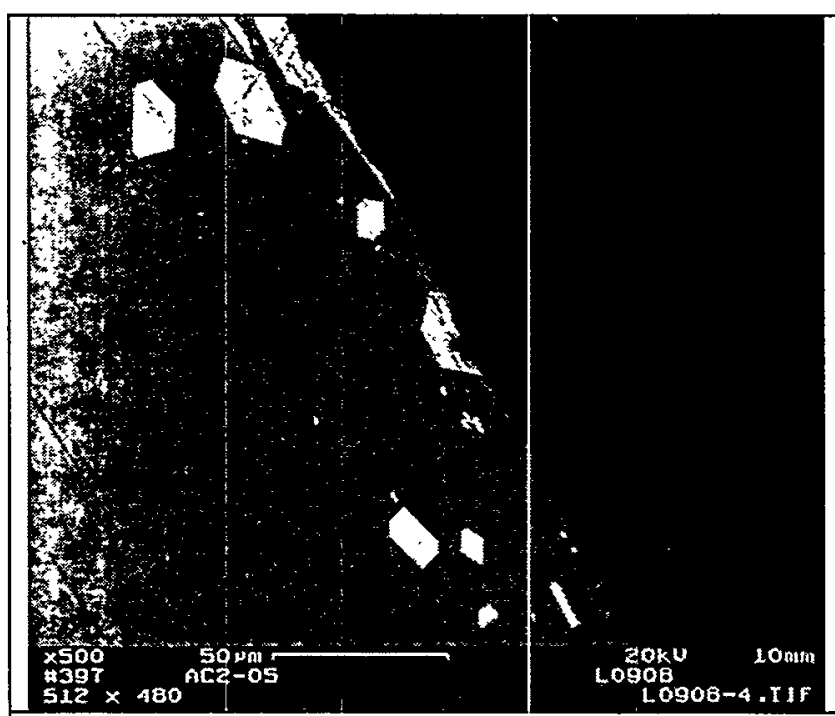

Figure 5.1. SEM Micrograph of AC2-05

$\left(1223^{\circ} \mathrm{C}\right)$

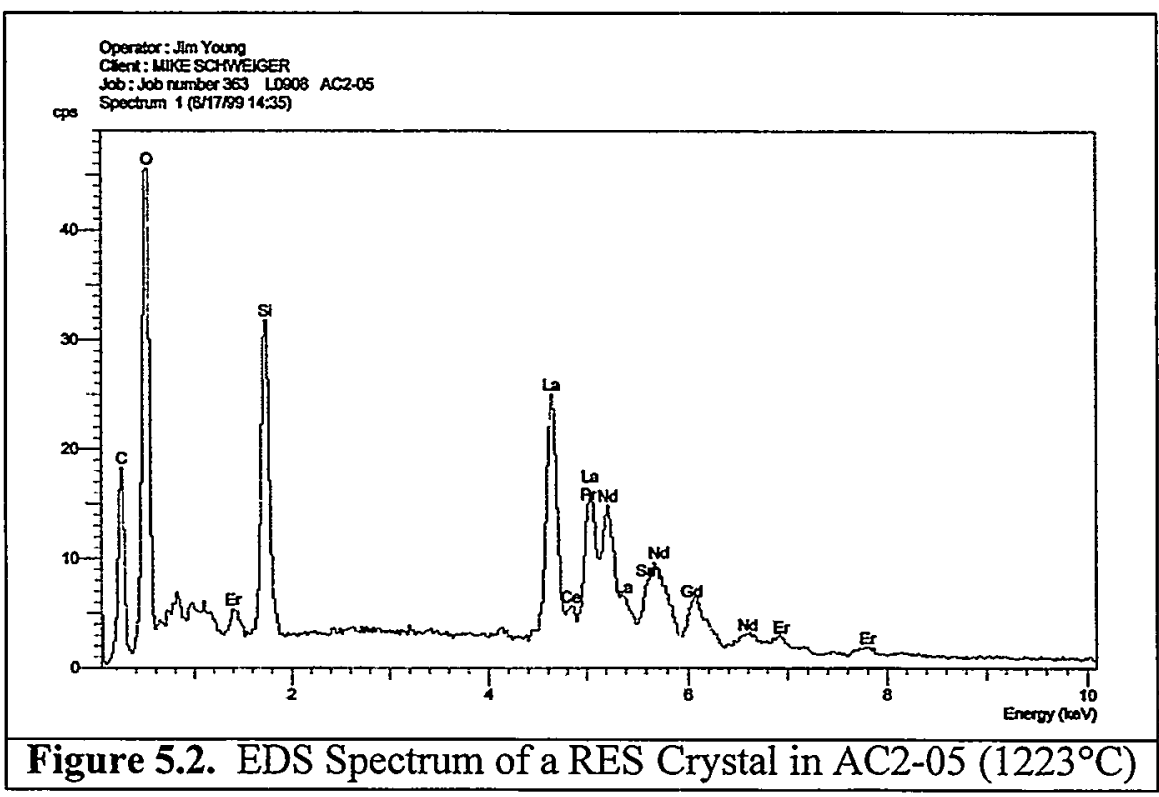




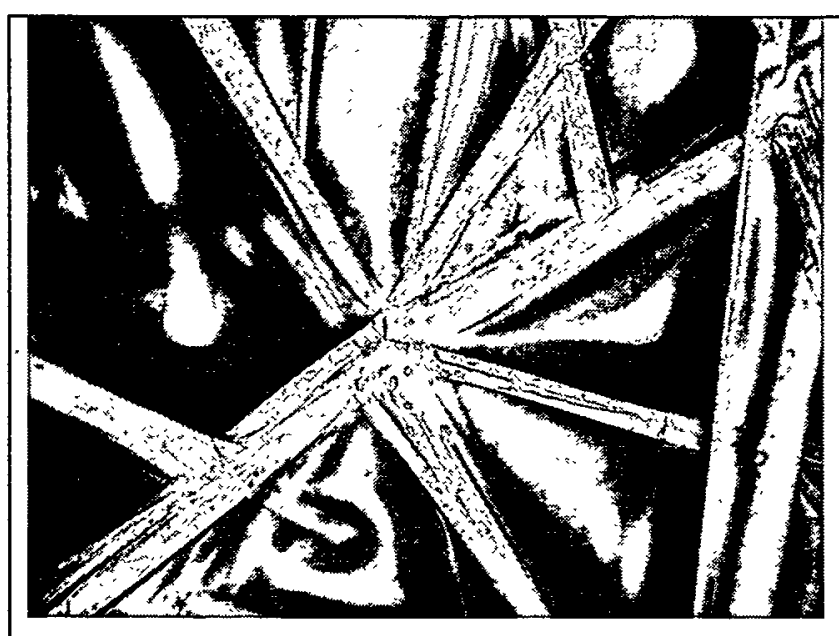

Figure 5.3. Optical Micrograph of AC2-05

$\left(1198^{\circ} \mathrm{C}\right)$ at $100 \times$

\subsection{Viscosity}

Table 5.2 lists the measured $\eta-T$ values for AC2-05 in chronological order. These data are shown on an Arrhenius plot ( $\ln \eta$ vs. 1/T) in Figure 5.4. Three data points from Table 5.2 were taken at $\mathrm{Ts}$ below $\mathrm{T}_{\mathrm{L}}$, two at $1234^{\circ} \mathrm{C}$ and one at $1185^{\circ} \mathrm{C}$, and were excluded from calculations. The excluded data are plotted as open circles and listed in strike-through font. Equation (2) was fitted to the remaining data, plotted as filled circles, to yield $E$ and $F$ values of 17.764 and $30253 \mathrm{~K}$, respectively. The data appear to be nonlinear. Therefore, a $\eta_{1350}$ value of $2.20 \mathrm{~Pa} \cdot \mathrm{s}$ was obtained by interpolation between the data points at $1332^{\circ} \mathrm{C}$ and $1382^{\circ} \mathrm{C}$ using Equation (2).

Table 5.2. Viscosity-Temperature Data for AC2-05

\begin{tabular}{cccc}
\hline $\mathrm{T}\left({ }^{\circ} \mathrm{C}\right)$ & $\eta(\mathrm{Pa} \cdot \mathrm{s})$ & $10000 / \mathrm{T}\left(\mathrm{K}^{-1}\right)$ & $\ln [\eta(\mathrm{Pa} \cdot \mathrm{s})]$ \\
\hline 1283 & 5.472 & 6.427 & 1.700 \\
1234 & 12.298 & 6.636 & 2.509 \\
1185 & 31.760 & 6.859 & 3.458 \\
1234 & 13.120 & 6.636 & 2.574 \\
1283 & 5.488 & 6.427 & 1.703 \\
1332 & 2.650 & 6.231 & 0.974 \\
1382 & 1.604 & 6.042 & 0.472 \\
1432 & 1.049 & 5.865 & 0.048 \\
1284 & 5.512 & 6.423 & 1.707 \\
\hline
\end{tabular}




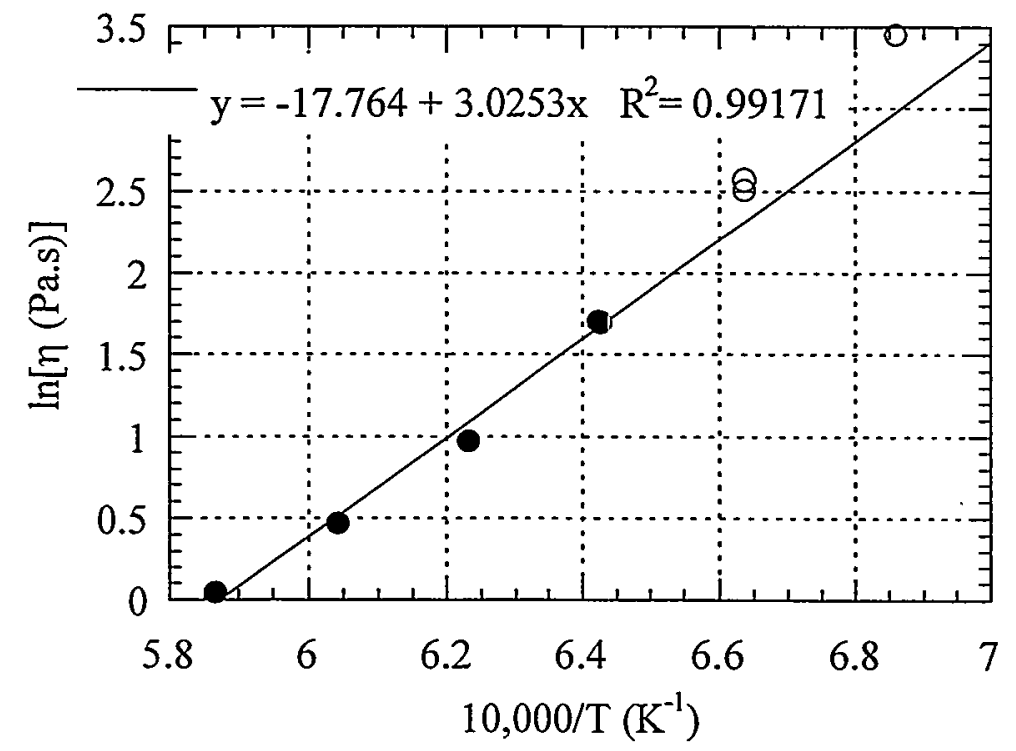

Figure 5.4. Measured ln Viscosity vs. 10000/T for AC2-05 


\subsection{AC2-06}

Glass AC2-06 is an extreme vertex on the inner level of glass compositions. This glass targets 61.3 mass percent $\mathrm{Ln}_{2} \mathrm{O}_{3}$. The ratio of $\mathrm{B}_{2} \mathrm{O}_{3}$ to other frit components is higher in this glass than in the baseline frit. In other words, the relative concentrations of $\mathrm{SiO}_{2}, \mathrm{Al}_{2} \mathrm{O}_{3}, \mathrm{~B}_{2} \mathrm{O}_{3}$, and $\mathrm{SrO}$ are low, low, high, and low, respectively, in comparison to the standard frit composition.

\subsection{Liquidus Temperature}

Table 6.1 summarizes the final heat treatments performed on this glass. The $T_{L}$ of this glass was estimated using Furnace $\# 3$ at $1309^{\circ} \mathrm{C}$, since one sample appeared to be crystal free after a heat treatment at $1314^{\circ} \mathrm{C}$, and a second sample contained only a few small crystals after a heat treatment at $1306^{\circ} \mathrm{C}$. RES crystals formed in samples of this glass heat treated at temperatures below $T_{L}$. These crystals were identified by the characteristic morphologies of the crystals formed below $T_{L}$. The morphologies matched those observed in samples of AC2-01, AC2-03, and other glasses that were shown by SEM and/or XRD to be RES crystals. Figure 6.1 shows the morphology of the crystals observed in AC2-06.

During the $1295^{\circ} \mathrm{C}$ heat treatment of $\mathrm{AC} 2-06$, small nodules or buds of glass formed at the upper edge of the Pt/Rh box folds. The buds are thought to be formed by capillary forces drawing glass to the top of the $\mathrm{Pt} / \mathrm{Rh}$ foil folds. Further analysis of these buds was performed and is reported in Section 4.1.4 of this report.

Six preliminary heat treatments were performed between $1153^{\circ} \mathrm{C}$ and $1343^{\circ} \mathrm{C}$ at approximately $50^{\circ} \mathrm{C}$ intervals. Abundant crystals were observed at $1248^{\circ} \mathrm{C}$ and $1296^{\circ} \mathrm{C}$, which matches observations from final heat treatments. The sample at $1319^{\circ} \mathrm{C}$ appeared to be crystal free by OM. An additional sample, heat treated in Furnace $\# 8$ at $1288^{\circ} \mathrm{C}$, contained crystals.

Table 6.i. Heat-Treatment Summary for Determination of $T_{L}$ for AC2-06

\begin{tabular}{ccccccc}
\hline Crucible & Furnace & Time/Date IN & $\mathrm{T}\left({ }^{\circ} \mathrm{C}\right)$ & Time/Date OUT & Observations & Comments \\
\hline 6 & 3 & $3: 00 \mathrm{pm} \mathrm{06/11}$ & 1314 & $2: 20 \mathrm{pm} \mathrm{06/12}$ & No crystals & $\mathrm{T}_{\mathrm{A}}$ \\
6 & 3 & $2: 56 \mathrm{pm} \mathrm{06/27}$ & 1295 & $1: 00 \mathrm{pm} \mathrm{06/28}$ & Full of crystals & Buds \\
6 & 3 & $11: 00 \mathrm{am} \mathrm{06/29}$ & 1306 & $9: 20 \mathrm{am} \mathrm{06/30}$ & Few corner crystals & $\mathrm{T}_{\mathrm{C}}$ \\
6 & 8 & $8: 54 \mathrm{am} \mathrm{07/07}$ & 1288 & $10: 50 \mathrm{am} \mathrm{07/07}$ & Full of crystals & different furnace, Buds \\
\hline
\end{tabular}




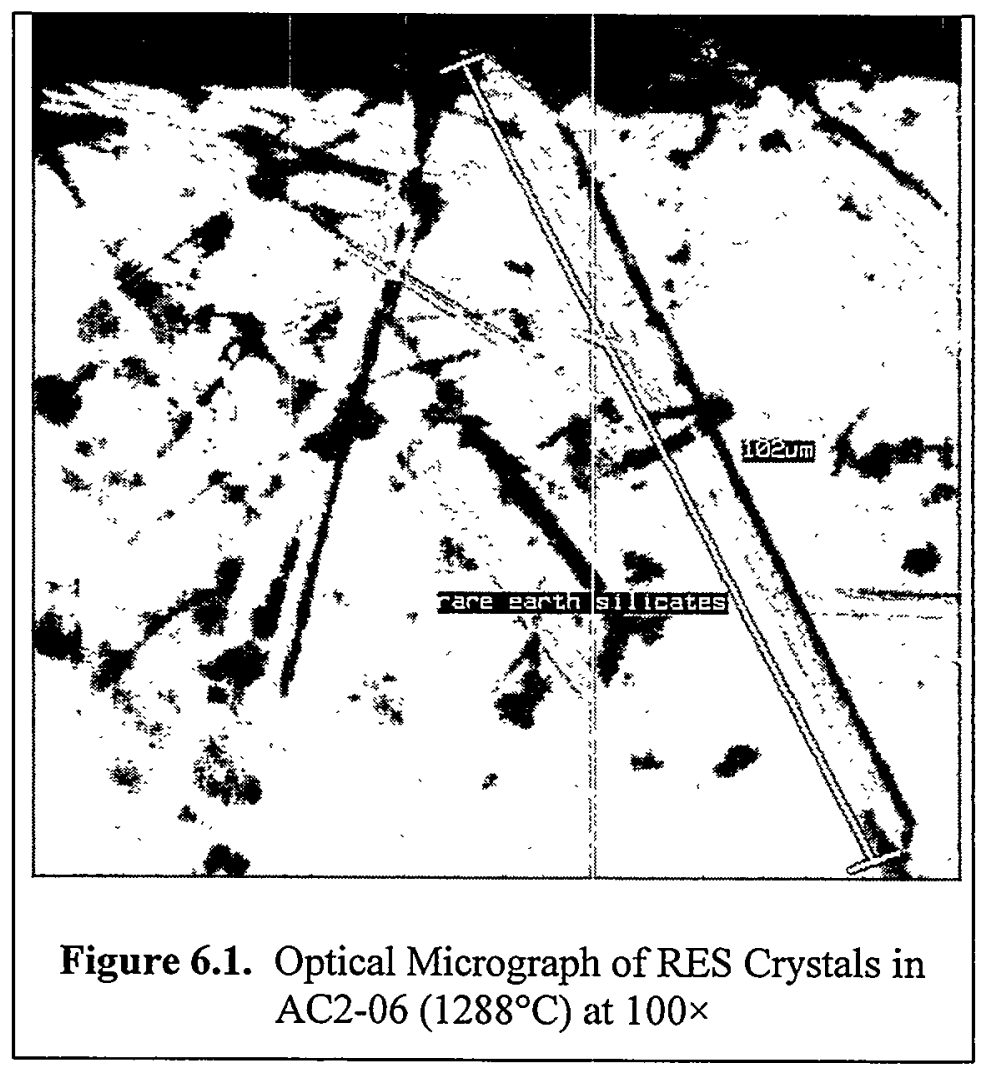

\subsection{Viscosity}

Table 6.2 lists the measured $\eta-T$ values for AC2-06 in chronological order. These data are shown on an Arrhenius plot $(\ln \eta$ vs. 1/T) in Figure 6.2. Four data points from Table 6.2 were excluded from calculations. Three of these points, two at $1382^{\circ} \mathrm{C}$ and one at $1363^{\circ} \mathrm{C}$, had measured $\eta$ values below the instrument's range while a datum, at $1304^{\circ} \mathrm{C}$, was at a $T$ below $T_{L}$. The excluded data are plotted as open circles and listed in strike-through font. Equation (2) was fitted to the remaining two data, plotted as filled circles, to yield $E$ and $F$ values of -9.177 and $14314 \mathrm{~K}$, respectively. This fit, based on only two valid data points (both below $1350^{\circ} \mathrm{C}$ ), was then used to calculate a $\eta_{1350}$ value of $0.70 \mathrm{~Pa} \cdot \mathrm{s}$.

Table 6.2. Viscosity-Temperature Data for AC2-06

\begin{tabular}{cccc}
\hline $\mathrm{T}\left({ }^{\circ} \mathrm{C}\right)$ & $\eta(\mathrm{Pa} \cdot \mathrm{s})$ & $10000 / \mathrm{T}\left(\mathrm{K}^{-1}\right)$ & $\ln [\eta(\mathrm{Pa} \cdot \mathrm{s})]$ \\
\hline 1382 & 0.411 & 6.042 & -0.889 \\
1363 & 0.524 & 6.113 & -0.647 \\
1343 & 0.727 & 6.188 & -0.319 \\
1323 & 0.812 & 6.266 & -0.208 \\
1304 & 1.085 & 6.341 & 0.081 \\
1382 & 0.422 & 6.042 & -0.862 \\
\hline
\end{tabular}




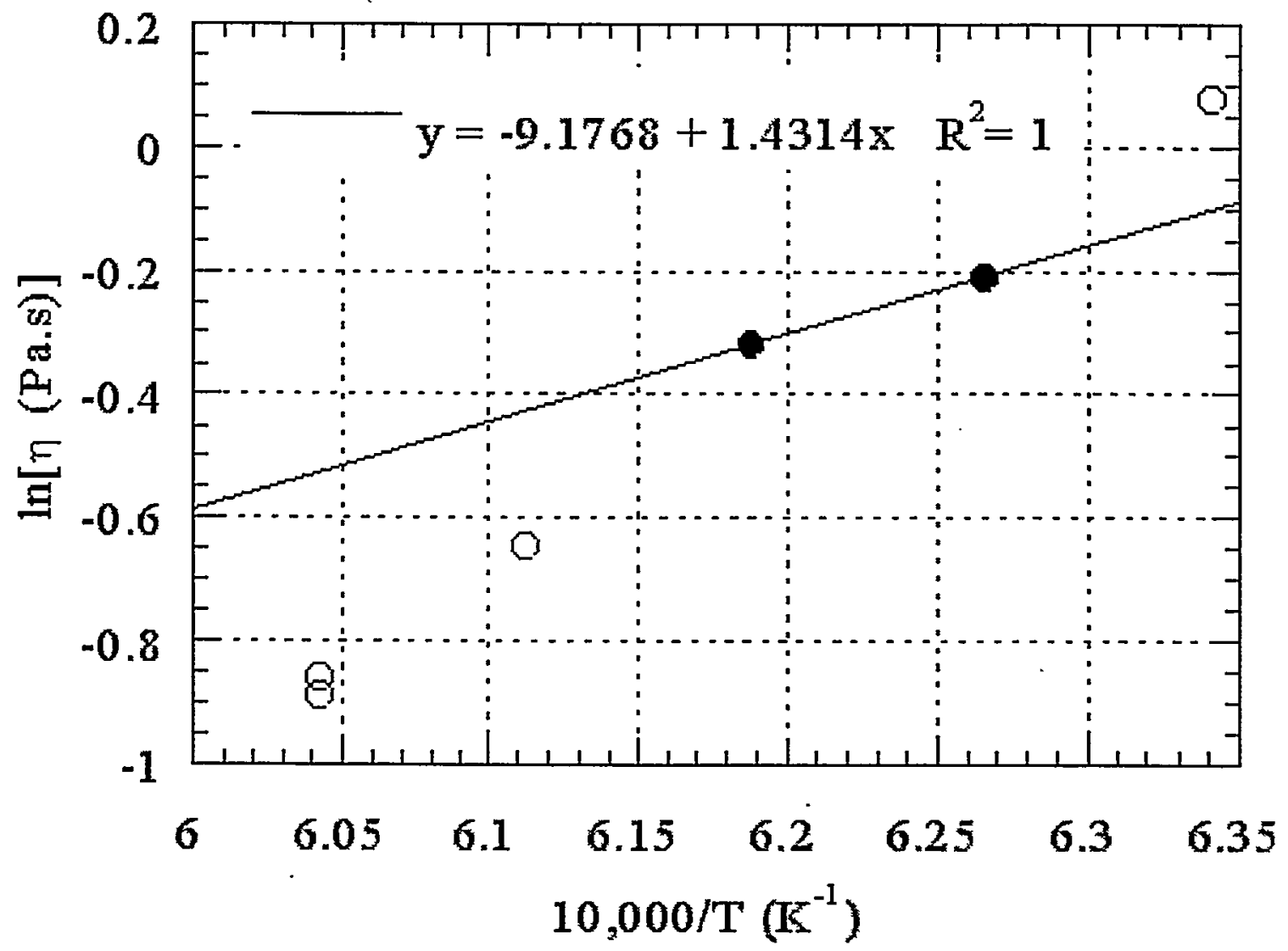

Figure 6.2. Measured ln Viscosity vs. 10000/T for AC2-06 
A. 26 


\subsection{AC2-07}

Glass AC2-07 is an extreme vertex on the inner level of glass compositions. This glass targets 52.2 mass percent $\mathrm{Ln}_{2} \mathrm{O}_{3}$. The ratios of $\mathrm{SiO}_{2}$ and $\mathrm{Al}_{2} \mathrm{O}_{3}$ to other frit components are higher in this glass than in the baseline frit. In other words, the relative concentrations of $\mathrm{SiO}_{2}$, $\mathrm{Al}_{2} \mathrm{O}_{3}, \mathrm{~B}_{2} \mathrm{O}_{3}$, and $\mathrm{SrO}$ are high, high, low and low, respectively, in comparison to the standard frit composition.

\subsection{Liquidus Temperature}

Table 7.1 summarizes the heat treatments performed on this glass. The $\mathrm{T}_{\mathrm{L}}$ of this glass was estimated using Furnace $\# 8$ at $1209^{\circ} \mathrm{C}$ since one sample appeared to be crystal free after a heat treatment at $1213^{\circ} \mathrm{C}$, and a second sample contained only a few small crystals after a heat treatment at $1204^{\circ} \mathrm{C}$. RES crystals formed in samples of this glass heat treated at temperatures below $T_{L}$. These crystals were identified by their characteristic morphologies. The morphology of crystals observed in AC2-07 (micrograph shown in Figure 7.1) matched those in samples of $\mathrm{AC2}-03, \mathrm{AC2}-05$, and other glasses that were shown by SEM and/or XRD to be RES crystals.

Seven preliminary heat treatments were performed with AC2-07 glass starting at $1153^{\circ} \mathrm{C}$ and increasing at approximately $50^{\circ} \mathrm{C}$ intervals to $1233^{\circ} \mathrm{C}$ where the sample appeared to be crystal free by $\mathrm{OM}$. The sample that was heat treated at $1198^{\circ} \mathrm{C}$ had fewer crystals compared to the $1153^{\circ} \mathrm{C}$ sample, indicatng that the glass was near $\mathrm{T}_{\mathrm{L}}$. An additional sample, heat treated in Furnace $\# 3$ at $1215^{\circ} \mathrm{C}$, appeared to be crystal free by $\mathrm{OM}$.

Table 7.1. Heat-Treatment Summary for Determination of $T_{L}$ for AC2-07

\begin{tabular}{ccccccc}
\hline Crucible & Furnace & Time/Date IN & $\mathrm{T}\left({ }^{\circ} \mathrm{C}\right)$ & Time/Date OUT & Observations & Comments \\
\hline 7 & 3 & $2: 30 \mathrm{pm} \mathrm{06/12}$ & 1215 & $3: 00 \mathrm{pm} \mathrm{06/13}$ & No crystals & different furnace \\
7 & 8 & $9: 20 \mathrm{am} \mathrm{06/28}$ & 1204 & $11: 00 \mathrm{am} \mathrm{06/29}$ & Very few crystals & $\mathrm{T}_{\mathrm{C}}$ \\
7 & 8 & $11: 15 \mathrm{am} \mathrm{07/03}$ & 1213 & $9: 15 \mathrm{am} \mathrm{07/04}$ & No crystals & $\mathrm{T}_{\mathrm{A}}$ \\
\hline
\end{tabular}




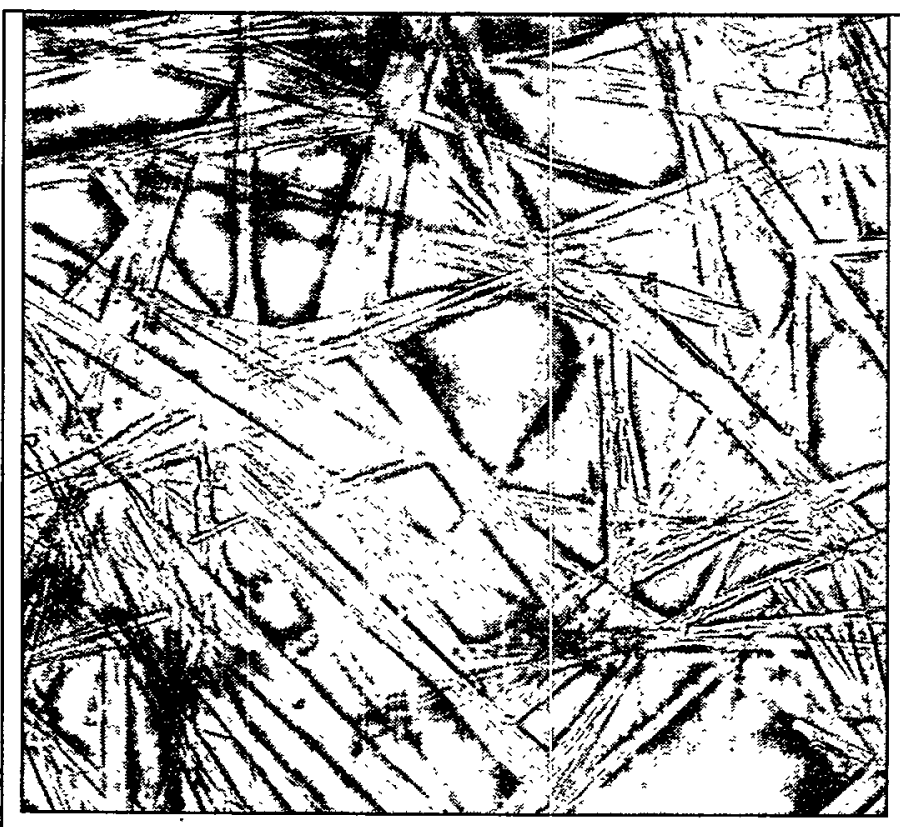

Figure 7.1. Optical Micrograph of RES Crystals in $\mathrm{AC} 2-07\left(1150^{\circ} \mathrm{C}\right)$ at $100 \times$

\subsection{Viscosity}

Table 7.2 lists the measured $\eta-\mathrm{T}$ values for $\mathrm{AC} 2-07$ in chronological order. These data are shown on an Arrhenius plot ( $\ln \eta$ vs. 1/T) in Figure 7.2. Two data points from Table 7.2 were taken at Ts below $\mathrm{T}_{\mathrm{L}}$, at $1204^{\circ} \mathrm{C}$ and $1184^{\circ} \mathrm{C}$, and were excluded from calculations. The excluded data are plotted as open circles and listed in strike-through font. Equation (2) was fitted to the remaining data, plotted as filled circles, to yield $E$ and $F$ values of -19.528 and $33144 \mathrm{~K}$, respectively. The data appear to be nonlinear. Therefore, a $\eta_{1350}$ value of $2.21 \mathrm{~Pa} \cdot \mathrm{s}$ was obtained by interpolation between the data points at $1334^{\circ} \mathrm{C}$ and $1382^{\circ} \mathrm{C}$ using Equation (2). 
Table 7.2. Viscosity-Temperature Data for $\mathrm{AC} 2-07$

\begin{tabular}{cccc}
\hline $\mathrm{T}\left({ }^{\circ} \mathrm{C}\right)$ & $\eta(\mathrm{Pa} \cdot \mathrm{s})$ & $10000 / \mathrm{T}\left(\mathrm{K}^{-1}\right)$ & $\ln [\eta(\mathrm{Pa} \cdot \mathrm{s})]$ \\
\hline 1383 & 1.499 & 6.039 & 0.405 \\
1403 & 1.412 & 5.967 & 0.345 \\
1453 & 0.886 & 5.794 & -0.121 \\
1384 & 1.438 & 6.035 & 0.363 \\
1334 & 2.717 & 6.223 & 1.000 \\
1283 & 5.536 & 6.427 & 1.711 \\
1264 & 7.479 & 6.506 & 2.012 \\
1244 & 10.638 & 6.592 & 2.364 \\
1224 & 15.570 & 6.680 & 2.745 \\
1204 & 22.185 & 6.770 & 3.099 \\
1184 & 32.926 & 6.863 & 3.494 \\
1382 & 1.480 & 6.042 & 0.392 \\
\hline
\end{tabular}

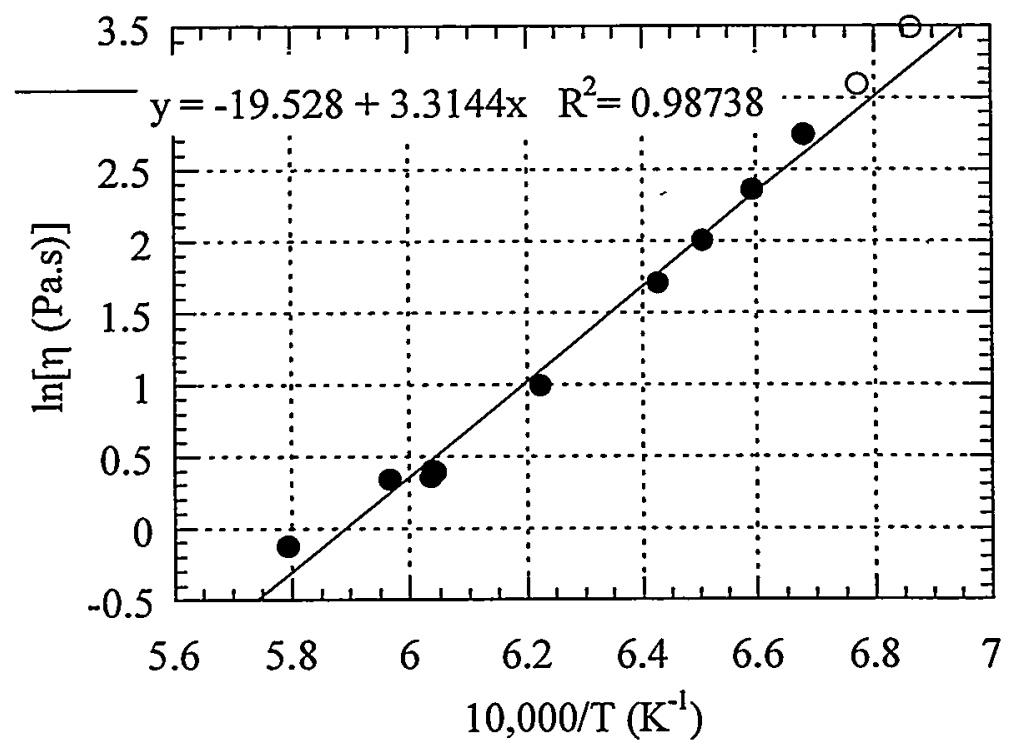

Figure 7.2. Measured ln Viscosity vs. 10000/T for AC2-07 
A. 30 


\subsection{AC2-08}

Glass AC2-08 is an extreme vertex on the inner level of glass compositions. This glass targets 52.9 mass percent $\mathrm{Ln}_{2} \mathrm{O}_{3}$. The ratios of $\mathrm{SiO}_{2}, \mathrm{Al}_{2} \mathrm{O}_{3}$, and $\mathrm{SrO}$ to other frit components are higher in this glass than in the baseline frit. In other words, the relative concentrations of $\mathrm{SiO}_{2}$, $\mathrm{Al}_{2} \mathrm{O}_{3}, \mathrm{~B}_{2} \mathrm{O}_{3}$, and $\mathrm{SrO}$ are high, high, low, and high, respectively, in comparison to the standard frit composition.

\subsection{Liquidus Temperature}

Table 8.1 summarizes the heat treatments performed on this glass. The $T_{L}$ of this glass was estimated using Furnace \#3 at $1242^{\circ} \mathrm{C}$ since one sample appeared to be crystal free after a heat treatment at $1240^{\circ} \mathrm{C}$, a second sample contained only a few small crystals after a heat treatment at $1241^{\circ} \mathrm{C}$, and only a few small rounded crystals remained in a sample heat treated at $1243^{\circ} \mathrm{C}$. These are likely caused by small glass composition inhomogeneities. RES crystals formed in samples of this glass heat treated at temperatures below $T_{L}$. These crystals were identified by the characteristic morphology of the crystal as seen in Figure 8.1. Figure 8.3 shows the EDS spectrum of a crystal in a $1233^{\circ} \mathrm{C}$ heat-treated sample (indicated in Figure 8.2). The crystal appears to be composed of $\mathrm{Ln}_{2} \mathrm{O}_{3}$ and $\mathrm{SiO}_{2}$; the ratio of $\mathrm{Ln}_{2} \mathrm{O}_{3}$ to $\mathrm{SiO}_{2}$ appears to be higher in the crystal than in the glass, similar to those seen in samples of AC2-05.

Five preliminary heat treatments were performed with $\mathrm{AC} 2-08$ glass starting at $1153^{\circ} \mathrm{C}$ and increasing at approximately $50^{\circ} \mathrm{C}$ intervals to $1247^{\circ} \mathrm{C}$ where the sample appeared to be crystal free by $\mathrm{OM}$. The sample heat treated at $1240^{\circ} \mathrm{C}$ had fewer crystals the $1233^{\circ} \mathrm{C}$ sample, which indicated that the glass was near $T_{L}$.

Table 8.1. Heat-Treatment Summary for Determination of $T_{L}$ for AC2-08

\begin{tabular}{ccccccc}
\hline Crucible & Furnace & Date/Time IN & $\mathrm{T}\left({ }^{\circ} \mathrm{C}\right)$ & Date/Time OUT & Observations & Comments \\
\hline 8 & 3 & $4: 00 \mathrm{pm} \mathrm{05/28}$ & 1241 & $2: 00 \mathrm{pm} \mathrm{05/29}$ & Few crystals & $\mathrm{T}_{\mathrm{C}}$ \\
8 & 3 & $4: 00 \mathrm{pm} \mathrm{06/01}$ & 1233 & $2: 30 \mathrm{pm} \mathrm{06/02}$ & Small crystals & SEM \\
8 & 3 & $3: 30 \mathrm{pm} \mathrm{06/02}$ & 1240 & $2: 30 \mathrm{pm} \mathrm{06/03}$ & No crystals & $\mathrm{T}_{\mathrm{A}}$ \\
8 & 3 & $4: 30 \mathrm{pm} \mathrm{06/09}$ & 1243 & $3: 00 \mathrm{pm} \mathrm{06/10}$ & Few round crystals & \\
8 & 3 & $4: 30 \mathrm{pm} \mathrm{06/10}$ & 1252 & $2: 30 \mathrm{pm} \mathrm{06/11}$ & No crystals & \\
\hline
\end{tabular}




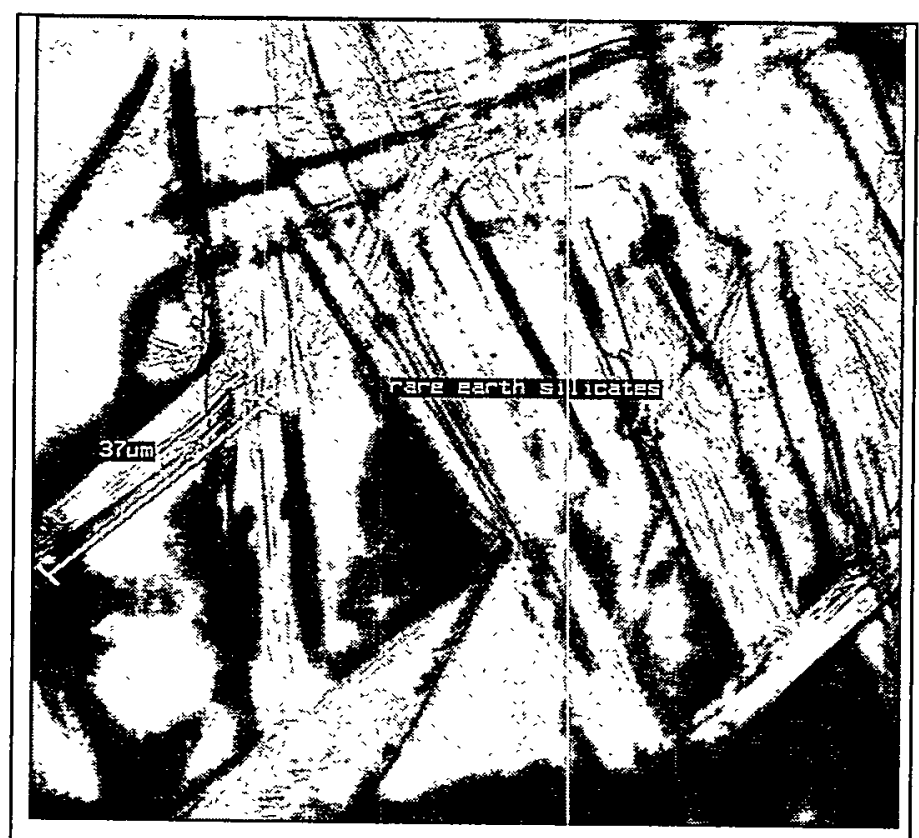

Figure 8.1. Optical Micrograph of RES Crystals in $\mathrm{AC} 2-08\left(1198^{\circ} \mathrm{C}\right)$ at $100 \times$

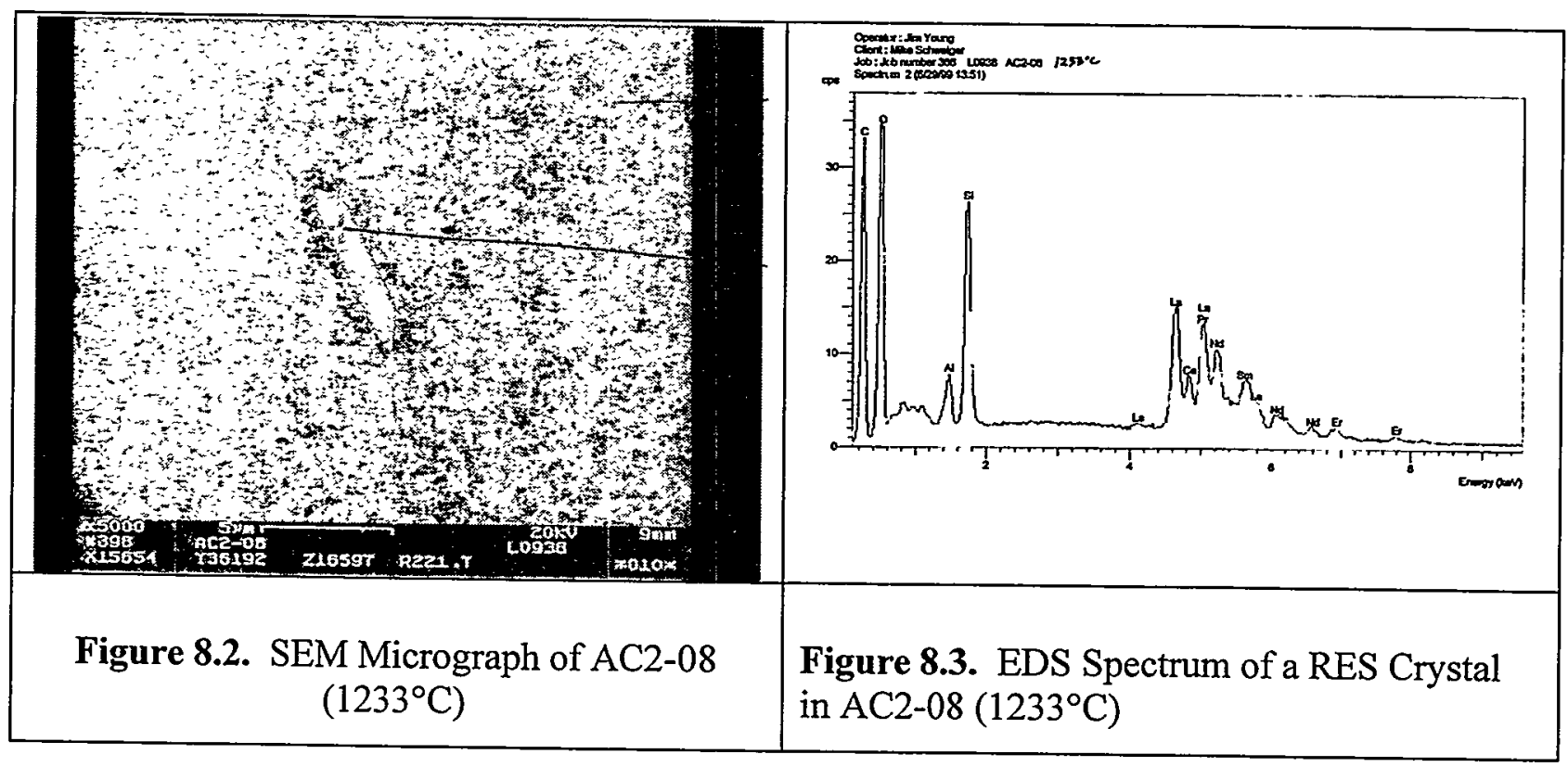

\subsection{Viscosity}

Table 8.2 lists the measured $\eta-T$ values for AC2-08 in chronological order. These data are shown on an Arrhenius plot $(\ln \eta$ vs. $1 / \mathrm{T})$ in Figure 8.4. Two data points from Table 8.2 were taken at Ts below $\mathrm{T}_{\mathrm{L}}$, at $1236^{\circ} \mathrm{C}$ and $1187^{\circ} \mathrm{C}$, and were excluded from calculations. The 
excluded data are plotted as open circles and listed in strike-through font. Equation (2) was fitted to the remaining data, plotted as filled circles, to yield $E$ and $F$ values of -15.776 and $26567 \mathrm{~K}$, respectively. The data appear to be nonlinear. Therefore, a $\eta_{1350}$ value of $1.70 \mathrm{~Pa} \cdot \mathrm{s}$ was obtained by interpolation between the data points at $1335^{\circ} \mathrm{C}$ and $1384^{\circ} \mathrm{C}$ using Equation (2).

Table 8.2. Viscosity-Temperature Data for $\mathrm{AC} 2-08$

\begin{tabular}{cccc}
\hline $\mathrm{T}\left({ }^{\circ} \mathrm{C}\right)$ & $\eta(\mathrm{Pa} \cdot \mathrm{s})$ & $10000 / \mathrm{T}\left(\mathrm{K}^{-1}\right)$ & $\ln [\eta(\mathrm{Pa} \cdot \mathrm{s})]$ \\
\hline 1384 & 1.289 & 6.035 & 0.254 \\
1335 & 1.928 & 6.219 & 0.656 \\
1285 & 3.989 & 6.418 & 1.384 \\
1335 & 1.908 & 6.219 & 0.646 \\
1384 & 1.326 & 6.035 & 0.283 \\
1434 & 0.840 & 5.858 & -0.175 \\
1384 & 1.320 & 6.035 & 0.278 \\
1236 & 8.800 & 6.627 & 2.175 \\
1187 & 24.908 & 6.849 & 3.215 \\
\hline
\end{tabular}

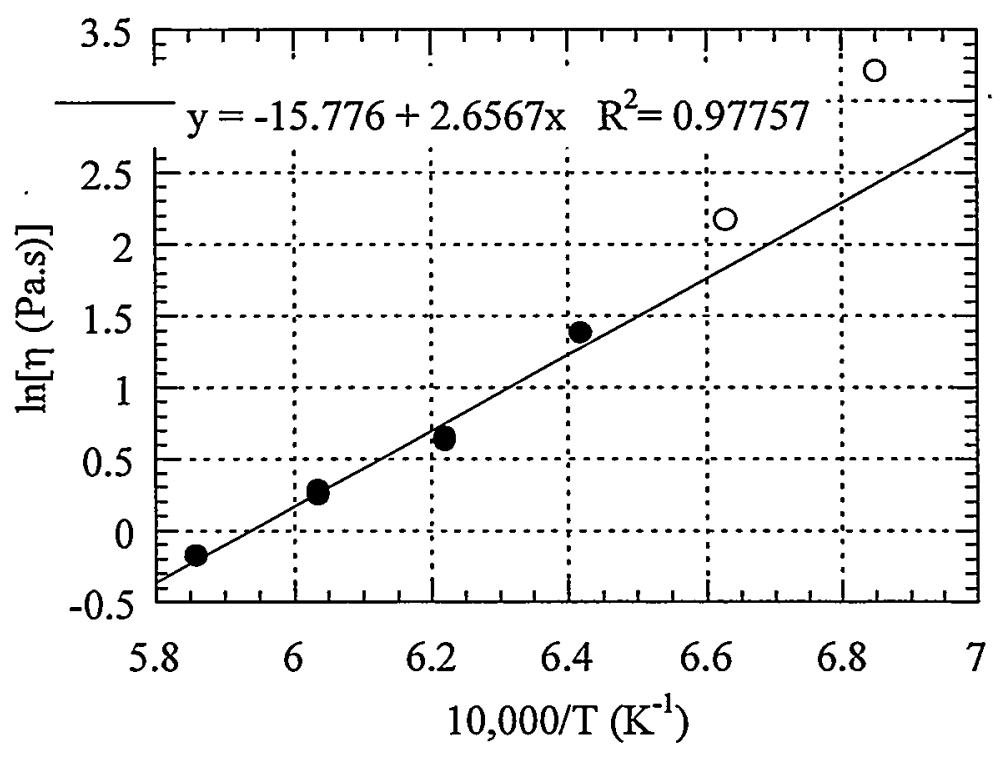

Figure 8.4. Measured ln Viscosity vs. 10000/T for AC2-08 
A.34 


\subsection{AC2-09}

Glass AC2-09 is an extreme vertex on the inner level of glass compositions. This glass targets 64.1 mass percent $\mathrm{Ln}_{2} \mathrm{O}_{3}$. The ratios of frit components, $\mathrm{SiO}_{2}, \mathrm{Al}_{2} \mathrm{O}_{3}, \mathrm{~B}_{2} \mathrm{O}_{3}$, and $\mathrm{SrO}$, are the same as those in the baseline frit.

\subsection{Liquidus Temperature}

Table 9.1 details the final heat treatments near $T_{L} . A T_{L}$ of $1323^{\circ} \mathrm{C}$ was estimated using Furnace $\# 8$ because the sample at $1327^{\circ} \mathrm{C}$ appeared to be crystal free by $\mathrm{OM}$, and at $1320^{\circ} \mathrm{C}$, crystals were observed in the corners and edges of the glass sample. An EDS spectrum of a crystal in the $1320^{\circ} \mathrm{C}$ sample identified the primary phase as RES. Several distinct crystal morphologies were observed near $\mathrm{T}_{\mathrm{L}}$. At $1314^{\circ} \mathrm{C}$, a crystal that is only seen on the surface of samples with an abundance of RES in the bulk glass and just below $T_{L}$ was observed. A sample from AC2-46 with similar morphology was analyzed by SEM/EDS (Figure 4.6 of the main report) and observed to be RES. A few samples near $\mathrm{T}_{\mathrm{L}}$, like the sample at $1320^{\circ} \mathrm{C}$, had dendritic ends on the RES crystals (Figures 4.4 and 4.5 of the main report). The EDS spectra matched those of other RES crystals.

Seven preliminary samples were heat treated between $1151^{\circ} \mathrm{C}$ and $1352^{\circ} \mathrm{C}$ at approximately $50^{\circ} \mathrm{C}$ intervals with samples full of crystals from $1151^{\circ} \mathrm{C}$ to $1315^{\circ} \mathrm{C}$, indicating gross crystallization occurred at temperatures slightly below $\mathrm{T}_{\mathrm{L}}$. Four additional samples were heat treated in Furnaces 3 and 12 between $1314^{\circ} \mathrm{C}$ and $1328^{\circ} \mathrm{C}$, all containing crystals.

Table 9.1. Heat-Treatment Summary for Determination of $T_{L}$ for AC2-09

\begin{tabular}{ccccccc}
\hline Crucible & Furnace & Time/Date IN & T $\left({ }^{\circ} \mathrm{C}\right)$ & Time/Date OUT & Observations & Comments \\
\hline 9 & 3 & $3: 00 \mathrm{pm} \mathrm{06/11}$ & 1314 & $2: 20 \mathrm{pm} \mathrm{06/12}$ & Crystals & different furnace, XRD \\
9 & 8 & $4: 30 \mathrm{pm} \mathrm{06/23}$ & 1327 & $3: 00 \mathrm{pm} \mathrm{06/24}$ & No crystals & $\mathrm{T}_{\mathrm{A}}$ \\
9 & 12 & $5: 00 \mathrm{pm} \mathrm{06/24}$ & 1320 & $3: 00 \mathrm{pm} \mathrm{06/25}$ & Crystals & different furnace, Buds \\
9 & 8 & $.1: 15 \mathrm{pm} \mathrm{07/08}$ & 1320 & $11: 15 \mathrm{am} \mathrm{07/09}$ & Crystals & $\mathrm{T}_{\mathrm{C}}$, Buds \\
9 & 3 & $1: 45 \mathrm{pm} \mathrm{07/14}$ & 1321 & $3: 05 \mathrm{pm} \mathrm{07/15}$ & Crystals & different furnace \\
9 & 3 & $3: 34 \mathrm{pm} \mathrm{07/16}$ & 1328 & $3: 44 \mathrm{pm} \mathrm{07/17}$ & Crystals & different furnace \\
\hline
\end{tabular}

\subsection{Viscosity}

Table 9.2 lists the measured $\eta$-T values for AC2-09 in chronological order. These data are shown on an Arrhenius plot $(\ln \eta$ vs. 1/T) in Figure 9.1. Two data points from Table 9.2 had measured $\eta$ values below the instrument's range, $1383^{\circ} \mathrm{C}$ and $1384^{\circ} \mathrm{C}$, and were excluded from calculations. The excluded data are shown as open circles and listed in strike-through font. Equation (2) was fitted to the remaining data, shown as solid circles, to yield $\mathrm{E}$ and $\mathrm{F}$ values of 18.999 and $30452 \mathrm{~K}$, respectively. This fit, which accurately portrays the data, was then used to calculate a $\eta_{1350}$ value of $0.79 \mathrm{~Pa} \cdot \mathrm{s}$. 
Table 9.2. Viscosity-Temperature Data for AC2-09

\begin{tabular}{cccc}
\hline $\mathrm{T}\left({ }^{\circ} \mathrm{C}\right)$ & $\eta(\mathrm{Pa} \cdot \mathrm{s})$ & $10000 / \mathrm{T}\left(\mathrm{K}^{-1}\right)$ & $\ln [\eta(\mathrm{Pa} \cdot \mathrm{s})]$ \\
\hline 1383 & 0.521 & 6.039 & -0.653 \\
1364 & 0.672 & 6.109 & -0.397 \\
1344 & 0.846 & 6.184 & -0.167 \\
1325 & 1.059 & 6.258 & 0.057 \\
1384 & 0.535 & 6.035 & -0.625 \\
\hline
\end{tabular}

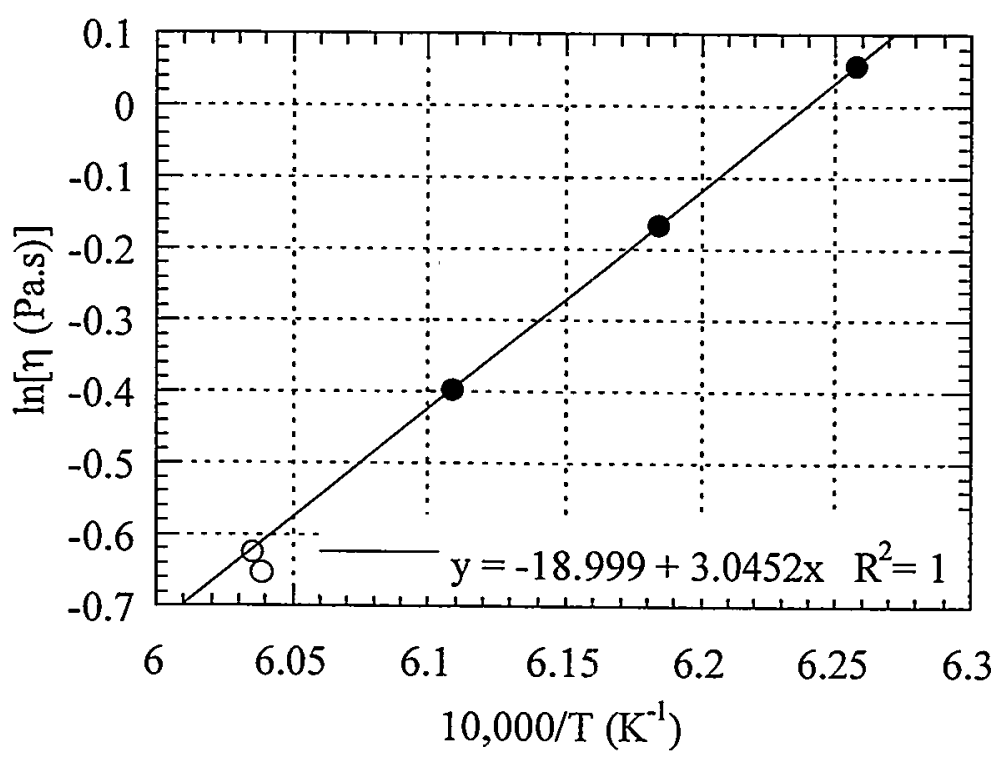

Figure 9.1. Measured ln Viscosity vs. 10000/T for AC2-09 


\subsection{AC2-10}

Glass AC2-10 is an extreme vertex on the inner level of glass compositions. This glass targets 54.0 mass percent $\mathrm{Ln}_{2} \mathrm{O}_{3}$. The ratios of $\mathrm{SiO}_{2}, \mathrm{~B}_{2} \mathrm{O}_{3}$ and $\mathrm{SrO}$ to other frit components are higher in this glass than in the baseline frit. In other words, the relative concentrations of $\mathrm{SiO}_{2}$, $\mathrm{Al}_{2} \mathrm{O}_{3}, \mathrm{~B}_{2} \mathrm{O}_{3}$, and $\mathrm{SrO}$ are high, low, high, and high, respectively, in comparison to the standard frit composition.

\subsection{Liquidus Temperature}

Table 10.1 summarizes the heat treatments performed on this glass. The $T_{L}$ of this glass was estimated using Furnace $\# 3$ at $1255^{\circ} \mathrm{C}$ since a sample heat treated at $1261^{\circ} \mathrm{C}$ appeared to be crystal free, and the sample heat treated at $1252^{\circ} \mathrm{C}$ contained only a few small crystals. The sample at $1243^{\circ} \mathrm{C}$ had an abundance of crystals throughout, indicating that gross crystallization occurred at temperatures slightly below $T_{L}$. RES crystals formed in samples of this glass heat treated at temperatures below $T_{L}$. This phase was identified by the characteristic morphologies and EDS analyses of the crystals as seen in Figure 10.1. Figure 10.2 shows the EDS spectrum of a crystal in the $1243^{\circ} \mathrm{C}$ heat-treated sample. The crystal appears to be composed of $\mathrm{Ln}_{2} \mathrm{O}_{3}$ and $\mathrm{SiO}_{2}$.

Five preliminary heat treatments were performed between $1212^{\circ} \mathrm{C}$ and $1268^{\circ} \mathrm{C}$ at approximately $25^{\circ} \mathrm{C}$ intervals with an abundance of crystals in the samples at $1212^{\circ} \mathrm{C}$ and $1229^{\circ} \mathrm{C}$. One additional sample, heat treated at $1259^{\circ} \mathrm{C}$ in Furnace \#12, appeared to be crystal free.

Table 10.1. Heat-Treatment Summary for Determination of $T_{L}$ for $A C 2-10$

\begin{tabular}{ccccccc}
\hline Crucible & Furnace & Time/Date IN & $T\left({ }^{\circ} \mathrm{C}\right)$ & Time/Date OUT & Observations & Comments \\
\hline 10 & 3 & $4: 30 \mathrm{pm} \mathrm{06/09}$ & 1243 & $3: 00 \mathrm{pm} \mathrm{06/10}$ & Lots of crystals & SEM \\
10 & 3 & $4: 30 \mathrm{pm} \mathrm{06/10}$ & 1252 & $2: 30 \mathrm{pm} \mathrm{06/11}$ & Few crystals & $\mathrm{T}_{\mathrm{C}}$ \\
10 & 12 & $2: 17 \mathrm{pm} \mathrm{06/20}$ & 1259 & $1: 00 \mathrm{pm} \mathrm{06/21}$ & No crystals & different furnace \\
10 & $\cdot 3$ & $8: 53 \mathrm{am} \mathrm{07/06}$ & 1261 & $10: 50 \mathrm{am} \mathrm{07/07}$ & No crystals & $\mathrm{T}_{\mathrm{A}}$ \\
\hline
\end{tabular}




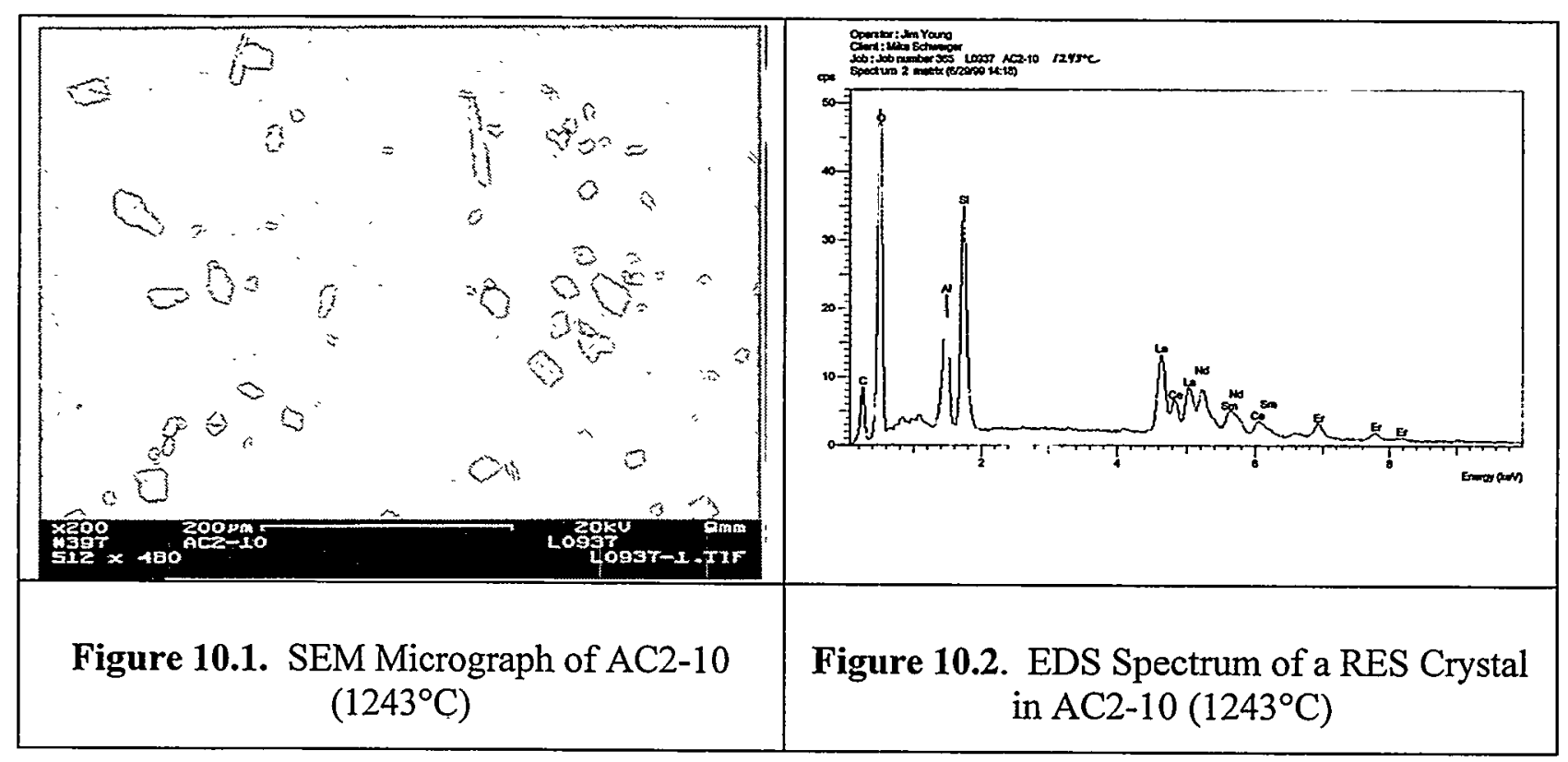

\subsection{Viscosity}

Table 10.2 lists the measured $\eta-\mathrm{T}$ values for $\mathrm{AC} 2-10$ in chronological order. These data are shown on an Arrhenius plot ( $\ln \eta$ vs. $1 / \mathrm{T}$ ) in Figure 10.3. A data point from Table 10.2 was taken at T's below $T_{L}$, at $1237^{\circ} \mathrm{C}$, and was excluded from calculations. The excluded data is plotted as an open circle and listed in strike-through font. Equation (2) was fitted to the remaining data, plotted as filled circles, to yield $\mathrm{E}$ and $\mathrm{F}$ values of -13.516 and $22451 \mathrm{~K}$, respectively. The data appear to be nonlinear. Therefore, a $\eta_{1350}$ value of $1.29 \mathrm{~Pa} \cdot \mathrm{s}$ was obtained by interpolation between the data points at $1335^{\circ} \mathrm{C}$ and $1384^{\circ} \mathrm{C}$ using Equation (2).

Table 10.2. Viscosity-temperature data for $\mathrm{AC} 2-10$

\begin{tabular}{cccc}
\hline $\mathrm{T}\left({ }^{\circ} \mathrm{C}\right)$ & $\eta(\mathrm{Pa} \cdot \mathrm{s})$ & $10000 / \mathrm{T}\left(\mathrm{K}^{-1}\right)$ & $\ln [\eta(\mathrm{Pa} \cdot \mathrm{s})]$ \\
\hline 1384 & 1.067 & 6.035 & 0.065 \\
1335 & 1.405 & 6.219 & 0.340 \\
1285 & 2.701 & 6.418 & 0.994 \\
1334 & 1.425 & 6.223 & 0.354 \\
1384 & 1.078 & 6.035 & 0.075 \\
1434 & 0.695 & 5.858 & -0.364 \\
1384 & 1.069 & 6.035 & 0.066 \\
1237 & 5.891 & 6.623 & 1.773 \\
\hline
\end{tabular}




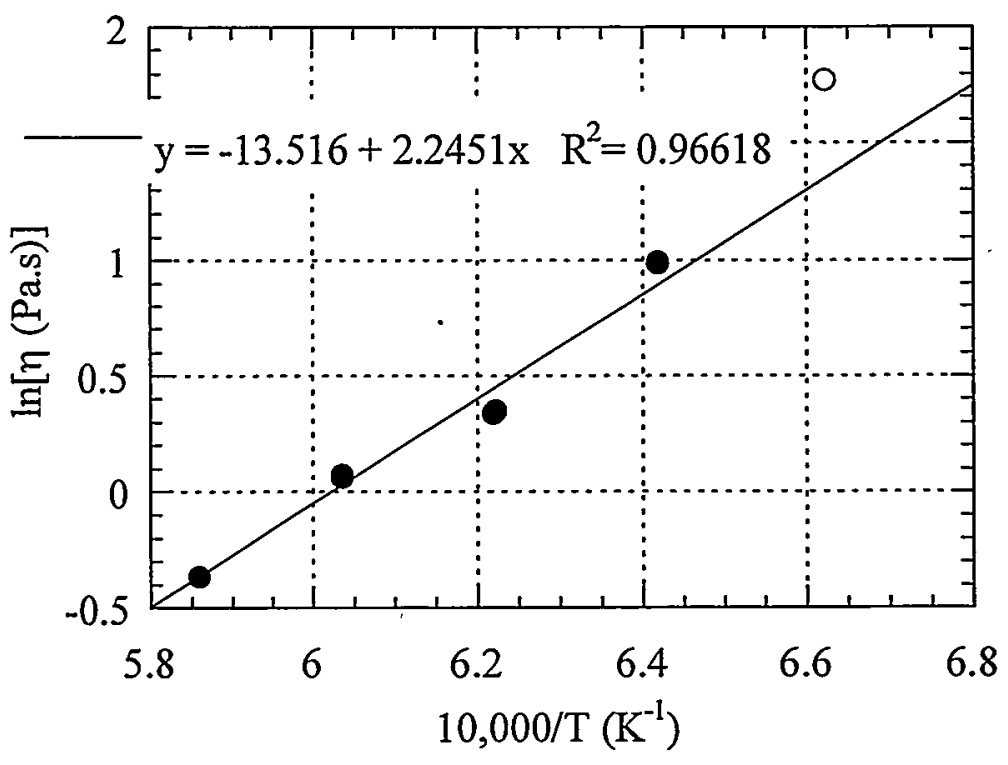

Figure 10.3. Measured $\ln$ viscosity vs. $10000 / \mathrm{T}$ for $\mathrm{AC} 2-10$ 


\subsection{AC2-11}

Glass AC2-11 is an extreme vertex on the inner level of glass compositions. This glass targets 59.0 mass percent $\mathrm{Ln}_{2} \mathrm{O}_{3}$. The ratio of $\mathrm{Al}_{2} \mathrm{O}_{3}$ to other frit components is higher in this glass than in the baseline frit. In other words, the relative concentrations of $\mathrm{SiO}_{2}, \mathrm{Al}_{2} \mathrm{O}_{3}, \mathrm{~B}_{2} \mathrm{O}_{3}$, and $\mathrm{SrO}$ are low, high, low, and low, respectively, in comparison to the standard frit composition.

\subsection{Liquidus Temperature}

Table 11.1 summarizes the heat treatments performed on samples of $A C 2-11$. The $T_{L}$ of this glass was estimated at $1292^{\circ} \mathrm{C}$ using Furnace \#3. A few large crystals remained in the sample near the surface in the $1289^{\circ} \mathrm{C}$ heat treatment, and no crystals were observed in samples heat treated at $1295^{\circ} \mathrm{C} . \mathrm{Al}_{2} \mathrm{O}_{3}$ crystals formed in samples of this glass heat treated at temperatures below $T_{L}$. These crystals were identified by the characteristic morphology of the crystal as seen in Figure 11.1 and by an XRD scan of a sample heat treated at $1175^{\circ} \mathrm{C}$, shown in Figure 11.2. During the $1286^{\circ} \mathrm{C}$ heat treatment of AC2-11 (in Furnace \#8), small nodules or buds of glass formed at the upper edge of the Pt/Rh box folds. These buds were similar to those seen in AC203 and AC2-06 and those discussed in Section 4.1.4.

Six preliminary heat treatments were performed between $1151^{\circ} \mathrm{C}$ and $1296^{\circ} \mathrm{C}$ with approximately $50^{\circ} \mathrm{C}$ intervals. Crystals were abundant in samples between $1151^{\circ} \mathrm{C}$ and $1248^{\circ} \mathrm{C}$, indicating that gross crystallization occurred at temperatures slightly below $\mathrm{T}_{\mathrm{L}}$. Two additional samples, heat treated at $1275^{\circ} \mathrm{C}$ in Furnace $\# 12$ and at $1286^{\circ} \mathrm{C}$ in Furnace $\# 8$, contained crystals.

Table 11.1. Heat-Treatment Summary for Determination of $T_{L}$ for AC2-11

\begin{tabular}{ccccccc}
\hline Crucible & Furnace & Time/Date IN & $\mathrm{T}\left({ }^{\circ} \mathrm{C}\right)$ & Time/Date OUT & Observations & Comments \\
\hline 11 & 12 & $3: 00 \mathrm{pm} \mathrm{06/18}$ & 1275 & $1: 20 \mathrm{pm} \mathrm{06/19}$ & Crystals throughout & different furnace \\
11 & 8 & $5: 00 \mathrm{pm} \mathrm{06/24}$ & 1286 & $3: 00 \mathrm{pm} \mathrm{06/25}$ & Small crystals & different furnace, Buds \\
11 & 3 & $2: 56 \mathrm{pm} \mathrm{06/27}$ & 1295 & $1: 00 \mathrm{pm} \mathrm{06/28}$ & No crystals & $\mathrm{T}_{\mathrm{A}}$ \\
11 & 3 & $9: 30 \mathrm{am} \mathrm{07/01}$ & 1289 & $10: 45 \mathrm{am} \mathrm{07/02}$ & Few crystals & $\mathrm{T}_{\mathrm{C}}$ \\
\hline
\end{tabular}



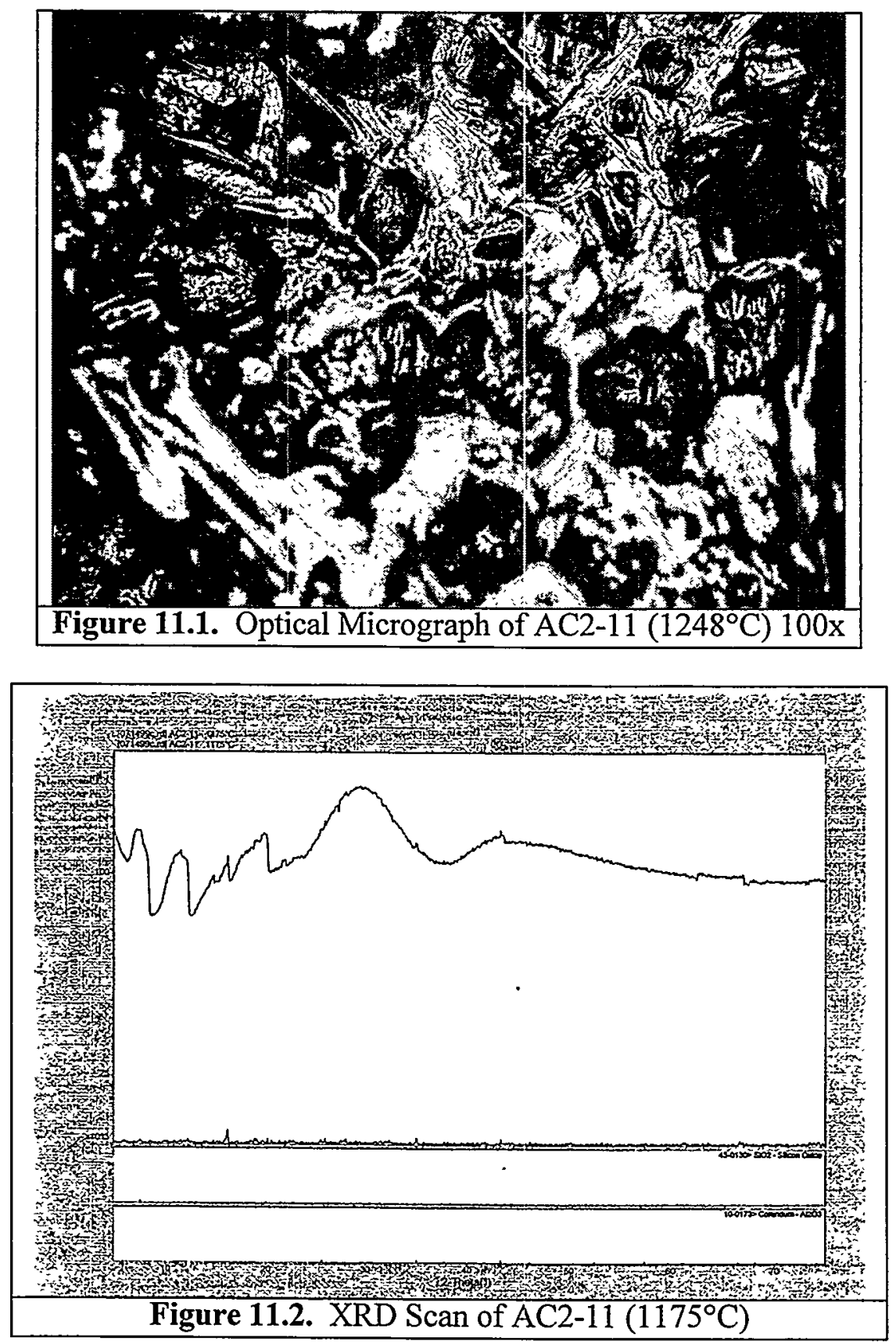

\subsection{Viscosity}

Table 11.2 lists the measured $\eta$-T values for $\mathrm{AC} 2-11$ in chronological order. These data are shown on an Arrhenius plot ( $\ln \eta$ vs. 1/T) in Figure 11.3. Four data points from Table 11.2 were excluded from calculations. One of these points, at $1403^{\circ} \mathrm{C}$, had a measured $\eta$ value below the instrument's range while three data points, at $1284^{\circ} \mathrm{C}, 1264^{\circ} \mathrm{C}$, and $1244^{\circ} \mathrm{C}$, were taken at Ts below $T_{L}$. The excluded data are plotted as open circles and listed in strike-through font.

Equation (2) was fitted to the remaining data, plotted as filled circles, to yield $\mathrm{E}$ and $\mathrm{F}$ values of -15.887 and $25700 \mathrm{~K}$, respectively. The data appear to be nonlinear. Therefore, a $\eta_{1350}$ value of 
$0.96 \mathrm{~Pa} \cdot \mathrm{S}$ was obtained by interpolation between the data points at $1344^{\circ} \mathrm{C}$ and $1364^{\circ} \mathrm{C}$ using Equation (2).

Table 11.2. Viscosity-Temperature Data for $\mathrm{AC} 2-11$

\begin{tabular}{cccc}
\hline $\mathrm{T}\left({ }^{\circ} \mathrm{C}\right)$ & $\eta(\mathrm{Pa} \cdot \mathrm{s})$ & $10000 / \mathrm{T}\left(\mathrm{K}^{-1}\right)$ & $\ln [\eta(\mathrm{Pa} \cdot \mathrm{s})]$ \\
\hline 1383 & 0.682 & 6.039 & -0.383 \\
1403 & 0.540 & 5.967 & -0.616 \\
1383 & 0.685 & 6.039 & -0.378 \\
1364 & 0.843 & 6.109 & -0.171 \\
1344 & 1.020 & 6.184 & 0.020 \\
1324 & 1.272 & 6.262 & 0.240 \\
1304 & 1.454 & 6.341 & 0.374 \\
1284 & 1.766 & 6.423 & 0.569 \\
1264 & 2.360 & 6.506 & 0.858 \\
1244 & 4.102 & 6.592 & 1.411 \\
1383 & 0.690 & 6.039 & -0.371 \\
\hline
\end{tabular}

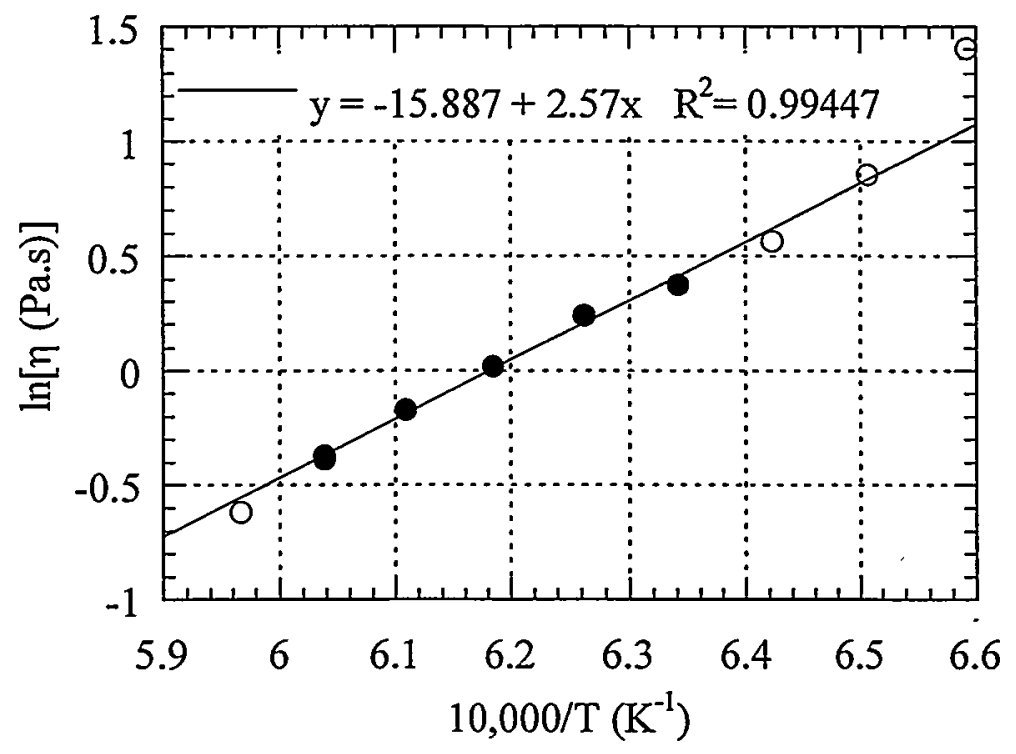

Figure 11.3. Measured ln Viscosity vs. 10000/T for AC2-11 
A. 44 


\subsection{AC2-12}

Glass AC2-12 is an extreme vertex on the inner level of glass compositions. This glass targets 56.7 mass percent $\mathrm{Ln}_{2} \mathrm{O}_{3}$. The ratios of $\mathrm{SiO}_{2}$ and $\mathrm{SrO}$ to other frit components are higher in this glass than in the baseline frit. In other words, the relative concentrations of $\mathrm{SiO}_{2}, \mathrm{Al}_{2} \mathrm{O}_{3}$, $\mathrm{B}_{2} \mathrm{O}_{3}$, and $\mathrm{SrO}$ are high, low, low, and high, respectively, in comparison to the standard frit composition.

\subsection{Liquidus Temperature}

Five final heat treatments were performed in Furnaces \#8 and \#3 (see Table 12.1) from $1314^{\circ} \mathrm{C}$ to $1335^{\circ} \mathrm{C}$, with $1314^{\circ} \mathrm{C}$ being heavily crystallized. Long needle-like crystals were observed at $1227^{\circ} \mathrm{C}$ and $1228^{\circ} \mathrm{C}$, and both samples measured at $1335^{\circ} \mathrm{C}$ appeared to be crystal free by $\mathrm{OM}$. The $\mathrm{T}_{\mathrm{L}}$ was estimated at $1333^{\circ} \mathrm{C}$ using two independent measurements (one in Furnace \#8 and the other in Furnace \#3). The RES crystals were identified by the characteristic morphology of the crystals as shown in (Figure 12.1).

Seven preliminary heat treatments were conducted between $1151^{\circ} \mathrm{C}$ and $1352^{\circ} \mathrm{C}$ with an approximately $50^{\circ} \mathrm{C}$ difference from sample to sample. Glasses were heavily crystallized in samples from $1151^{\circ} \mathrm{C}$ and $1315^{\circ} \mathrm{C}$, indicating that gross crystallization occurred at temperatures slightly below $\mathrm{T}_{\mathrm{L}}$.

Table 12.1. Heat-Treatment Summary for Determination of $T_{L}$ for $A C 2-12$

\begin{tabular}{ccccccc}
\hline Crucible & Furnace & Time/Date IN & $\mathrm{T}\left({ }^{\circ} \mathrm{C}\right)$ & Time/Date OUT & Observations & Comments \\
\hline 12 & 3 & $3: 00 \mathrm{pm} \mathrm{06/11}$ & 1314 & $2: 20 \mathrm{pm} \mathrm{06/12}$ & Very crystalline & \\
12 & 8 & $4: 30 \mathrm{pm} \mathrm{06/23}$ & 1327 & $3: 00 \mathrm{pm} \mathrm{06/24}$ & Crystals & $\mathrm{T}_{\mathrm{C}}-1$ \\
12 & 3 & $1: 30 \mathrm{pm} \mathrm{06/26}$ & 1335 & $2: 52 \mathrm{pm} \mathrm{06/27}$ & No crystals & $\mathrm{T}_{\mathrm{A}}-2$ \\
12 & 8 & $1: 15 \mathrm{pm} \mathrm{07/10}$ & 1335 & $2: 47 \mathrm{pm} \mathrm{07/11}$ & No crystals & $\mathrm{T}_{\mathrm{A}}-1$ \\
12 & 3 & $3: 34 \mathrm{pm} \mathrm{07/16}$ & 1328 & $3: 44 \mathrm{pm} \mathrm{07/17}$ & Crystals & $\mathrm{T}_{\mathrm{C}}-2$ \\
\hline
\end{tabular}




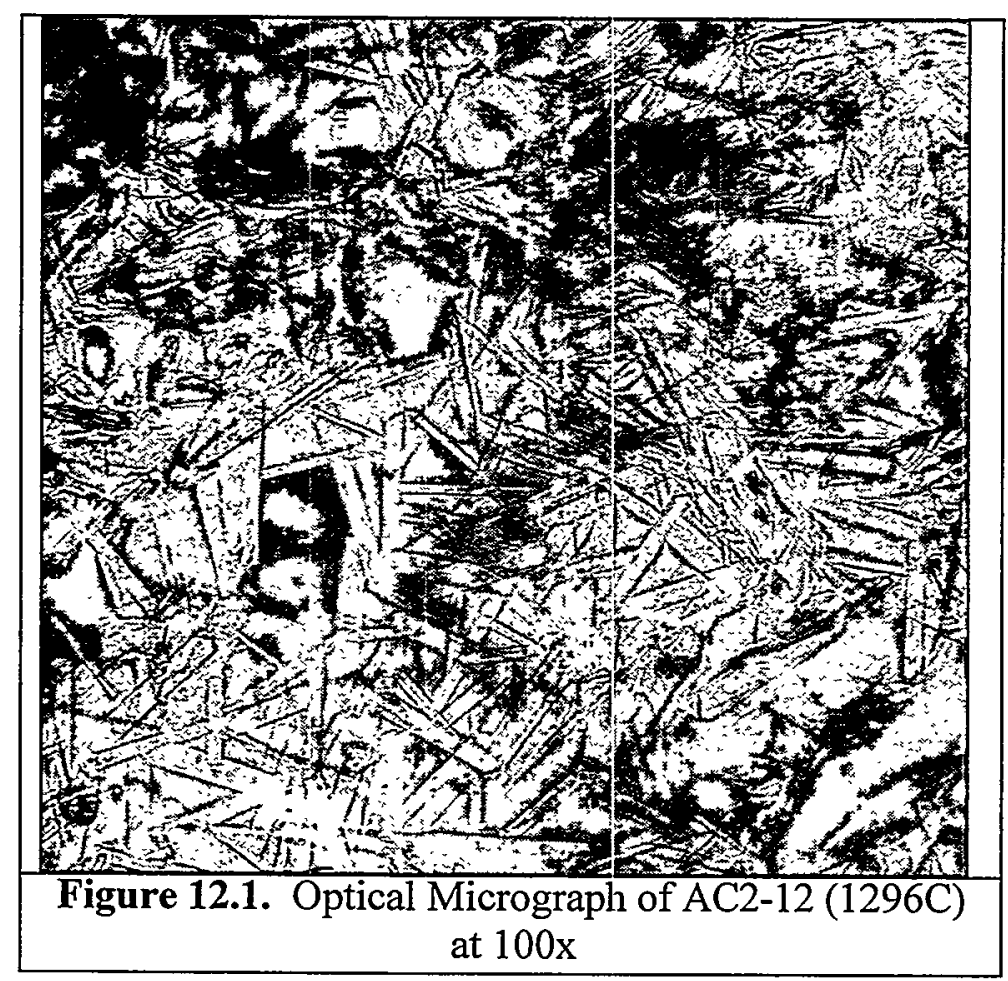

\subsection{Viscosity}

Table 12.2 lists the measured $\eta-\mathrm{T}$ values for $\mathrm{AC} 2-12$ in chronological order. These data are shown on an Arrhenius plot ( $\ln \eta$ vs. 1/T) in Figure 12.2. A datum from Table 12.2 was taken at $\mathrm{Ts}$ below $\mathrm{T}_{\mathrm{L}}$, at $1324^{\circ} \mathrm{C}$, and was excluded from calculations. The excluded data point is plotted as an open circle and listed in strike-through font. Equation (2) was fitted to the remaining data, plotted as filled circles, to yield $\mathrm{E}$ and $\mathrm{F}$ values of -15.760 and $26240 \mathrm{~K}$, respectively. The data appear to be nonlinear. Therefore, a $\eta_{1350}$ value of $1.42 \mathrm{~Pa} \cdot \mathrm{s}$ was obtained by interpolation between the data points at $1344^{\circ} \mathrm{C}$ and $1364^{\circ} \mathrm{C}$ using Equation (2).

Table 12.2. Viscosity-Temperature Data for $\mathrm{AC} 2-12$

\begin{tabular}{cccc}
\hline $\mathrm{T}\left({ }^{\circ} \mathrm{C}\right)$ & $\eta(\mathrm{Pa} \cdot \mathrm{s})$ & $10000 / \mathrm{T}\left(\mathrm{K}^{-1}\right)$ & $\ln [\eta(\mathrm{Pa} \cdot \mathrm{s})]$ \\
\hline 1383 & 1.114 & 6.039 & 0.108 \\
1403 & 0.930 & 5.967 & -0.073 \\
1422 & 0.766 & 5.900 & -0.267 \\
1433 & 0.627 & 5.862 & -0.467 \\
1384 & 1.115 & 6.035 & 0.109 \\
1364 & 1.368 & 6.109 & 0.314 \\
1344 & 1.444 & 6.184 & 0.368 \\
1324 & 1.837 & 6.262 & 0.608 \\
1384 & 1.127 & 6.035 & 0.119 \\
\hline
\end{tabular}




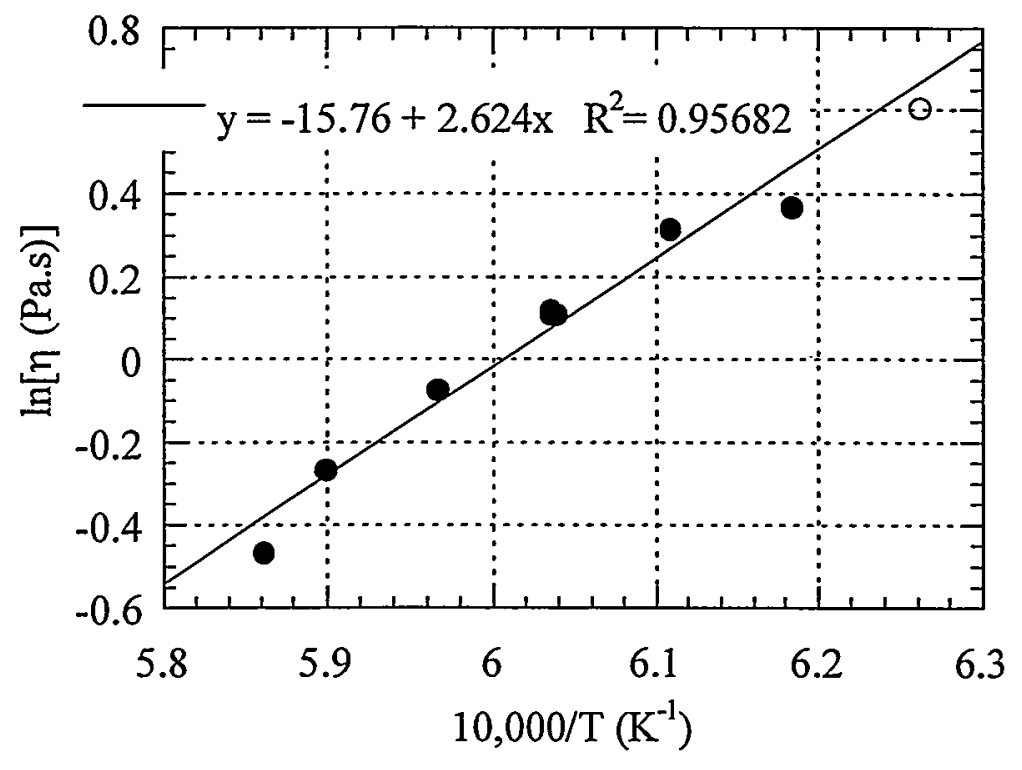

Figure 12.2. Measured ln Viscosity vs. $10000 / \mathrm{T}$ for $\mathrm{AC} 2-12$ 
A. 48 


\subsection{AC2-13}

Glass AC2-13 is an extreme vertex on the inner level of glass compositions. This glass targets 49.4 mass percent $\mathrm{Ln}_{2} \mathrm{O}_{3}$. The ratio of $\mathrm{SrO}$ to other frit components is lower in this glass than in the baseline frit. In other words, the relative concentrations of $\mathrm{SiO}_{2}, \mathrm{Al}_{2} \mathrm{O}_{3}, \mathrm{~B}_{2} \mathrm{O}_{3}$, and $\mathrm{SrO}$ are same, same, same, and low, respectively, in comparison to the standard frit composition.

\subsection{Liquidus Temperature}

Table 13.1 summarizes the heat treatments performed on this glass. The $T_{L}$ of this glass was estimated using Furnace $\# 3$ at $1186^{\circ} \mathrm{C}$ since one sample appeared to be crystal free after a heat treatment at $1191^{\circ} \mathrm{C}$, and a second sample contained only a few crystals or crystal clusters after a heat treatment at $1179^{\circ} \mathrm{C}$. RES crystals formed in samples of this glass heat treated at temperatures below $T_{L}$. These crystals were identified by the characteristic morphologies of the crystals formed below $T_{L}$. The morphologies matched those observed in samples of AC2-03, AC2-05, and other glasses that were shown by SEM and/or XRD to be RES crystals. During the $1179^{\circ} \mathrm{C}$ heat treatment, small nodules or buds of glass formed at the upper edge of the $\mathrm{Pt} / \mathrm{Rh}$ box folds as discussed in Section 4.1.4.

Five preliminary heat treatments were conducted between $1151^{\circ} \mathrm{C}$ and $1200^{\circ} \mathrm{C}$ with approximately $20^{\circ} \mathrm{C}$ difference from sample to sample. The glass was heavily crystallized in the sample at $1151^{\circ} \mathrm{C}$, indicating that gross crystallization occurred at temperatures slightly below $\mathrm{T}_{\mathrm{L}}$.

Table 13.1. Heat-Treatment Summary for Determination of $T_{L}$ for AC2-13

\begin{tabular}{ccccccc}
\hline Crucible & Furnace & Date/Time IN & $\mathrm{T}\left({ }^{\circ} \mathrm{C}\right)$ & Date/Time OUT & Observations & Comments \\
\hline 13 & 3 & $2: 18 \mathrm{pm} \mathrm{06/20}$ & 1173 & $1: 00 \mathrm{pm} \mathrm{06/21}$ & Crystals throughout & \\
13 & 3 & $1: 05 \mathrm{pm} \mathrm{06/28}$ & 1185 & $11: 00 \mathrm{am} \mathrm{06/29}$ & One single crystal & \\
13 & 3. & $9: 25 \mathrm{am} \mathrm{06/30}$ & 1179 & $9: 25 \mathrm{am} \mathrm{07/01}$ & Few clusters & \\
13 & 3 & $8: 45 \mathrm{am} \mathrm{07/04}$ & 1179 & $8: 45 \mathrm{am} \mathrm{07/05}$ & Few crystals & $\mathrm{T}_{\mathrm{C}}$, Buds \\
13 & 3 & $3: 30 \mathrm{pm} \mathrm{07/12}$ & 1191 & $2: 45 \mathrm{pm} \mathrm{07/13}$ & No crystals & $\mathrm{T}_{\mathrm{A}}$ \\
13 & 3 & $4: 30 \mathrm{pm} \mathrm{07/15}$ & 1150 & $2: 37 \mathrm{pm} \mathrm{07/16}$ & Very crystalline & \\
\hline
\end{tabular}

\subsection{Viscosity}

Table 13.2 lists the measured $\eta-T$ values for $A C 2-13$ in chronological order. These data are shown on an Arrhenius plot $(\ln \eta$ vs. 1/T) in Figure 13.1. Two data points from Table 13.2 were taken at $\mathrm{Ts}$ below $\mathrm{T}_{\mathrm{L}}$, at $1137^{\circ} \mathrm{C}$ and $1088^{\circ} \mathrm{C}$, and were excluded from calculations. The excluded data are plotted as open circles and listed in strike-through font. Equation (2) was fitted to the remaining data, plotted as filled circles, to yield $\mathrm{E}$ and $\mathrm{F}$ values of -20.323 and $33987 \mathrm{~K}$, respectively. The data appear to be nonlinear. Therefore, a $\eta_{1350}$ value of $1.86 \mathrm{~Pa} \cdot \mathrm{s}$ was obtained by interpolation between the data points at $1334^{\circ} \mathrm{C}$ and $1383^{\circ} \mathrm{C}$ using Equation (2). 
Table 13.2. Viscosity-Temperature Data for $\mathrm{AC} 2-13$

\begin{tabular}{cccc}
\hline $\mathrm{T}\left({ }^{\circ} \mathrm{C}\right)$ & $\eta(\mathrm{Pa} \cdot \mathrm{s})$ & $10000 / \mathrm{T}\left(\mathrm{K}^{-1}\right)$ & $\ln [\eta(\mathrm{Pa} \cdot \mathrm{s})]$ \\
\hline 1284 & 4.263 & 6.423 & 1.450 \\
1235 & 8.929 & 6.631 & 2.189 \\
1186 & 21.999 & 6.854 & 3.091 \\
1235 & 8.994 & 6.631 & 2.197 \\
1285 & 4.223 & 6.418 & 1.440 \\
1334 & 2.134 & 6.223 & 0.758 \\
1383 & 1.417 & 6.039 & 0.348 \\
1285 & 4.215 & 6.418 & 1.439 \\
1137 & 62.841 & 7.092 & 4.141 \\
1088 & 238.531 & 7.348 & 5.474 \\
\hline
\end{tabular}

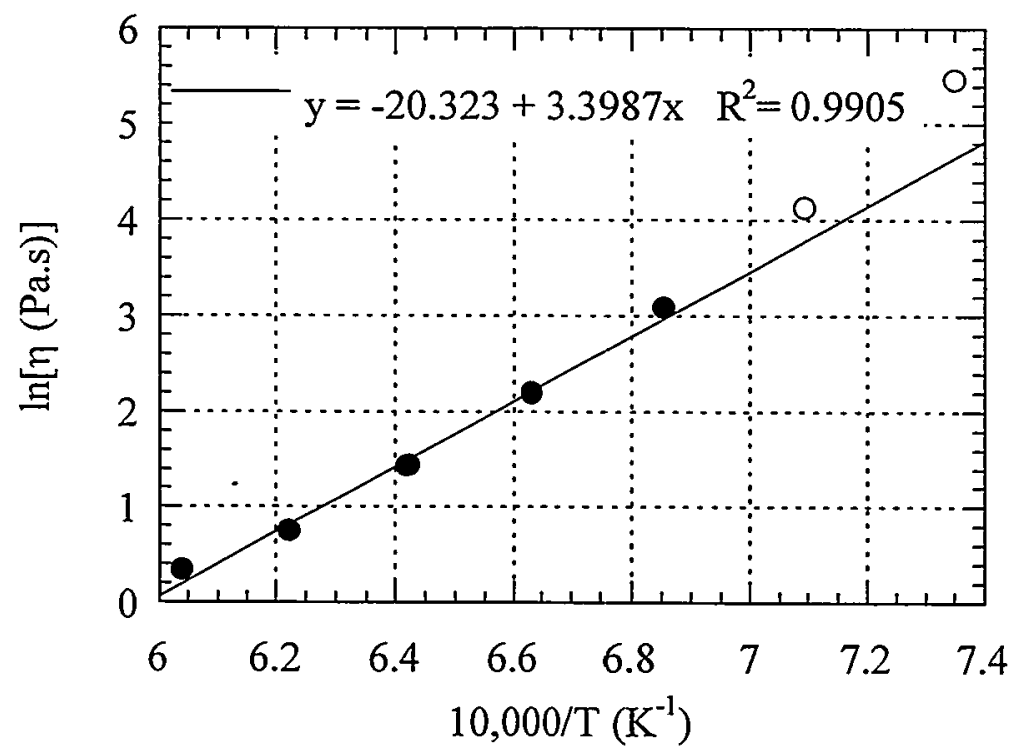

Figure 13.1. Measured ln Viscosity vs. 10000/T for AC2-13 


\subsection{AC2-14}

Glass AC2-14 is an extreme vertex on the inner level of glass compositions. This glass targets 55.6 mass percent $\mathrm{Ln}_{2} \mathrm{O}_{3}$. The ratios of $\mathrm{Al}_{2} \mathrm{O}_{3}, \mathrm{~B}_{2} \mathrm{O}_{3}$ and $\mathrm{SrO}$ to other frit components are higher in this glass than in the baseline frit. In other words, the relative concentrations of $\mathrm{SiO}_{2}$, $\mathrm{Al}_{2} \mathrm{O}_{3}, \mathrm{~B}_{2} \mathrm{O}_{3}$, and $\mathrm{SrO}$ are low, high, high, and high, respectively, in comparison to the standard frit composition.

\subsection{Liquidus Temperature}

Table 14.1 summarizes the final heat treatments performed on this glass. The $T_{L}$ of this glass was estimated using Furnace $\# 3$ at $1250^{\circ} \mathrm{C}$ since the sample at $1252^{\circ} \mathrm{C}$ appeared to be crystal free, and samples heat-treated at $1232^{\circ} \mathrm{C}, 1237^{\circ} \mathrm{C}, 1243^{\circ} \mathrm{C}$, and $1246^{\circ} \mathrm{C}$ formed crystals. Aluminum oxide crystals formed in samples of this glass heat treated at temperatures below $\mathrm{T}_{\mathrm{L}}$. These crystals were identified by SEM/EDS of a crystal observed in the $1232^{\circ} \mathrm{C}$ heat-treated sample as shown in Figure 14.1 and Figure 14.2. The crystal appears to be composed of aluminum and oxygen alone.

Five preliminary heat treatments were conducted from 1201 to $1247^{\circ} \mathrm{C}$ with a combination of RES and $\mathrm{Al}_{2} \mathrm{O}_{3}$ crystals filling the three samples between 1201 and $1223^{\circ} \mathrm{C}$, and $\mathrm{Al}_{2} \mathrm{O}_{3}$ crystals only in the samples at 1233 and $1247^{\circ} \mathrm{C}$ (just a few crystals at $1247^{\circ} \mathrm{C}$ ).

Table 14.1. Heat-Treatment Summary for Determination of $T_{L}$ for AC2-14

\begin{tabular}{ccccccc}
\hline Crucible & Furnace & Date/Time IN & $\mathrm{T}\left({ }^{\circ} \mathrm{C}\right)$ & Date/Time OUT & Observations & Comments \\
\hline 14 & 3 & $2: 30 \mathrm{pm} \mathrm{05/18}$ & 1246 & $2: 40 \mathrm{pm} \mathrm{05/19}$ & Few crystals & $\mathrm{T}_{\mathrm{C}}$ \\
14 & 3 & $3: 20 \mathrm{pm} \mathrm{05/20}$ & 1232 & $3: 35 \mathrm{pm} \mathrm{05/21}$ & Crystals on surface & SEM \\
14 & 3 & $3: 45 \mathrm{pm} \mathrm{05/25}$ & 1237 & $1: 45 \mathrm{pm} \mathrm{05/26}$ & Crystals on surface & \\
14 & 3 & $4: 30 \mathrm{pm} \mathrm{06/09}$ & 1243 & $3: 00 \mathrm{pm} \mathrm{06/10}$ & Crystals throughout & \\
14 & 3 & $4: 30 \mathrm{pm} \mathrm{06/10}$ & 1252 & $2: 30 \mathrm{pm} \mathrm{06/11}$ & No crystals & $\mathrm{T}_{\mathrm{A}}$ \\
\hline
\end{tabular}

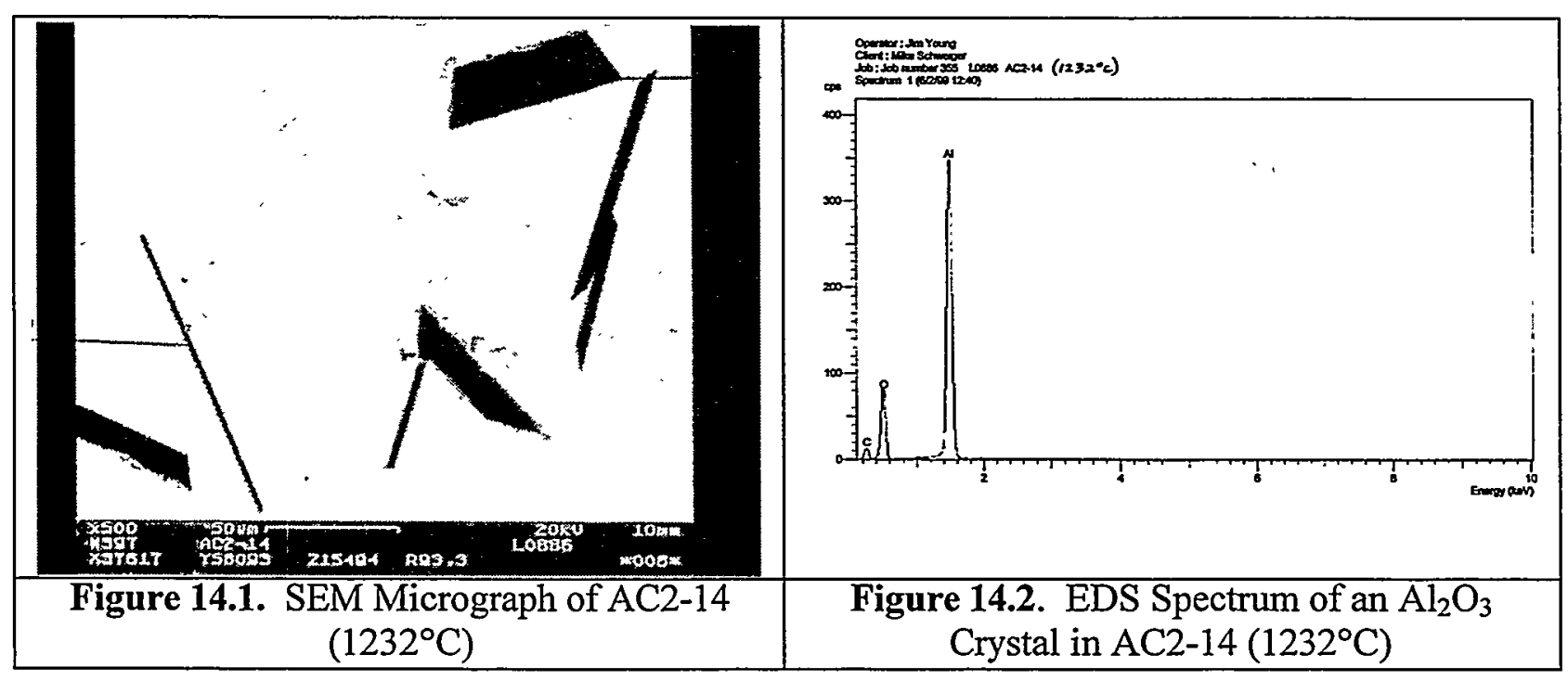




\subsection{Viscosity}

Table 14.2 lists the measured $\eta-T$ values for $\mathrm{AC} 2-14$ in chronological order. These data are shown on an Arrhenius plot ( $\ln \eta$ vs. $1 / \mathrm{T})$ in Figure 14.3. Four data points from Table 14.2 were taken at $\mathrm{Ts}$ below $\mathrm{T}_{\mathrm{L}}$, at $1244^{\circ} \mathrm{C}, 1225^{\circ} \mathrm{C}, 1205^{\circ} \mathrm{C}$, and $1185^{\circ} \mathrm{C}$, and were excluded from calculations. The excluded data are plotted as open circles and listed in strike-through font. Equation (2) was fitted to the remaining data, plotted as filled circles, to yield $\mathrm{E}$ and $\mathrm{F}$ values of -16.124 and $25960 \mathrm{~K}$, respectively. The data appear to be nonlinear. Therefore, a $\eta_{1350}$ value of $0.89 \mathrm{~Pa} \cdot \mathrm{s}$ was obtained by interpolation between the data points at $1343^{\circ} \mathrm{C}$ and $1363^{\circ} \mathrm{C}$ using Equation (2).

Table 14.2. Viscosity-Temperature Data for AC2-14

\begin{tabular}{cccc}
\hline $\mathrm{T}\left({ }^{\circ} \mathrm{C}\right)$ & $\eta(\mathrm{Pa} \cdot \mathrm{s})$ & $10000 / \mathrm{T}\left(\mathrm{K}^{-1}\right)$ & $\ln [\eta(\mathrm{Pa} \cdot \mathrm{s})]$ \\
\hline 1382 & 0.614 & 6.042 & -0.488 \\
1363 & 0.790 & 6.112 & -0.236 \\
1343 & 0.957 & 6.188 & -0.044 \\
1324 & 1.183 & 6.262 & 0.168 \\
1304 & 1.473 & 6.341 & 0.387 \\
1284 & 1.615 & 6.423 & 0.479 \\
1264 & 2.150 & 6.506 & 0.766 \\
1244 & 2.911 & 6.592 & 1.068 \\
1225 & 4.054 & 6.676 & 1.400 \\
1205 & 5.730 & 6.766 & 1.746 \\
1185 & 8.172 & 6.859 & 2.101 \\
1382 & 0.643 & 6.042 & -0.441 \\
\hline
\end{tabular}




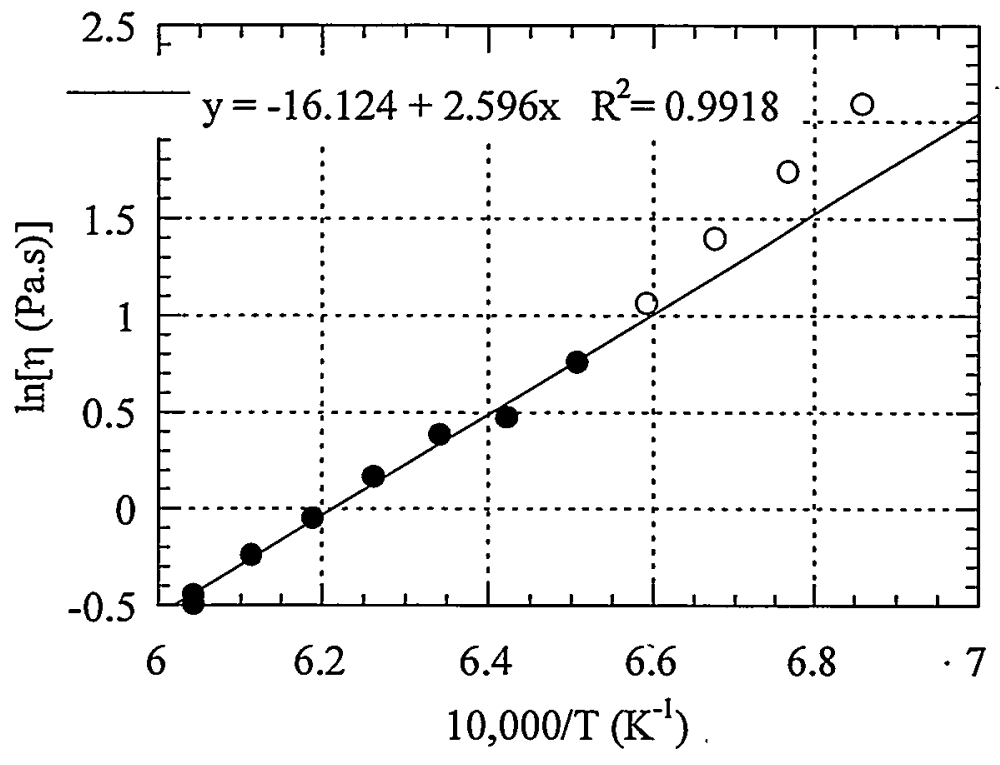

Figure 14.3. Measured ln Viscosity vs. $10000 / \mathrm{T}$ for $\mathrm{AC} 2-14$ 
A. 54 


\subsection{AC2-15}

Glass AC2-15 is an extreme vertex on the inner level of glass compositions. This glass targets 54.5 mass percent $\mathrm{Ln}_{2} \mathrm{O}_{3}$. The ratios of $\mathrm{SiO}_{2}$ and $\mathrm{B}_{2} \mathrm{O}_{3}$ to other frit components are higher in this glass than in the baseline frit. In other words, the relative concentrations of $\mathrm{SiO}_{2}$, $\mathrm{Al}_{2} \mathrm{O}_{3}, \mathrm{~B}_{2} \mathrm{O}_{3}$, and $\mathrm{SrO}$ are high, low, high, and low, respectively, in comparison to the standard frit composition.

\subsection{Liquidus Temperature}

Three final heat treatments were performed in Furnace $\# 3$ on AC2-15 between $1265^{\circ} \mathrm{C}$ and $1283^{\circ} \mathrm{C}$ (see Table 15.1). The RES crystals were abundant at $1265^{\circ} \mathrm{C}$, filling the sample. Only a few needle-like RES were observed in the corners at $1275^{\circ} \mathrm{C}$, and the sample at $1283^{\circ} \mathrm{C}$ appeared to be crystal free by $\mathrm{OM}$. The $\mathrm{T}_{\mathrm{L}}$ was estimated at $1279^{\circ} \mathrm{C}$ with a primary crystalline phase of RES. The crystals were identified by the characteristic morphologies of the crystals that formed below $T_{L}$. The morphologies matched those observed in samples of AC2-03, AC2-05, and other glasses that were shown by SEM and/or XRD to be RES crystals.

Preliminary heat treatments were accomplished on five samples from 1223 to $1295^{\circ} \mathrm{C}$. An additional sample, heat treated in Furnace $\# 12$ at $1275^{\circ} \mathrm{C}$, appeared to be crystal free.

Table 15.1. Heat-Treatment Summary for Determination of $T_{L}$ for $A C 2-15$

\begin{tabular}{ccccccc}
\hline Crucible & Furnace & Time/Date IN & $\mathrm{T}\left({ }^{\circ} \mathrm{C}\right)$ & Time/Date OUT & Observations & Comments \\
\hline 15 & 12 & $3: 00 \mathrm{pm} \mathrm{06/18}$ & 1275 & $1: 20 \mathrm{pm} \mathrm{06/19}$ & No crystals & different furnace \\
15 & 3 & $3: 00 \mathrm{pm} \mathrm{06/25}$ & 1265 & $1: 20 \mathrm{pm} \mathrm{06/26}$ & Crystals throughout & \\
15 & 3 & $1: 30 \mathrm{pm} \mathrm{07/09}$ & 1275 & $1: 00 \mathrm{pm} \mathrm{07/10}$ & Few crystals & $\mathrm{T}_{\mathrm{C}}$ \\
15 & 3 & $4: 06 \mathrm{pm} \mathrm{07/17}$ & 1283 & $3: 22 \mathrm{pm} \mathrm{07/18}$ & No crystals & $\mathrm{T}_{\mathrm{A}}$ \\
\hline
\end{tabular}

\subsection{Viscosity}

Table 15.2 lists the measured $\eta-T$ values for $\mathrm{AC} 2-15$ in chronological order. These data are shown on an Arrhenius plot ( $\ln \eta$ vs. 1/T) in Figure 15.1. A datum from Table 15.2 had a measured $\eta$ value below the instrument's range, at $1482^{\circ} \mathrm{C}$, which was excluded from calculations. The excluded point is shown as an open circle and listed in strike-through font. Equation (2) was fitted to the remaining data, shown as solid circles, to yield $\mathrm{E}$ and $\mathrm{F}$ values of 15.571 and $25731 \mathrm{~K}$, respectively. This fit, which accurately portrays the data, was then used to calculate a $\eta_{1350}$ value of $1.33 \mathrm{~Pa} \cdot \mathrm{s}$. 
Table 15.2. Viscosity-Temperature Data for $\mathrm{AC} 2-15$

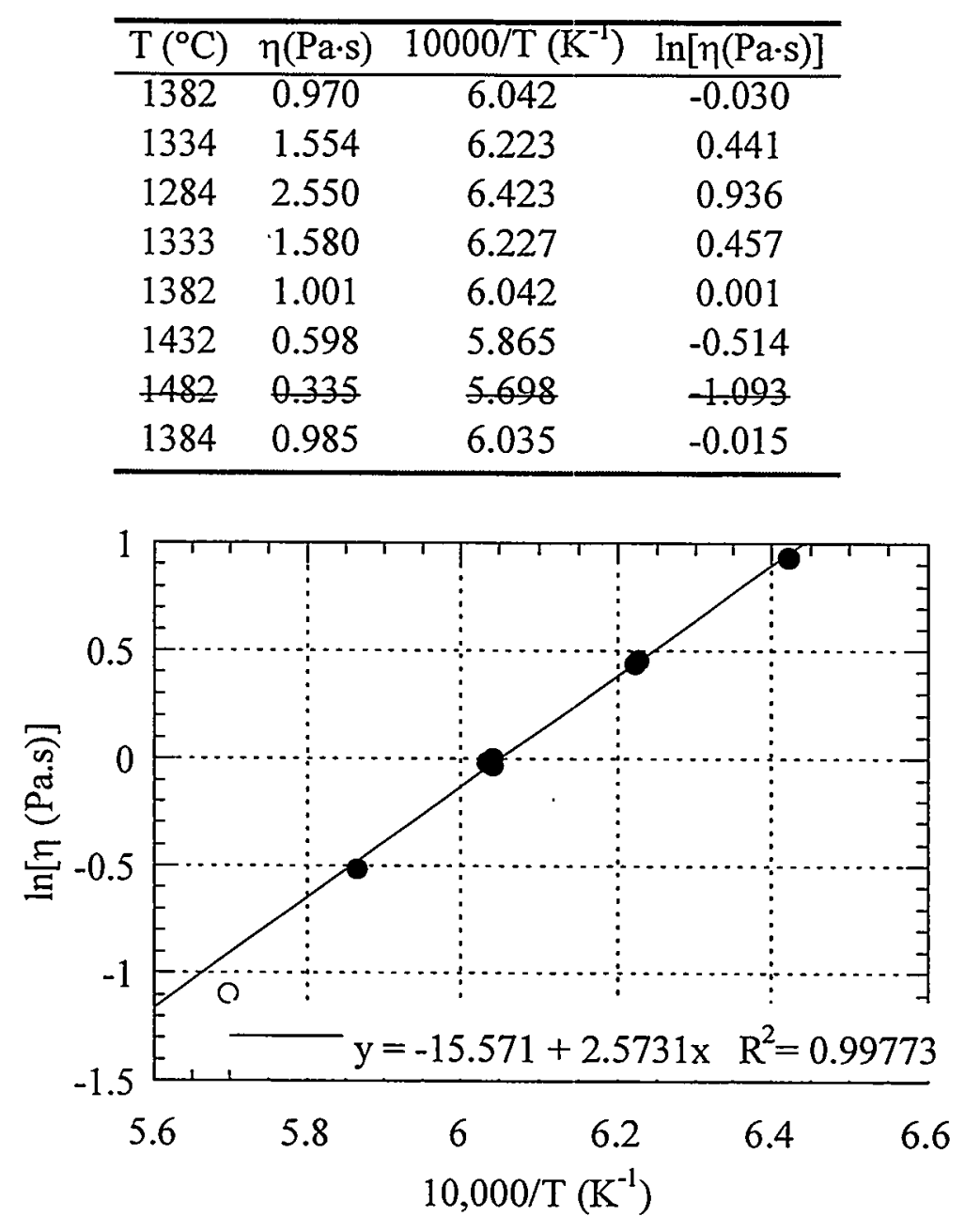

Figure 15.1. Measured ln Viscosity vs. 10000/T for $\mathrm{AC} 2-15$ 


\subsection{AC2-16}

Glass AC2-16 is an extreme vertex on the inner level of glass compositions. This glass targets 58.4 mass percent $\mathrm{Ln}_{2} \mathrm{O}_{3}$. The ratios of $\mathrm{Al}_{2} \mathrm{O}_{3}$ and $\mathrm{SrO}$ to other frit components are higher in this glass than in the baseline frit. In other words, the relative concentrations of $\mathrm{SiO}_{2}$, $\mathrm{Al}_{2} \mathrm{O}_{3}, \mathrm{~B}_{2} \mathrm{O}_{3}$, and $\mathrm{SrO}$ are low, high, low, and high, respectively, in comparison to the standard frit composition.

\subsection{Liquidus Temperature}

Table 16.1 summarizes the final heat treatments performed on this glass in Furnace \#3. The $T_{L}$ of this glass was estimated at $1298^{\circ} \mathrm{C}$. The sample heat-treated at $1299^{\circ} \mathrm{C}$ appeared to be crystal free, and the sample at $1295^{\circ} \mathrm{C}$ formed a few $\mathrm{Al}_{2} \mathrm{O}_{3}$ crystals. Aluminum oxide crystals formed in samples of this glass heat treated at temperatures below $\mathrm{T}_{\mathrm{L}}$. The crystals were identified by the characteristic morphologies of the crystals formed below $T_{L}$ and match those observed in samples of AC2-02, AC2-11, AC2-14, AC2-16, and AC2-21.

Six preliminary heat treatments were conducted from $1201^{\circ} \mathrm{C}$ to $1303^{\circ} \mathrm{C}$ with a combination of RES and $\mathrm{Al}_{2} \mathrm{O}_{3}$ crystals filling the sample at $1201^{\circ} \mathrm{C}$. $\mathrm{Al}_{2} \mathrm{O}_{3}$ crystals were only in the three samples between $1273^{\circ} \mathrm{C}$ and $1286^{\circ} \mathrm{C}$. Additional samples, heat treated in Furnace $\# 8$ between $1291^{\circ} \mathrm{C}$ and $1306^{\circ} \mathrm{C}$, appeared crystal free; while samples heat treated in Furnaces $\# 8$ and $\# 12$ between $1275^{\circ} \mathrm{C}$ and $1286^{\circ} \mathrm{C}$ contained crystals.

Table 16.1. Heat-Treatment Summary for Determination of $\mathrm{T}_{\mathrm{L}}$ for AC2-16

\begin{tabular}{ccccccc}
\hline Crucible & Furnace & Time/Date IN & $\mathrm{T}\left({ }^{\circ} \mathrm{C}\right)$ & Time/Date OUT & Observations & Comments \\
\hline 16 & 12 & $3: 00 \mathrm{pm} \mathrm{06/18}$ & 1275 & $1: 20 \mathrm{pm} \mathrm{06/19}$ & Crystals throughout & different furnace \\
16 & 8 & $5: 00 \mathrm{pm} \mathrm{06/24}$ & 1286 & $3: 00 \mathrm{pm} \mathrm{06/25}$ & Crystals & different furnace, Buds \\
16 & 3 & $2: 56 \mathrm{pm} \mathrm{06/27}$ & 1295 & $1: 00 \mathrm{pm} \mathrm{06/28}$ & Few crystals & $\mathrm{T}_{\mathrm{C}}$ \\
16 & 8 & $11: 00 \mathrm{am} \mathrm{06/29}$ & 1306 & $9: 20 \mathrm{am} \mathrm{06/30}$ & No crystals & different furnace \\
16 & 3 & $3: 20 \mathrm{pm} \mathrm{07/13}$ & 1299 & $2: 45 \mathrm{pm} \mathrm{07/14}$ & No crystals & $\mathrm{T}_{\mathrm{A}}$ \\
16 & 8 & $4: 06 \mathrm{pm} \mathrm{07/17}$ & 1297 & $3: 21 \mathrm{pm} \mathrm{07/18}$ & No crystals & different furnace, Buds \\
16 & 8 & $2: 45 \mathrm{pm} \mathrm{07/23}$ & 1291 & $12: 45 \mathrm{pm} \mathrm{07/24}$ & No crystals & different furnace, Buds \\
\hline
\end{tabular}

\subsection{Viscosity}

Table 16.2 lists the measured $\eta-T$ values for $\mathrm{AC} 2-16$ in chronological order. These data are shown on an Arrhenius plot $(\ln \eta$ vs. $1 / \mathrm{T})$ in Figure 16.1. Four data points from Table 16.2 were taken at Ts below $\mathrm{T}_{\mathrm{L}}$, at $1284^{\circ} \mathrm{C}, 1264^{\circ} \mathrm{C}, 1244^{\circ} \mathrm{C}$, and $1225^{\circ} \mathrm{C}$, and were excluded from calculations. The excluded data are plotted as open circles and listed in strike-through font. Equation (2) was fitted to the remaining data, plotted as filled circles, to yield $\mathrm{E}$ and $\mathrm{F}$ values of -17.013 and $27690 \mathrm{~K}$, respectively. The data appear to be nonlinear. Therefore, a $\eta_{1350}$ value of 
$1.09 \mathrm{~Pa} \cdot \mathrm{s}$ was obtained by interpolation between the data points at $1344^{\circ} \mathrm{C}$ and $1363^{\circ} \mathrm{C}$ using Equation (2).

Table 16.2. Viscosity-Temperature Data for $\mathrm{AC} 2-16$

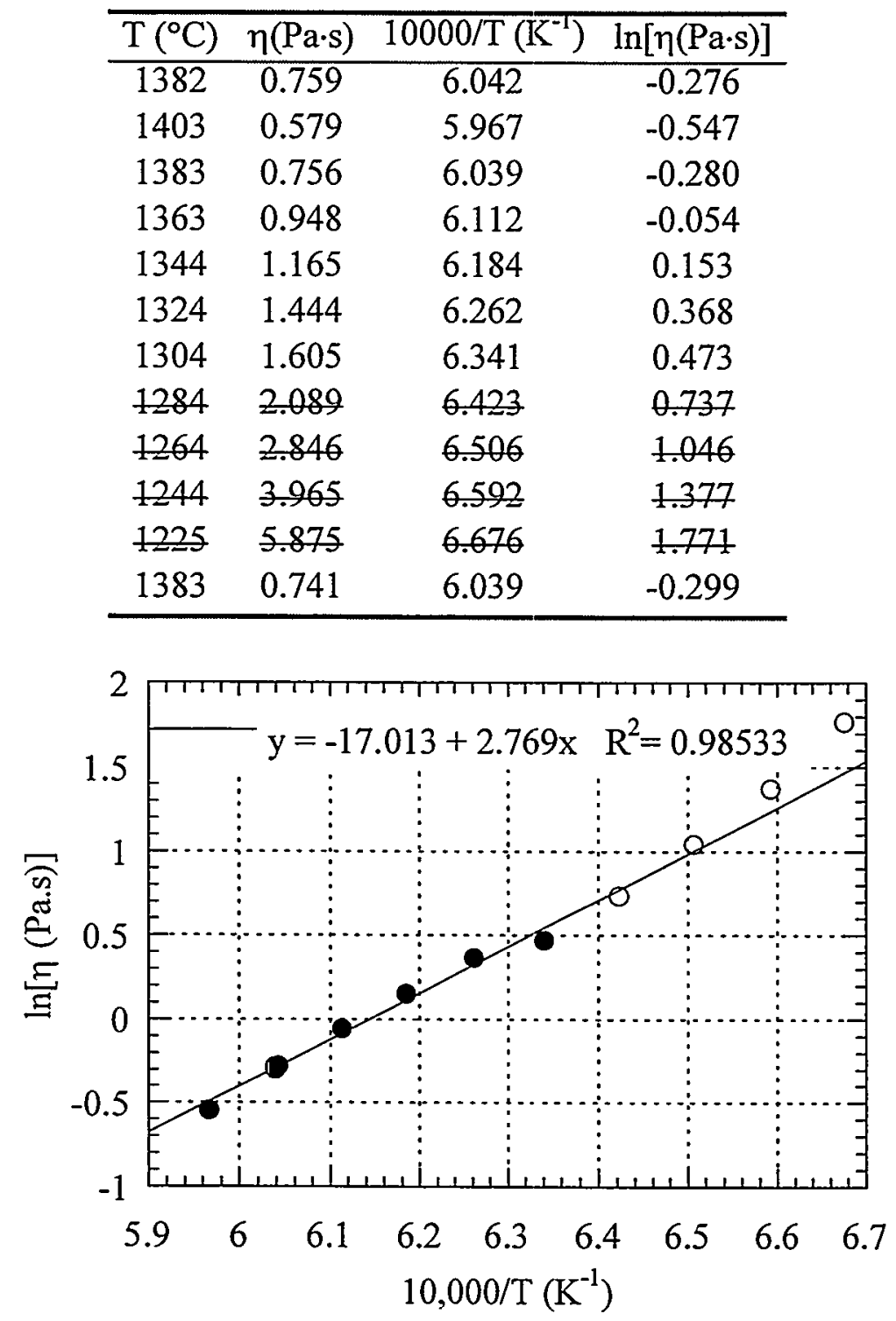

Figure 16.1. Measured ln Viscosity vs. $10000 / \mathrm{T}$ for $\mathrm{AC} 2-16$ 


\subsection{AC2-17}

Glass AC2-17 is a centroid of the inner level of glass compositions. This glass targets 56.6 mass percent $\mathrm{Ln}_{2} \mathrm{O}_{3}$. The ratios of frit components, $\mathrm{SiO}_{2}, \mathrm{Al}_{2} \mathrm{O}_{3}, \mathrm{~B}_{2} \mathrm{O}_{3}$, and $\mathrm{SrO}$, are the same as those in the baseline frit.

\subsection{Liquidus Temperature}

Table 17.1 summarizes the final heat treatments performed on this glass. The $T_{L}$ of this glass was estimated using Furnace $\# 3$ at $1273^{\circ} \mathrm{C}$ since a sample heat treated at $1275^{\circ} \mathrm{C}$ appeared to be crystal free, and a sample heat treated at $1265^{\circ} \mathrm{C}$ contained many crystals. This indicated that gross crystallization occurred at temperatures slightly below $T_{L}$. RES crystals formed in samples of this glass heat-treated at temperatures below $T_{L}$. These crystals were identified by the characteristic morphologies of the crystals formed below $T_{L}$. The morphologies matched those observed in samples of $\mathrm{AC} 2-03, \mathrm{AC} 2-05$, and other glasses that were shown by SEM and/or XRD to be RES crystals.

Five preliminary heat treatments were performed on samples from $1223^{\circ} \mathrm{C}$ to $1295^{\circ} \mathrm{C}$ with RES observed in the three samples below $\mathrm{T}_{L}$, and no crystals were observed in samples at $1283^{\circ} \mathrm{C}$ and $1295^{\circ} \mathrm{C}$. An additional sample, heat treated in Furnace $\# 12$ at 1275 , appeared to be crystal free.

Table 17.1. Heat-Treatment Summary for Determination of $T_{L}$ for AC2-17

\begin{tabular}{ccccccc}
\hline Crucible & Furnace & Date/Time IN & T $\left({ }^{\circ} \mathrm{C}\right)$ & Date/Time OUT & Observations & Comments \\
\hline 17 & 12 & $3: 00 \mathrm{pm} \mathrm{06/18}$ & 1275 & $1: 20 \mathrm{pm} \mathrm{06/19}$ & No crystals & different furnace \\
17 & 3 & $3: 00 \mathrm{pm} \mathrm{06/25}$ & 1265 & $1: 20 \mathrm{pm} \mathrm{06/26}$ & Crystals throughout & $\mathrm{T}_{\mathrm{C}}$ \\
17 & 3 & $1: 30 \mathrm{pm} \mathrm{07/09}$ & 1275 & $1: 00 \mathrm{pm} \mathrm{07/10}$ & No crystals & $\mathrm{T}_{\mathrm{A}}$ \\
\hline
\end{tabular}

\subsection{Viscosity}

Table 17.2 lists the measured $\eta$-T values for AC2-17 in chronological order. These data are shown on an Arrhenius plot $(\ln \eta$ vs. $1 / \mathrm{T})$ in Figure 17.1. Three data points from Table 17.2 were excluded from calculations. One of these points, at $1433^{\circ} \mathrm{C}$, had a measured $\eta$ value below the instrument's range while two data points, at $1266^{\circ} \mathrm{C}$ and $1246^{\circ} \mathrm{C}$, were taken at $\mathrm{Ts}$ below $\mathrm{T}_{\mathrm{L}}$. The excluded data are plotted as open circles and listed in strike-through font. Equation (2) was fitted to the remaining data, shown as solid circles, to yield $E$ and $F$ values of -15.154 and 24804 $\mathrm{K}$, respectively. This fit, which accurately portrays the data, was then used to calculate a $\eta_{1350}$ value of $1.14 \mathrm{~Pa} \cdot \mathrm{s}$. 
Table 17.2. Viscosity-Temperature Data for $\mathrm{AC} 2-17$

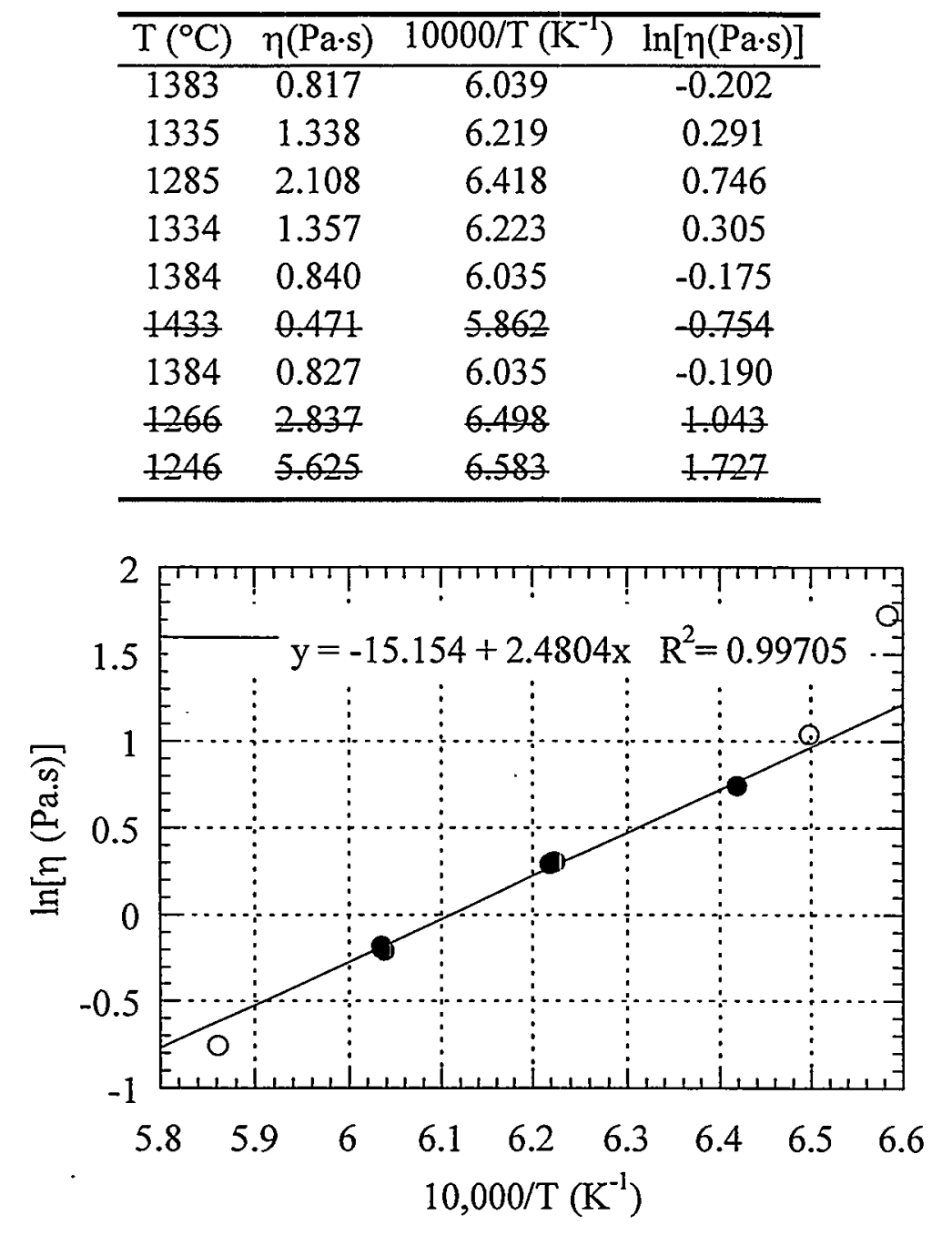

Figure 17.1. Measured ln Viscosity vs. $10000 / \mathrm{T}$ for $\mathrm{AC} 2-17$ 


\subsection{AC2-18}

Glass AC2-18 is an extreme vertex on the outer level of glass compositions. This glass targets 63.5 mass percent $\mathrm{Ln}_{2} \mathrm{O}_{3}$. The ratio of $\mathrm{SrO}$ to other frit components is higher in this glass than in the baseline frit. In other words, the relative concentrations of $\mathrm{SiO}_{2}, \mathrm{Al}_{2} \mathrm{O}_{3}, \mathrm{~B}_{2} \mathrm{O}_{3}$, and $\mathrm{SrO}$ are same, same, same, and high, respectively, in comparison to the standard frit composition.

\subsection{Liquidus Temperature}

Table 18.1 summarizes the final heat treatments performed on this glass. The $T_{L}$ of this glass was estimated using Furnace $\# 8$ at $1366^{\circ} \mathrm{C}$ since four samples were crystal free from $1374^{\circ} \mathrm{C}$ to $1401^{\circ} \mathrm{C}$. The sample heat treated at $1364^{\circ} \mathrm{C}$ contained only a few small crystals on the bottom, and a sample heat treated at $1354^{\circ} \mathrm{C}$ was loaded with crystals. RES crystals formed in samples of this glass heat treated at temperatures below $T_{L}$. These crystals were identified by the characteristic morphologies and by XRD. Figure 18.2 shows an XRD scan from a sample heat treated at $1303^{\circ} \mathrm{C}$; the characteristic pattern obtained from RES crystals is apparent.

Nine preliminary heat treatments were performed on $\mathrm{AC} 2-18$ starting at $1215^{\circ} \mathrm{C}$ up to $1400^{\circ} \mathrm{C}$. Many heat treatments were needed on this glass since it was at a higher $T_{L}$ than most other Phase II glasses. An additional sample, heat treated at $1344^{\circ} \mathrm{C}$ in Furnace \#5, was nearly completely crystallized, indicating that gross crystallization occurred at temperatures slightly below $T_{L}$.

Table 18.1. Heat-Treatment Summary for Determination of $T_{L}$ for AC2-18

\begin{tabular}{ccccccc}
\hline Crucible & Furnace & Time/Date IN & $\mathrm{T}\left({ }^{\circ} \mathrm{C}\right)$ & Time/Date OUT & Observations & Comments \\
\hline $\mathrm{L}$ & 8 & $2: 00 \mathrm{pm} \mathrm{05/10}$ & 1303 & $1: 20 \mathrm{pm} \mathrm{05/11}$ & Crystals & Preliminary/XRD \\
18 & 8 & $9: 25 \mathrm{am} \mathrm{06/30}$ & 1401 & $9: 25 \mathrm{am} \mathrm{07/01}$ & No crystals & \\
18 & 8 & $4: 02 \mathrm{pm} \mathrm{07/11}$ & 1393 & $2: 45 \mathrm{pm} \mathrm{07/12}$ & No crystals & \\
18 & 8 & $3: 20 \mathrm{pm} \mathrm{07/13}$ & 1384 & $2: 45 \mathrm{pm} \mathrm{07/14}$ & No crystals & \\
18 & 8 & $4: 30 \mathrm{pm} \mathrm{07/15}$ & 1374 & $2: 40 \mathrm{pm} \mathrm{07/16}$ & No crystals & $\mathrm{T}_{\mathrm{A}}$ \\
18 & 8 & $3: 32 \mathrm{pm} \mathrm{07/16}$ & 1364 & $2: 57 \mathrm{pm} \mathrm{07/17}$ & Crystals & $\mathrm{T}_{\mathrm{C}}$ \\
18 & 5 & $5: 10 \mathrm{pm} \mathrm{07/17}$ & 1344. & $3: 19 \mathrm{pm} \mathrm{07/18}$ & Full of crystals & different furnace \\
18 & 8 & $4: 30 \mathrm{pm} \mathrm{07/22}$ & 1354 & $2: 35 \mathrm{pm} \mathrm{07/23}$ & Full of crystals & \\
\hline
\end{tabular}




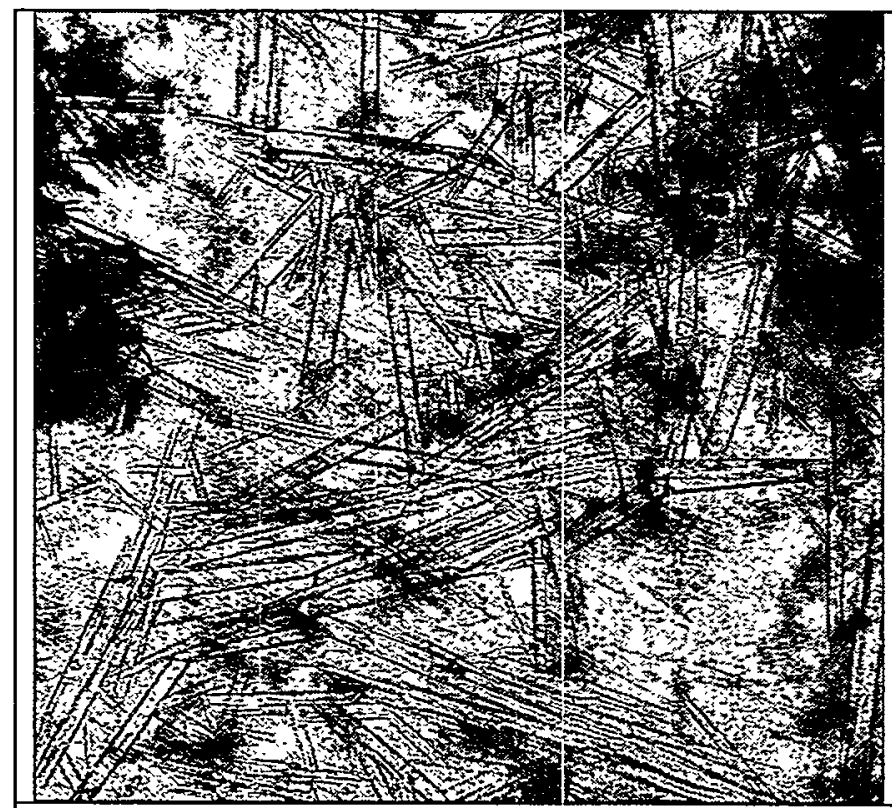

Figure 18.1. Optical Micrograph of RES Crystals in $\mathrm{AC} 2-18\left(1344^{\circ} \mathrm{C}\right)$ at $100 \times$

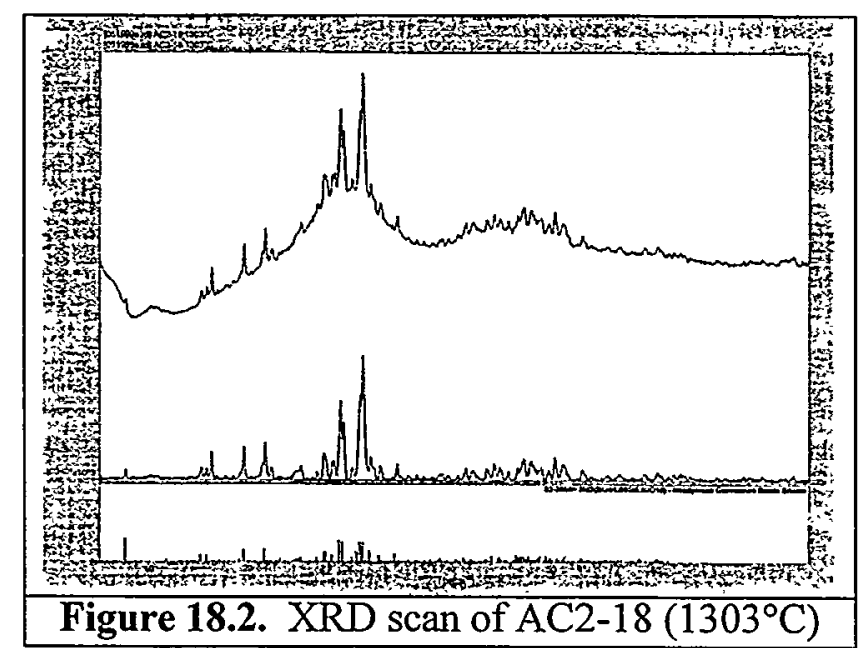

\subsection{Viscosity}

Table 18.2 lists the measured $\eta-T$ values for $\mathrm{AC} 2-18$ in chronological order. These data are shown on an Arrhenius plot ( $\ln \eta$ vs. 1/T) in Figure 18.3. Three data points from Table 18.2 had measured $\eta$ values below the instrument's range, at $1384^{\circ} \mathrm{C}, 1395^{\circ} \mathrm{C}$, and $1385^{\circ} \mathrm{C}$, and were excluded from calculations. The excluded data are plotted as open circles and listed in strikethrough font. With only one valid data point for calculations, Equation (2) was not fitted for this glass. 
Table 18.2. Viscosity-Temperature Data for AC2-18

\begin{tabular}{cccc}
\hline $\mathrm{T}\left({ }^{\circ} \mathrm{C}\right)$ & $\eta(\mathrm{Pa} \cdot \mathrm{s})$ & $10000 / \mathrm{T}\left(\mathrm{K}^{-1}\right)$ & $\ln [\eta(\mathrm{Pa} \cdot \mathrm{s})]$ \\
\hline 1384 & 0.469 & 6.035 & -0.757 \\
1380 & 0.640 & 6.050 & -0.446 \\
1395 & 0.427 & 5.995 & -0.851 \\
1385 & 0.504 & 6.031 & -0.684 \\
\hline
\end{tabular}

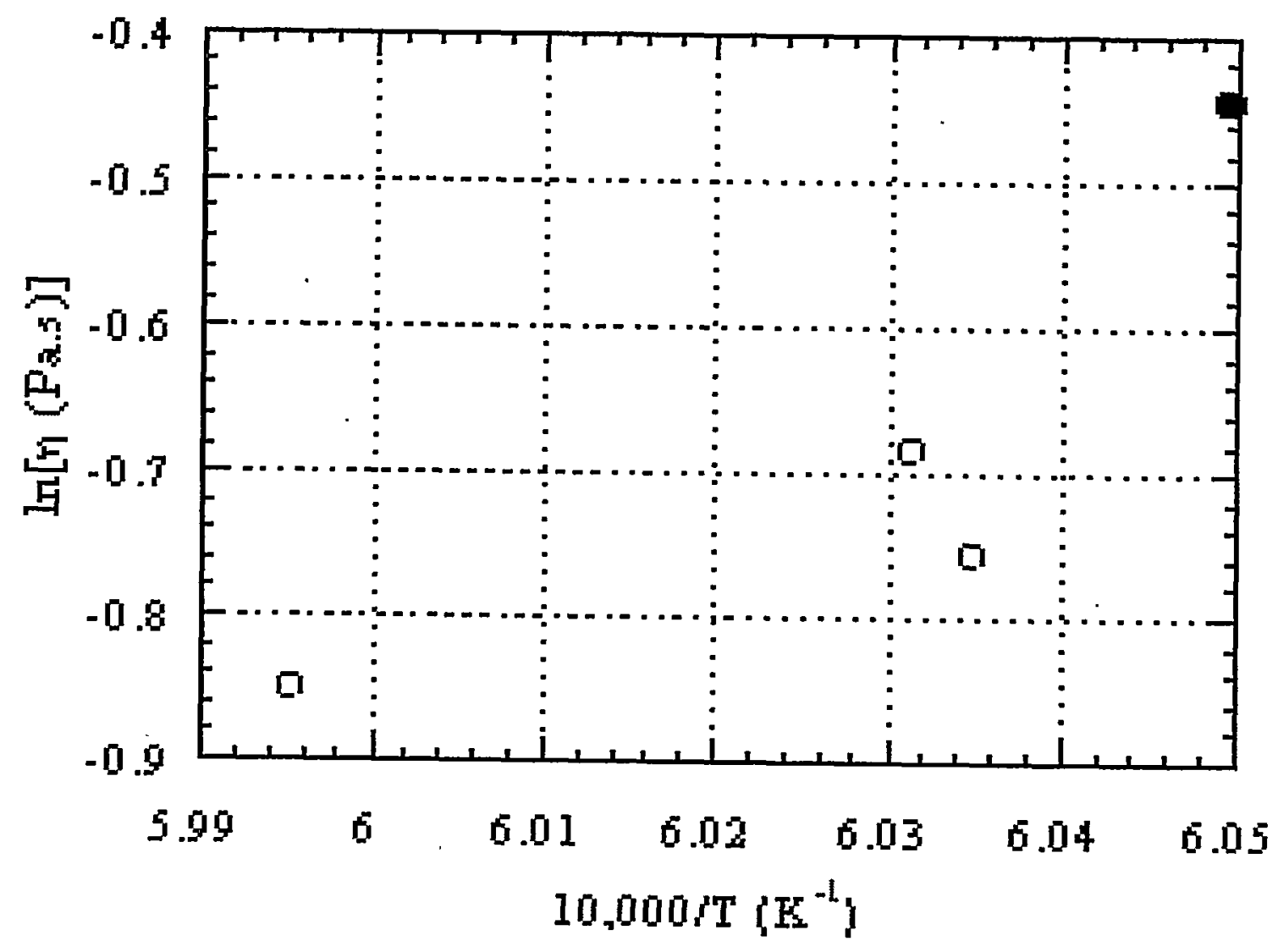

Figure 18.3. Measured ln Viscosity vs. 10000/T for AC2-18 
A. 64 


\subsection{AC2-19}

Glass AC2-19 is an extreme vertex on the outer level of glass compositions. This glass targets 53.9 mass percent $\mathrm{Ln}_{2} \mathrm{O}_{3}$. The ratios of $\mathrm{SiO}_{2}, \mathrm{~B}_{2} \mathrm{O}_{3}$, and $\mathrm{SrO}$ to other frit components are higher in this glass than in the baseline frit. In other words, the relative concentrations of $\mathrm{SiO}_{2}$, $\mathrm{Al}_{2} \mathrm{O}_{3}, \mathrm{~B}_{2} \mathrm{O}_{3}$, and $\mathrm{SrO}$ are high, low, high, and high, respectively, in comparison to the standard frit composition.

\subsection{Liquidus Temperature}

Table 19.1 summarizes the heat treatments performed on this glass in Furnace \#3. The $\mathrm{T}_{\mathrm{L}}$ of this glass was estimated at $1249^{\circ} \mathrm{C}$ since a sample appeared crystal free after heat treatment at $1252^{\circ} \mathrm{C}$, and a sample grossly crystallized during a heat treatment at $1242^{\circ} \mathrm{C}$. This indicated that gross crystallization occurred at temperatures slightly below $T_{L}$. RES crystals formed in samples of this glass heat treated at temperatures below $T_{L}$. These crystals were identified by the characteristic morphologies of the crystals formed below $\mathrm{T}_{\mathrm{L}}$. The morphologies matched those observed in samples of AC2-03, AC2-05, and other glasses that were shown by SEM and/or XRD to be RES crystals.

Preliminary heat treatments were performed on five samples between $1215^{\circ} \mathrm{C}$ and $1261^{\circ} \mathrm{C}$ with RESs observed at $1215^{\circ} \mathrm{C}, 1240^{\circ} \mathrm{C}$, and $1248^{\circ} \mathrm{C}$, and no crystals were observed at $1257^{\circ} \mathrm{C}$ and $1261^{\circ} \mathrm{C}$.

Table 19.1. Heat-Treatment Summary for Determination of $T_{L}$ for $A C 2-19$

\begin{tabular}{ccccccc}
\hline Crucible & Furnace & Date/Time IN & $\mathrm{T}\left({ }^{\circ} \mathrm{C}\right)$ & Date/Time OUT & Observations & Comments \\
\hline 19 & 3 & $4: 45 \mathrm{pm} \mathrm{06/08}$ & 1242 & $2: 45 \mathrm{pm} \mathrm{06/09}$ & Crystals throughout & $\mathrm{T}_{\mathrm{C}}$ \\
19 & 3 & $4: 30 \mathrm{pm} \mathrm{06/10}$ & 1252 & $2: 30 \mathrm{pm} \mathrm{06/11}$ & No crystals & $\mathrm{T}_{\mathrm{A}}$ \\
\hline
\end{tabular}

\subsection{Viscosity}

Table 19.2 lists the measured $\eta-T$ values for $\mathrm{AC} 2-19$ in chronological order. These data are shown on an Arrhenius plot $(\ln \eta$ vs. $1 / \mathrm{T})$ in Figure 19.1. A datum from Table 19.2, at $1235^{\circ} \mathrm{C}$, was taken at a $\mathrm{T}$ below $\mathrm{T}_{\mathrm{L}}$ and was excluded from calculations. The excluded point was plotted as an open circle and listed in strike-through font. Equation (2) was fitted to the remaining data, shown as solid circles, to yield $\mathrm{E}$ and $\mathrm{F}$ values of -14.837 and $24619 \mathrm{~K}$, respectively. This fit, which accurately portrays the data, was then used to calculate a $\eta_{1350}$ value of $1.39 \mathrm{~Pa} \cdot \mathrm{s}$. 
Table 19.2. Viscosity-Temperature Data for AC2-19

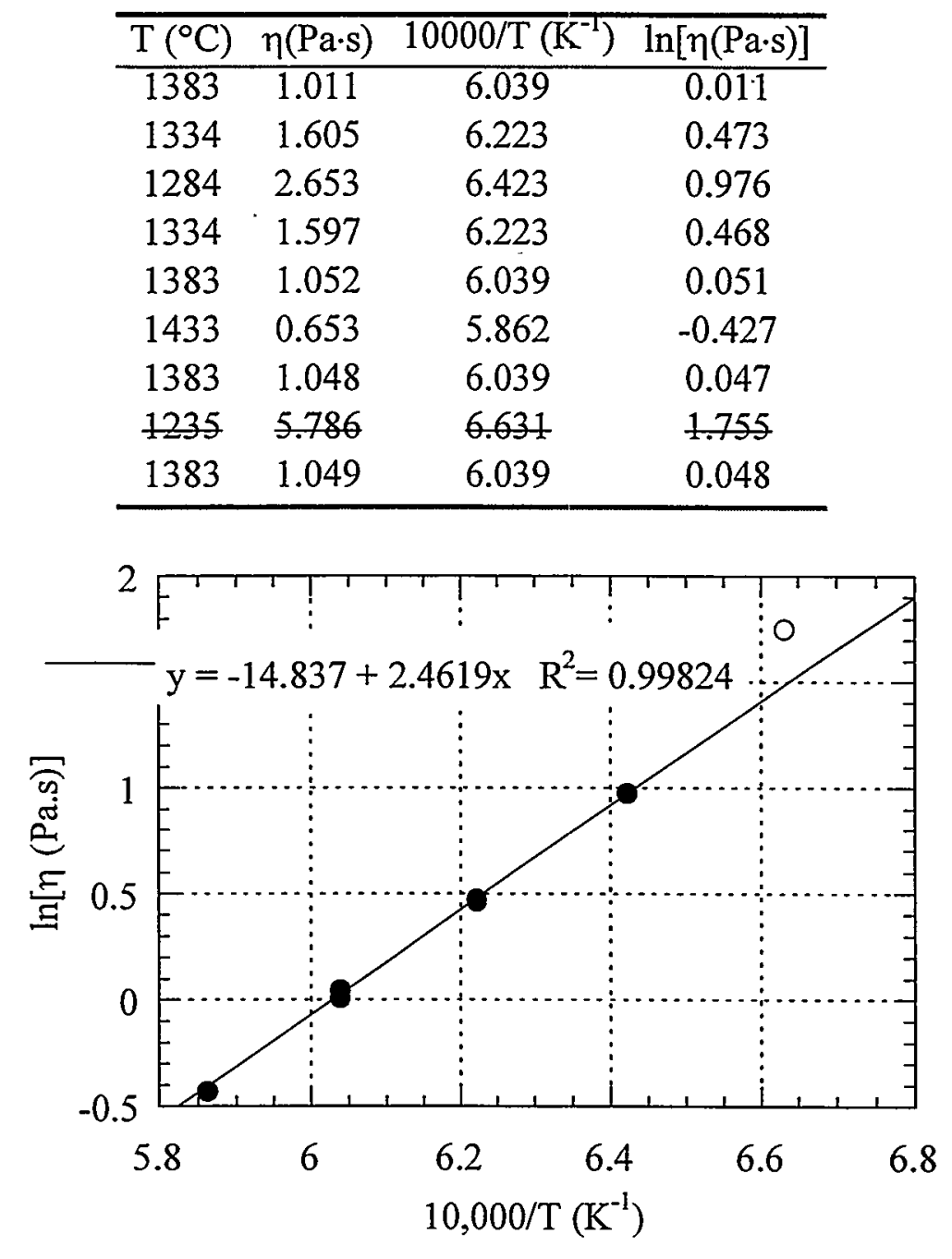

Figure 19.1. Measured ln Viscosity vs. 10000/T for AC2-19 


\subsection{AC2-20}

Glass AC2-20 is an extreme vertex on the outer level of glass compositions. This glass targets 64.1 mass percent $\mathrm{Ln}_{2} \mathrm{O}_{3}$. The ratios of frit components, $\mathrm{SiO}_{2}, \mathrm{Al}_{2} \mathrm{O}_{3}, \mathrm{~B}_{2} \mathrm{O}_{3}$, and $\mathrm{SrO}$, are the same as those in the baseline frit.

\subsection{Liquidus Temperature}

Table 20.1 summarizes the heat treatments performed on this glass using Furnace \#8. The $T_{L}$ of this glass was estimated at $1343^{\circ} \mathrm{C}$ since a sample appeared to be crystal free after a heat treatment at $1349^{\circ} \mathrm{C}$, and a sample formed crystals after a heat treatment at $1336^{\circ} \mathrm{C}$. RES crystals formed in samples of this glass heat treated at temperatures below $T_{L}$. These crystals were identified by the characteristic morphologies of the crystals formed below $\mathrm{T}_{\mathrm{L}}$. The morphologies matched those observed in samples of AC2-03, AC2-05, and other glasses that were shown by SEM and/or XRD to be RES crystals. $1400^{\circ} \mathrm{C}$.

Preliminary heat treatments were performed on eight samples between $1215^{\circ} \mathrm{C}$ and

Table 20.1. Heat-Treatment Summary for Determination of $T_{L}$ for AC2-20

\begin{tabular}{ccccccc}
\hline Crucible & Furnace & Date/Time IN & $\mathrm{T}\left({ }^{\circ} \mathrm{C}\right)$ & Date/Time OUT & Observations & Comments \\
\hline 20 & 8 & $1: 30 \mathrm{pm} \mathrm{07/09}$ & 1349 & $1: 00 \mathrm{pm} \mathrm{07/10}$ & No crystals & $\mathrm{T}_{\mathrm{A}}$ \\
20 & 8 & $3: 00 \mathrm{pm} \mathrm{07/14}$ & 1336 & $3: 05 \mathrm{pm} \mathrm{07/15}$ & Crystals & $\mathrm{T}_{\mathrm{C}}$, Buds \\
\hline
\end{tabular}

\subsection{Viscosity}

Table 20.2 lists the measured $\eta-T$ values for $A C 2-20$ in chronological order. These data are shown on an Arrhenius plot ( $\ln \eta$ vs. 1/T) in Figure 20.1. Two data points from Table 20.2 had measured $\eta$ values below the instrument's range, at $1384^{\circ} \mathrm{C}$ and $1385^{\circ} \mathrm{C}$, and were excluded from calculations. The excluded data are plotted as open circles and listed in strike-through font. With only one valid data point for calculations, Equation (2) was not fitted for this glass.

Table 20.2. . Viscosity-Temperature Data for $\mathrm{AC} 2-20$

\begin{tabular}{cccc}
\hline $\mathrm{T}\left({ }^{\circ} \mathrm{C}\right)$ & $\eta(\mathrm{Pa} \cdot \mathrm{s})$ & $10000 / \mathrm{T}\left(\mathrm{K}^{-1}\right)$ & $\ln [\eta(\mathrm{Pa} \cdot \mathrm{s})]$ \\
\hline 1384 & 0.4416 & 6.035 & -0.817 \\
1365 & 0.6254 & 6.105 & -0.469 \\
1385 & 0.4787 & 6.031 & -0.737 \\
\hline
\end{tabular}




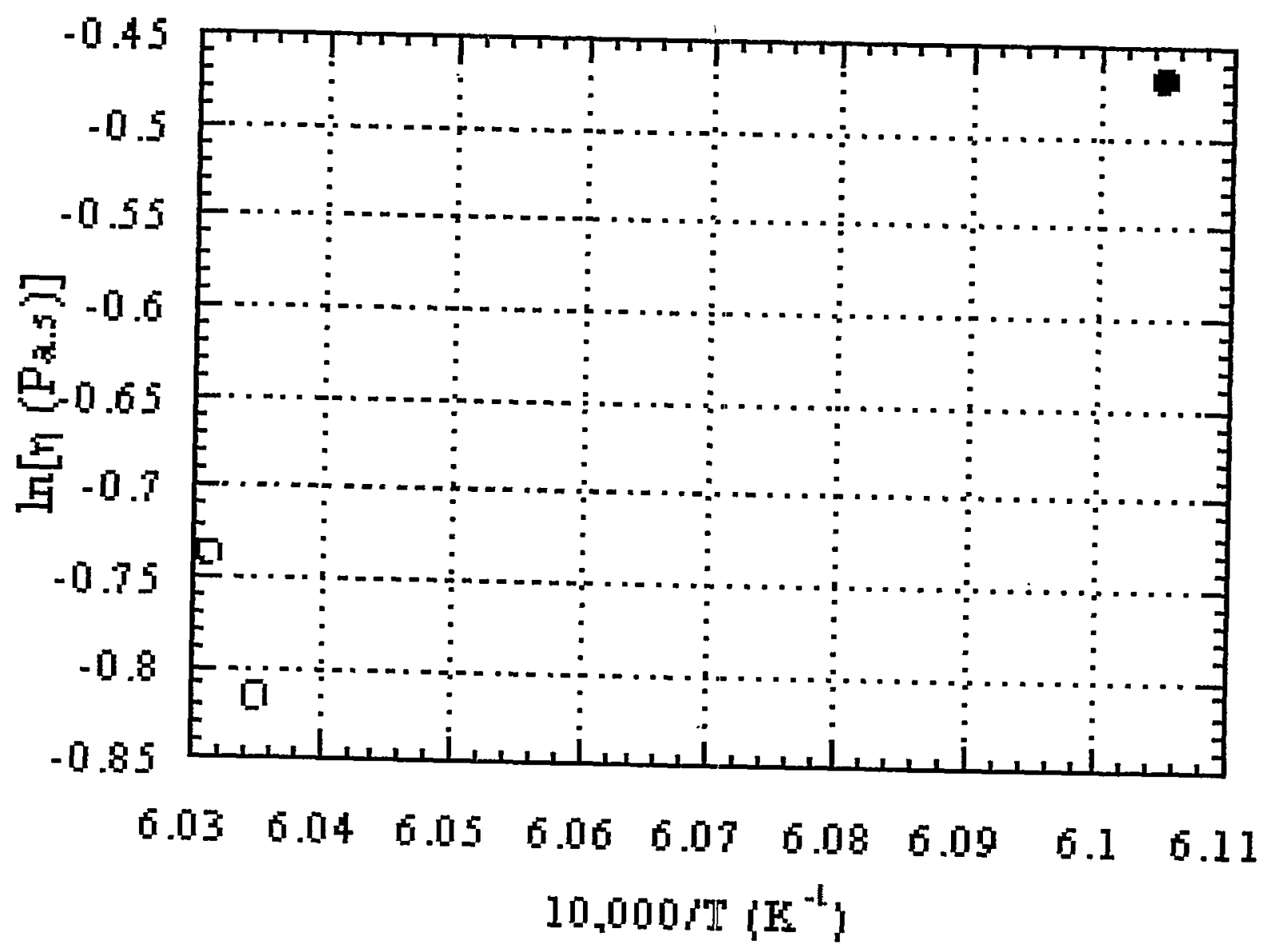

Figure 20.1. Measured ln Viscosity vs. 10000/T for AC2-20 


\subsection{AC2-21}

Glass AC2-21 is an extreme vertex on the outer level of glass compositions. This glass targets 55.6 mass percent $\mathrm{Ln}_{2} \mathrm{O}_{3}$. The ratios of $\mathrm{Al}_{2} \mathrm{O}_{3}, \mathrm{~B}_{2} \mathrm{O}_{3}$, and $\mathrm{SrO}$ to other frit components are higher in this glass than in the baseline frit. In other words, the relative concentrations of $\mathrm{SiO}_{2}, \mathrm{Al}_{2} \mathrm{O}_{3}, \mathrm{~B}_{2} \mathrm{O}_{3}$, and $\mathrm{SrO}$ are low, high, high, and high, respectively, in comparison to the standard frit composition.

\subsection{Liquidus Temperature}

Table 21.1 summarizes the heat treatments performed on this glass. The $T_{L}$ was estimated using Furnace $\# 8$ at $1242^{\circ} \mathrm{C}$. Aluminum oxide crystals formed in samples of this glass heat treated at temperatures below $T_{L}$. The crystals were identified by the characteristic morphologies of the crystals formed below $T_{L}$. The crystal morphologies matched those observed in samples of $\mathrm{AC} 2-02, \mathrm{AC} 2-11, \mathrm{AC} 2-14$, and $\mathrm{AC} 2-16$. In addition, EDS spectra of a preliminary glass sample suggested that the crystal contains $\mathrm{Al}$ and $\mathrm{O}$ alone (see Figure 21.1, Figure 21.2, and Figure 21.3).

Four preliminary heat treatments were conducted from $1212^{\circ} \mathrm{C}$ to $1275^{\circ} \mathrm{C}$. Samples at $1220^{\circ} \mathrm{C}$ and $1229^{\circ} \mathrm{C}$ both were analyzed by SEM/EDS. Additional samples were heat treated in Furnaces $\# 10, \# 3$, and \#12. One small crystal was identified in the $1243^{\circ} \mathrm{C}$ heat-treated sample.

Table 21.1. Heat-Treatment Summary for Determination of $T_{L}$ for AC2-21

\begin{tabular}{ccccccc}
\hline Crucible & Furnace & Time/Date IN T $\left({ }^{\circ} \mathrm{C}\right)$ & Time/Date OUT & Observations & Comments \\
\hline 11 & 10 & $5: 51 \mathrm{pm} \mathrm{06/07}$ & 1229 & $4: 28 \mathrm{pm} \mathrm{06/08}$ & Large plate-like crystals different furnace, SEM \\
$\mathrm{L}$ & 8 & $3: 00 \mathrm{pm} \mathrm{06/13}$ & 1220 & $3: 30 \mathrm{pm} \mathrm{06/14}$ & Lots of crystals & Preliminary, SEM \\
21 & 3 & $4: 30 \mathrm{pm} \mathrm{06/09}$ & 1243 & $3: 00 \mathrm{pm} \mathrm{06/10}$ & One little crystal & different furnace \\
21 & 12 & $2: 17 \mathrm{pm} \mathrm{06/20}$ & 1259 & $1: 00 \mathrm{pm} \mathrm{06/21}$ & No crystals & different furnace \\
21 & 8 & $2: 00 \mathrm{pm} \mathrm{06/22}$ & 1249 & $12: 35 \mathrm{pm} \mathrm{06/23}$ & No crystals & $\mathrm{T}_{\mathrm{A}}$ \\
21 & 12 & $8: 45 \mathrm{am} \mathrm{07/04}$ & 1255 & $8: 44 \mathrm{am} \mathrm{07/05}$ & No crystals & different furnace \\
21 & 8 & $4: 29 \mathrm{pm} \mathrm{07/18}$ & 1240 & $2: 43 \mathrm{pm} \mathrm{07/19}$ & Few crystals & $\mathrm{T}_{\mathrm{C}}$ \\
\hline
\end{tabular}




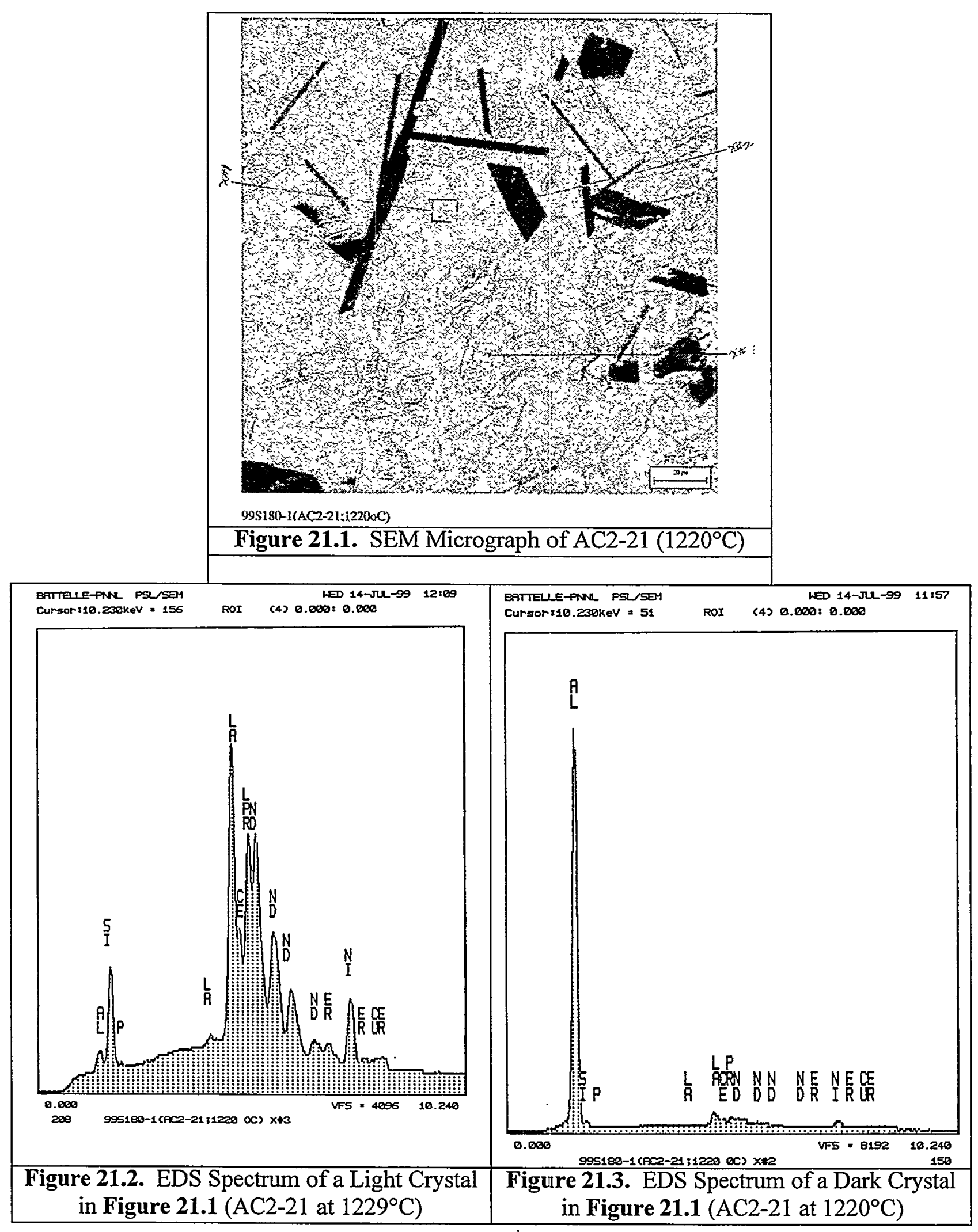




\subsection{Viscosity}

Table 21.2 lists the measured $\eta-T$ values for AC2-21 in chronological order. These data are shown on an Arrhenius plot ( $\ln \eta$ vs. $1 / \mathrm{T}$ ) in Figure 21.4. Three data points from Table 21.2 were excluded from calculations. One of these points, at $1404^{\circ} \mathrm{C}$, had a measured $\eta$ value below the instrument's range while two data points, at $1236^{\circ} \mathrm{C}$ and $1186^{\circ} \mathrm{C}$, were taken at $\mathrm{Ts}$ below $\mathrm{T}_{\mathrm{L}}$. The excluded data are plotted as open circles and listed in strike-through font. Equation (2) was fitted to the remaining data, shown as solid circles, to yield $E$ and $F$ values of -14.596 and 23443 $\mathrm{K}$, respectively. This fit, which accurately portrays the data, was then used to calculate a $\eta_{1350}$ value of $0.86 \mathrm{~Pa} \cdot \mathrm{s}$.

Table 21.2. Viscosity-Temperature Data for $A C 2-21$

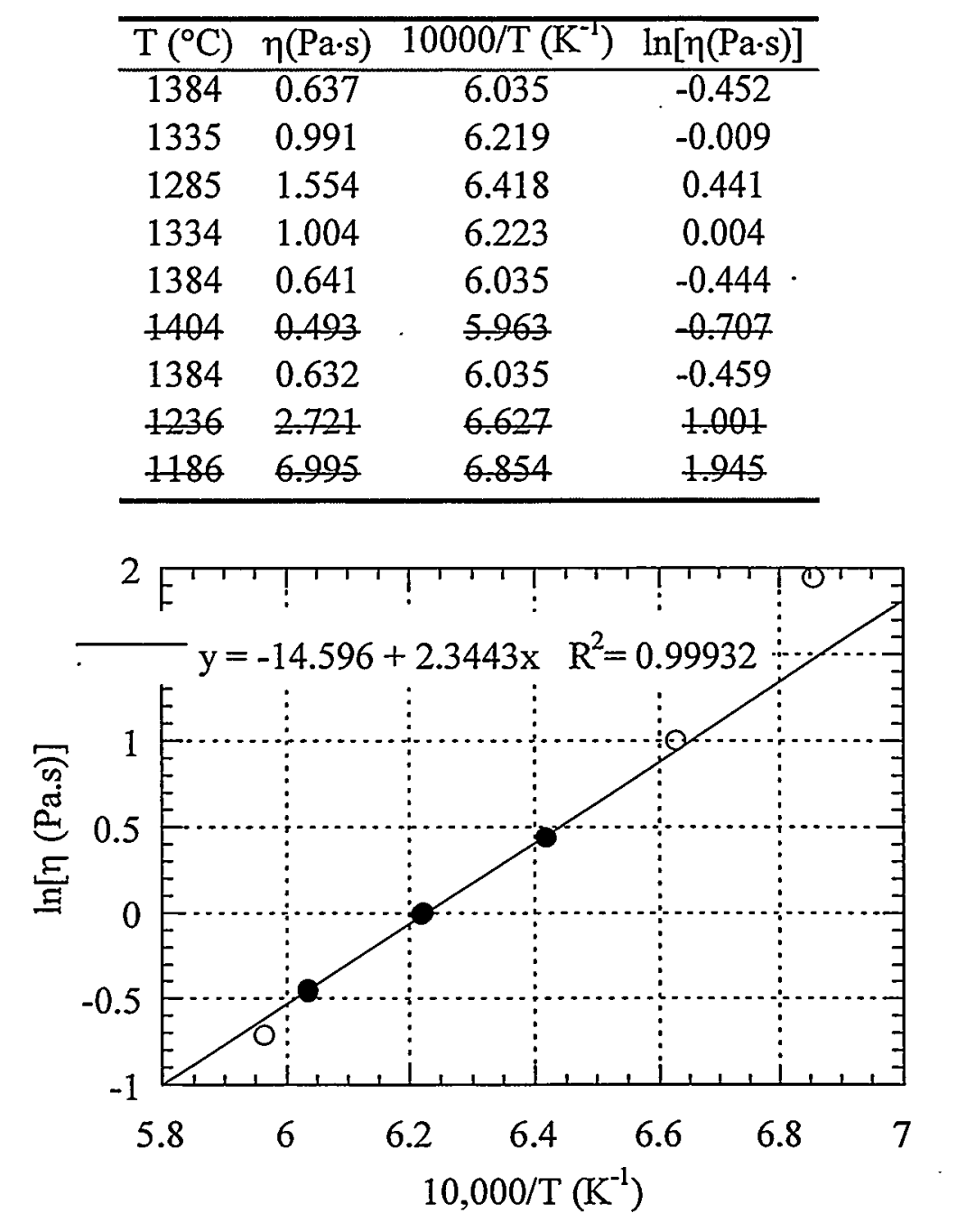

Figure 21.4. Measured In Viscosity vs. 10000/T for AC2-21 


\section{$22.0 \quad \mathrm{AC} 2-22$}

Glass AC2-22 is an extreme vertex on the outer level of glass compositions. This glass targets 53.9 mass percent $\mathrm{Ln}_{2} \mathrm{O}_{3}$. The ratios of $\mathrm{SiO}_{2}, \mathrm{~B}_{2} \mathrm{O}_{3}$, and $\mathrm{SrO}$ to other frit components are higher in this glass than in the baseline frit. In other words, the relative concentrations of $\mathrm{SiO}_{2}$, $\mathrm{Al}_{2} \mathrm{O}_{3}, \mathrm{~B}_{2} \mathrm{O}_{3}$, and $\mathrm{SrO}$ are high, low, high, and high, respectively, in comparison to the standard frit composition.

\subsection{Liquidus Temperature}

In the final $\mathrm{T}_{\mathrm{L}}$ measurements, four heat treatments were performed in Furnace \#3 between $1265^{\circ} \mathrm{C}$ and $1287^{\circ} \mathrm{C}$ (Table 22.1). The sample heat treated at $1265^{\circ} \mathrm{C}$ was filled with crystals, indicating that gross crystallization occurred at temperatures slightly below $\mathrm{T}_{\mathrm{L}}$. At $1275^{\circ} \mathrm{C}$, only a few clusters remained on the bottom of the sample; at $1283^{\circ} \mathrm{C}$, only one crystal was observed in a corner; and at $1287^{\circ} \mathrm{C}$, the heat-treated sample appeared to be crystal free by $\mathrm{OM}$. The $\mathrm{T}_{\mathrm{L}}$ was estimated to be $1284^{\circ} \mathrm{C}$ with RES as the primary phase. These crystals were identified by the characteristic morphologies of the crystals formed below $T_{L}$. The morphologies matched those observed in samples of AC2-03, AC2-05, and other glasses that were shown by SEM and/or XRD to be RES crystals.

Four preliminary heat treatments were performed between $1222^{\circ} \mathrm{C}$ and $1275^{\circ} \mathrm{C}$ at approximately $20^{\circ} \mathrm{C}$ intervals. Abundant crystals were observed at $1251^{\circ} \mathrm{C}$ and $1263^{\circ} \mathrm{C}$, which matches the observations in the final heat treatments. The sample at $1275^{\circ} \mathrm{C}$ appeared to be crystal free by $\mathrm{OM}$ of the preliminary sample. An additional sample was heat treated at $1275^{\circ} \mathrm{C}$ in Furnace \#12. This sample contained a few crystals, validating the $T_{L}$ measurement.

Table 22.1. Heat-Treatment Summary for Determination of $T_{L}$ for $A C 2-22$

\begin{tabular}{|c|c|c|c|c|c|c|}
\hline Crucible & Furnace & Time/Date IN & $\mathrm{T}\left({ }^{\circ} \mathrm{C}\right)$ & Time/Date OUT & Observations & Comments \\
\hline 22 & 12 & 3:00pm 06/18 & 1275 & $1: 20 \mathrm{pm} \mathrm{06/19}$ & Few crystals & different furnace \\
\hline 22 & 3 & $3: 00 \mathrm{pm} 06 / 25$ & 1265 & $1: 20 \mathrm{pm} \mathrm{06/26}$ & Crystals throughout & \\
\hline 22 & 3 & 1:30pm 07/09 & 1275 & $1: 00 \mathrm{pm} 07 / 10$ & Crystals on bottom & \\
\hline 22 & 3 & 4:06pm 07/17 & 1283 & $3: 22 \mathrm{pm} \mathrm{07/18}$ & One crystal & $T_{c}$ \\
\hline 22 & 3 & $4: 30 \mathrm{pm} 07 / 22$ & 1287 & $2: 35 \mathrm{pm} 07 / 23$ & No crystals & $\mathrm{T}_{\mathrm{A}}$ \\
\hline
\end{tabular}

\subsection{Viscosity}

Table 22.2 lists the measured $\eta-T$ values for $\mathrm{AC} 2-22$ in chronological order. These data are shown on an Arrhenius plot ( $\ln \eta$ vs. 1/T) in Figure 22.1. A datum from Table 22.2 had a measured $\eta$ value below the instrument's range, at $1483^{\circ} \mathrm{C}$, which was excluded from calculations. The excluded point is shown as an open circle and listed in strike-through font. Equation (2) was fitted to the remaining data, shown as solid circles, to yield $\mathrm{E}$ and $\mathrm{F}$ values of - 
15.045 and $24893 \mathrm{~K}$, respectively. This fit, which accurately portrays the data, was then used to calculate a $\eta_{1350}$ value of $1.34 \mathrm{~Pa} \cdot \mathrm{s}$.

Table 22.2. Viscosity-Temperature Data for $\mathrm{AC} 2-22$

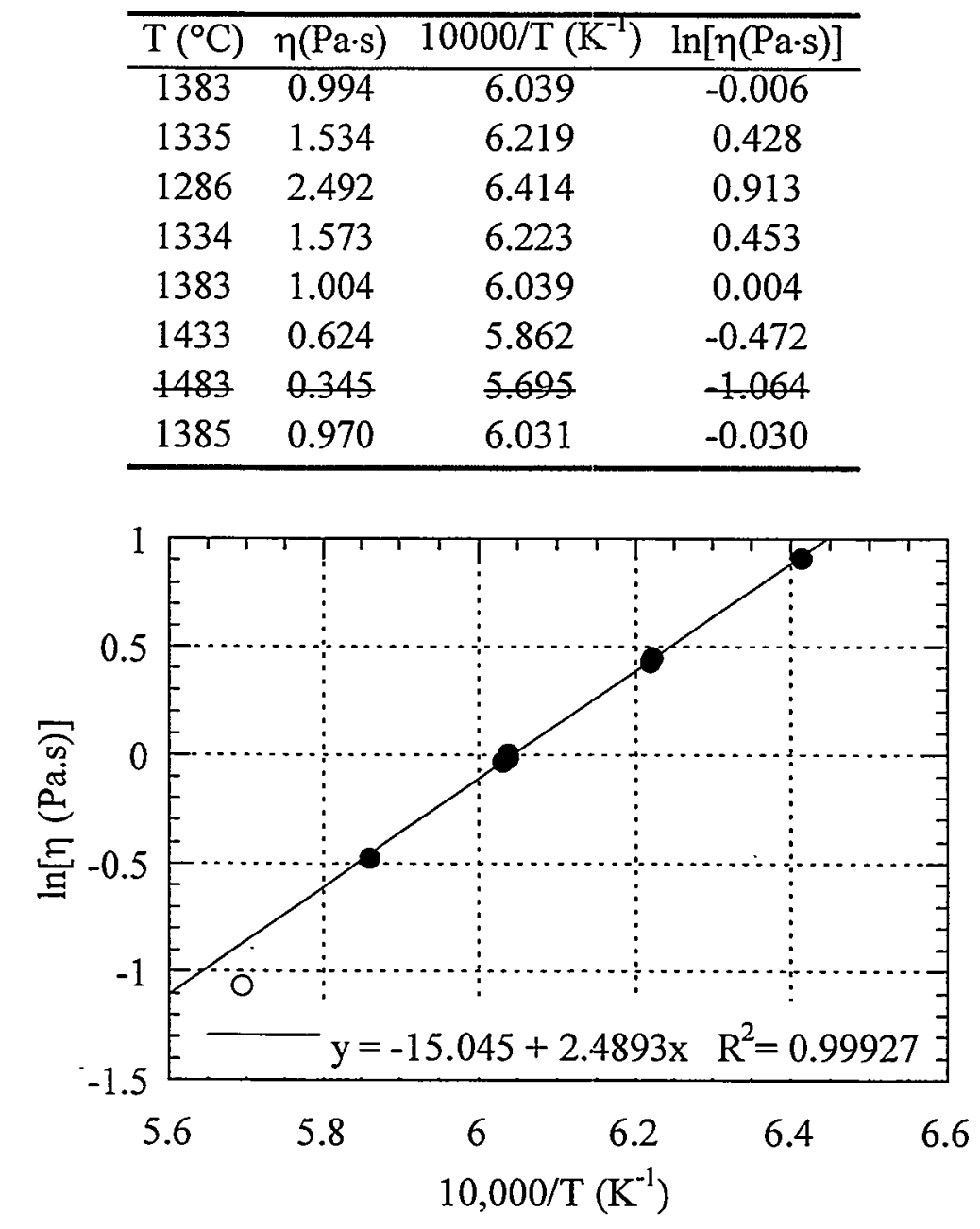

Figure 22.1. Measured ln Viscosity vs. $10000 / \mathrm{T}$ for $\mathrm{AC} 2-22$ 


\subsection{AC2-23}

Glass AC2-23 is an extreme vertex on the outer level of glass compositions. This glass targets 58.4 mass percent $\mathrm{Ln}_{2} \mathrm{O}_{3}$. The ratios of $\mathrm{B}_{2} \mathrm{O}_{3}$ and $\mathrm{SrO}$ to other frit components are higher in this glass than in the baseline frit. In other words, the relative concentrations of $\mathrm{SiO}_{2}, \mathrm{Al}_{2} \mathrm{O}_{3}$, $\mathrm{B}_{2} \mathrm{O}_{3}$, and $\mathrm{SrO}$ are low, low, high, and high, respectively, in comparison to the standard frit composition.

\subsection{Liquidus Temperature}

Table 23.1 summarizes the heat treatments performed on this glass using Furnace \#3. The $\mathrm{T}_{\mathrm{L}}$ of this glass was estimated at $1282^{\circ} \mathrm{C}$ since samples were crystal free after heat treatments at $1284^{\circ} \mathrm{C}$ and $1292^{\circ} \mathrm{C}$, and a sample heat-treated at $1278^{\circ} \mathrm{C}$ contained crystals throughout. This indicated that gross crystallization occurred at temperatures slightly below $T_{L}$. Aluminum oxide crystals formed in samples of this glass heat treated at temperatures below $T_{L}$. These crystals (Figure 23.1) were identified by EDS analysis of a crystal observed in the $1278^{\circ} \mathrm{C}$ heat-treated sample as shown in Figure 23.2. The crystal appears to be composed of $\mathrm{Al}$ and $\mathrm{O}$ alone.

Three preliminary heat treatments were performed between $1223^{\circ} \mathrm{C}$ and $1288^{\circ} \mathrm{C}$ at approximately $20^{\circ} \mathrm{C}$ intervals. Abundant crystals were observed at $1223^{\circ} \mathrm{C}$, which matches the observations in the final heat treatments. The sample at $1288^{\circ} \mathrm{C}$ appeared to be crystal free by OM.

Table 23.1. Heat-Treatment Summary for Determination of $T_{L}$ for AC2-23

\begin{tabular}{ccccccc}
\hline Crucible & Furnace & Date/Time IN & $\mathrm{T}\left({ }^{\circ} \mathrm{C}\right)$ & Date/Time OUT & Observations & Comments \\
\hline 23 & 3 & $3: 00 \mathrm{pm} \mathrm{6/13}$ & 1278 & $3: 30 \mathrm{pm} \mathrm{6/14}$ & Crystals throughout & $\mathrm{T}_{\mathrm{C}}, \mathrm{SEM}$ \\
23 & 3 & $5: 00 \mathrm{pm} \mathrm{6/15}$ & 1292 & $3: 20 \mathrm{pm} \mathrm{6/16}$ & No crystals & \\
23 & 3 & $5: 00 \mathrm{pm} \mathrm{6/16}$ & 1284 & $3: 00 \mathrm{pm} \mathrm{6/17}$ & No crystals & $\mathrm{T}_{\mathrm{A}}$, Buds \\
\hline
\end{tabular}




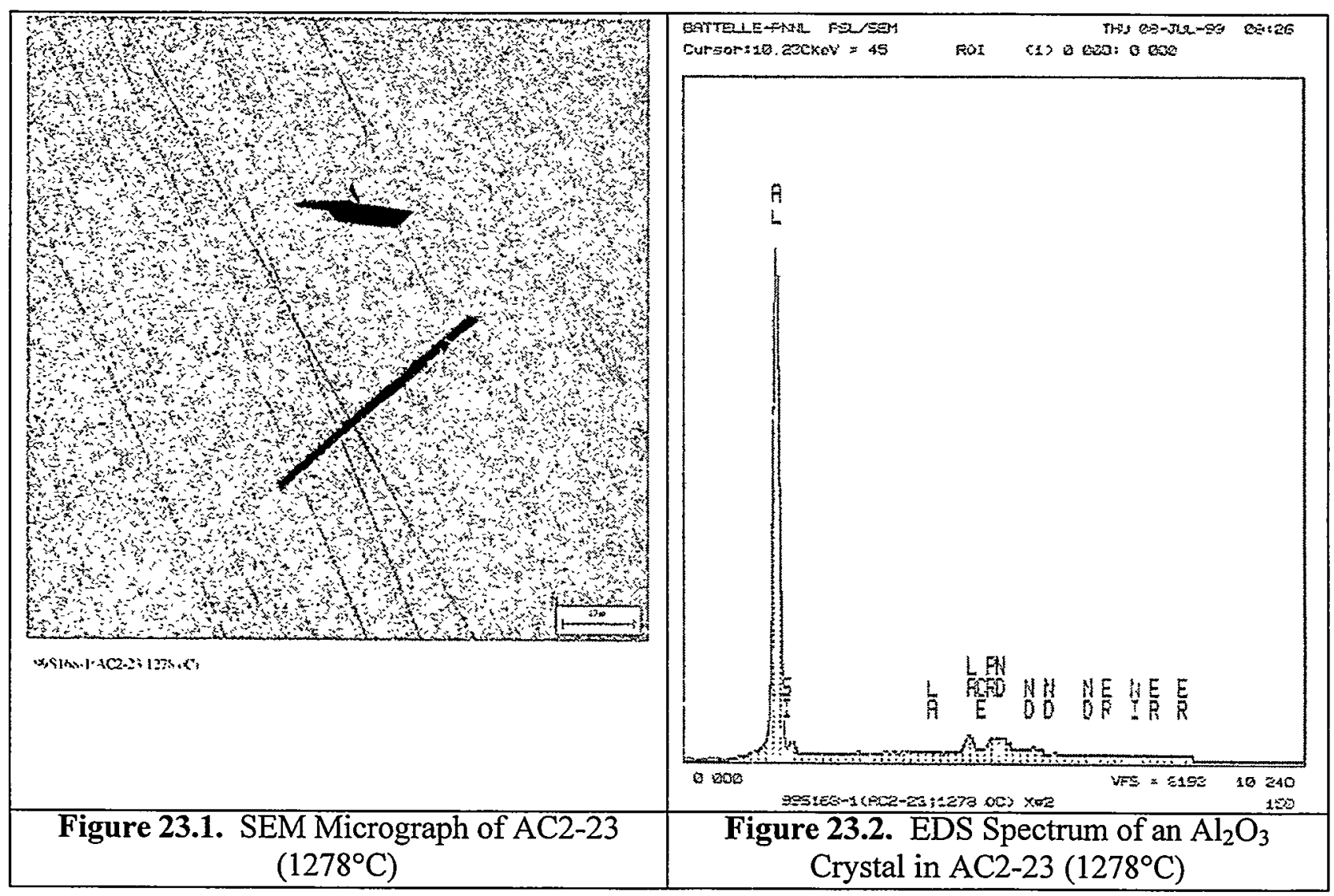

\subsection{Viscosity}

Table 23.2 lists the measured $\eta-\mathrm{T}$ values for $\mathrm{AC} 2-23$ in chronological order. These data are shown on an Arrhenius plot ( $\ln \eta$ vs. 1/T) in Figure 23.3. Two data points from were excluded from calculations. One of these points, at $1434^{\circ} \mathrm{C}$, had a measured $\eta$ value below the instrument's range while the other, at $1266^{\circ} \mathrm{C}$, was taken at a $\mathrm{T}$ below $\mathrm{T}_{\mathrm{L}}$. The excluded data are plotted as open circles and listed in strike-through font. Equation (2) was fitted to the remaining data, shown as solid circles, to yield $\mathrm{E}$ and $\mathrm{F}$ values of -14.288 and $23182 \mathrm{~K}$, respectively. This fit, which accurately portrays the data, was then used to calculate a $\eta_{1350}$ value of $1.00 \mathrm{~Pa} \cdot \mathrm{s}$. 
Table 23.2. Viscosity-Temperature Data for AC2-23

\begin{tabular}{cccc}
\hline $\mathrm{T}\left({ }^{\circ} \mathrm{C}\right)$ & $\eta(\mathrm{Pa} \cdot \mathrm{s})$ & $10000 / \mathrm{T}\left(\mathrm{K}^{-1}\right)$ & $\ln [\eta(\mathrm{Pa} \cdot \mathrm{s})]$ \\
\hline 1383 & 0.712 & 6.039 & -0.339 \\
1334 & 1.172 & 6.223 & 0.158 \\
1285 & 1.763 & 6.418 & 0.567 \\
1334 & 1.181 & 6.223 & 0.167 \\
1384 & 0.753 & 6.035 & -0.284 \\
1434 & 0.430 & 5.858 & -0.843 \\
1385 & 0.743 & 6.031 & -0.297 \\
1266 & 3.043 & 6.498 & 1.113 \\
\hline
\end{tabular}

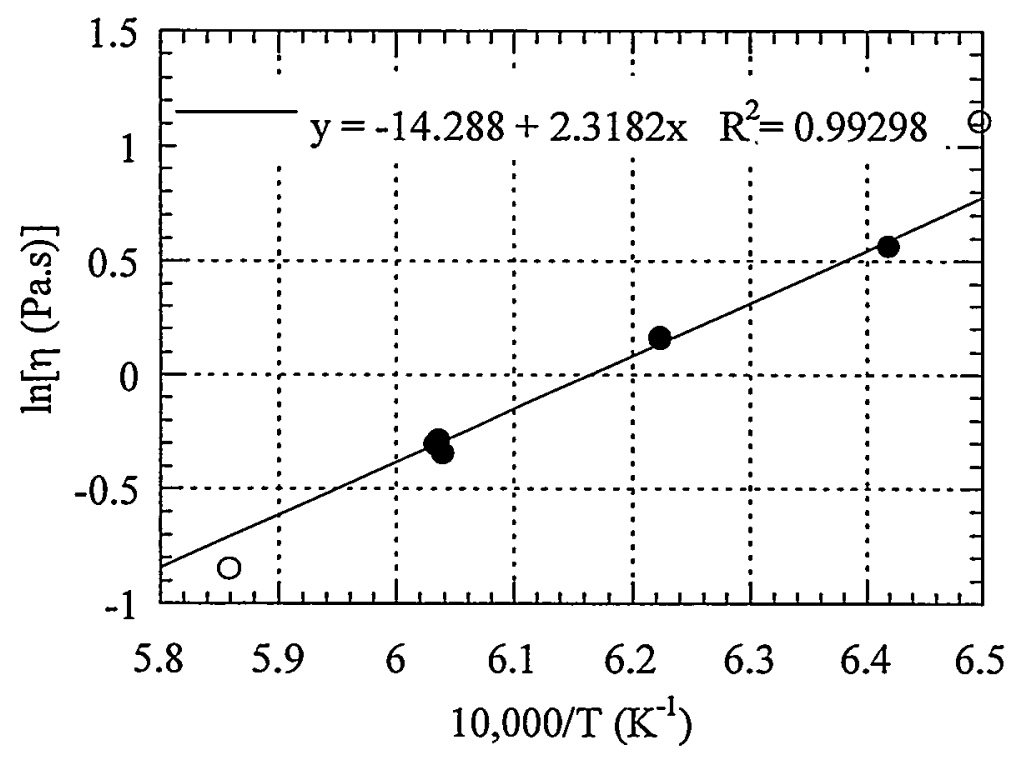

Figure 23.3. Measured ln Viscosity vs. 10000/T for $\mathrm{AC} 2-23$ 


\section{$24.0 \quad$ AC2-24}

Glass AC2-24 is an extreme vertex on the outer level of glass compositions. This glass targets 61.3 mass percent $\mathrm{Ln}_{2} \mathrm{O}_{3}$. The ratio of $\mathrm{B}_{2} \mathrm{O}_{3}$ to other frit components is higher in this glass than in the baseline frit. In other words, the relative concentrations of $\mathrm{SiO}_{2}, \mathrm{Al}_{2} \mathrm{O}_{3}, \mathrm{~B}_{2} \mathrm{O}_{3}$, and $\mathrm{SrO}$ are low, low, high, and low, respectively, in comparison to the standard frit composition.

\subsection{Liquidus Temperature}

Table 24.1 details the final heat treatments near $T_{L} . A T_{L}$ of $1319^{\circ} \mathrm{C}$ was estimated using Furnace \#3. A sample heat treated at $1321^{\circ} \mathrm{C}$ appeared to be crystal free by $\mathrm{OM}$, and a sample heat treated at $1313^{\circ} \mathrm{C}$ was full of crystals. This indicated that gross crystallization occurred at temperatures slightly below $T_{L}$. The primary phase was identified by the characteristic morphologies of the crystals formed below $T_{L}$. The morphology matches that observed in samples of AC2-03, AC2-05, and other glasses that were shown by SEM and/or XRD to be RES crystals. The sample heat treated at $1313^{\circ} \mathrm{C}$ contained dendritic ends on the RES crystals similar the observations in AC2-44 (Figure 4.4 in the main report). An EDS spectrum taken on one of these dendritic ends was indistinguishable from those measured on other RES crystals.

Six preliminary samples were heat treated between $1222^{\circ} \mathrm{C}$ and $1339^{\circ} \mathrm{C}$ at approximately $50^{\circ} \mathrm{C}$ intervals with samples full of crystals from $1222^{\circ} \mathrm{C}$ to $1292^{\circ} \mathrm{C}$. Additional samples, heat treated at $1320^{\circ} \mathrm{C}$ and $1327^{\circ} \mathrm{C}$ in Furnaces $\# 12$ and $\# 8$, did not contain crystals.

Table 24.1. Heat-Treatment Summary for Determination of $T_{L}$ for $A C 2-24$

\begin{tabular}{ccccccc}
\hline Crucible & Furnace & Time/Date IN & T $\left({ }^{\circ} \mathrm{C}\right)$ & Time/Date OUT & Observations & Comments \\
\hline 24 & 3 & $3: 00 \mathrm{pm} \mathrm{06/18}$ & 1313 & $1: 30 \mathrm{pm} \mathrm{06/19}$ & Very crystalline & $\mathrm{T}_{\mathrm{C}}$ \\
24 & 8 & $4: 30 \mathrm{pm} \mathrm{06/23}$ & 1327 & $3: 00 \mathrm{pm} \mathrm{06/24}$ & No crystals & different furnace \\
24 & 12 & $5: 00 \mathrm{pm} \mathrm{06/24}$ & 1320 & $3: 00 \mathrm{pm} \mathrm{06/25}$ & No crystals & different furnace \\
24 & 3 & $3: 00 \mathrm{pm} \mathrm{07/14}$ & 1321 & $3: 05 \mathrm{pm} \mathrm{07/15}$ & No crystals & $\mathrm{T}_{\mathrm{A}}$ \\
\hline
\end{tabular}

\subsection{Viscosity}

Table 24.2 lists the measured $\eta$-T values for AC2-24 in chronological order. These data are shown on an Arrhenius plot ( $\ln \eta$ vs. 1/T) in Figure 24.1. Three data points from Table 24.2 had measured $\eta$ values below the instrument's range, at $1383^{\circ} \mathrm{C}, 1363^{\circ} \mathrm{C}$, and $1382^{\circ} \mathrm{C}$, and were excluded from calculations. The excluded data are plotted as open circles and listed in strikethrough font. Equation (2) was fitted to the remaining two data, plotted as filled circles, to yield $\mathrm{E}$ and $\mathrm{F}$ values of -19.831 and $31376 \mathrm{~K}$, respectively. This fit, based on only two valid data points, was then used to calculate a $\eta_{1350}$ value of $0.61 \mathrm{~Pa} \cdot \mathrm{s}$. 
Table 24.2. Viscosity-Temperature Data for AC2-24

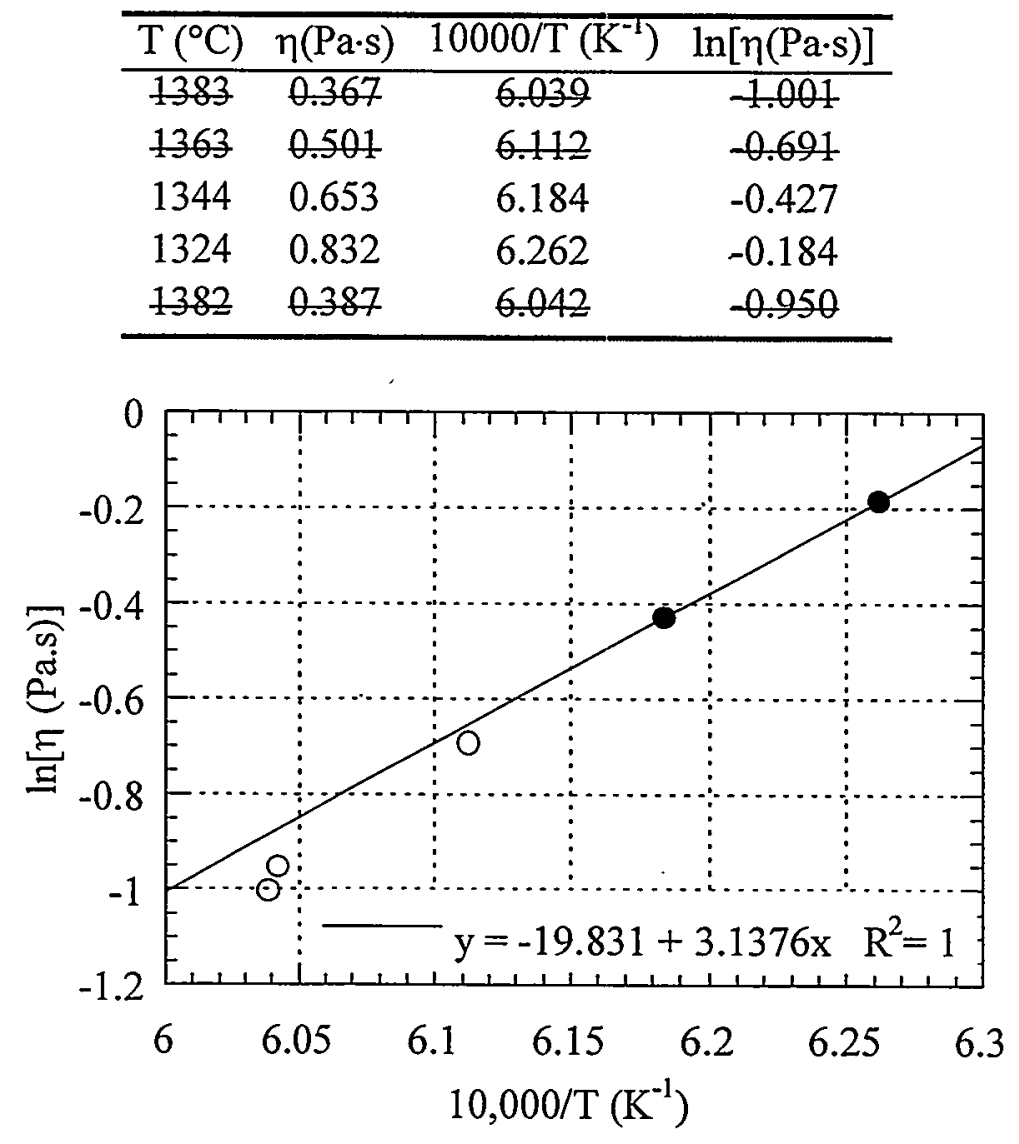

Figure 24.1. Measured ln Viscosity vs. 10000/T for AC2-24 


\section{$25.0 \quad \mathrm{AC} 2-25$}

Glass $\mathrm{AC} 2-25$ is an extreme vertex on the outer level of glass compositions. This glass targets 58.4 mass percent $\mathrm{Ln}_{2} \mathrm{O}_{3}$. The ratios of $\mathrm{Al}_{2} \mathrm{O}_{3}$ and $\mathrm{SrO}$ to other frit components are higher in this glass than in the baseline frit. In other words, the relative concentrations of $\mathrm{SiO}_{2}$, $\mathrm{Al}_{2} \mathrm{O}_{3}, \mathrm{~B}_{2} \mathrm{O}_{3}$, and $\mathrm{SrO}$ are low, high, low, and high, respectively, in comparison to the standard frit composition.

\subsection{Liquidus Temperature}

Four final heat treatments were performed in Furnace $\# 3$ between $1278^{\circ} \mathrm{C}$ and $1314^{\circ} \mathrm{C}$. They are summarized in Table 25.1. The $\mathrm{T}_{\mathrm{L}}$ of $\mathrm{AC} 2-25$ was estimated at $1305^{\circ} \mathrm{C}$. Aluminum oxide crystals formed in samples of this glass heat treated at temperatures below $T_{L}$. The crystals were identified by the characteristic morphologies of the crystals formed below $T_{L}$ and match those observed in samples of AC2-02, AC2-11, AC2-14, AC2-16, and AC2-21. Aluminum oxide crystals were observed by $\mathrm{OM}$ at $1278^{\circ} \mathrm{C}, 1292^{\circ} \mathrm{C}$, and $1299^{\circ} \mathrm{C}$, with no crystals observed at $1314^{\circ} \mathrm{C}$.

Five preliminary heat treatments were conducted from $1222^{\circ} \mathrm{C}$ to $1292^{\circ} \mathrm{C}$. An additional sample, heat treated in Furnace $\# 8$ at $1305^{\circ} \mathrm{C}$, did not contain crystals.

Table 25.1. Heat-Treatment Summary for Determination of $T_{L}$ for AC2-25

\begin{tabular}{ccccccc}
\hline Crucible & Furnace & Time/Date IN & T $\left({ }^{\circ} \mathrm{C}\right)$ & Time/Date OUT & Observations & Comments \\
\hline 25 & 3 & $3: 00 \mathrm{pm} \mathrm{06/13}$ & 1278 & $3: 30 \mathrm{pm} \mathrm{06/14}$ & Crystals throughout & \\
25 & 3 & $5: 00 \mathrm{pm} \mathrm{06/15}$ & 1292 & $3: 20 \mathrm{pm} \mathrm{06/16}$ & Crystals throughout &. \\
25 & 8 & $11: 00 \mathrm{am} \mathrm{06/29}$ & 1305 & $9: 20 \mathrm{am} \mathrm{06/30}$ & No crystals & different furnace \\
25 & 3 & $11: 00 \mathrm{am} \mathrm{06/29}$ & 1314 & $9: 20 \mathrm{am} \mathrm{06/30}$ & No crystals & $\mathrm{T}_{\mathrm{A}}$ \\
25 & 3 & $3: 20 \mathrm{pm} \mathrm{07/13}$ & 1299 & $2: 45 \mathrm{pm} \mathrm{07/14}$ & Surface crystals & $\mathrm{T}_{\mathrm{C}}$ \\
\hline
\end{tabular}

\subsection{Viscosity}

Table 25.2 lists the measured $\eta-T$ values for AC2-25 in chronological order. These data are shown on an Arrhenius plot ( $\ln \eta$ vs. 1/T) in Figure 25.1. Four data points from Table 25.2 were excluded from calculations. One of these points, at $1432^{\circ} \mathrm{C}$, had measured $\eta$ values below the instrument's range while three data points, at $1285^{\circ} \mathrm{C}, 1265^{\circ} \mathrm{C}$, and $1245^{\circ} \mathrm{C}$, were taken at Ts below $\mathrm{T}_{\mathrm{L}}$. The excluded data are plotted as open circles and listed in strike-through font.

Equation (2) was fitted to the remaining data, plotted as filled circles, to yield $E$ and $F$ values of -15.537 and $25492 \mathrm{~K}$, respectively. This fit, based on five data points at effectively two temperatures $\left(1383^{\circ} \mathrm{C}\right.$ and $\left.1333.5 \pm 0.5^{\circ} \mathrm{C}\right)$, was then used to calculate $\eta_{1350}$ value of $1.18 \mathrm{~Pa} \cdot \mathrm{s}$. 
Table 25.2. Viscosity-Temperature Data for $\mathrm{AC} 2-25$

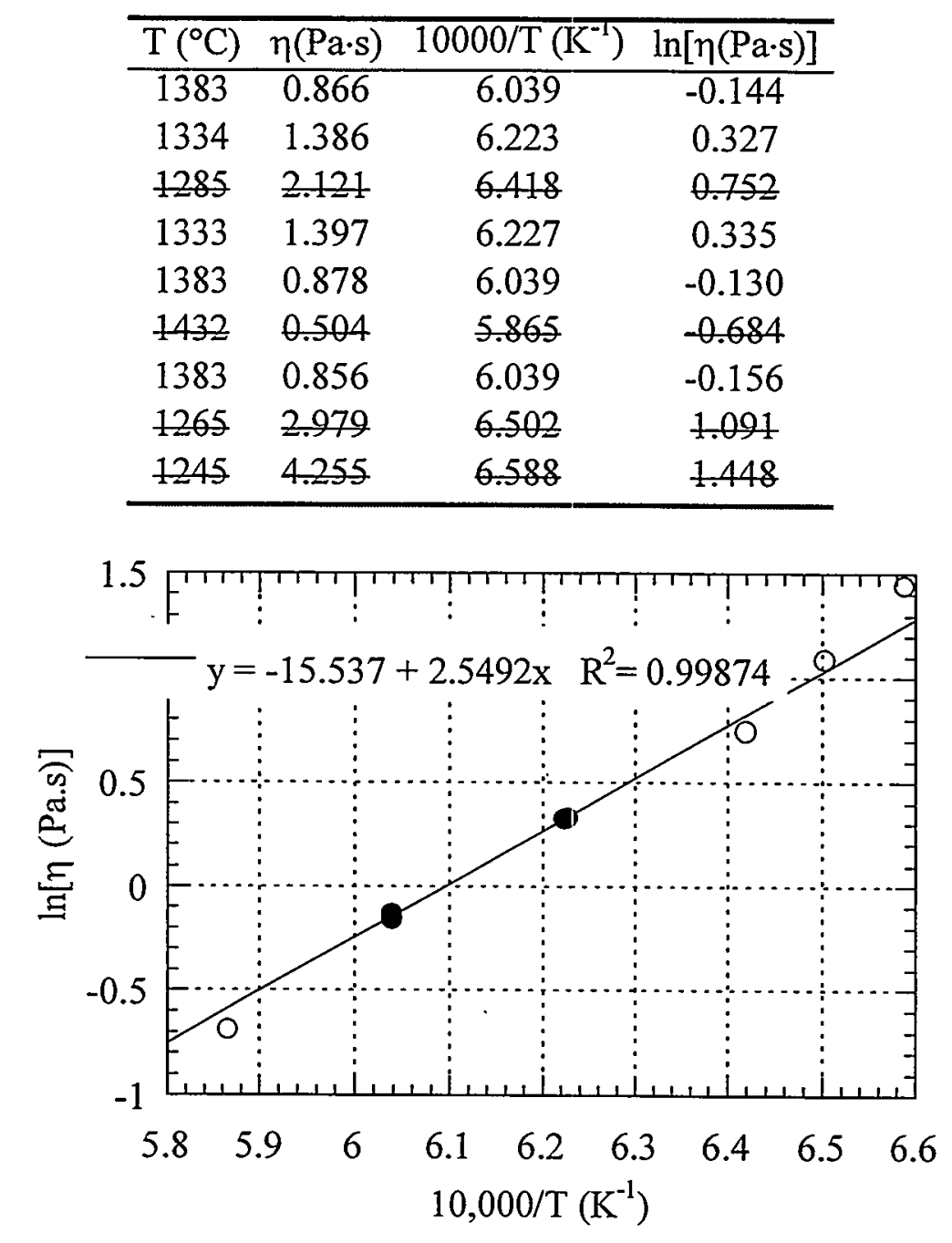

Figure 25.1. Measured ln Viscosity vs. 10000/T for $\mathrm{AC} 2-25$ 


\subsection{AC2-26}

Glass AC2-26 is an extreme vertex on the outer level of glass compositions. This glass targets 52.2 mass percent $\mathrm{Ln}_{2} \mathrm{O}_{3}$. The ratios of $\mathrm{SiO}_{2}$ and $\mathrm{Al}_{2} \mathrm{O}_{3}$ to other frit components are higher in this glass than in the baseline frit. In other words, the relative concentrations of $\mathrm{SiO}_{2}$, $\mathrm{Al}_{2} \mathrm{O}_{3}, \mathrm{~B}_{2} \mathrm{O}_{3}$, and $\mathrm{SrO}$ are high, high, low, and low respectively, in comparison to the standard frit composition.

\subsection{Liquidus Temperature}

Table 26.1 summarizes the heat treatments performed on this glass. The $T_{L}$ of this glass was estimated using Furnace $\# 8$ at $1208^{\circ} \mathrm{C}$. The sample heat treated at $1210^{\circ} \mathrm{C}$ did not contain crystals, and clusters of needle-like crystals were observed on the bottom of the sample heat treated at $1204^{\circ} \mathrm{C}$. The crystal number density increased when the sample was heat treated at $1196^{\circ} \mathrm{C}$, and at $1191^{\circ} \mathrm{C}$, there was a thin layer of crystals on the bottom. RES crystals formed in samples of this glass heat treated at temperatures below $T_{L}$. These crystals were identified by the characteristic morphologies of the crystals formed below $T_{L}$. The morphologies matched those observed in samples of AC2-03, AC2-05, and other glasses that were shown by SEM and/or $\mathrm{XRD}$ to be RES crystals.

Five preliminary heat treatments were performed starting at $1149^{\circ} \mathrm{C}$ up to $1222^{\circ} \mathrm{C}$ with three of the samples above $T_{L}$, one at $1198^{\circ} \mathrm{C}$ containing a few crystals, and one loaded with RES crystals at $1149^{\circ} \mathrm{C}$. An additional sample, heat treated at $1192^{\circ} \mathrm{C}$ in Furnace \#12, contained hair-like crystals.'

Table 26.1. Heat-Treatment Summary for Determination of TL for AC2-26

\begin{tabular}{ccccccc}
\hline Crucible & Furnace & Time/Date IN & $\mathrm{T}\left({ }^{\circ} \mathrm{C}\right)$ & Time/Date OUT & Observations & Comments \\
\hline 26 & 12 & $4: 15 \mathrm{pm} \mathrm{06/08}$ & 1192 & $2: 45 \mathrm{pm} \mathrm{06/09}$ & hair-like crystals & different furnace \\
26 & 8 & $9: 20 \mathrm{am} \mathrm{06/28}$ & 1204 & $11: 00 \mathrm{am} \mathrm{06/29}$ & Few crystals on the bottom & $\mathrm{T}_{\mathrm{C}}$ \\
26 & 8 & $11: 00 \mathrm{am} \mathrm{07/02}$ & 1196 & $11: 10 \mathrm{am} \mathrm{07/03}$ & Few crystals & \\
26 & 8 & $2: 30 \mathrm{pm} \mathrm{07/07}$ & 1191 & $1: 10 \mathrm{pm} \mathrm{07/08}$ & Crystals throughout & \\
26 & 8 & $3: 30 \mathrm{pm} \mathrm{07/21}$ & 1210 & $4: 10 \mathrm{pm} \mathrm{07/22}$ & No crystals & $\mathrm{T}_{\mathrm{A}}$ \\
\hline
\end{tabular}

\subsection{Viscosity}

Table 26.2 lists the measured $\eta-T$ values for AC2-26 in chronological order. These data are shown on an Arrhenius plot ( $\ln \eta$ vs. 1/T) in Figure 26.1. A datum from Table 26.2, at $1185^{\circ} \mathrm{C}$, was taken at Ts below $T_{L}$ and was excluded from calculations. The excluded point was plotted as an open circle and listed in strike-through font. Equation (2) was fitted to the remaining data and plotted as filled circles to yield $\mathrm{E}$ and $\mathrm{F}$ values of -18.735 and $31846 \mathrm{~K}$, respectively. The data appear to be nonlinear. Therefore, a $\eta_{1350}$ value of $2.17 \mathrm{~Pa} \cdot \mathrm{s}$ was obtained by interpolation between the data points at $1334^{\circ} \mathrm{C}$ and $1383^{\circ} \mathrm{C}$ using Equation (2). 
Table 26.2. Viscosity-Temperature Data for AC2-26

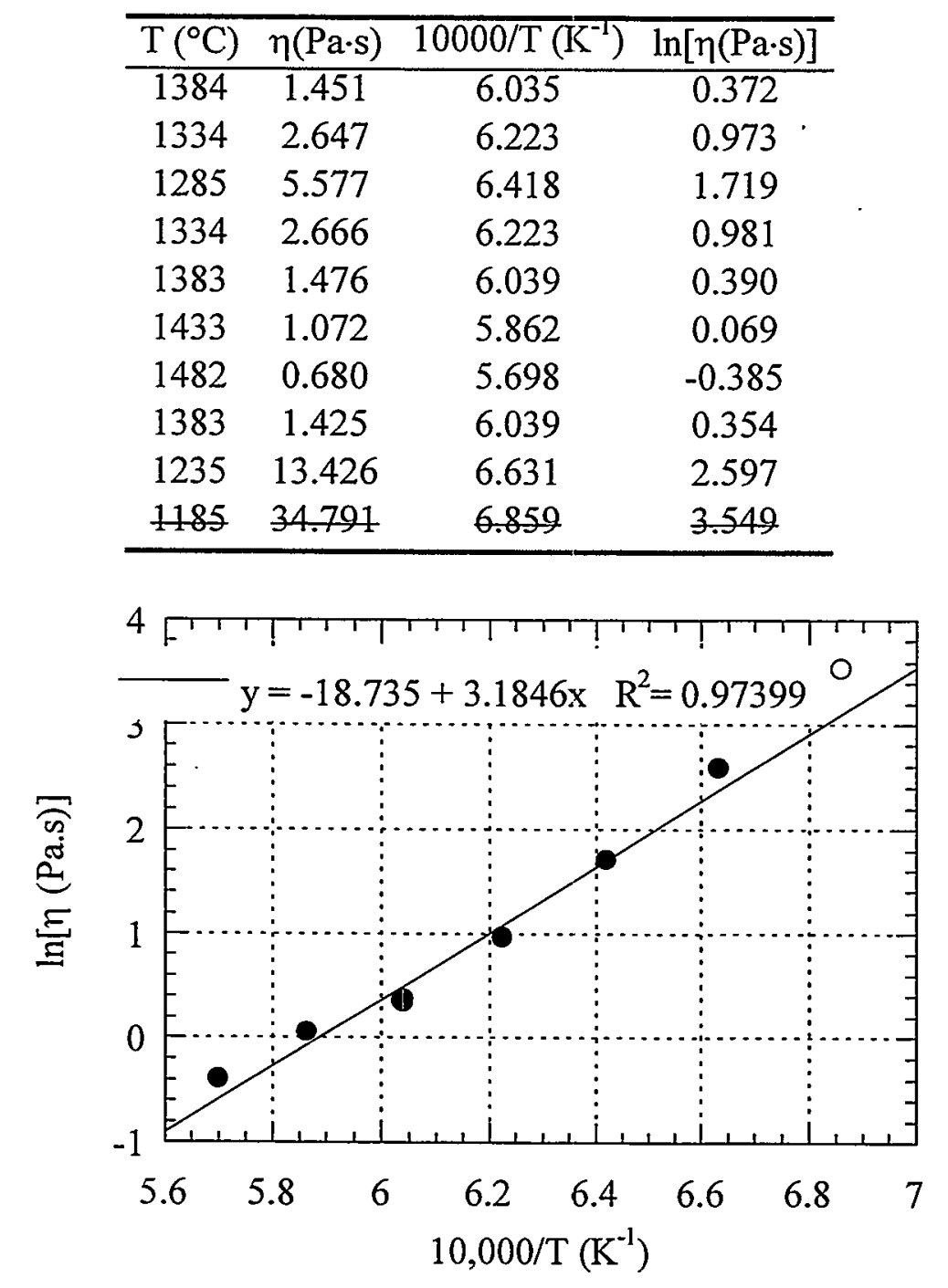

Figure 26.1. Measured ln Viscosity vs. 10000/T for AC2-26 


\section{$27.0 \quad$ AC2-27}

Glass AC2-27 is an extreme vertex on the outer level of glass compositions. This glass targets 52.9 mass percent $\mathrm{Ln}_{2} \mathrm{O}_{3}$. The ratios of $\mathrm{SiO}_{2}$ and $\mathrm{Al}_{2} \mathrm{O}_{3}$ to other frit components are higher in this glass than in the baseline frit. In other words, the relative concentrations of $\mathrm{SiO}_{2}$, $\mathrm{Al}_{2} \mathrm{O}_{3}, \mathrm{~B}_{2} \mathrm{O}_{3}$, and $\mathrm{SrO}$ are high, high, low, and low respectively, in comparison to the standard frit composition.

\subsection{Liquidus Temperature}

Table 27.1 summarizes the final heat treatments performed on samples of AC2-27 in Furnace \#3. The $T_{L}$ of this glass was estimated at $1242^{\circ} \mathrm{C}$ since only three small crystal clusters formed during the $1241^{\circ} \mathrm{C}$ heat treatment, and no crystals were observed in samples heat treated at $1240^{\circ} \mathrm{C}$ and $1242^{\circ} \mathrm{C}$. This could have been caused by small composition fluctuations in the glass. RES crystals formed in samples of this glass heat treated at temperatures below $\mathrm{T}_{\mathrm{L}}$. These crystals were identified by their characteristic morphologies. The morphologies matched those observed in samples of AC2-03, AC2-05, and other glasses that were shown by SEM and/or XRD to be RES crystals.

Three preliminary heat treatments were performed starting at $1222^{\circ} \mathrm{C}$ up to $1240^{\circ} \mathrm{C}$. The sample at $1240^{\circ} \mathrm{C}$ appeared to be crystal free by OM.

Table 27.1. Heat-Treatment Summary for Determination of $T_{L}$ for AC2-27

\begin{tabular}{ccccccc}
\hline Crucible & Furnace & Date/Time IN & $\mathrm{T}\left({ }^{\circ} \mathrm{C}\right)$ & Date/Time OUT & Observations & Comments \\
\hline 27 & 3 & $4: 00 \mathrm{pm} \mathrm{05/28}$ & 1241 & $2: 00 \mathrm{pm} \mathrm{05/29}$ & Three small clusters & $\mathrm{T}_{\mathrm{C}}$ \\
27 & 3 & $4: 00 \mathrm{pm} \mathrm{06/01}$ & 1233 & $2: 30 \mathrm{pm} \mathrm{06/02}$ & Crystals throughout & XRD \\
27 & 3 & $3: 30 \mathrm{pm} \mathrm{06/02}$ & 1240 & $2: 30 \mathrm{pm} \mathrm{06/03}$ & No crystals & $\mathrm{T}_{\mathrm{A}}$ \\
27 & 3 & $4: 45 \mathrm{pm} \mathrm{06/08}$ & 1242 & $2: 45 \mathrm{pm} \mathrm{06/09}$ & No crystals & \\
\hline
\end{tabular}

\subsection{Viscosity}

Table 27.2 lists the measured $\eta-T$ values for $A C 2-27$ in chronological order. These data are shown on an Arrhenius plot ( $\ln \eta$ vs. 1/T) in Figure 27.1. Three data points from Table 27.2 were excluded from calculations. One of these points, at $1484^{\circ} \mathrm{C}$, had a measured $\eta$ value below the instrument's range while two data points, at $1237^{\circ} \mathrm{C}$ and $1187^{\circ} \mathrm{C}$, were taken at $\mathrm{Ts}$ below $\mathrm{T}_{\mathrm{L}}$. The excluded data are plotted as open circles and listed in strike-through font. Equation (2) was fitted to the remaining data, plotted as filled circles, to yield $E$ and $F$ values of -16.069 and $27223 \mathrm{~K}$, respectively. The data appear to be nonlinear. Therefore, a $\eta_{1350}$ value of $1.93 \mathrm{~Pa} \cdot \mathrm{s}$ was obtained by interpolation between the data points at $1335^{\circ} \mathrm{C}$ and $1385^{\circ} \mathrm{C}$ using Equation (2). 
Table 27.2. Viscosity-Temperature Data for AC2-27

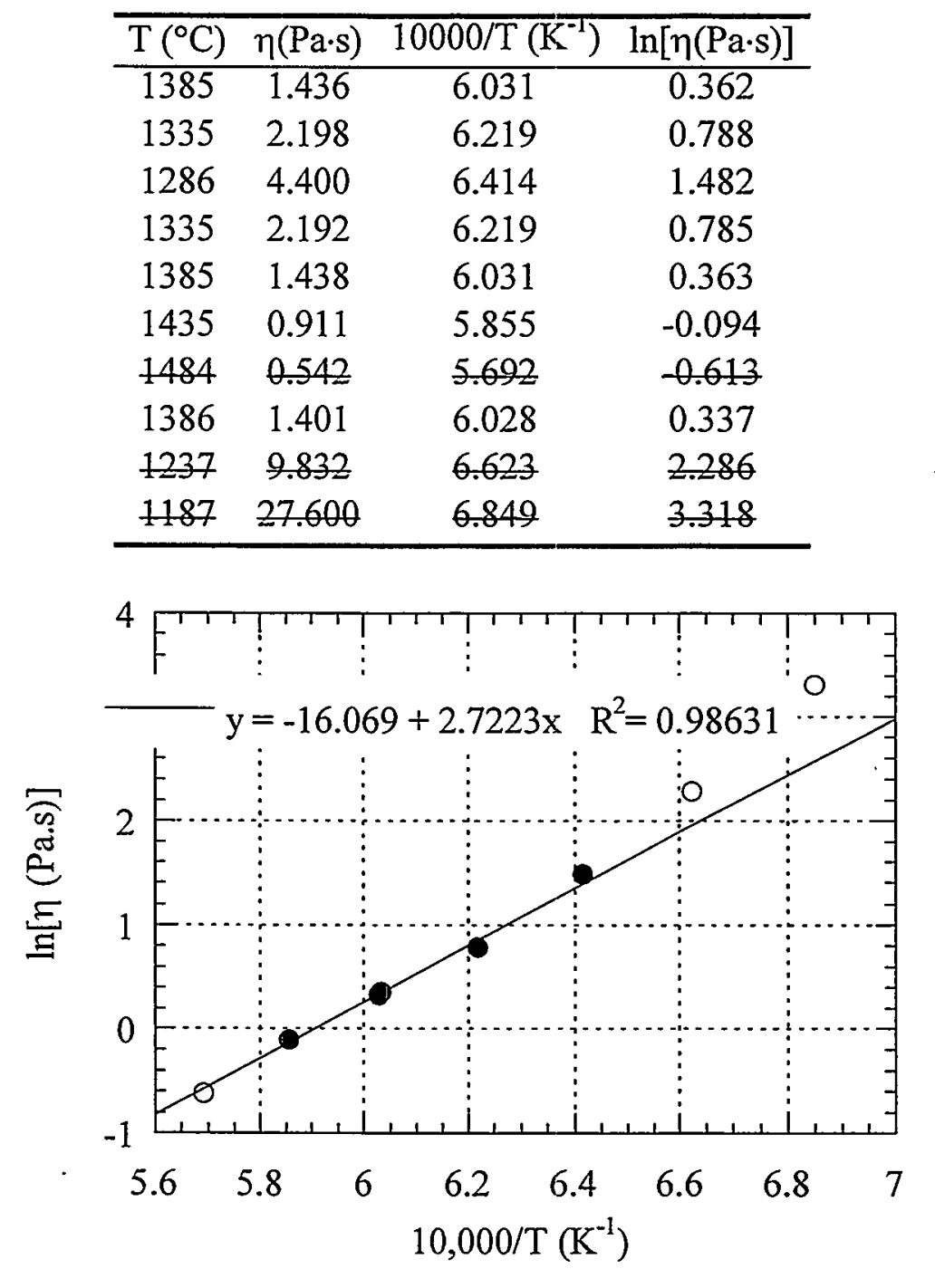

Figure 27.1. Measured ln Viscosity vs. $10000 / \mathrm{T}$ for $\mathrm{AC} 2-27$ 


\subsection{AC2-28}

Glass AC2-28 is an extreme vertex on the outer level of glass compositions. This glass targets 55.6 mass percent $\mathrm{Ln}_{2} \mathrm{O}_{3}$. The ratios of $\mathrm{Al}_{2} \mathrm{O}_{3}, \mathrm{~B}_{2} \mathrm{O}_{3}$, and $\mathrm{SrO}$ to other frit components are higher in this glass than in the baseline frit. In other words, the relative concentrations of $\mathrm{SiO}_{2}, \mathrm{Al}_{2} \mathrm{O}_{3}, \mathrm{~B}_{2} \mathrm{O}_{3}$, and $\mathrm{SrO}$ are low, high, high, and high, respectively, in comparison to the standard frit composition.

\subsection{Liquidus Temperature}

Table 28.1 summarizes the final heat treatments performed on AC2-28. The $T_{L}$ was estimated using Furnace $\# 8$ at $1260^{\circ} \mathrm{C}$. Aluminum oxide crystals formed in samples of this glass heat-treated at temperatures below $\mathrm{T}_{\mathrm{L}}$. The crystals were identified by the characteristic morphologies of the crystals formed below $T_{L}$ and match those observed in samples of $A C 2-02$, $\mathrm{AC} 2-11, \mathrm{AC} 2-14, \mathrm{AC} 2-16$, and $\mathrm{AC} 2-21$. Aluminum oxide crystals were observed by $\mathrm{OM}$ at $1249^{\circ} \mathrm{C}$ with no crystals observed at $1264^{\circ} \mathrm{C}$. A sample treated at $1202^{\circ} \mathrm{C}$ was scanned under XRD (Figure 28.1), which showed that RES crystals formed at $T$ significantly under $T_{L}$.

Six preliminary heat treatments were conducted from $1202^{\circ} \mathrm{C}$ to $1261^{\circ} \mathrm{C}$ with $\mathrm{Al}_{2} \mathrm{O}_{3}$ observed in all samples, except the sample heat treated at $1202^{\circ} \mathrm{C}$ in which a white, opaque layer was observed on the sample surface. Additional heat treatments were performed at $1242^{\circ} \mathrm{C}$ (Furnace \#3), $1255^{\circ} \mathrm{C}$ (Furnace \#12), and $1259^{\circ} \mathrm{C}$ (Furnace \#12). All three of these samples contained crystals.

Table 28.1. Heat-Treatment Summary for Determination of $T_{L}$ for AC2-28

\begin{tabular}{ccccccc}
\hline Crucible & Furnace & Date/Time IN & $\mathrm{T}\left({ }^{\circ} \mathrm{C}\right)$ & Date/Time OUT & Observations & Comments \\
\hline $\mathrm{M}$ & 8 & $3: 00 \mathrm{pm} \mathrm{05/17}$ & 1202 & $3: 15 \mathrm{pm} \mathrm{05/18}$ & Many crystals & Preliminary, XRD \\
28 & 3 & $4: 45 \mathrm{pm} \mathrm{06/08}$ & 1242 & $2: 45 \mathrm{pm} \mathrm{06/09}$ & Crystals throughout & different furnace \\
28 & 12 & $2: 17 \mathrm{pm} \mathrm{06/20}$ & 1259 & $1: 00 \mathrm{pm} \mathrm{06/21}$ & One crystal & different furnace \\
28 & 8 & $2: 00 \mathrm{pm} \mathrm{06/22}$ & 1249 & $12: 35 \mathrm{pm} \mathrm{06/23}$ & Crystals & $\mathrm{T}_{\mathrm{C}}$ \\
28 & 12 & $8: 45 \mathrm{am} \mathrm{07/04}$ & 1255 & $8: 44 \mathrm{am} \mathrm{07/05}$ & Crystals on bottom & different furnace \\
28 & 8 & $4: 00 \mathrm{pm} \mathrm{07/12}$ & 1264 & $2: 45 \mathrm{pm} \mathrm{07/13}$ & No crystals & $\mathrm{T}_{\mathrm{A}}$ \\
\hline
\end{tabular}




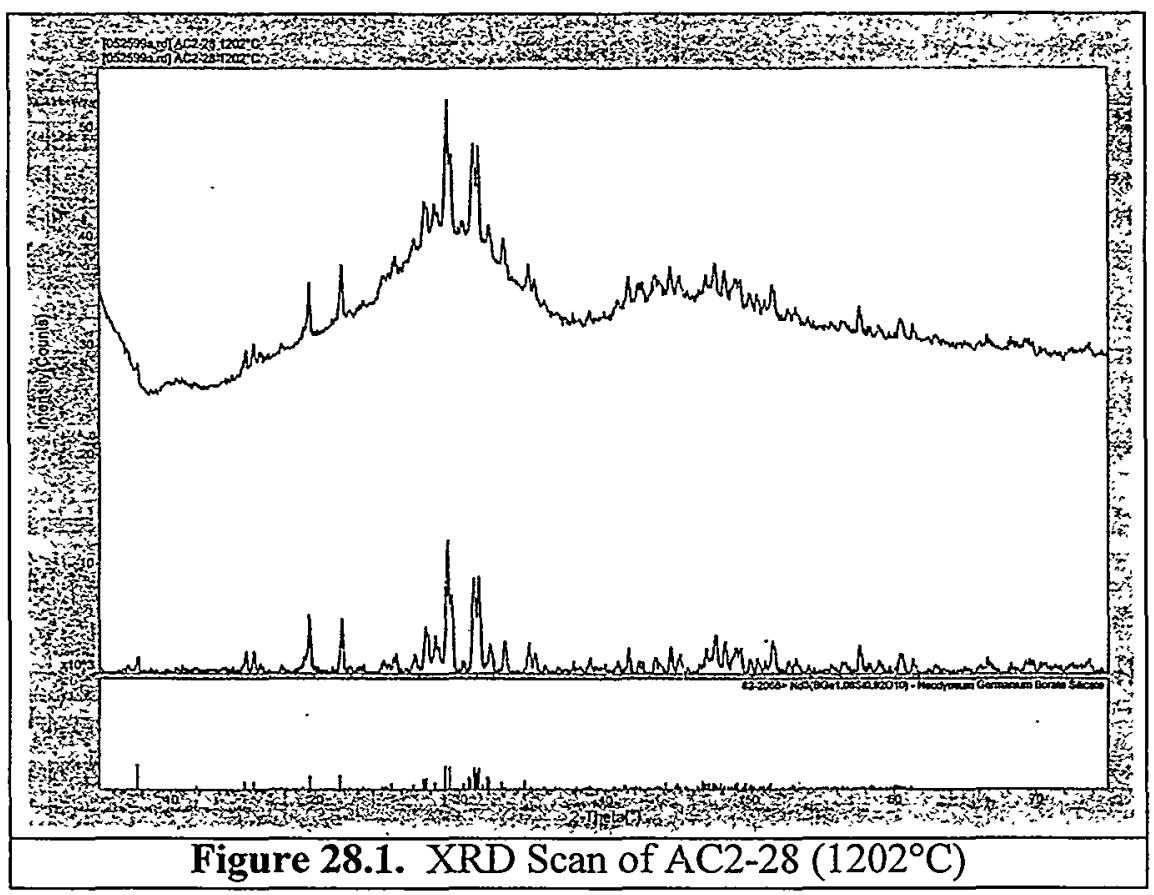

\subsection{Viscosity}

Table 28.2 lists the measured $\eta$-T values for AC2-28 in chronological order. These data are shown on an Arrhenius plot ( $\ln \eta$ vs. 1/T) in Figure 28.2. Five data points from Table 28.2 were excluded from calculations. One of these points, at $1404^{\circ} \mathrm{C}$, had a measured $\eta$ value below the instrument's range while four data points, at $1247^{\circ} \mathrm{C}, 1227^{\circ} \mathrm{C}, 1206^{\circ} \mathrm{C}$, and $1187^{\circ} \mathrm{C}$, were taken at $\mathrm{Ts}$ below $\mathrm{T}_{\mathrm{L}}$. The excluded data are plotted as open circles and listed in strike-through font. Equation (2) was fitted to the remaining. data, plotted as filled circles, to yield $\mathrm{E}$ and $\mathrm{F}$ values of -16.096 and $25843 \mathrm{~K}$, respectively. The data appear to be nonlinear. Therefore, a $\eta_{1350}$ value of $0.86 \mathrm{~Pa} \cdot \mathrm{s}$ was obtained by interpolation between the data points at $1335^{\circ} \mathrm{C}$ and $1383^{\circ} \mathrm{C}$ using Equation (2). 
Table 28.2. Viscosity-Temperature Data for $\mathrm{AC} 2-28$

\begin{tabular}{cccc}
\hline $\mathrm{T}\left({ }^{\circ} \mathrm{C}\right)$ & $\eta(\mathrm{Pa} \cdot \mathrm{s})$ & $10000 / \mathrm{T}\left(\mathrm{K}^{-1}\right)$ & $\ln [\eta(\mathrm{Pa} \cdot \mathrm{s})]$ \\
\hline 1383 & 0.593 & 6.039 & -0.522 \\
1335 & 1.028 & 6.219 & 0.028 \\
1286 & 1.512 & 6.414 & 0.413 \\
1334 & 1.040 & 6.223 & 0.039 \\
1384 & 0.601 & 6.035 & -0.509 \\
1404 & 0.487 & 5.963 & -0.720 \\
1384 & 0.601 & 6.035 & -0.509 \\
1266 & 2.034 & 6.498 & 0.710 \\
1247 & 2.788 & 6.579 & 1.025 \\
1227 & 3.876 & 6.667 & 1.355 \\
1206 & 5.391 & 6.761 & 1.685 \\
1187 & 7.793 & 6.849 & 2.053 \\
\hline
\end{tabular}

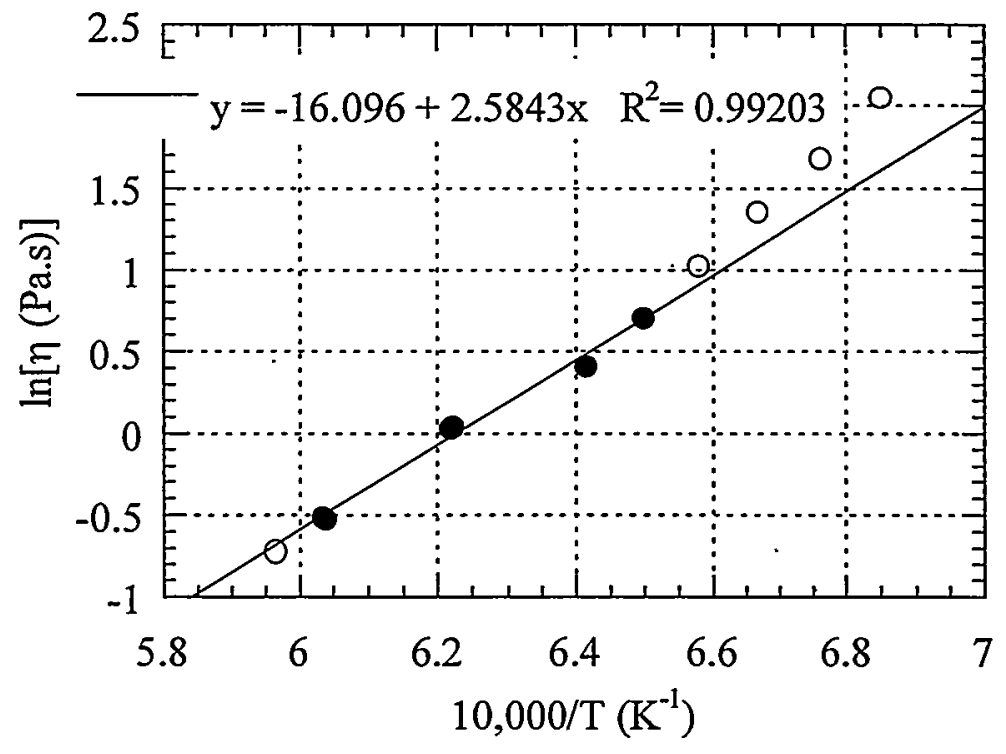

Figure 28.2. Measured ln Viscosity vs. $10000 / \mathrm{T}$ for $\mathrm{AC} 2-28$ 


\subsection{AC2-29}

Glass AC2-29 is an extreme vertex on the outer level of glass compositions. This glass targets 61.3 mass percent $\mathrm{Ln}_{2} \mathrm{O}_{3}$. The ratio of $\mathrm{B}_{2} \mathrm{O}_{3}$ to other frit components is higher in this glass than in the baseline frit. In other words, the relative concentrations of $\mathrm{SiO}_{2}, \mathrm{Al}_{2} \mathrm{O}_{3}, \mathrm{~B}_{2} \mathrm{O}_{3}$, and $\mathrm{SrO}$ are low, low, high, and low, respectively, in comparison to the standard frit composition.

\subsection{Liquidus Temperature}

Table 29.1 summarizes the final heat treatments performed on this glass. The $T_{L}$ of this glass was estimated using Furnace $\# 12$ at $1300^{\circ} \mathrm{C}$. One sample formed RES crystals in the corners of the crucible after a heat treatment at $1296^{\circ} \mathrm{C}$ while other samples, heat treated at $1306^{\circ} \mathrm{C}$ and above, did not contain crystals. RES crystals formed in samples of this glass heat treated at temperatures below $T_{L}$. These crystals were identified by the characteristic morphologies of the crystals formed below $\mathrm{T}_{\mathrm{L}}$. The morphologies matched those observed in samples of AC2-03, AC2-05, and other glasses that were shown by SEM and/or XRD to be RES crystals. During the $1296^{\circ} \mathrm{C}$ and $1287^{\circ} \mathrm{C}$ heat treatments, small nodules or buds of glass formed at the upper edge of the $\mathrm{Pt} / \mathrm{Rh}$ box folds.

Five preliminary heat treatments were performed between $1222^{\circ} \mathrm{C}$ and $1349^{\circ} \mathrm{C}$ at approximately $50^{\circ} \mathrm{C}$ intervals. Abundant crystals were observed at $1222^{\circ} \mathrm{C}$ and $1276^{\circ} \mathrm{C}$, which matches the observations from final heat treatments. A sample heat treated at $1322^{\circ} \mathrm{C}$ also contained crystals, but this did not match any of the other observations for this glass. Samples heat treated at $1327^{\circ} \mathrm{C}$ and $1349^{\circ} \mathrm{C}$ appeared to be crystal free by OM. An additional sample, heat treated at $1289^{\circ} \mathrm{C}$ in Furnace \#3, contained crystals.

Table 29.1. Heat-Treatment Summary for Determination of $\mathrm{T}_{\mathrm{L}}$ for AC2-29

\begin{tabular}{ccccccc}
\hline Crucible & Furnace & Date/Time IN & $\mathrm{T}\left({ }^{\circ} \mathrm{C}\right)$ & Date/Time OUT & Observations & Comments \\
\hline 29 & 12 & $6: 40 \mathrm{pm} \mathrm{06/06}$ & 1338 & $3: 30 \mathrm{pm} \mathrm{06/07}$ & No crystals & \\
29 & 12 & $1: 35 \mathrm{pm} \mathrm{06/19}$ & 1320 & $2: 09 \mathrm{pm} \mathrm{06/20}$ & No crystals & \\
29 & 12 & $3: 40 \mathrm{pm} \mathrm{06/21}$ & 1312 & $3: 30 \mathrm{pm} \mathrm{06/22}$ & No crystals & \\
29 & 12 & $3: 00 \mathrm{pm} \mathrm{06/25}$ & 1296 & $1: 20 \mathrm{pm} \mathrm{06/26}$ & crystals in corner & $\mathrm{T}_{\mathrm{C}}$, Buds \\
29 & 12 & $2: 00 \mathrm{pm} \mathrm{06/23}$ & 1306 & $3: 00 \mathrm{pm} \mathrm{06/24}$ & No crystals & $\mathrm{T}_{\mathrm{A}}$ \\
29 & 3 & $9: 30 \mathrm{am} \mathrm{07/01}$ & 1289 & $10: 45 \mathrm{am} \mathrm{07/02}$ & Crystals & different furnace \\
29 & 12 & $4: 03 \mathrm{pm} \mathrm{07/11}$ & 1288 & $2: 15 \mathrm{pm} \mathrm{07/12}$ & Crystals & Buds \\
\hline
\end{tabular}




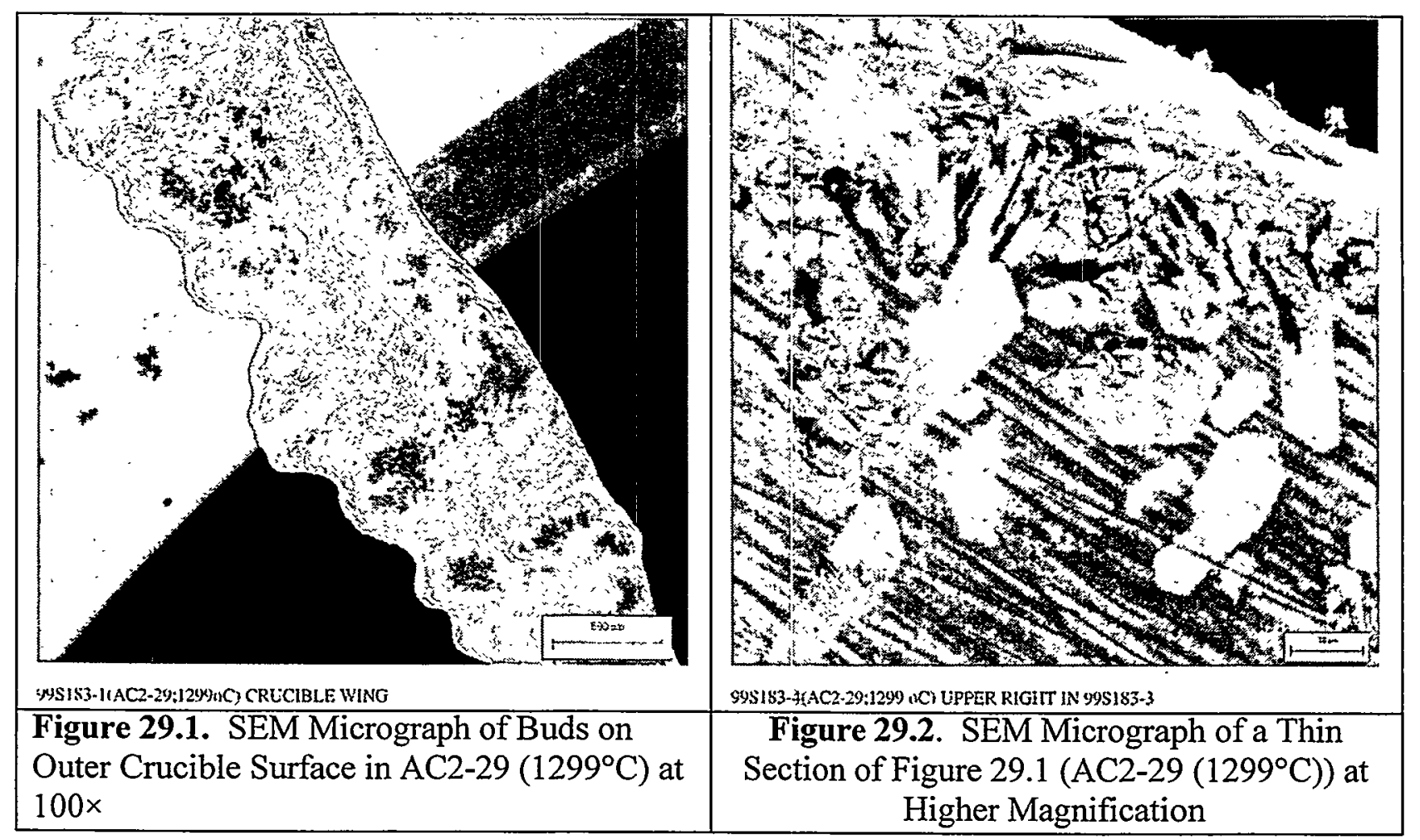

\subsection{Viscosity}

Table 29.2 lists the measured $\eta-T$ values for AC2-29 in chronological order. These data are shown on an Arrhenius plot ( $\ln \eta$ vs. 1/T) in Figure 29.3. Five data points from Table 29.2 were excluded from calculations. Four of these points, at $1383^{\circ} \mathrm{C}, 1403^{\circ} \mathrm{C}$, and $1384^{\circ} \mathrm{C}$, had measured $\eta$ values below the instrument's range while the other, at $1285^{\circ} \mathrm{C}$, was taken at a $\mathrm{T}$ below $T_{L}$. The excluded data are plotted as open circles and listed in strike-through font. Equation (2) was fitted to the remaining data, shown as solid circles, to yield $\mathrm{E}$ and $\mathrm{F}$ values of 16.871 and $26717 \mathrm{~K}$, respectively. This fit, which accurately portrays the data, was then used to calculate a $\eta_{1350}$ value of $0.66 \mathrm{~Pa} \cdot \mathrm{s}$.

Table 29.2. Viscosity-Temperature Data for AC2-29

\begin{tabular}{cccc}
\hline $\mathrm{T}\left({ }^{\circ} \mathrm{C}\right)$ & $\eta(\mathrm{Pa} \cdot \mathrm{s})$ & $10000 / \mathrm{T}\left(\mathrm{K}^{-1}\right)$ & $\ln [\eta(\mathrm{Pa} \cdot \mathrm{s})]$ \\
\hline 1383 & 0.459 & 6.039 & 0.778 \\
1403 & 0.337 & 5.967 & -1.088 \\
1384 & 0.424 & 6.035 & -0.858 \\
1364 & 0.571 & 6.109 & -0.561 \\
1345 & 0.711 & 6.180 & -0.341 \\
1325 & 0.856 & 6.258 & -0.156 \\
1305 & 1.059 & 6.337 & 0.057 \\
1285 & 1.602 & 6.418 & 0.471 \\
1384 & 0.413 & 6.035 & -0.885 \\
\hline
\end{tabular}




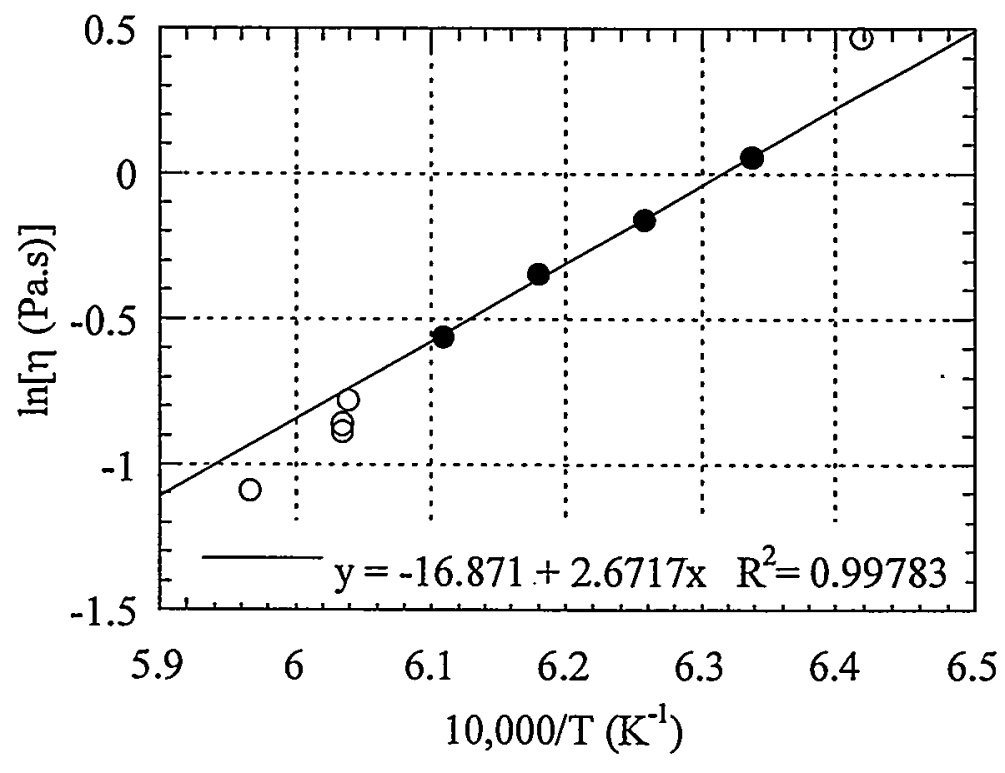

Figure 29.3. Measured ln Viscosity vs. 10000/T for AC2-29 


\subsection{AC2-30}

Glass AC2-30 is an extreme vertex on the outer level of glass compositions. This glass targets 49.4 mass percent $\mathrm{Ln}_{2} \mathrm{O}_{3}$. The ratio of $\mathrm{SrO}$ to other frit components is lower in this glass than in the baseline frit. In other words, the relative concentrations of $\mathrm{SiO}_{2}, \mathrm{Al}_{2} \mathrm{O}_{3}, \mathrm{~B}_{2} \mathrm{O}_{3}$, and $\mathrm{SrO}$ are same, same, same, and low, respectively, in comparison to the standard frit composition.

\subsection{Liquidus Temperature}

Table 30.1 summarizes the final heat treatments performed on this glass. The $T_{L}$ of this glass was estimated using Furnace $\# 3$ at $1227^{\circ} \mathrm{C}$ since only a few crystals formed in a sample heat treated at $1225^{\circ} \mathrm{C}$ while another sample formed no crystals after heat treatment at $1236^{\circ} \mathrm{C}$. RES crystals formed in samples of this glass heat treated at temperatures below $\mathrm{T}_{\mathrm{L}}$. These crystals were identified by the characteristic morphologies of the crystals formed below $T_{L}$. The morphologies matched those observed in samples of AC2-03, AC2-05, and other glasses that were shown by SEM and/or XRD to be RES crystals.

Six preliminary heat treatments were accomplished on this glass between $1201^{\circ} \mathrm{C}$ and $1274^{\circ} \mathrm{C}$. RES crystals were observed at $1201^{\circ} \mathrm{C}$ and $1222^{\circ} \mathrm{C}$ with no crystals observed in the four samples heat treated above $\mathrm{T}_{\mathrm{L}}: 1229^{\circ} \mathrm{C}, 1240^{\circ} \mathrm{C}, 1251^{\circ} \mathrm{C}$, and $1274^{\circ} \mathrm{C}$. Two additional samples, heat treated in Furnace $\# 12$ at $1227^{\circ} \mathrm{C}$ and $1225^{\circ} \mathrm{C}$, did not contain crystals.

Table 30.1. Heat-Treatment Summary for Determination of $T_{L}$ for AC2-30

\begin{tabular}{ccccccc}
\hline Crucible & Furnace & Date/Time IN & T $\left({ }^{\circ} \mathrm{C}\right)$ & Date/Time OUT & Observations & Comments \\
\hline 30 & 3 & $2: 30 \mathrm{pm} \mathrm{06/12}$ & 1215 & $3: 00 \mathrm{pm} \mathrm{06/13}$ & Very crystalline & \\
30 & 3 & $4: 30 \mathrm{pm} \mathrm{06/14}$ & 1236 & $3: 40 \mathrm{pm} \mathrm{06/15}$ & No crystals & $\mathrm{T}_{\mathrm{A}}$ \\
30 & 12 & $5: 00 \mathrm{pm} \mathrm{06/15}$ & 1227 & $3: 20 \mathrm{pm} \mathrm{06/16}$ & No crystals & different furnace \\
30 & 12 & $5: 00 \mathrm{pm} \mathrm{06/16}$ & 1225 & $3: 00 \mathrm{pm} \mathrm{06/17}$ & No crystals & different furnace \\
30 & 3 & $8: 48 \mathrm{am} \mathrm{07/05}$ & 1225 & $8: 49 \mathrm{am} \mathrm{07/06}$ & Few crystals & $\mathrm{T}_{\mathrm{C}}$ \\
\hline
\end{tabular}

\subsection{Viscosity}

Table 30.2 lists the measured $\eta-T$ values for $\mathrm{AC} 2-30$ in chronological order. These data are shown on an Arrhenius plot $(\ln \eta$ vs. 1/T) in Figure 30.1. Two data points from Table 30.2 were excluded from calculations. One of these points, at $1482^{\circ} \mathrm{C}$, had a measured $\eta$ value below the instrument's range while the other, at $1186^{\circ} \mathrm{C}$, was taken at a $\mathrm{T}$ below $\mathrm{T}_{\mathrm{L}}$. The excluded data are plotted as open circles and listed in strike-through font. Equation (2) was fitted to the remaining data, plotted as filled circles, to yield $\mathrm{E}$ and $\mathrm{F}$ values of -16.765 and $27877 \mathrm{~K}$, respectively. The data appear to be nonlinear. Therefore, a $\eta_{1350}$ value of $1.35 \mathrm{~Pa} \cdot \mathrm{s}$ was obtained by interpolation between the data points at $1334^{\circ} \mathrm{C}$ and $1383^{\circ} \mathrm{C}$ using Equation (2). 
Table 30.2. Viscosity-Temperature Data for $\mathrm{AC} 2-30$

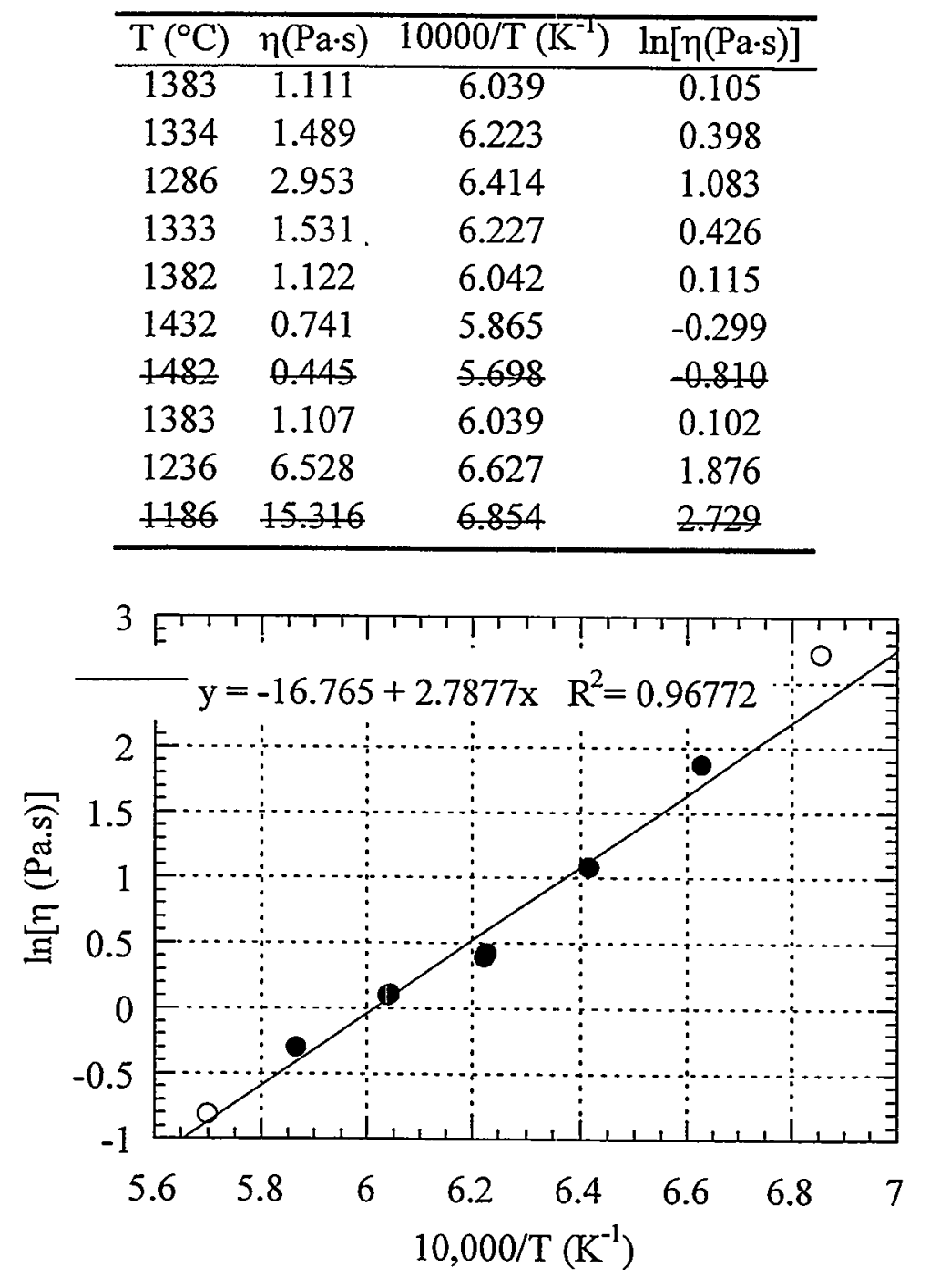

Figure 30.1. Measured ln Viscosity vs. $10000 / \mathrm{T}$ for $\mathrm{AC} 2-30$ 


\subsection{AC2-31.}

Glass AC2-31 is an extreme vertex on the outer level of glass compositions. This glass targets 56.7 mass percent $\mathrm{Ln}_{2} \mathrm{O}_{3}$. The ratios of $\mathrm{SiO}_{2}$ and $\mathrm{SrO}$ to other frit components are higher in this glass than in the baseline frit. In other words, the relative concentrations of $\mathrm{SiO}_{2}, \mathrm{Al}_{2} \mathrm{O}_{3}$, $\mathrm{B}_{2} \mathrm{O}_{3}$, and $\mathrm{SrO}$ are high, low, low, and high, respectively, in comparison to the standard frit composition.

\subsection{Liquidus Temperature}

Table 31.1 summarizes the heat treatments performed on this glass. The $T_{L}$ of this glass was estimated using Furnace $\# 12$ at $1305^{\circ} \mathrm{C}$. Gross crystallinity was observed in samples heattreated at $1296^{\circ} \mathrm{C}$ and $1301^{\circ} \mathrm{C}$ while a sample heat treated at $1306^{\circ} \mathrm{C}$ did not contain crystals. This indicated that gross crystallization occurred at temperatures slightly below $T_{L}$. RES crystals formed in samples of this glass heat treated at temperatures below $T_{L}$. These crystals were identified by the characteristic morphologies of the crystals formed below $T_{L}$. The morphologies matched those observed in samples of $\mathrm{AC} 2-03, \mathrm{AC} 2-05$, and other glasses that were shown by SEM and/or XRD to be RES crystals.

Six preliminary heat treatments were performed on this glass between $1222^{\circ} \mathrm{C}$ and $1322^{\circ} \mathrm{C}$ in $50^{\circ} \mathrm{C}$ intervals, followed by three heat treatments near $\mathrm{T}_{\mathrm{L}}$ at $1295^{\circ} \mathrm{C}, 1302^{\circ} \mathrm{C}$, and $1312^{\circ} \mathrm{C}$. An additional sample, heat treated in Furnace $\# 3$ at $1313^{\circ} \mathrm{C}$, did not contain crystals.

Table 31.1. Heat-Treatment Summary for Determination of $T_{L}$ for $A C 2-31$

\begin{tabular}{ccccccc}
\hline Crucible & Furnace & Date/Time IN & $\mathrm{T}\left({ }^{\circ} \mathrm{C}\right)$ & Date/Time OUT & Observations & Comments \\
\hline 31 & 3 & $3: 00 \mathrm{pm} \mathrm{06/18}$ & 1313 & $1: 30 \mathrm{pm} \mathrm{06/19}$ & No crystals & different furnace \\
31 & 12 & $3: 40 \mathrm{pm} \mathrm{06/21}$ & 1312 & $3: 30 \mathrm{pm} \mathrm{06/22}$ & No crystals & \\
31 & 12 & $2: 00 \mathrm{pm} \mathrm{06/23}$ & 1306 & $3: 00 \mathrm{pm} \mathrm{06/24}$ & No crystals & $\mathrm{T}_{\mathrm{A}}$ \\
31 & 12 & $3: 00 \mathrm{pm} \mathrm{06/25}$ & 1296 & $1: 20 \mathrm{pm} \mathrm{06/26}$ & Very crystalline & \\
31 & 12 & $8: 52 \mathrm{am} \mathrm{07/06}$ & 1301 & $10: 50 \mathrm{am} \mathrm{07/07}$ & Lots of crystals & $\mathrm{T}_{\mathrm{C}}$ \\
\hline
\end{tabular}

\subsection{Viscosity}

Table 31.2 lists the measured $\eta$-T values for $A C 2-31$ in chronological order. These data are shown on an Arrhenius plot $(\ln \eta$ vs. $1 / \mathrm{T})$ in Figure 31.1. A datum from Table 31.2, at $1483^{\circ} \mathrm{C}$, had a measured $\eta$ value below the instrument's range and was excluded from calculations. The excluded point is plotted as an open circle and listed in strike-through font. Equation (2) was fitted to the remaining data, plotted as filled circles, to yield $\mathrm{E}$ and $\mathrm{F}$ values of -13.314 and $22414 \mathrm{~K}$, respectively. The data appear to be nonlinear. Therefore, a $\eta_{1350}$ value of $1.49 \mathrm{~Pa} \cdot \mathrm{s}$ was obtained by interpolation between the data points at $1345^{\circ} \mathrm{C}$ and $1384^{\circ} \mathrm{C}$ using Equation (2). 
Table 31.2. Viscosity-Temperature Data for $\mathrm{AC} 2-31$

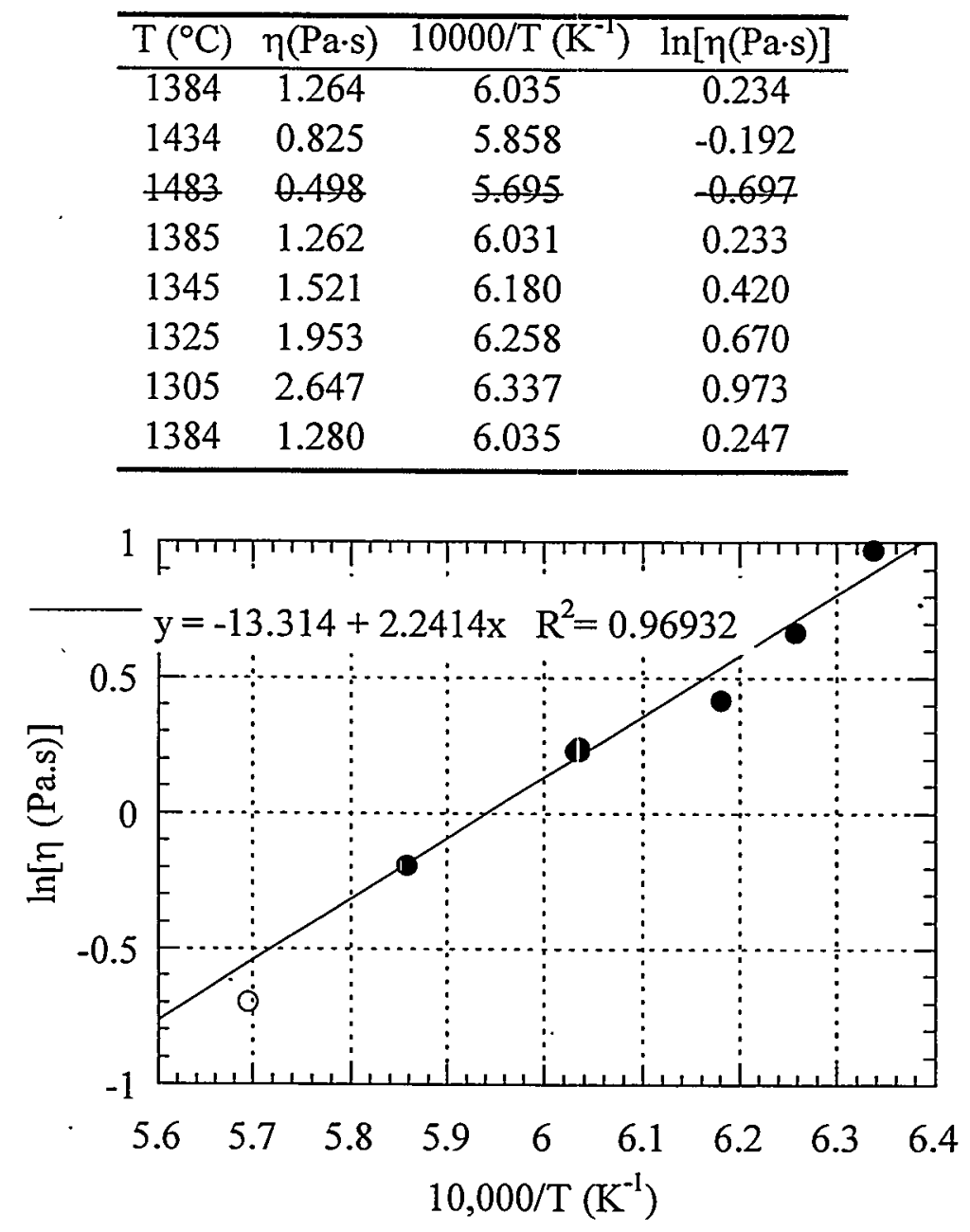

Figure 31.1. Measured ln Viscosity vs. 10000/T for AC2-31 
Glass AC2-32 is a centroid of the outer level of glass compositions. This glass targets 56.6 mass percent $\mathrm{Ln}_{2} \mathrm{O}_{3}$. The ratios of frit components, $\mathrm{SiO}_{2}, \mathrm{Al}_{2} \mathrm{O}_{3}, \mathrm{~B}_{2} \mathrm{O}_{3}$, and $\mathrm{SrO}$, are the same as those in the baseline frit.

\subsection{Liquidus Temperature}

Table 32.1 summarizes the heat treatments performed on this glass. The $T_{L}$ of this glass was estimated using Furnace $\# 12$ at $1264^{\circ} \mathrm{C}$. A sample heat treated at $1260^{\circ} \mathrm{C}$ contained crystals throughout while a sample heat treated at $1265^{\circ} \mathrm{C}$ appeared crystal free. This indicated that gross crystallization occurred at temperatures slightly below $T_{L}$. RES crystals formed in samples of this glass heat treated at temperatures below $\mathrm{T}_{\mathrm{L}}$. These crystals were identified by the characteristic morphologies of the crystals formed below $T_{\mathrm{L}}$. The morphologies matched those observed in samples of $\mathrm{AC} 2-03, \mathrm{AC} 2-05$, and other glasses that were shown by SEM and/or XRD to be RES crystals. During the $1265^{\circ} \mathrm{C}$ and $1273^{\circ} \mathrm{C}$ heat treatments, small nodules or buds of glass formed at the upper edge of the $\mathrm{Pt} / \mathrm{Rh}$ box folds.

Six preliminary heat treatments were performed between $1222^{\circ} \mathrm{C}$ and $1274^{\circ} \mathrm{C}$, with four of the heat treatments within $10^{\circ} \mathrm{C}$ of $T_{L}$.

Table 32.1. Heat-Treatment Summary for Determination of $T_{L}$ for AC2-32

\begin{tabular}{ccccccc}
\hline Crucible & Furnace & Date/Time IN & T $\left({ }^{\circ} \mathrm{C}\right)$ & Date/Time OUT & Observations & Comments \\
\hline 32 & 12 & $5: 00 \mathrm{pm} \mathrm{06/17}$ & 1260 & $3: 00 \mathrm{pm} \mathrm{06/18}$ & Crystals throughout & $\mathrm{T}_{\mathrm{C}}$ \\
32 & 8 & $3: 00 \mathrm{pm} \mathrm{06/25}$ & 1273 & $1: 25 \mathrm{pm} \mathrm{06/26}$ & No crystals & different furnace, Buds \\
32 & 12 & $2: 55 \mathrm{pm} \mathrm{06/27}$ & 1265 & $1: 00 \mathrm{pm} \mathrm{06/28}$ & No crystals & $\mathrm{T}_{\mathrm{A}, \text { Buds }}$ \\
\hline
\end{tabular}

\subsection{Viscosity}

Table 32.2 lists the measured $\eta-T$ values for $\mathrm{AC} 2-32$ in chronological order. These data are shown on an Arrhenius plot $(\ln \eta$ vs. $1 / \mathrm{T})$ in Figure 32.1. A datum from Table 32.2, at $1246^{\circ} \mathrm{C}$, was taken at a $\mathrm{T}$ below $\mathrm{T}_{\mathrm{L}}$ and was excluded from calculations. The excluded point was plotted as an open circle and listed in strike-through font. Equation (2) was fitted to the remaining data, plotted as filled circles, to yield $\mathrm{E}$ and $\mathrm{F}$ values of -15.834 and $25929 \mathrm{~K}$, respectively. The data appear to be nonlinear. Therefore, a $\eta_{1350}$ value of $1.18 \mathrm{~Pa} \cdot \mathrm{s}$ was obtained by interpolation between the data points at $1345^{\circ} \mathrm{C}$ and $1383^{\circ} \mathrm{C}$ using Equation (2). 
Table 32.2. Viscosity-Temperature Data for AC2-32

\begin{tabular}{cccc}
\hline $\mathrm{T}\left({ }^{\circ} \mathrm{C}\right)$ & $\eta(\mathrm{Pa} \cdot \mathrm{s})$ & $10000 / \mathrm{T}\left(\mathrm{K}^{-1}\right)$ & $\ln [\eta(\mathrm{Pa} \cdot \mathrm{s})]$ \\
\hline 1383 & 0.790 & 6.039 & -0.236 \\
1403 & 0.700 & 5.967 & -0.357 \\
1424 & 0.554 & 5.893 & -0.590 \\
1385 & 0.859 & 6.031 & -0.152 \\
1345 & 1.256 & 6.180 & 0.228 \\
1325 & 1.521 & 6.258 & 0.420 \\
1305 & 1.660 & 6.337 & 0.507 \\
1285 & 2.150 & 6.418 & 0.766 \\
1266 & 2.930 & 6.498 & 1.075 \\
1246 & 4.311 & 6.583 & 1.461 \\
1384 & 0.878 & 6.035 & -0.130 \\
\hline
\end{tabular}

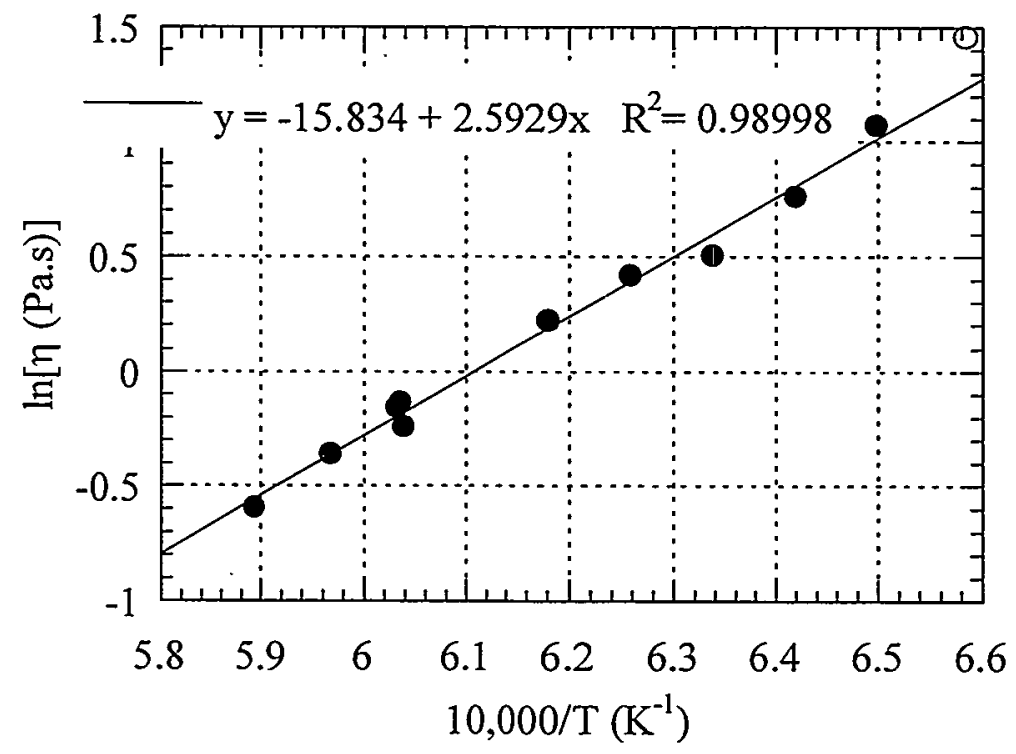

Figure 32.1. Measured ln Viscosity vs. $10000 / \mathrm{T}$ for $\mathrm{AC} 2-32$ 


\subsection{AC2-33}

Glass AC2-33 is an interior point of the designed glass-composition region. This glass targets 56.4 mass percent $\mathrm{Ln}_{2} \mathrm{O}_{3}$. The ratios of frit components, $\mathrm{SiO}_{2}, \mathrm{Al}_{2} \mathrm{O}_{3}, \mathrm{~B}_{2} \mathrm{O}_{3}$, and $\mathrm{SrO}$, are the same as those in the baseline frit.

\subsection{Liquidus Temperature}

Table 33.1 summarizes the heat treatments performed on this glass. The $T_{L}$ of this glass was estimated at $1271^{\circ} \mathrm{C}$ using Furnaces $\# 8$ and \#12. In Furnace \#12, a sample heat treated at $1265^{\circ} \mathrm{C}$ contained crystals throughout while a sample heat treated at $1274^{\circ} \mathrm{C}$ did not contain crystals. In Furnace \#8, a sample heat treated at $1264^{\circ} \mathrm{C}$ contained crystals while a sample heat treated at $1273^{\circ} \mathrm{C}$ did not. RES crystals formed in samples of this glass heat treated at temperatures below $T_{L}$. These crystals were identified by the characteristic morphologies of the crystals formed below $T_{L}$. The morphologies matched those observed in samples of AC2-03, AC2-05, and other glasses that were shown by SEM and/or XRD to be RES crystals. During the heat treatments in Furnace \#8, small nodules or buds of glass formed at the upper edge of the $\mathrm{Pt} / \mathrm{Rh}$ box folds.

Six preliminary heat treatments were done between $1215^{\circ} \mathrm{C}$ and $1303^{\circ} \mathrm{C}$ with four of the heat treatments near $\mathrm{T}_{\mathrm{L}}$.

Table 33.1. Heat-Treatment Summary for Determination of $T_{L}$ for AC2-33

\begin{tabular}{ccccccc}
\hline Crucible & Furnace & Date/Time IN & $\mathrm{T}\left({ }^{\circ} \mathrm{C}\right)$ & Date/Time OUT & Observations & Comments \\
\hline 33 & 12 & $5: 00 \mathrm{pm} \mathrm{06/17}$ & 1260 & $3: 00 \mathrm{pm} \mathrm{06/18}$ & Crystals throughout & \\
33 & 8 & $3: 00 \mathrm{pm} \mathrm{06/25}$ & 1273 & $1: 25 \mathrm{pm} \mathrm{06/26}$ & No crystals & $\mathrm{T}_{\mathrm{A}}-2$, Buds \\
33 & 12 & $2: 55 \mathrm{pm} \mathrm{06/27}$ & 1265 & $1: 00 \mathrm{pm} \mathrm{06/28}$ & Crystals throughout & $\mathrm{T}_{\mathrm{C}}-1$ \\
33 & 12 & $8: 50 \mathrm{am} 07 / 05$ & 1274 & $8: 51 \mathrm{am} 07 / 06$ & No crystals & $\mathrm{T}_{\mathrm{A}}-1$ \\
33 & 8 & $8: 52 \mathrm{am} \mathrm{07/05}$ & 1264 & $8: 50 \mathrm{am} 07 / 06$ & Some crystals & $\mathrm{T}_{\mathrm{C}}-2$, Buds \\
\hline
\end{tabular}

\subsection{Viscosity}

Table 33.2 lists the measured $\eta-T$ values for AC2-33 in chronological order. These data are shown on an Arrhenius plot ( $\ln \eta$ vs. 1/T) in Figure 33.1. Two data points from Table 33.2 were excluded from calculations. One of these points, at $1433^{\circ} \mathrm{C}$, had measured $\eta$ value below the instrument's range while the other, at $1237^{\circ} \mathrm{C}$, was taken at a $T$ below $T_{L}$. The excluded data are plotted as open circles and listed in strike-through font. Equation (2) was fitted to the remaining data, shown as solid circles, to yield $\mathrm{E}$ and $\mathrm{F}$ values of -14.740 and $24182 \mathrm{~K}$, respectively. This fit, which accurately portrays the data, was then used to calculate a $\eta_{1350}$ value of $1.17 \mathrm{~Pa} \cdot \mathrm{s}$. 
Table 33.2. Viscosity-Temperature Data for $\mathrm{AC} 2-33$

\begin{tabular}{cccc}
\hline $\mathrm{T}\left({ }^{\circ} \mathrm{C}\right)$ & $\eta(\mathrm{Pa} \cdot \mathrm{s})$ & $10000 / \mathrm{T}\left(\mathrm{K}^{-1}\right)$ & $\ln [\eta(\mathrm{Pa} \cdot \mathrm{s})]$ \\
\hline 1384 & 0.866 & 6.035 & -0.144 \\
1334 & 1.396 & 6.223 & 0.333 \\
1285 & 2.128 & 6.418 & 0.755 \\
1334 & 1.402 & 6.223 & 0.338 \\
1383 & 0.875 & 6.039 & -0.133 \\
1433 & 0.542 & 5.862 & -0.613 \\
1384 & 0.837 & 6.035 & -0.179 \\
1237 & 7.027 & 6.623 & 1.950 \\
\hline
\end{tabular}

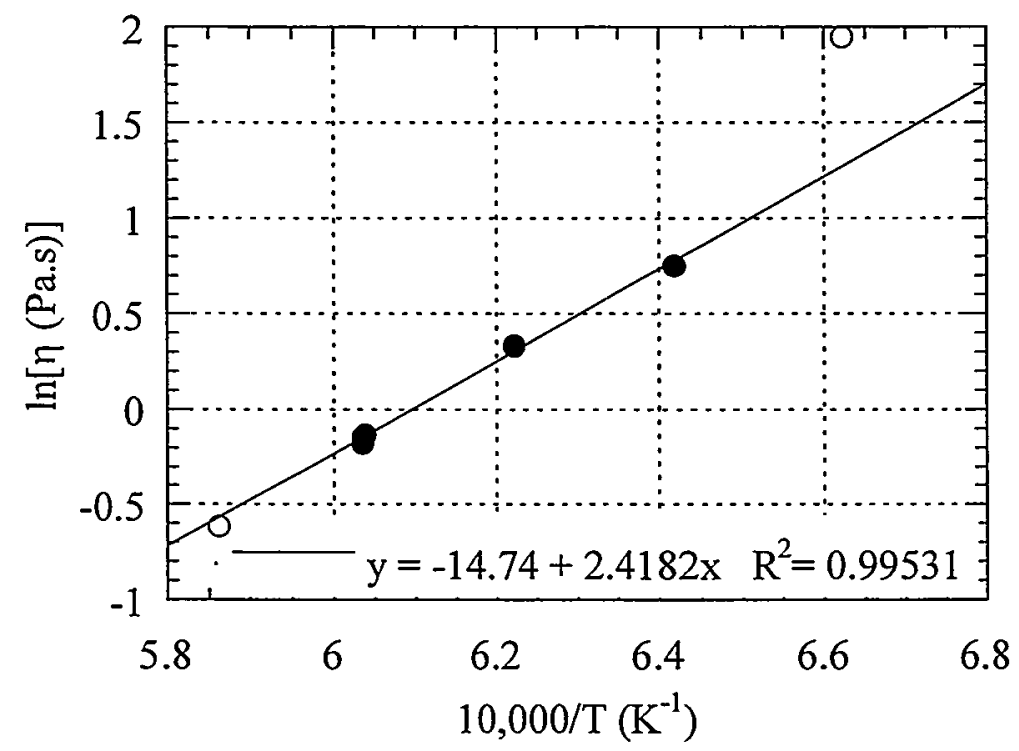

Figure 33.1. Measured ln Viscosity vs. $10000 / \mathrm{T}$ for $\mathrm{AC} 2-33$ 


\subsection{AC2-34}

Glass $\mathrm{AC} 2-34$ is an interior point of the designed glass-composition region. This glass targets 57.2 mass percent $\mathrm{Ln}_{2} \mathrm{O}_{3}$. The ratios of frit components, $\mathrm{SiO}_{2}, \mathrm{Al}_{2} \mathrm{O}_{3}, \mathrm{~B}_{2} \mathrm{O}_{3}$, and $\mathrm{SrO}$, are the same as those in the baseline frit.

\subsection{Liquidus Temperature}

Four final heat treatments of AC2-34 glass were performed in Furnace \#3 between $1215^{\circ} \mathrm{C}$ and $1236^{\circ} \mathrm{C}$ (see Table 34.1 ). The sample at $1225^{\circ} \mathrm{C}$ had needle-like crystals present, while the sample at $1235^{\circ} \mathrm{C}$ appeared to be crystal free by $\mathrm{OM}$; therefore, $\mathrm{T}_{\mathrm{L}}$ was estimated at $1232^{\circ} \mathrm{C}$. A sample heat treated at $1236^{\circ} \mathrm{C}$ had a few dissolving, rounded RES crystals at some of the corners. This sample did not fit with the other heat-treatment measurements performed near $\mathrm{T}_{\mathrm{L}}$ and was probably affected by inhomogeneity in the glass, volitilization, or impurities from another source. RES crystals formed in samples of this glass heat treated at temperatures below $T_{L}$. These crystals were identified by the characteristic morphologies of the crystals formed below $\mathrm{T}_{\mathrm{L}}$. The morphologies matched those observed in samples of AC2-03, AC2-05, and other glasses that were shown by SEM and/or XRD to be RES crystals.

Six preliminary heat treatments were performed at $1198^{\circ} \mathrm{C}, 1212^{\circ} \mathrm{C}, 1220^{\circ} \mathrm{C}, 1222^{\circ} \mathrm{C}$, $1223^{\circ} \mathrm{C}$, and $1233^{\circ} \mathrm{C}$. Additional heat treatments were performed in Furnace $\# 12$ at $1225^{\circ} \mathrm{C}$ and $1227^{\circ} \mathrm{C}$; neither sample contained crystals.

Table 34.1. Heat-Treatment Summary for Determination of $\mathrm{T}_{\mathrm{L}}$ for $\mathrm{AC} 2-34$

\begin{tabular}{ccccccc}
\hline Crucible & Furnace & Date/Time IN & T $\left({ }^{\circ} \mathrm{C}\right)$ & Date/Time OUT & Observations & Comments \\
\hline 34 & 3 & $2: 30 \mathrm{pm} \mathrm{06/12}$ & 1215 & $3: 00 \mathrm{pm} \mathrm{06/13}$ & very crystalline & \\
34 & 3 & $4: 30 \mathrm{pm} \mathrm{06/14}$ & 1236 & $3: 40 \mathrm{pm} \mathrm{06/15}$ & few crystals & \\
34 & 12 & $5: 00 \mathrm{pm} \mathrm{06/15}$ & 1227 & $3: 20 \mathrm{pm} \mathrm{06/16}$ & no crystals & different furnace \\
34 & 12 & $5: 00 \mathrm{pm} \mathrm{06/16}$ & 1225 & $3: 00 \mathrm{pm} \mathrm{06/17}$ & no crystals & different furnace \\
34 & 3 & $8: 48 \mathrm{am} \mathrm{07/05}$ & 1225 & $8: 49 \mathrm{am} \mathrm{07/06}$ & crystals throughout & $\mathrm{T}_{\mathrm{C}}$ \\
34 & 3 & $4: 17 \mathrm{pm} \mathrm{07/19}$ & 1235 & $3: 10 \mathrm{pm} \mathrm{07/20}$ & no crystals & $\mathrm{T}_{\mathrm{A}}$ \\
\hline
\end{tabular}

\subsection{Viscosity}

Table 34.2 lists the measured $\eta-T$ values for $\mathrm{AC} 2-34$ in chronological order. These data are shown on an Arrhenius plot (ln $\eta$ vs. $1 / \mathrm{T}$ ) in Figure 34.1 . With a $\mathrm{T}_{\mathrm{L}}$ of $1232^{\circ} \mathrm{C}$, all the data in Table 34.2 are valid for calculations. Equation (2) was fitted to the remaining data, plotted as filled circles, to yield $E$ and $F$ values of -14.092 and $23418 \mathrm{~K}$, respectively. The data appear to be nonlinear. Therefore, a $\eta_{1350}$ value of $1.44 \mathrm{~Pa} \cdot \mathrm{s}$ was obtained by interpolation between the data points at $1345^{\circ} \mathrm{C}$ and $1365^{\circ} \mathrm{C}$ using Equation (2). 
Table 34.2. Viscosity-Temperature Data for AC2-34

\begin{tabular}{cccc}
\hline $\mathrm{T}\left({ }^{\circ} \mathrm{C}\right)$ & $\eta(\mathrm{Pa} \cdot \mathrm{s})$ & $10000 / \mathrm{T}\left(\mathrm{K}^{-1}\right)$ & $\ln [\eta(\mathrm{Pa} \cdot \mathrm{s})]$ \\
\hline 1384 & 1.061 & 6.035 & 0.059 \\
1434 & 0.679 & 5.858 & -0.388 \\
1385 & 1.046 & 6.031 & 0.045 \\
1365 & 1.286 & 6.105 & 0.252 \\
1345 & 1.494 & 6.180 & 0.402 \\
1325 & 1.547 & 6.258 & 0.437 \\
1305 & 2.044 & 6.337 & 0.715 \\
1285 & 2.759 & 6.418 & 1.015 \\
1384 & 1.041 & 6.035 & 0.040 \\
\hline
\end{tabular}

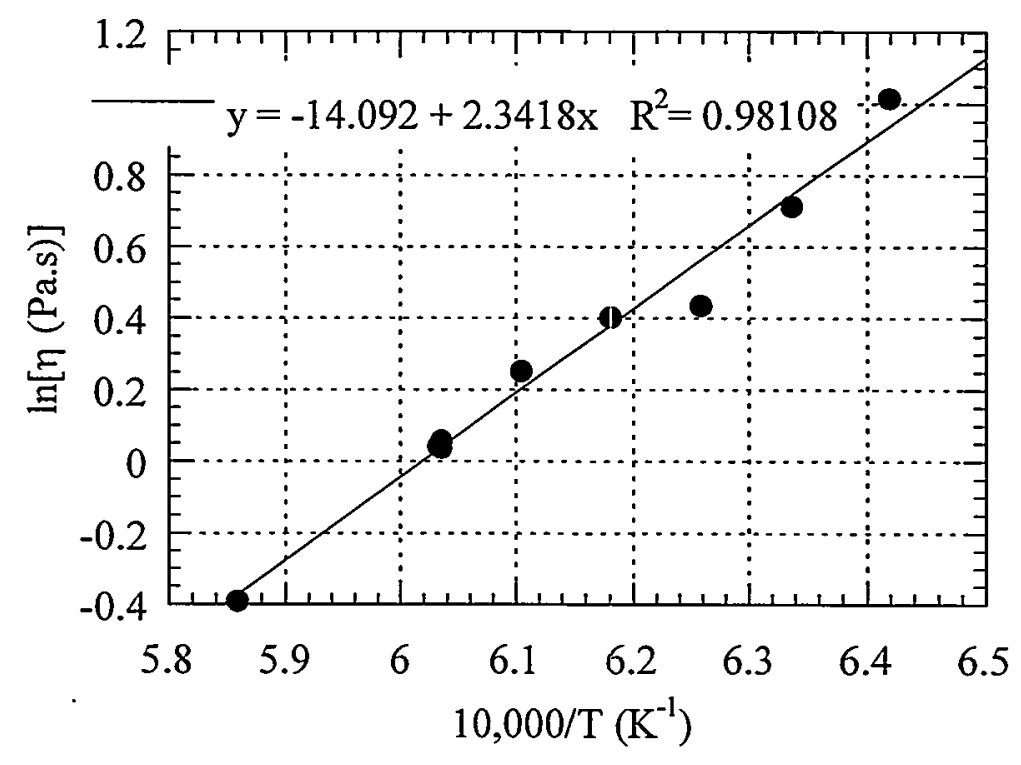

Figure 34.1. Measured ln Viscosity vs. $10000 / \mathrm{T}$ for $\mathrm{AC} 2-34$ 


\section{$35.0 \quad$ AC2-35}

Glass $\mathrm{AC} 2-35$ is an interior point of the designed glass-composition region. This glass targets 57.9 mass percent $\mathrm{Ln}_{2} \mathrm{O}_{3}$. The ratios of frit components, $\mathrm{SiO}_{2}, \mathrm{Al}_{2} \mathrm{O}_{3}, \mathrm{~B}_{2} \mathrm{O}_{3}$, and $\mathrm{SrO}$, are the same as those in the baseline frit.

\subsection{Liquidus Temperature}

Table 35.1 summarizes the heat treatments performed on this glass in Furnace \#3. The $\mathrm{T}_{\mathrm{L}}$ of this glass was estimated at $1287^{\circ} \mathrm{C}$ since one sample appeared to be crystal free after a heat treatment at $1289^{\circ} \mathrm{C}$, and a second sample formed crystals during a heat treatment at $1284^{\circ} \mathrm{C}$. RES crystals formed in samples of this glass heat treated at temperatures below $T_{L}$. These crystals were identified by the characteristic morphology of the crystal as seen in Figure 35.1 and by SEM/EDS. Figure 35.2 shows the EDS spectrum of a crystal observed in the $1284^{\circ} \mathrm{C}$ heattreated sample. The crystal appears to be composed of $\mathrm{Ln}_{2} \mathrm{O}_{3}$ and $\mathrm{SiO}_{2}$.

Three preliminary heat treatments were performed at $1223^{\circ} \mathrm{C}, 1278^{\circ} \mathrm{C}$, and $1288^{\circ} \mathrm{C}$.

Table 35.1. Heat-Treatment Summary for Determination of $T_{L}$ for AC2-35

\begin{tabular}{ccccccc}
\hline Crucible & Furnace & Date/Time IN & $\mathrm{T}\left({ }^{\circ} \mathrm{C}\right)$ & Date/Time OUT & Observations & Comments \\
\hline 35 & 3 & $3: 00 \mathrm{pm} \mathrm{06/13}$ & 1278 & $3: 30 \mathrm{pm} \mathrm{06/14}$ & Crystals & \\
35 & 3 & $5: 00 \mathrm{pm} \mathrm{06/15}$ & 1292 & $3: 20 \mathrm{pm} \mathrm{06/16}$ & No crystals & \\
35 & 3 & $5: 00 \mathrm{pm} \mathrm{06/16}$ & 1284 & $3: 00 \mathrm{pm} \mathrm{06/17}$ & Crystals & $\mathrm{T}_{\mathrm{C}}, \mathrm{SEM}$ \\
35 & 3 & $9: 30 \mathrm{am} \mathrm{07/01}$ & 1289 & $10: 45 \mathrm{am} \mathrm{07/02}$ & No crystals & $\mathrm{T}_{\mathrm{A}}$ \\
\hline
\end{tabular}




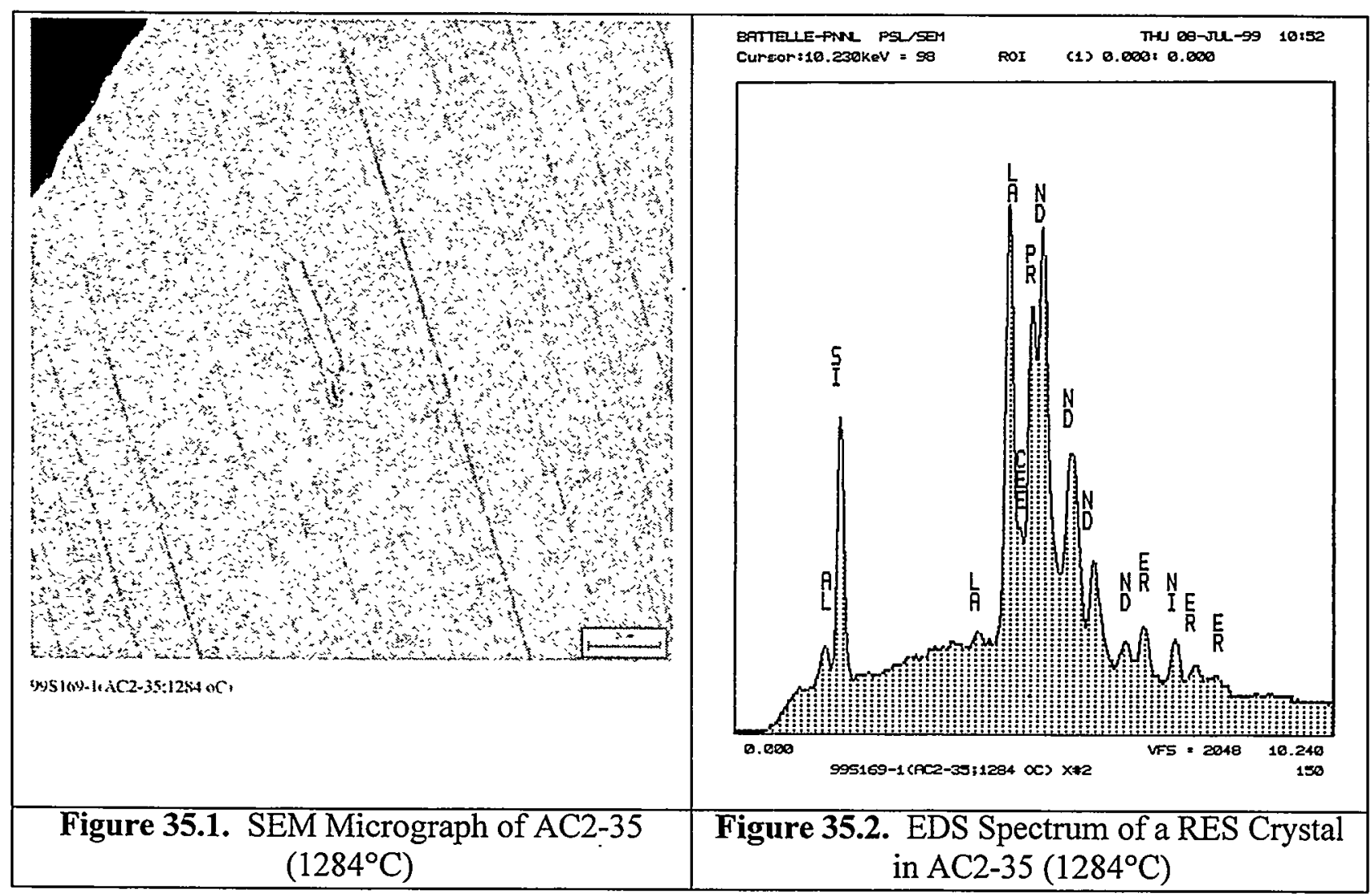

\subsection{Viscosity}

Table 35.2 lists the measured $\eta-T$ values for AC2-35 in chronological order. These data are shown on an Arrhenius plot ( $\ln \eta$ vs. 1/T) in Figure 35.3. Two data points from Table 35.2 were excluded from calculations. One of these points, at $1432^{\circ} \mathrm{C}$, had measured $\eta$ values below the instrument's range while the other, at $1285^{\circ} \mathrm{C}$, was taken at a $\mathrm{T}$ below $\mathrm{T}_{\mathrm{L}}$. The excluded data are plotted as open circles and listed in strike-through font. Equation (2) was fitted to the remaining data, plotted as filled circles, to yield $E$ and $F$ values of -15.684 and $25573 \mathrm{~K}$, respectively. This fit, based on five data points at effectively two temperatures $\left(1382.5 \pm 0.5^{\circ} \mathrm{C}\right.$ and $1333^{\circ} \mathrm{C}$ ), was then used to calculate a $\eta_{1350}$ value of $1.08 \mathrm{~Pa} \cdot \mathrm{s}$.

Table 35.2. Viscosity-Temperature Data for $\mathrm{AC} 2-35$

\begin{tabular}{cccc}
\hline $\mathrm{T}\left({ }^{\circ} \mathrm{C}\right)$ & $\eta(\mathrm{Pa} \cdot \mathrm{s})$ & $10000 / \mathrm{T}\left(\mathrm{K}^{-1}\right)$ & $\ln [\eta(\mathrm{Pa} \cdot \mathrm{s})]$ \\
\hline 1382 & 0.777 & 6.042 & -0.252 \\
1333 & 1.275 & 6.227 & 0.243 \\
1285 & 1.915 & 6.418 & 0.650 \\
1333 & 1.267 & 6.227 & 0.237 \\
1383 & 0.791 & 6.039 & -0.234 \\
1432 & 0.459 & 5.865 & -0.778 \\
1383 & 0.796 & 6.039 & -0.228 \\
\hline
\end{tabular}




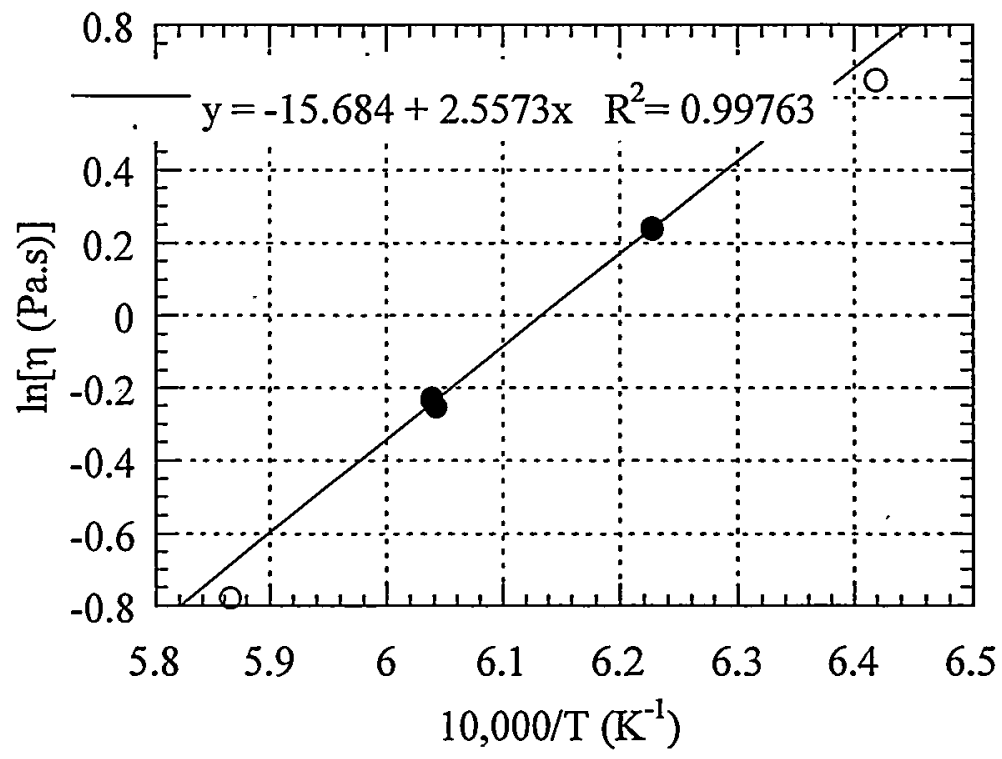

Figure 35.3. Measured ln Viscosity vs. 10000/T for AC2-35 


\subsection{AC2-36}

Glass AC2-36 is an interior point of the designed glass-composition region. This glass targets 58.7 mass percent $\mathrm{Ln}_{2} \mathrm{O}_{3}$. The ratios of frit components, $\mathrm{SiO}_{2}, \mathrm{Al}_{2} \mathrm{O}_{3}, \mathrm{~B}_{2} \mathrm{O}_{3}$, and $\mathrm{SrO}$, are the same as those in the baseline frit.

\subsection{Liquidus Temperature}

Table 36.1 summarizes the final heat treatments performed on this glass. The $T_{L}$ of this glass was estimated using Furnace $\# 8$ at $1294^{\circ} \mathrm{C}$. A sample heat treated at $1289^{\circ} \mathrm{C}$ contained crystals while a sample heat treated at $1295^{\circ} \mathrm{C}$ did not. RES crystals formed in samples of this glass heat treated at temperatures below $T_{L}$. These crystals were identified by SEM/EDS analyses performed on a sample heat treated at $1278^{\circ} \mathrm{C}$ (Figure 36.1 and Figure 36.2 ) and by the characteristic morphologies of the crystals formed below $\mathrm{T}_{\mathrm{L}}$ (Figure 36.3). The morphologies matched those observed in samples of $\mathrm{AC} 2-03, \mathrm{AC2}-05$, and other glasses that were shown by SEM and/or XRD to be RES crystals. During the $1286^{\circ} \mathrm{C}$ heat treatment, small nodules or buds of glass formed at the upper edge of the $\mathrm{Pt} / \mathrm{Rh}$ box folds.

Eight preliminary heat treatments were accomplished at temperatures between $1223^{\circ} \mathrm{C}$ and $1349^{\circ} \mathrm{C}$, and most of the samples measured near $\mathrm{T}_{\mathrm{L}}$. Two samples, heat treated in Furnace \#12 above $T_{L}$, did not form crystals.

Table 36.1. Heat-Treatment Summary for Determination of $\mathrm{T}_{\mathrm{L}}$ for AC2-36

\begin{tabular}{ccccccc}
\hline Crucible & Furnace & Date/Time IN & $\mathrm{T}\left({ }^{\circ} \mathrm{C}\right)$ & Date/Time OUT & Observations & Comments \\
\hline 36 & 12 & $4: 40 \mathrm{pm} \mathrm{06/05}$ & 1349 & $5: 55 \mathrm{pm} \mathrm{06/06}$ & No crystals & different furnace \\
36 & 12 & $6: 40 \mathrm{pm} \mathrm{0606}$ & 1338 & $3: 30 \mathrm{pm} \mathrm{06/07}$ & No crystals & different furnace \\
36 & 3 & $5: 00 \mathrm{pm} \mathrm{06/17}$ & 1302 & $3: 00 \mathrm{pm} \mathrm{06/18}$ & No crystals & \\
36 & 8 & $5: 00 \mathrm{pm} \mathrm{06/24}$ & 1286 & $3: 00 \mathrm{pm} \mathrm{06/25}$ & Crystals & different furnace, Buds \\
36 & 3 & $2: 56 \mathrm{pm} \mathrm{06/27}$ & 1295 & $1: 00 \mathrm{pm} \mathrm{06/28}$ & No crystals & $\mathrm{T}_{\mathrm{A}}$ \\
36 & 3 & $9: 30 \mathrm{am} \mathrm{07/01}$ & 1289 & $10: 45 \mathrm{am} \mathrm{07/02}$ & Crystals & $\mathrm{T}_{\mathrm{C}}$ \\
\hline
\end{tabular}



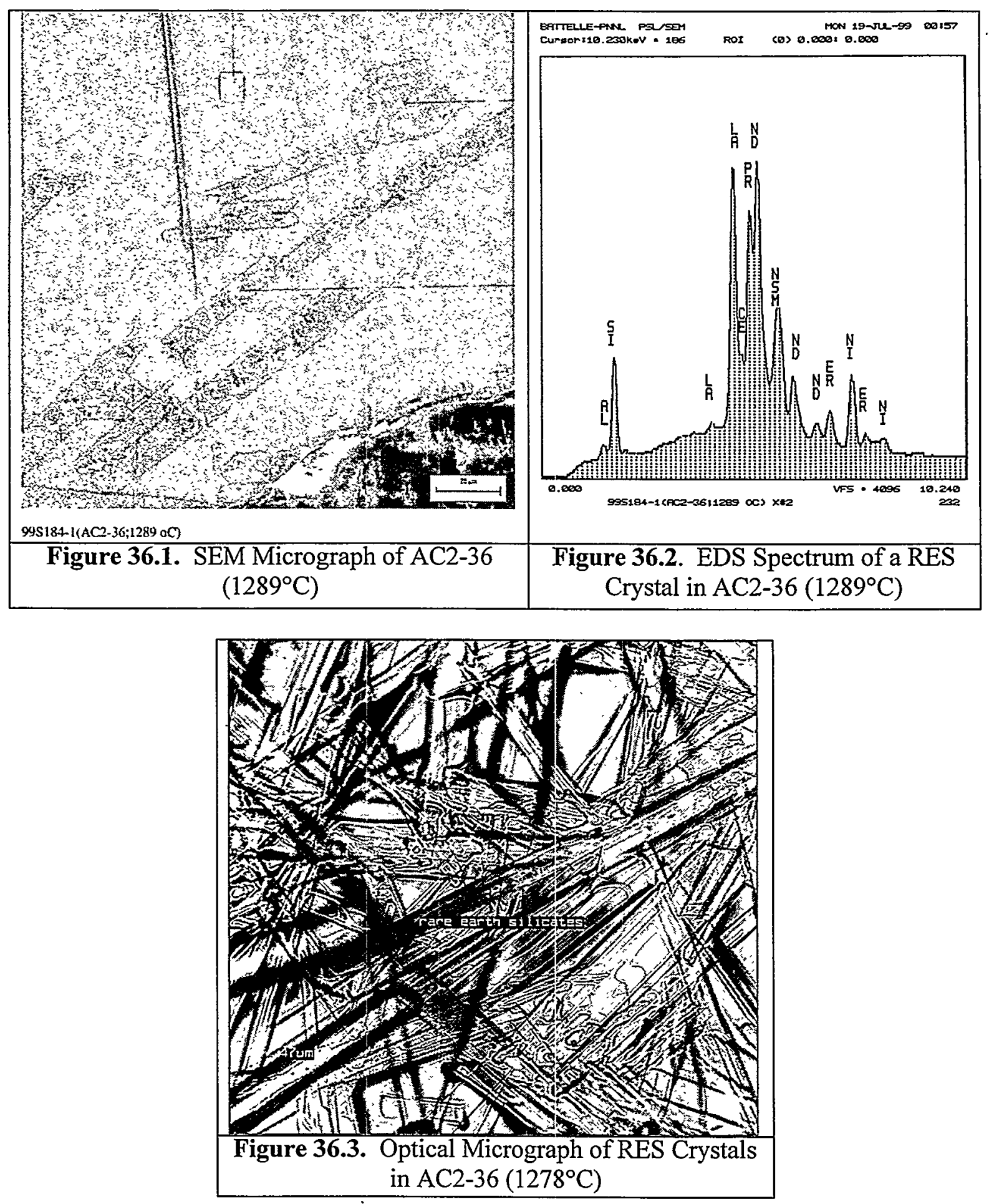

\subsection{Viscosity}

Table 36.2 lists the measured $\eta-T$ values for AC2-36 in chronological order. These data are shown on an Arrhenius plot ( $\ln \eta$ vs. 1/T) in Figure 36.4. Two data points from Table 36.2 were excluded from calculations. One of these points, at $1433^{\circ} \mathrm{C}$, had measured $\eta$ value below 
the instrument's range while the other, at $1286^{\circ} \mathrm{C}$, was taken at a $\mathrm{T}$ below $\mathrm{T}_{\mathrm{L}}$. The excluded data are plotted as open circles and listed in strike-through font. Equation (2) was fitted to the remaining data, shown as solid circles, to yield $E$ and $F$ values of -15.187 and $24702 \mathrm{~K}$, respectively. This fit, which accurately portrays the data, was then used to calculate a $\eta_{1350}$ value of $1.03 \mathrm{~Pa} \cdot \mathrm{s}$.

Table 36.2. Viscosity-Temperature Data for $\mathrm{AC} 2-36$

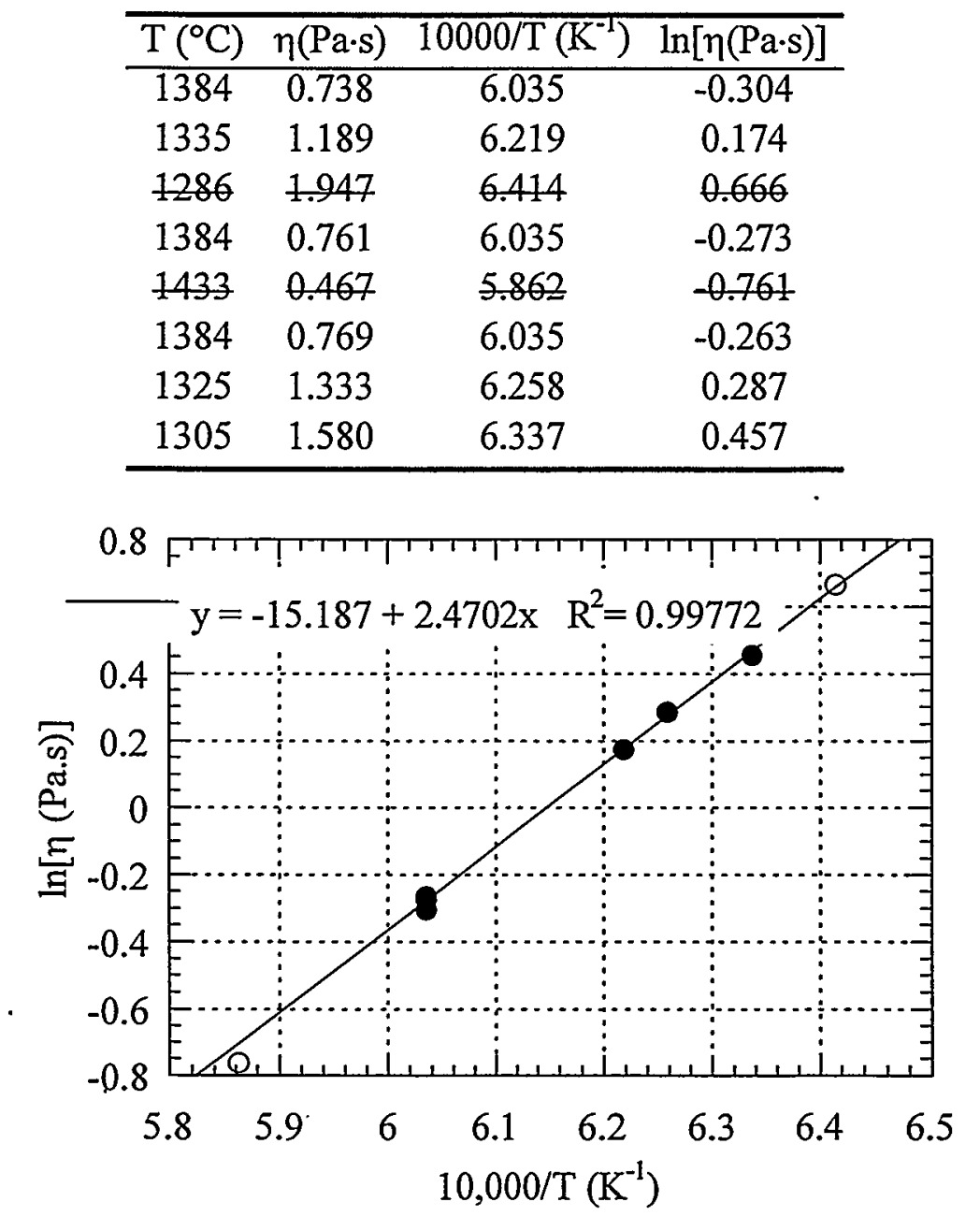

Figure 36.4. Measured ln Viscosity vs. 10000/T for AC2-36 
A. 112 


\subsection{AC2-37}

Glass AC2-37 is an interior point of the designed glass-composition region. This glass targets 59.4 mass percent $\mathrm{Ln}_{2} \mathrm{O}_{3}$. The ratios of frit components, $\mathrm{SiO}_{2}, \mathrm{Al}_{2} \mathrm{O}_{3}, \mathrm{~B}_{2} \mathrm{O}_{3}$, and $\mathrm{SrO}$, are the same as those in the baseline frit.

\subsection{Liquidus Temperature}

Table 37.1 summarizes the final heat treatments performed on this glass. The $T_{L}$ of this glass was estimated at $1305^{\circ} \mathrm{C}$ using Furnace \#3. One sample appeared to be crystal free after a heat treatment at $1307^{\circ} \mathrm{C}$, and a second sample formed crystals during a heat treatment at $1302^{\circ} \mathrm{C}$. RES crystals formed in samples of this glass heat treated at temperatures below $T_{L}$. These crystals were of a similar morphology to those seen in previous glasses; however, the ends of the crystals were "frizzed" as seen in Figure 37.1 and Figure 37.3. Figure 37.2 and Figure 37.4 confirm, by EDS spectra, that the crystals observed in the $1292^{\circ} \mathrm{C}$ and $1302^{\circ} \mathrm{C}$ heat-treated samples were RES.

Six preliminary heat treatments were performed at temperatures between $1223^{\circ} \mathrm{C}$ and $1339^{\circ} \mathrm{C}$. The sample heat treated in Furnace $\# 8$ at $1292^{\circ} \mathrm{C}$ was used for SEM/EDS analysis since it had some unusual crystalline characteristics (heavily crystallized, very large needle-shaped crystals, and voids in some of the crystals). Two samples were heat treated in Furnace \#12 at $1306^{\circ} \mathrm{C}$ and $1312^{\circ} \mathrm{C}$; both were free of crystals.

Table 37.1. Heat-Treatment Summary for Determination of $T_{L}$ for AC2-37

\begin{tabular}{ccccccc}
\hline Crucible & Furnace & Date/Time IN & $\mathrm{T}\left({ }^{\circ} \mathrm{C}\right)$ & Date/Time OUT & Observations & Comments \\
\hline 37 & 3 & $5: 00 \mathrm{pm} \mathrm{06/17}$ & 1302 & $3: 00 \mathrm{pm} \mathrm{06/18}$ & Crystals throughout & $\mathrm{T}_{\mathrm{C}}, \mathrm{SEM}$ \\
37 & 12 & $3: 40 \mathrm{pm} \mathrm{06/21}$ & 1312 & $3: 30 \mathrm{pm} \mathrm{06/22}$ & No crystals & different furnace \\
37 & 12 & $2: 00 \mathrm{pm} \mathrm{06/23}$ & 1306 & $3: 00 \mathrm{pm} \mathrm{06/24}$ & No crystals & different furnace \\
37 & 3 & $9: 30 \mathrm{am} \mathrm{07/01}$ & 1289 & $10: 45 \mathrm{am} \mathrm{07/02}$ & Very crystalline & \\
$\mathrm{A}$ & 8 & $2: 30 \mathrm{pm} \mathrm{05/27}$ & 1292 & $2: 40 \mathrm{pm} \mathrm{05/28}$ & Very crystalline & different furnace, SEM \\
37 & 3 & $1: 15 \mathrm{pm} \mathrm{07/08}$ & 1307 & $11: 15 \mathrm{am} \mathrm{07/09}$ & No crystals & $\mathrm{T}_{\mathrm{A}}$ \\
\hline
\end{tabular}



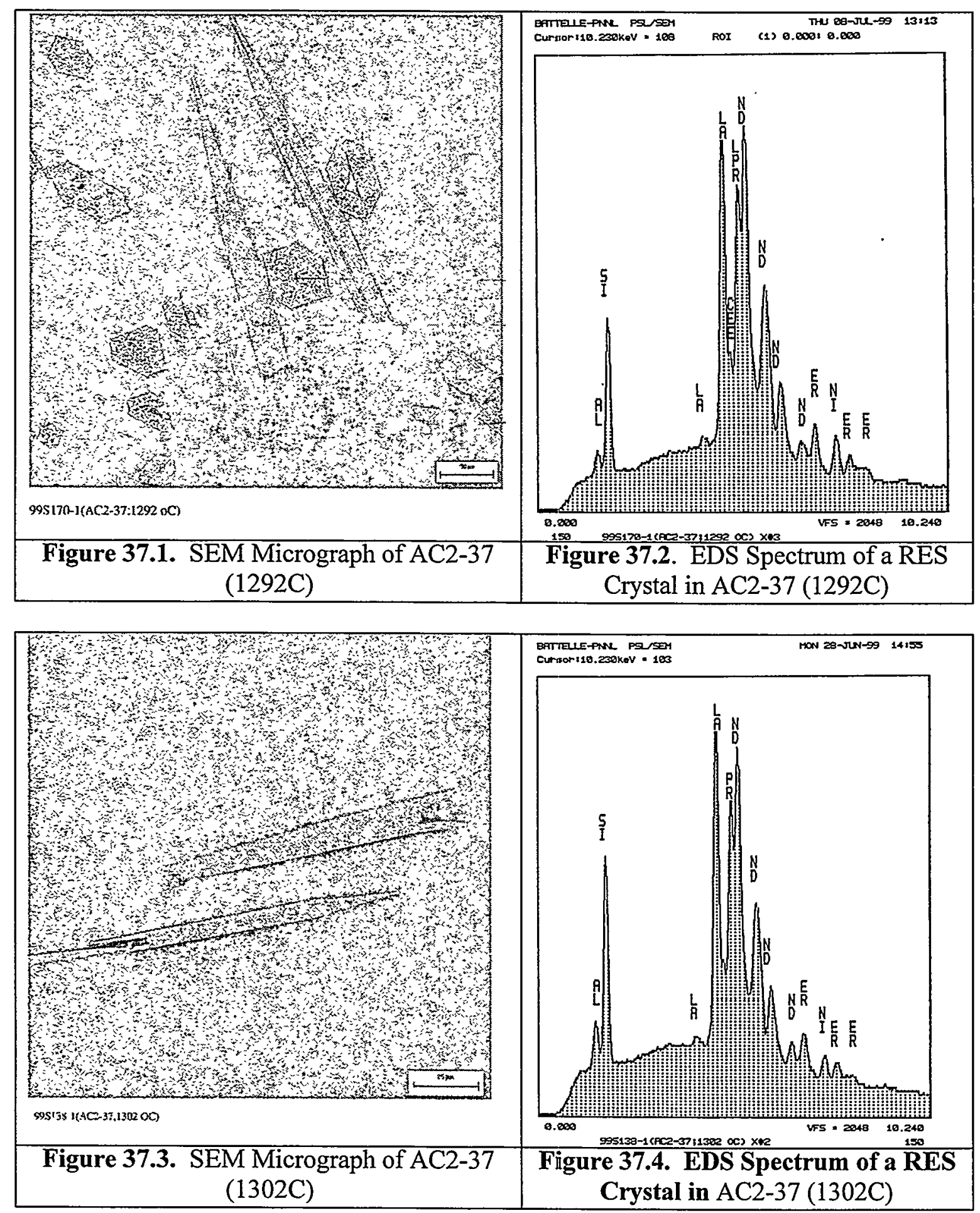

\subsection{Viscosity}

Table 37.2 lists the measured $\eta-T$ values for $A C 2-37$ in chronological order. These data are shown on an Arrhenius plot $(\ln \eta$ vs. $1 / \mathrm{T})$ in Figure 37.5. A datum from Table 37.2, at 
$1404^{\circ} \mathrm{C}$, had a measured $\eta$ value below the instrument's range and was excluded from calculations. The excluded point is shown as an open circle and listed in strike-through font. Equation (2) was fitted to the remaining data, shown as solid circles, to yield $\mathrm{E}$ and $\mathrm{F}$ values of 17.594 and $28495 \mathrm{~K}$, respectively. This fit, which accurately portrays the data, was then used to calculate a $\eta_{1350}$ value of $0.96 \mathrm{~Pa} \cdot \mathrm{s}$.

Table 37.2. Viscosity-Temperature Data for AC2-37

\begin{tabular}{cccc}
\hline $\mathrm{T}\left({ }^{\circ} \mathrm{C}\right)$ & $\eta(\mathrm{Pa} \cdot \mathrm{s})$ & $10000 / \mathrm{T}\left(\mathrm{K}^{-1}\right)$ & $\ln [\eta(\mathrm{Pa} \cdot \mathrm{s})]$ \\
\hline 1383 & 0.670 & 6.039 & -0.400 \\
1335 & 1.140 & 6.219 & 0.131 \\
1383 & 0.677 & 6.039 & -0.390 \\
1404 & 0.540 & 5.963 & -0.616 \\
1384 & 0.683 & 6.035 & -0.381 \\
1325 & 1.265 & 6.258 & 0.235 \\
1305 & 1.591 & 6.337 & 0.464 \\
\hline
\end{tabular}

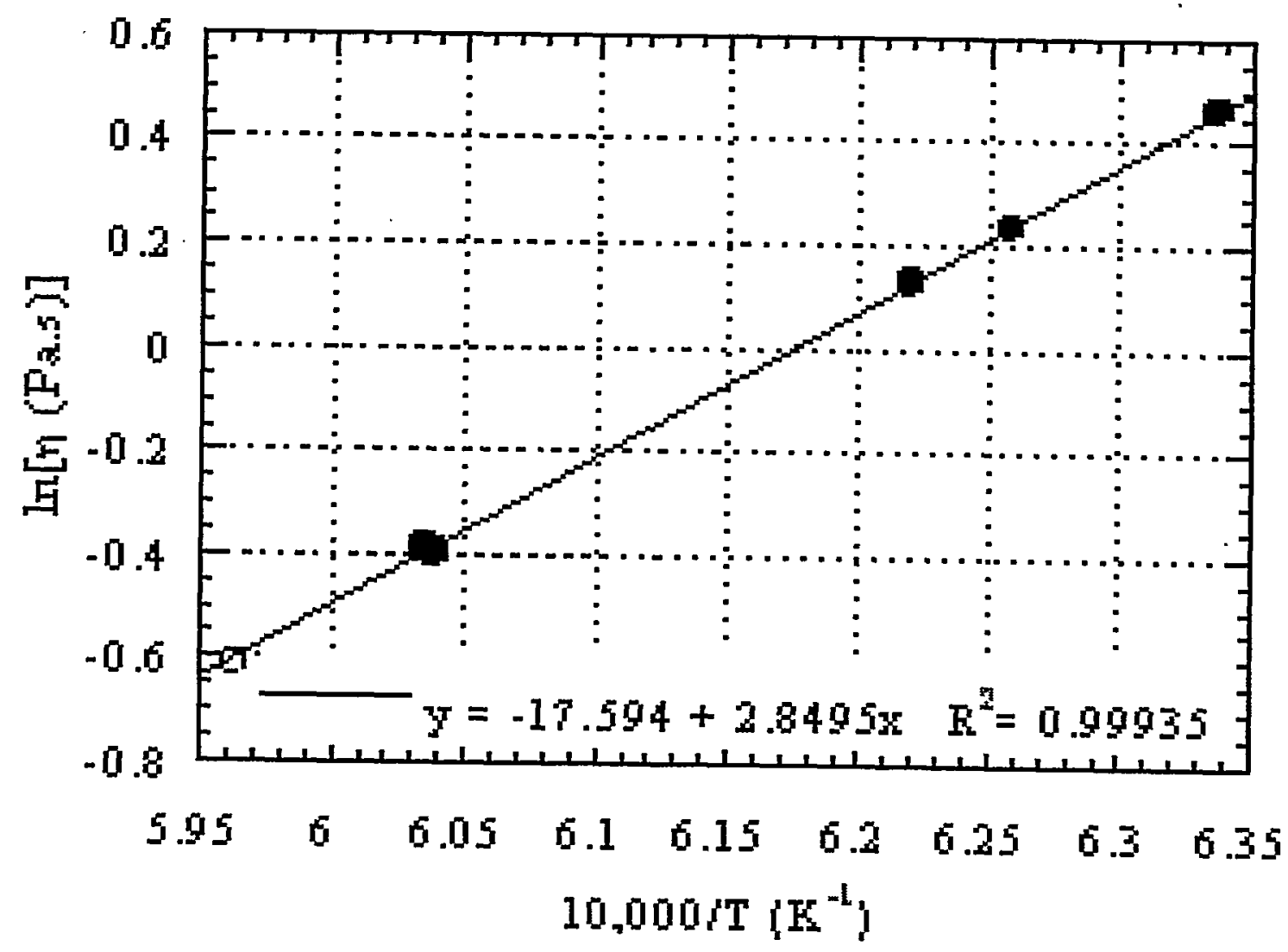

Figure 37.5. Measured ln Viscosity vs. $10000 / \mathrm{T}$ for AC2-37 
A.116 


\subsection{AC2-38}

Glass AC2-38 is an interior point of the designed glass-composition region. This glass targets 60.2 mass percent $\mathrm{Ln}_{2} \mathrm{O}_{3}$. The ratios of frit components, $\mathrm{SiO}_{2}, \mathrm{Al}_{2} \mathrm{O}_{3}, \mathrm{~B}_{2} \mathrm{O}_{3}$, and $\mathrm{SrO}$, are the same as those in the baseline frit.

\subsection{Liquidus Temperature}

Table 38.1 summarizes the final heat treatments performed on this glass. The $T_{L}$ of this glass was estimated at $1308^{\circ} \mathrm{C}$ using Furnace \#3. Crystals formed in samples heat treated at $1307^{\circ} \mathrm{C}$ and $1302^{\circ} \mathrm{C}$ while the sample heat treated at $1313^{\circ} \mathrm{C}$ remained crystal free. RES crystals formed in samples of this glass heat treated at temperatures below $T_{L}$. These crystals were identified by the characteristic morphologies of the crystals formed below $T_{L}$. The morphologies matched those observed in samples of $\mathrm{AC} 2-03, \mathrm{AC} 2-05$, and other glasses that were shown by $\mathrm{SEM}$ and/or XRD to be RES crystals.

Six preliminary heat treatments were performed at temperatures between $1251^{\circ} \mathrm{C}$ and $1339^{\circ} \mathrm{C}$. Two additional samples were heat treated in Furnace $\# 12$ at $1312^{\circ} \mathrm{C}$ and $1306^{\circ} \mathrm{C}$; both were crystal free.

Table 38.1. Heat-Treatment Summary for Determination of $\mathrm{T}_{\mathrm{L}}$ for AC2-38

\begin{tabular}{ccccccc}
\hline Crucible & Furnace & Date/Time IN & $\mathrm{T}\left({ }^{\circ} \mathrm{C}\right)$ & Date/Time OUT & Observations & Comments \\
\hline 38 & 3 & $5: 00 \mathrm{pm} \mathrm{06/17}$ & 1302 & $3: 00 \mathrm{pm} \mathrm{06/18}$ & Many surface crystals & \\
38 & 12 & $3: 40 \mathrm{pm} \mathrm{06/21}$ & 1312 & $3: 30 \mathrm{pm} \mathrm{06/22}$ & No crystals & different furnace \\
38 & 12 & $2: 00 \mathrm{pm} \mathrm{06/23}$ & 1306 & $3: 00 \mathrm{pm} \mathrm{06/24}$ & No crystals & different furnace \\
38 & 3 & $1: 15 \mathrm{pm} \mathrm{07/08}$ & 1307 & $11: 15 \mathrm{am} \mathrm{07/09}$ & Crystals throughout & $\mathrm{T}_{\mathrm{C}}$ \\
38 & 3 & $3: 10 \mathrm{pm} \mathrm{7/21}$ & 1313 & $4: 10 \mathrm{pm} \mathrm{7/22}$ & No crystals & $\mathrm{T}_{\mathrm{A}}$ \\
\hline
\end{tabular}

\subsection{Viscosity}

Table 38.2 lists the measured $\eta-T$ values for $\mathrm{AC} 2-38$ in chronological order. These data are shown on an Arrhenius plot ( $\ln \eta$ vs. 1/T) in Figure 38.1. Two data points from Table 38.2 were excluded from calculations. One of these points, at $1424^{\circ} \mathrm{C}$, had measured $\eta$ value below the instrument's range while the other, at $1305^{\circ} \mathrm{C}$, was taken at a $\mathrm{T}$ below $\mathrm{T}_{\mathrm{L}}$. The excluded data are plotted as open circles and listed in strike-through font. Equation (2) was fitted to the remaining data, shown as solid circles, to yield $E$ and $F$ values of -16.272 and $26319 \mathrm{~K}$, respectively. This fit, which accurately portrays the data, was then used to calculate a $\eta_{1350}$ value of $0.95 \mathrm{~Pa} \cdot \mathrm{s}$. 
Table 38.2. Viscosity-Temperature Data for AC2-38

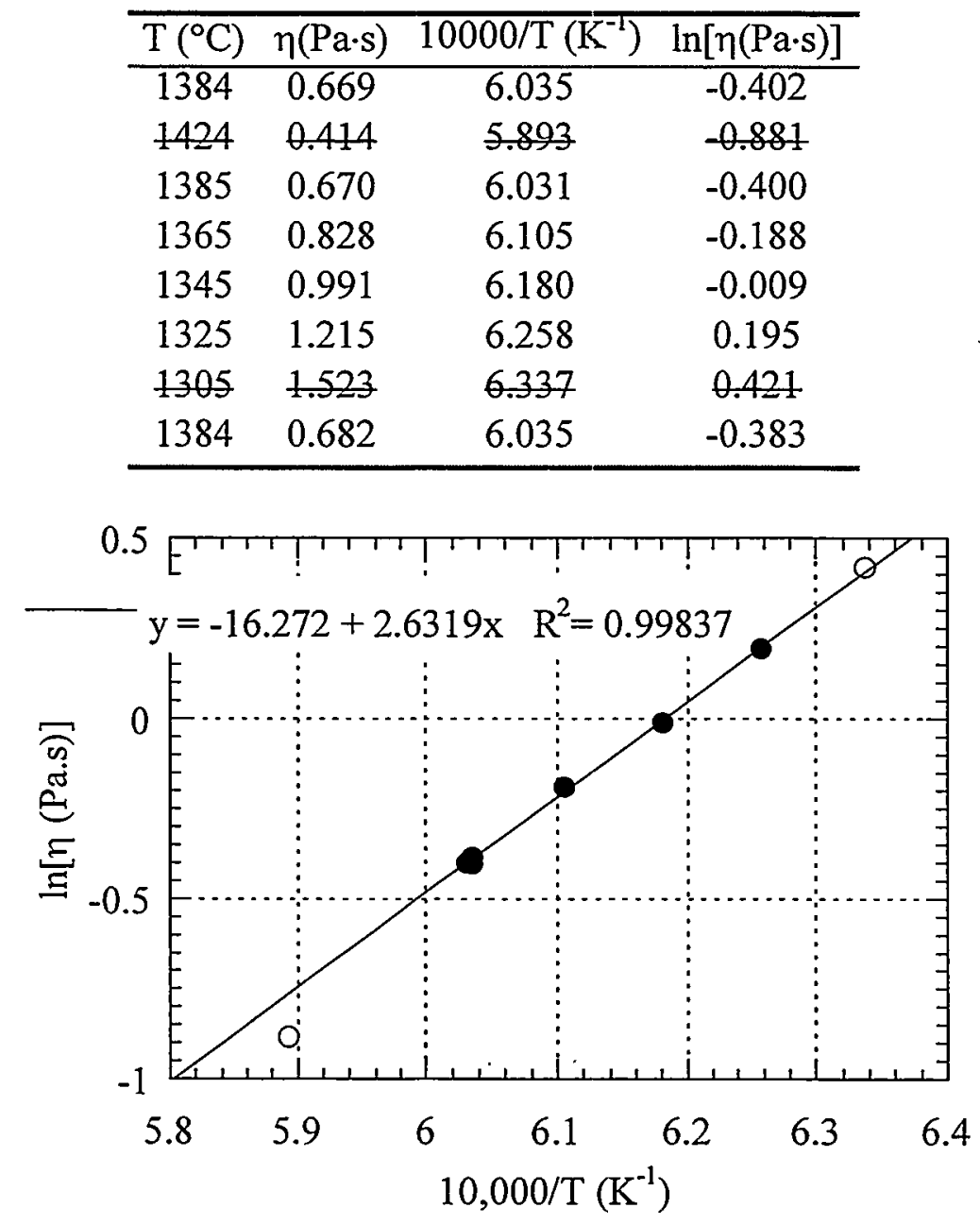

Figure 38.1. Measured ln Viscosity vs. 10000/T for AC2-38 


\subsection{AC2-39}

Glass AC2-39 is an interior point of the designed glass-composition region. This glass targets 60.9 mass percent $\mathrm{Ln}_{2} \mathrm{O}_{3}$. The ratios of frit components, $\mathrm{SiO}_{2}, \mathrm{Al}_{2} \mathrm{O}_{3}, \mathrm{~B}_{2} \mathrm{O}_{3}$, and $\mathrm{SrO}$, are the same as those in the baseline frit.

\subsection{Liquidus Temperature}

Four final heat treatments of AC2-39 glass were performed in Furnace \#3 between $1302^{\circ} \mathrm{C}$ and $1321^{\circ} \mathrm{C}$ (see Table 39.1). The sample heat treated at $1314^{\circ} \mathrm{C}$ contained plate-like crystals, while the sample heat treated at $1321^{\circ} \mathrm{C}$ appeared to be crystal free by $\mathrm{OM}$; therefore, $\mathrm{T}_{\mathrm{L}}$ was estimated at $1318^{\circ} \mathrm{C}$. RES crystals formed in samples of this glass heat treated at temperatures below $T_{L}$. These crystals were identified by the characteristic morphologies of the crystals formed below $\mathrm{T}_{\mathrm{L}}$. The morphologies matched those observed in samples of $\mathrm{AC} 2-03$, AC2-05, and other glasses that were shown by SEM and/or XRD to be RES crystals.

Six preliminary heat treatments were performed at identical temperatures as those measured in AC2-38. Two additional samples were heat treated in Furnace $\# 12$ at $1312^{\circ} \mathrm{C}$ and $1306^{\circ} \mathrm{C}$; both contained crystals.

Table 39.1. Heat-Treatment Summary for Determination of $T_{L}$ for AC2-39

\begin{tabular}{ccccccc}
\hline Crucible & Furnace & Date/Time IN & $\mathrm{T}\left({ }^{\circ} \mathrm{C}\right)$ & Date/Time OUT & Observations & Comments \\
\hline 39 & 3 & $5: 00 \mathrm{pm} \mathrm{06/17}$ & 1302 & $3: 00 \mathrm{pm} \mathrm{06/18}$ & many crystals & XRD \\
39 & 12 & $3: 40 \mathrm{pm} \mathrm{06/21}$ & 1312 & $3: 30 \mathrm{pm} \mathrm{06/22}$ & one large cluster & different furnace \\
39 & 12 & $2: 00 \mathrm{pm} \mathrm{06/23}$ & 1306 & $3: 00 \mathrm{pm} \mathrm{06/24}$ & crystals & different furnace \\
39 & 3 & $11: 00 \mathrm{am} \mathrm{06/29}$ & 1314 & $9: 20 \mathrm{am} \mathrm{06/30}$ & plate-like crystals & $\mathrm{T}_{\mathrm{C}}$ \\
39 & 3 & $1: 15 \mathrm{pm} \mathrm{07/08}$ & 1307 & $11: 15 \mathrm{am} \mathrm{07/09}$ & lots of crystals & \\
39 & 3 & $3: 00 \mathrm{pm} \mathrm{07/14}$ & 1321 & $3: 05 \mathrm{pm} \mathrm{07/15}$ & no crystals & $\mathrm{T}_{\mathrm{A}}$ \\
\hline
\end{tabular}

\subsection{Viscosity}

Table 39.2 lists the measured $\eta-T$ values for AC2-39 in chronological order. These data are shown on an Arrhenius plot ( $\ln \eta$ vs. 1/T) in Figure 39.1. Two data points from Table 39.2 were excluded from calculations. One of these points, at $1424^{\circ} \mathrm{C}$, had measured $\eta$ value below the instrument's range while the other, at $1306^{\circ} \mathrm{C}$, was taken at a $\mathrm{T}$ below $\mathrm{T}_{\mathrm{L}}$. The excluded data are plotted as open circles and listed in strike-through font. Equation (2) was fitted to the remaining data, shown as solid circles, to yield $\mathrm{E}$ and $\mathrm{F}$ values of -16.986 and $27416 \mathrm{~K}$, respectively. This fit, which accurately portrays the data, was then used to calculate a $\eta_{1350}$ value of $0.91 \mathrm{~Pa} \cdot \mathrm{s}$. 
Table 39.2. Viscosity-Temperature Data for AC2-39

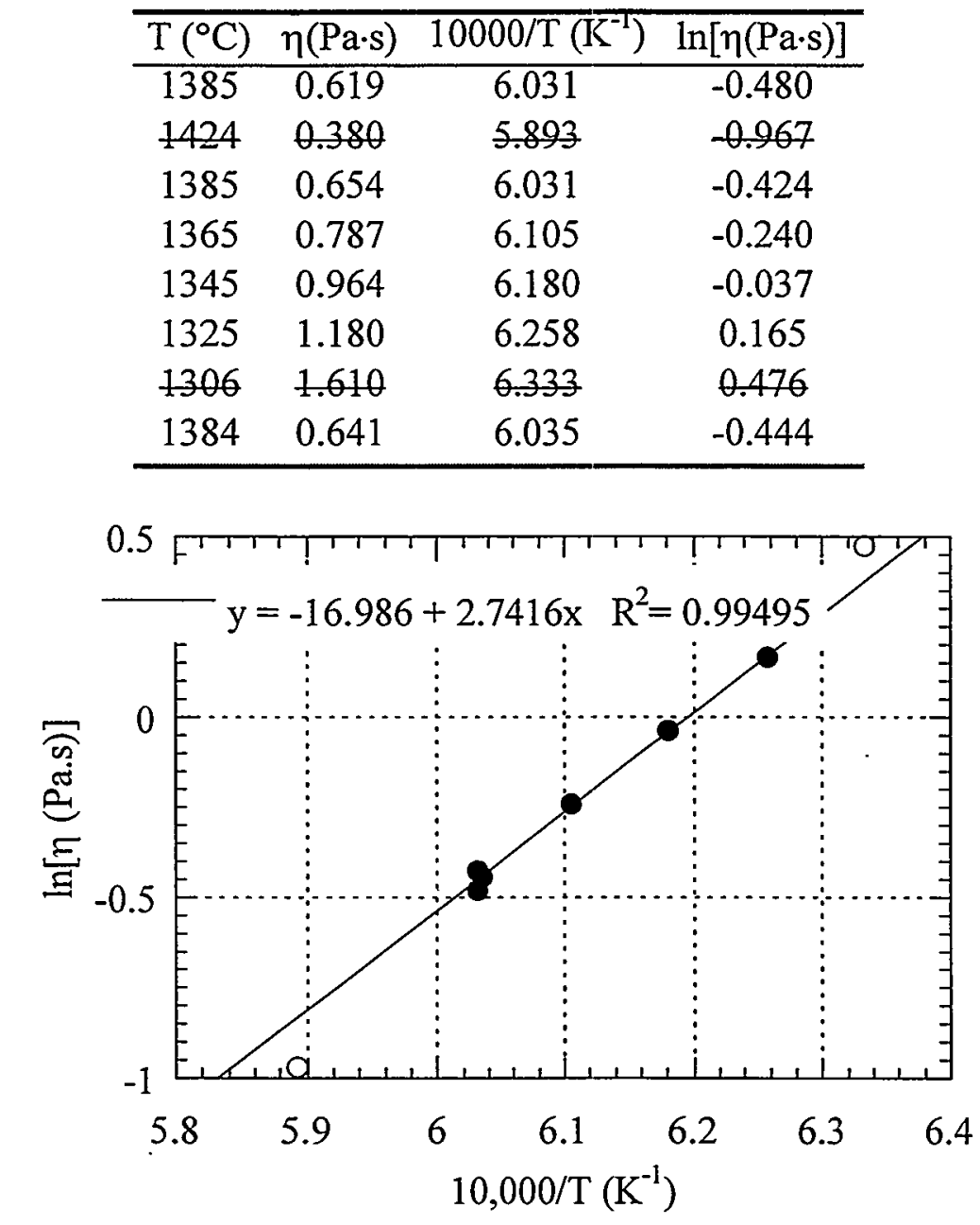

Figure 39.1. Measured ln Viscosity vs. 10000/T for AC2-39 


\subsection{AC2-40}

Glass $\mathrm{AC} 2-40$ is an interior point of the designed glass-composition region. This glass targets 61.7 mass percent $\mathrm{Ln}_{2} \mathrm{O}_{3}$. The ratios of frit components, $\mathrm{SiO}_{2}, \mathrm{Al}_{2} \mathrm{O}_{3}, \mathrm{~B}_{2} \mathrm{O}_{3}$, and $\mathrm{SrO}$, are the same as those in the baseline frit.

\subsection{Liquidus Temperature}

Table 40.1 summarizes the final heat treatments performed on this glass. The $T_{L}$ of this glass was estimated at $1325^{\circ} \mathrm{C}$ using Furnace \#3. Crystals formed in samples heat treated at $1321^{\circ} \mathrm{C}$ and $1313^{\circ} \mathrm{C}$ while the sample heat treated at $1328^{\circ} \mathrm{C}$ did not contain crystals. RES crystals formed in samples of this glass heat treated at temperatures below $T_{L}$. These crystals were identified by the characteristic morphologies of the crystals formed below $T_{L}$. The morphologies matched those observed in samples of $\mathrm{AC} 2-03, \mathrm{AC2}-05$, and other glasses that were shown by SEM and/or XRD to be RES crystals.

Six preliminary heat treatments were performed at temperatures between $1251^{\circ} \mathrm{C}$ and $1339^{\circ} \mathrm{C}$. Two additional heat treatments were performed at $1327^{\circ} \mathrm{C}$ (Furnace \#8) and $1320^{\circ} \mathrm{C}$ (Furnace \#12); neither appeared to contain crystals.

Table 40.1. Heat-Treatment Summary for Determination of $T_{L}$ for AC2-40

\begin{tabular}{ccccccc}
\hline Crucible & Furnace & Date/Time IN & $\mathrm{T}\left({ }^{\circ} \mathrm{C}\right)$ & Date/Time OUT & Observations & Comments \\
\hline 40 & 3 & $3: 00 \mathrm{pm} \mathrm{06/18}$ & 1313 & $1: 30 \mathrm{pm} \mathrm{06/19}$ & Many crystals & \\
40 & 8 & $4: 30 \mathrm{pm} \mathrm{06/23}$ & 1327 & $3: 00 \mathrm{pm} \mathrm{06/24}$ & No crystals & different furnace \\
40 & 12 & $5: 00 \mathrm{pm} \mathrm{06/24}$ & 1320 & $3: 00 \mathrm{pm} \mathrm{06/25}$ & No crystals & different furnace \\
40 & 3 & $3: 00 \mathrm{pm} \mathrm{07/14}$ & 1321 & $3: 05 \mathrm{pm} \mathrm{07/15}$ & Weird crystals & $\mathrm{T}_{\mathrm{C}}$ \\
40 & 3 & $3: 34 \mathrm{pm} \mathrm{07/16}$ & 1328 & $3: 44 \mathrm{pm} \mathrm{07/17}$ & No crystals & $\mathrm{T}_{\mathrm{A}}$ \\
\hline
\end{tabular}

\subsection{Viscosity}

Table 40.2 lists the measured $\eta$ - $T$ values for $A C 2-40$ in chronological order. These data are shown on an Arrhenius plot $(\ln \eta$ vs. $1 / \mathrm{T})$ in Figure 40.1. Two data points from Table 40.2 were excluded from calculations. One of these points, at $1422^{\circ} \mathrm{C}$, had measured $\eta$ values below the instrument's range while the other, at $1324^{\circ} \mathrm{C}$, was taken at a $\mathrm{T}$ below $\mathrm{T}_{\mathrm{L}}$. The excluded data are plotted as open circles and listed in strike-through font. Equation (2) was fitted to the remaining data, plotted as filled circles, to yield $\mathrm{E}$ and $\mathrm{F}$ values of -18.659 and $30139 \mathrm{~K}$, respectively. This fit, based on four data points at effectively two temperatures $\left(1382.5 \pm 0.5^{\circ} \mathrm{C}\right.$ and $1344^{\circ} \mathrm{C}$ ), was then used to calculate a $\eta_{1350}$ value of $0.91 \mathrm{~Pa} \cdot \mathrm{s}$. 
Table 40.2. Viscosity-Temperature Data for $A C 2-40$

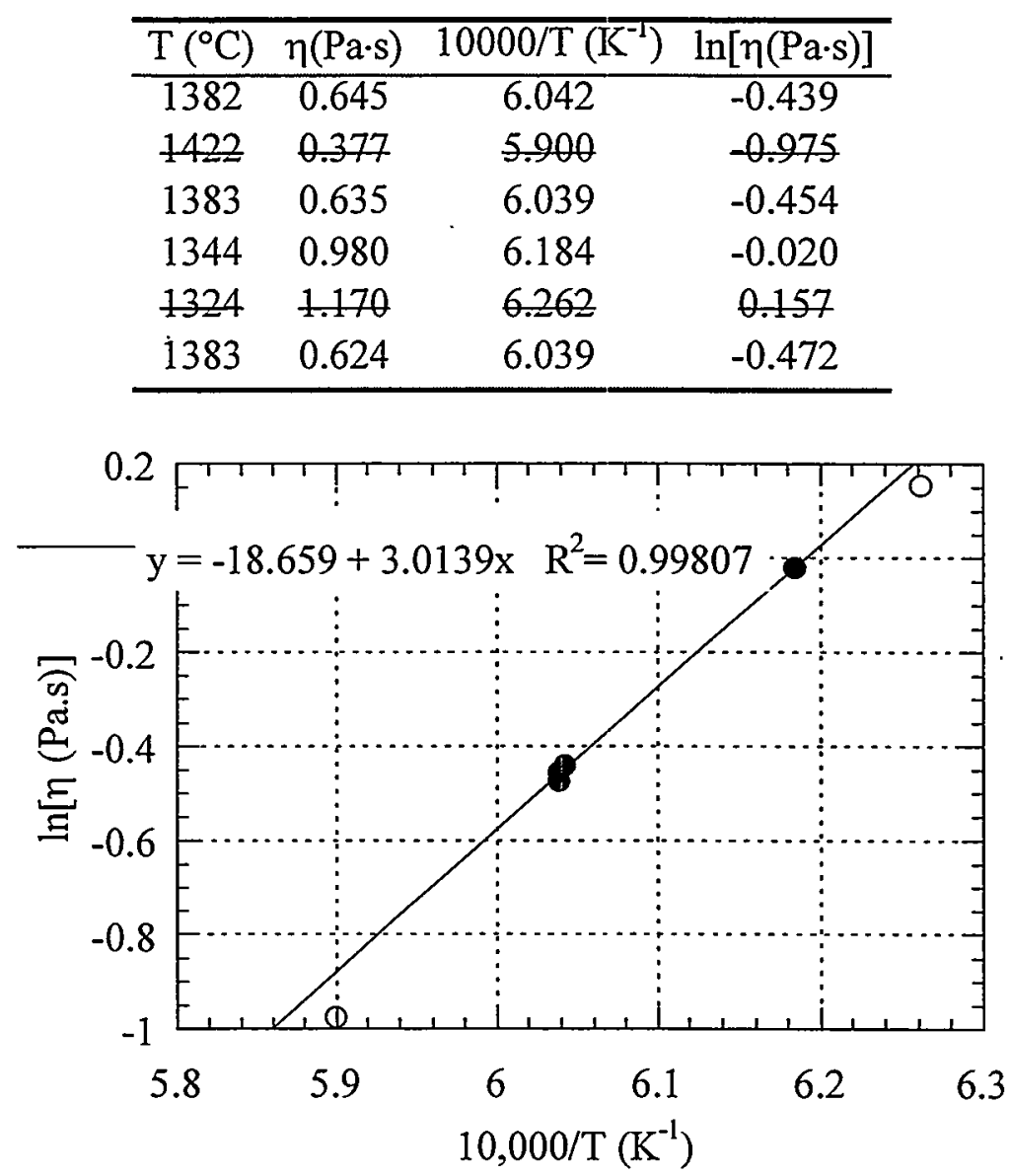

Figure 40.1. Measured ln Viscosity vs. 10000/T for $\mathrm{AC} 2-40$ 


\subsection{AC2-41}

Glass $\mathrm{AC} 2-41$ is an interior point of the designed glass-composition region. This glass targets 62.4 mass percent $\mathrm{Ln}_{2} \mathrm{O}_{3}$. The ratios of frit components, $\mathrm{SiO}_{2}, \mathrm{Al}_{2} \mathrm{O}_{3}, \mathrm{~B}_{2} \mathrm{O}_{3}$, and $\mathrm{SrO}$, are . the same as those in the baseline frit.

\subsection{Liquidus Temperature}

Table 41.1 summarizes the heat treatments performed on this glass. The $T_{L}$ of this glass was estimated at $1324^{\circ} \mathrm{C}$ using Furnace $\# 8$. A sample heat treated at $1320^{\circ} \mathrm{C}$ contained crystals while a sample heat treated at $1327^{\circ} \mathrm{C}$ did not. RES crystals formed in samples of this glass heat treated at temperatures below $T_{L}$. These crystals were identified by the characteristic morphologies of the crystals formed below $T_{\mathrm{L}}$. The morphologies matched those observed in samples of $\mathrm{AC2}-03, \mathrm{AC2}-05$, and other glasses that were shown by SEM and/or XRD to be RES crystals. During the $1320^{\circ} \mathrm{C}$ heat treatments, small nodules or buds of glass formed at the upper edge of the $\mathrm{Pt} / \mathrm{Rh}$ box folds.

Seven preliminary heat treatments were performed between $1198^{\circ} \mathrm{C}$ and $1339^{\circ} \mathrm{C}$ at approximately $50^{\circ} \mathrm{C}$ intervals. Abundant crystals were observed at $1274^{\circ} \mathrm{C}$ and $1292^{\circ} \mathrm{C}$, which matches the observations in the final heat treatments. Samples heat treated at $1326^{\circ} \mathrm{C}$ and $1339^{\circ} \mathrm{C}$ appeared to be crystal free by $\mathrm{OM}$. Additional samples were heat treated at $1313^{\circ} \mathrm{C}$ (Furnace \#3) and $1320^{\circ} \mathrm{C}$ (Furnace \#12). The $1320^{\circ} \mathrm{C}$ sample contained crystals.

Table 41.1. Heat-Treatment Summary for Determination of $T_{L}$ for AC2-41

\begin{tabular}{ccccccc}
\hline Crucible & Furnace & Date/Time IN & $\mathrm{T}\left({ }^{\circ} \mathrm{C}\right)$ & Date/Time OUT & Observations & Comments \\
\hline 41 & 3 & $3: 00 \mathrm{pm} \mathrm{06/18}$ & 1313 & $1: 30 \mathrm{pm} 06 / 19$ & Many crystals & different furnace \\
41 & 8 & $4: 30 \mathrm{pm} \mathrm{06/23}$ & 1327 & $3: 00 \mathrm{pm} 06 / 24$ & No crystals & $\mathrm{T}_{\mathrm{A}}$ \\
41 & 12 & $5: 00 \mathrm{pm} \mathrm{06/24}$ & 1320 & $3: 00 \mathrm{pm} 06 / 25$ & Few crystals & different furnace \\
41 & 8 & $1: 15 \mathrm{pm} \mathrm{07/08}$ & 1320 & $11: 15 \mathrm{am} 07 / 09$ & Crystals & $\mathrm{T}_{\mathrm{C}}$, Buds \\
\hline
\end{tabular}

\subsection{Viscosity}

Table 41.2 lists the measured $\eta-T$ values for AC2-41 in chronological order. These data are shown on an Arrhenius plot $(\ln \eta$ vs. $1 / \mathrm{T})$ in Figure 41.1 . With a $T_{L}$ of $1324^{\circ} \mathrm{C}$, all the data in Table 41.2 are valid for calculations. Equation (2) was fitted to the data to yield $E$ and $F$ values of -17.554 and $28261 \mathrm{~K}$, respectively. This fit, which accurately portrays the data, was then used to calculate a $\eta_{1350}$ value of $0.87 \mathrm{~Pa} \cdot \mathrm{s}$. 
Table 41.2. Viscosity-Temperature Data for AC2-41

\begin{tabular}{cccc}
\hline $\mathrm{T}\left({ }^{\circ} \mathrm{C}\right)$ & $\eta(\mathrm{Pa} \cdot \mathrm{s})$ & $10000 / \mathrm{T}\left(\mathrm{K}^{-1}\right)$ & $\ln [\eta(\mathrm{Pa} \cdot \mathrm{s})]$ \\
\hline 1384 & 0.590 & 6.035 & -0.528 \\
1364 & 0.754 & 6.109 & -0.282 \\
1345 & 0.914 & 6.180 & -0.090 \\
1326 & 1.127 & 6.254 & 0.119 \\
1385 & 0.616 & 6.031 & -0.485 \\
\hline
\end{tabular}

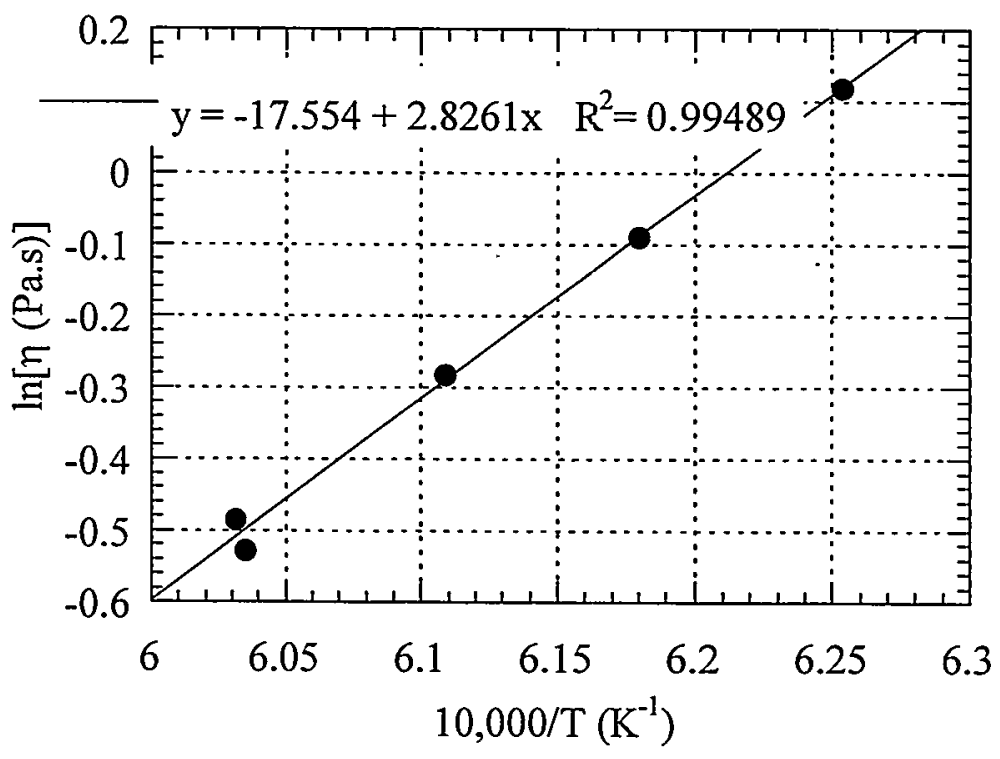

Figure 41.1. Measured ln Viscosity vs. 10000/T for $\mathrm{AC} 2-41$ 


\subsection{AC2-42}

Glass AC2-42 is an interior point of the designed glass-composition region. This glass targets 49.0 mass percent $\mathrm{Ln}_{2} \mathrm{O}_{3}$. The ratios of frit components, $\mathrm{SiO}_{2}, \mathrm{Al}_{2} \mathrm{O}_{3}, \mathrm{~B}_{2} \mathrm{O}_{3}$, and $\mathrm{SrO}$, are the same as those in the baseline frit.

\subsection{Liquidus Temperature .}

Table 42.1 summarizes the heat treatments performed on this glass in Furnace \#3. The $\mathrm{T}_{\mathrm{L}}$ of this glass was estimated at $1180^{\circ} \mathrm{C}$ since a sample heat treated at $1179^{\circ} \mathrm{C}$ contained crystals while a sample heat treated at $1191^{\circ} \mathrm{C}$ did not. RES crystals formed in samples of this glass heat treated at temperatures below $T_{L}$. These crystals were identified by the characteristic morphologies of the crystals formed below $\mathrm{T}_{\mathrm{L}}$. The morphologies matched those observed in samples of $\mathrm{AC2}-03, \mathrm{AC} 2-05$, and other glasses that were shown by SEM and/or XRD to be RES crystals.

Seven preliminary samples were heat treated at temperatures ranging from $1135^{\circ} \mathrm{C}$ to $1223^{\circ} \mathrm{C}$.

Table 42.1. Heat-Treatment Summary for Determination of $T_{L}$ for AC2-42

\begin{tabular}{|c|c|c|c|c|c|c|}
\hline Crucible & Furnace & Date/Time IN & $\mathrm{T}\left({ }^{\circ} \mathrm{C}\right)$ & Date/Time OUT & Observations & Comments \\
\hline 42 & 3 & $9: 25$ am $06 / 30$ & 1179 & $9: 25 a m$ 07/01 & Few crystals & $T_{C}$ \\
\hline 42 & 3 & 2:00pm $07 / 02$ & 1164 & $1: 55 \mathrm{pm} 07 / 03$ & Many crystals & \\
\hline 42 & 3 & 2:00pm 07/03 & 1172 & $8: 42$ am $07 / 04$ & One crystals & \\
\hline 42 & 3 & $3: 30 \mathrm{pm} 07 / 12$ & 1191 & $2: 45 \mathrm{pm} 07 / 13$ & No crystals & $\mathrm{T}_{\mathrm{A}}$ \\
\hline
\end{tabular}

\subsection{Viscosity}

Table 42.2 lists the measured $\eta-T$ values for $\mathrm{AC} 2-42$ in chronological order. These data are shown on an Arrhenius plot $(\ln \eta$ vs. $1 / \mathrm{T})$ in Figure 42.1 . With a $T_{L}$ of $1180^{\circ} \mathrm{C}$, all the data in Table 42.2 are valid for calculations. Equation (2) was fitted to the remaining data, plotted as filled circles, to yield $E$ and $F$ values of -18.192 and $30646 \mathrm{~K}$, respectively. The data appear to be nonlinear. Therefore, a $\eta_{1350}$ value of $1.75 \mathrm{~Pa} \cdot \mathrm{s}$ was obtained by interpolation between the data points at $1333^{\circ} \mathrm{C}$ and $1382^{\circ} \mathrm{C}$ using Equation (2). 
Table 42.2. Viscosity-Temperature Data for $\mathrm{AC} 2-42$

\begin{tabular}{cccc}
\hline $\mathrm{T}\left({ }^{\circ} \mathrm{C}\right)$ & $\eta(\mathrm{Pa} \cdot \mathrm{s})$ & $10000 / \mathrm{T}\left(\mathrm{K}^{-1}\right)$ & $\ln [\eta(\mathrm{Pa} \cdot \mathrm{s})]$ \\
\hline 1382 & 1.381 & 6.042 & 0.323 \\
1333 & 1.992 & 6.227 & 0.689 \\
1284 & 4.005 & 6.423 & 1.388 \\
1332 & 2.008 & 6.231 & 0.697 \\
1382 & 1.391 & 6.042 & 0.330 \\
1432 & 0.899 & 5.865 & -0.106 \\
1481 & 0.569 & 5.701 & -0.564 \\
1383 & 1.373 & 6.039 & 0.317 \\
1235 & 8.558 & 6.631 & 2.147 \\
1186 & 20.731 & 6.854 & 3.032 \\
\hline
\end{tabular}

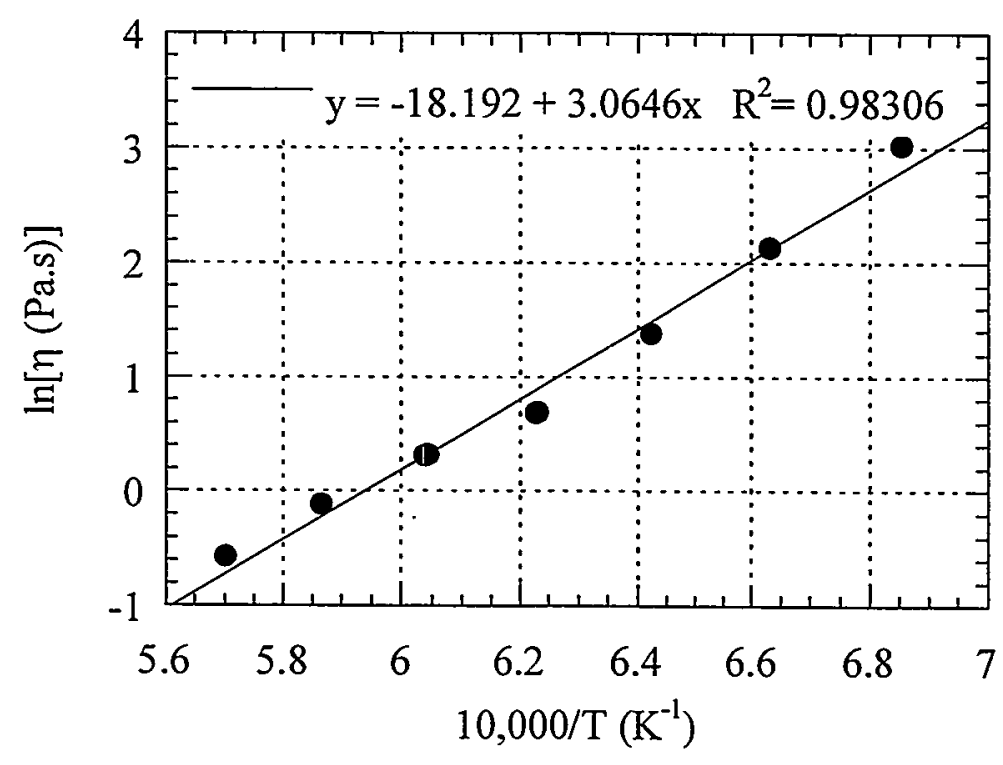

Figure 42.1. Measured In Viscosity vs. 10000/T for AC2-42 


\subsection{AC2-43}

Glass AC2-43 is an interior point of the designed glass-composition region. This glass targets 52.7 mass percent $\mathrm{Ln}_{2} \mathrm{O}_{3}$. The ratios of frit components, $\mathrm{SiO}_{2}, \mathrm{Al}_{2} \mathrm{O}_{3}, \mathrm{~B}_{2} \mathrm{O}_{3}$, and $\mathrm{SrO}$, are the same as those in the baseline frit.

\subsection{Liquidus Temperature}

Table 43.1 summarizes the heat treatments performed on this glass. The $T_{L}$ of this glass was estimated at $1227^{\circ} \mathrm{C}$ using Furnace \#3. Crystals formed in a sample heat treated at $1225^{\circ} \mathrm{C}$ while a sample heat treated at $1236^{\circ} \mathrm{C}$ did not contain crystals. RES crystals formed in samples of this glass heat treated at temperatures below $T_{L}$. These crystals were identified by the characteristic morphologies of the crystals formed below $T_{L}$. The morphologies matched those observed in samples of $\mathrm{AC} 2-03, \mathrm{AC} 2-05$, and other glasses that were shown by SEM and/or XRD to be RES crystals.

Three preliminary heat treatments were performed at $1226^{\circ} \mathrm{C}, 1227^{\circ} \mathrm{C}$, and $1233^{\circ} \mathrm{C}$. This minute range of $7^{\circ} \mathrm{C}$ narrowed the $T_{L}$ for final testing (Table 43.1) where five measurements were used to complete the testing on this glass. This is very uncommon, although nice. Additional heat treatments at $1225^{\circ} \mathrm{C}$ and $1227^{\circ} \mathrm{C}$ (in Furnace \#12) produced samples that did not contain crystals.

Table 43.1. Heat-Treatment Summary for Determination of $T_{L}$ for AC2-43

\begin{tabular}{ccccccc}
\hline Crucible & Furnace & Time/Date IN & $\mathrm{T}\left({ }^{\circ} \mathrm{C}\right)$ & Time/Date OUT & Observations & Comments \\
\hline 43 & 3 & $2: 30 \mathrm{pm} \mathrm{06/12}$ & 1215 & $3: 00 \mathrm{pm} \mathrm{06/13}$ & Very crystalline & \\
43 & 3 & $4: 30 \mathrm{pm} \mathrm{06/14}$ & 1236 & $3: 40 \mathrm{pm} \mathrm{06/15}$ & No crystals & $\mathrm{T}_{\mathrm{A}}$ \\
43 & 12 & $5: 00 \mathrm{pm} \mathrm{06/15}$ & 1227 & $3: 20 \mathrm{pm} \mathrm{06/16}$ & No crystals & different furnace \\
43 & 12 & $5: 00 \mathrm{pm} \mathrm{06/16}$ & 1225 & $3: 00 \mathrm{pm} \mathrm{06/17}$ & No crystals & different furnace \\
43 & 3 & $8: 48 \mathrm{am} \mathrm{07/05}$ & 1225 & $8: 49 \mathrm{am} \mathrm{07/06}$ & Few crystals & $\mathrm{T}_{\mathrm{C}}$ \\
\hline
\end{tabular}

\subsection{Viscosity}

Table 43.2 lists the measured $\eta$-T values for $\mathrm{AC} 2-43$ in chronological order. These data are shown on an Arrhenius plot (ln $\eta$ vs. 1/T) in Figure 43.1. Two data points from Table 43.2 were excluded from calculations. One of these points, at $1482^{\circ} \mathrm{C}$, had a measured $\eta$ value below the instrument's range while the other, at $1187^{\circ} \mathrm{C}$, was taken at a $\mathrm{T}$ below $\mathrm{T}_{\mathrm{L}}$. The excluded data are plotted as open circles and listed in strike-through font. Equation (2) was fitted to the remaining data, plotted as filled circles, to yield $\mathrm{E}$ and $\mathrm{F}$ values of -18.055 and $30044 \mathrm{~K}$, respectively. The data appear to be nonlinear. Therefore, a $\eta_{1350}$ value of $1.32 \mathrm{~Pa} \cdot \mathrm{s}$ was obtained by interpolation between the data points at $1333^{\circ} \mathrm{C}$ and $1382^{\circ} \mathrm{C}$ using Equation (2). 
Table 43.2. Viscosity-Temperature Data for $A C 2-43$

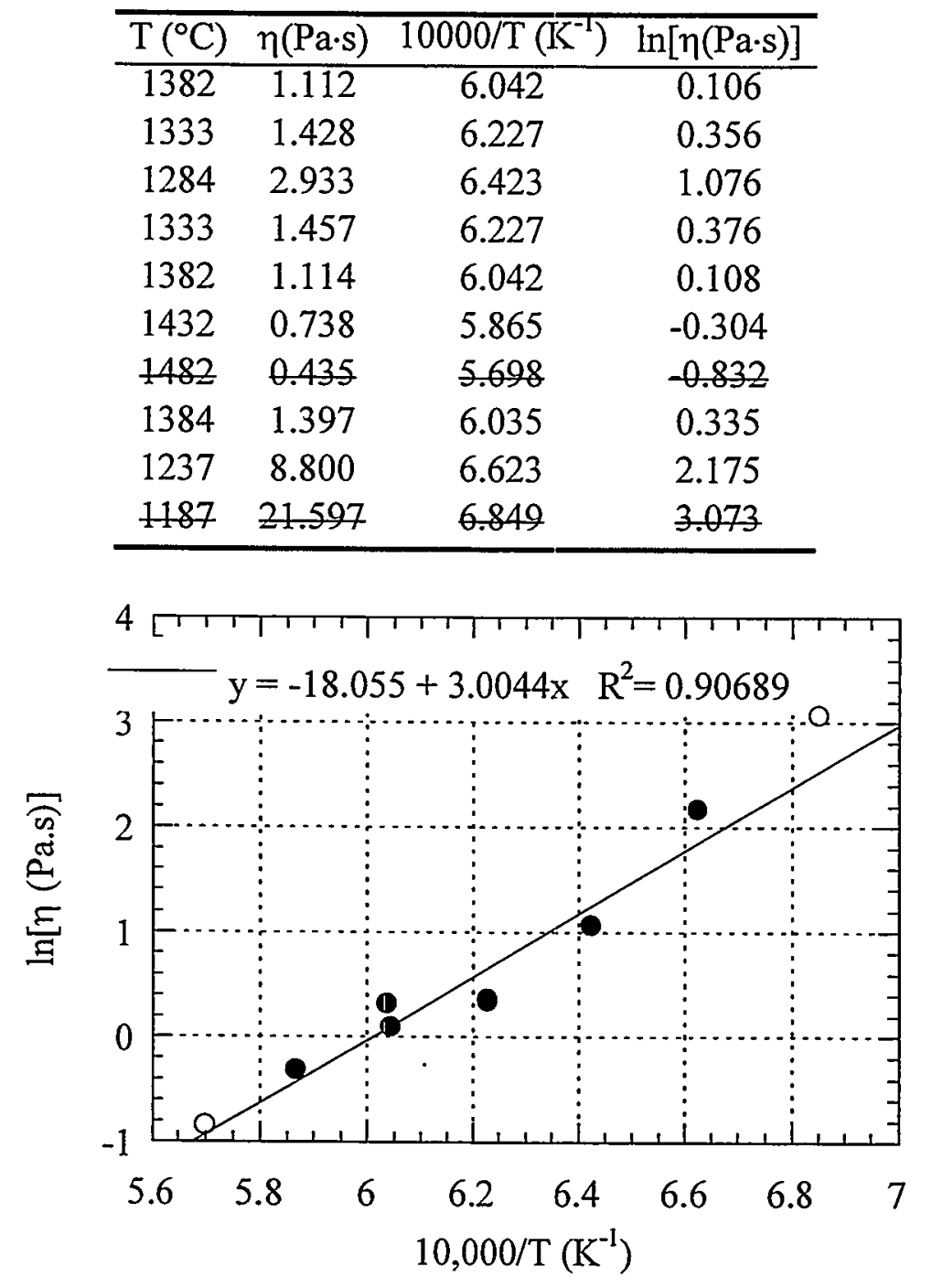

Figure 43.1. Measured ln Viscosity vs. 10000/T for AC2-43 


\subsection{AC2-44}

Glass AC2-44 is an interior point of the designed glass-composition region. This glass targets 63.9 mass percent $\mathrm{Ln}_{2} \mathrm{O}_{3}$. The ratios of frit components, $\mathrm{SiO}_{2}, \mathrm{Al}_{2} \mathrm{O}_{3}, \mathrm{~B}_{2} \mathrm{O}_{3}$, and $\mathrm{SrO}$, are the same as those in the baseline frit.

\subsection{Liquidus Temperature}

Table 44.1 summarizes the heat treatments performed on this glass. The $T_{L}$ of this glass was estimated at $1305^{\circ} \mathrm{C}$ using Furnace \#3. A sample heat treated at $1302^{\circ} \mathrm{C}$ formed crystals while one heat treated at $1307^{\circ} \mathrm{C}$ did not. RES crystals formed in samples of this glass heat treated at temperatures below $T_{L}$. These crystals were identified by the characteristic morphologies of the crystals formed below $T_{L}$ and confirmed by SEM with EDS as shown in Figure 44.1 and Figure 44.2. These crystals, like those observed in samples of AC2-37 and AC2-39, had "frizzed" ends. During the $1307^{\circ} \mathrm{C}$ heat treatment, small nodules or buds of glass formed at the upper edge of the $\mathrm{Pt} / \mathrm{Rh}$ box folds.

Six preliminary heat treatments were performed between $1251^{\circ} \mathrm{C}$ and $1339^{\circ} \mathrm{C}$ at approximately $50^{\circ} \mathrm{C}$ intervals. Abundant crystals were observed at $1292^{\circ} \mathrm{C}$. This indicated that gross crystallization occurred at temperatures slightly below $\mathrm{T}_{\mathrm{L}}$. Samples at $1318^{\circ} \mathrm{C}$ and $1339^{\circ} \mathrm{C}$ appeared to be crystal free by OM. Additional samples were heat treated at $1312^{\circ} \mathrm{C}$ and $1306^{\circ} \mathrm{C}$ in Furnace \#12; neither sample contained crystals.

Table 44.1. Heat-Treatment Summary for Determination of $T_{L}$ for AC2-44

\begin{tabular}{ccccccc}
\hline Crucible & Furnace & Date/Time IN & $\mathrm{T}\left({ }^{\circ} \mathrm{C}\right)$ & Date/Time OUT & Observations & Comments \\
\hline 44 & 3 & $5: 00 \mathrm{pm} \mathrm{06/17}$ & 1302 & $3: 00 \mathrm{pm} \mathrm{06/18}$ & Crystals throughout & $\mathrm{T}_{\mathrm{C}}, \mathrm{SEM}$ \\
44 & 12 & $3: 40 \mathrm{pm} \mathrm{06/21}$ & 1312 & $3: 30 \mathrm{pm} \mathrm{06/22}$ & No crystals & different furnace \\
44 & 12 & $2: 00 \mathrm{pm} \mathrm{06/23}$ & 1306 & $3: 00 \mathrm{pm} \mathrm{06/24}$ & No crystals & different furnace \\
44 & 3 & $1: 15 \mathrm{pm} \mathrm{07/08}$ & 1307 & $11: 15 \mathrm{am} \mathrm{07/09}$ & No crystals & $\mathrm{T}_{\mathrm{A}}$, Buds \\
\hline
\end{tabular}




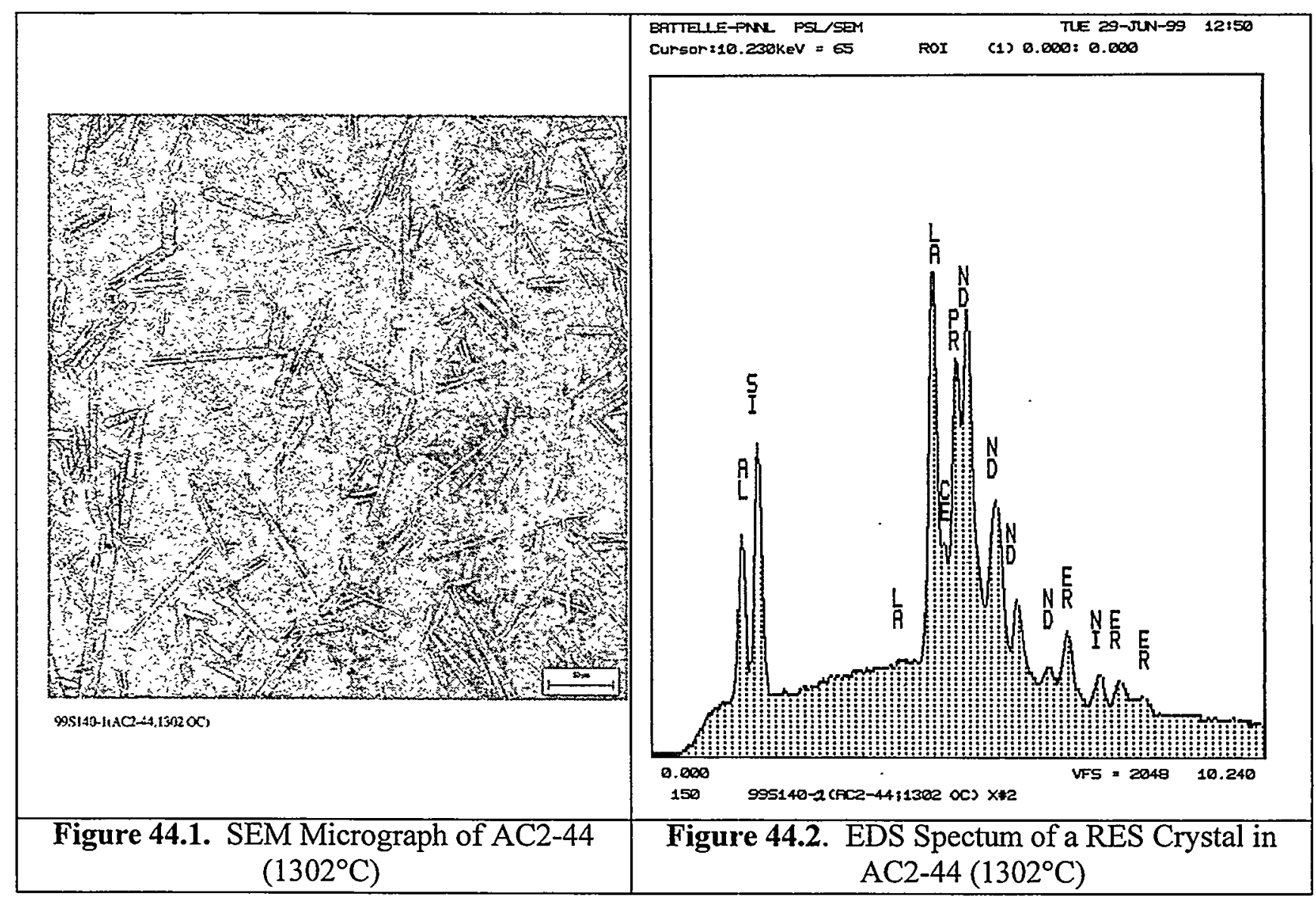

\subsection{Viscosity}

Table 44.2 lists the measured $\eta-T$ values for $\mathrm{AC} 2-41$ in chronological order. These data are shown on an Arrhenius plot $(\ln \eta$ vs. $1 / \mathrm{T})$ in Figure 44.3 . With a $\mathrm{T}_{\mathrm{L}}$ of $1305^{\circ} \mathrm{C}$, all the data in Table 44.2 are valid for calculations. Equation (2) was fitted to the data to yield $E$ and $F$ values of -15.956 and $25803 \mathrm{~K}$, respectively. This fit, which accurately portrays the data, was then used to calculate a $\eta_{1350}$ value of $0.94 \mathrm{~Pa} \cdot \mathrm{s}$.

Table 44.2. Viscosity-Temperature Data for AC2-44

\begin{tabular}{cccc}
\hline $\mathrm{T}\left({ }^{\circ} \mathrm{C}\right)$ & $\eta(\mathrm{Pa} \cdot \mathrm{s})$ & $10000 / \mathrm{T}\left(\mathrm{K}^{-1}\right)$ & $\ln [\eta(\mathrm{Pa} \cdot \mathrm{s})]$ \\
\hline 1384 & 0.667 & 6.035 & -0.405 \\
1404 & 0.55 & 5.963 & -0.598 \\
1384 & 0.69 & 6.035 & -0.371 \\
1364 & 0.833 & 6.109 & -0.183 \\
1345 & 0.996 & 6.180 & -0.004 \\
1325 & 1.204 & 6.258 & 0.186 \\
1305 & 1.473 & 6.337 & 0.387 \\
1383 & 0.711 & 6.039 & -0.341 \\
\hline
\end{tabular}




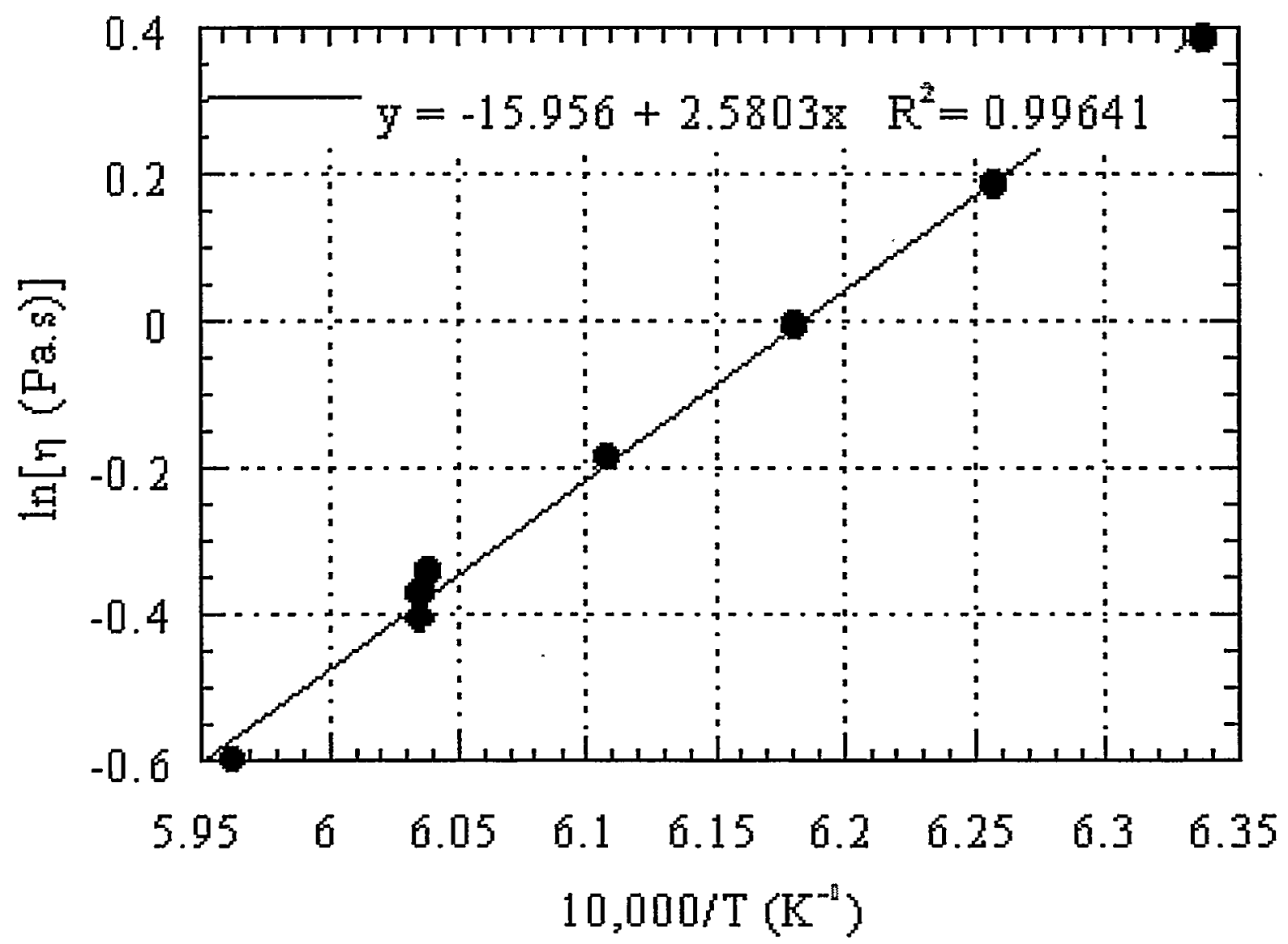

Figure 44.3. Measured ln Viscosity vs. 10000/T for AC2-44 
A. 132 


\subsection{AC2-45}

Glass AC2-45 is an interior point of the designed glass-composition region. This glass targets 56.4 mass percent $\mathrm{Ln}_{2} \mathrm{O}_{3}$, with double the $\mathrm{Ce}_{2} \mathrm{O}_{3}$ from the normal feed. The ratios of frit components, $\mathrm{SiO}_{2}, \mathrm{Al}_{2} \mathrm{O}_{3}, \mathrm{~B}_{2} \mathrm{O}_{3}$, and $\mathrm{SrO}$, are the same as those in the baseline frit.

\subsection{Liquidus Temperature}

Table 45.1 summarizes the heat treatments performed on this glass. The $T_{L}$ of this glass was estimated at $1259^{\circ} \mathrm{C}$ using Furnace $\# 12$. Crystals formed in a sample heat treated at $1255^{\circ} \mathrm{C}$ while a sample heat treated at $1260^{\circ} \mathrm{C}$ did not contain crystals. RES crystals formed in samples of this glass heat treated at temperatures below $T_{L}$. These crystals were identified by the characteristic morphologies of the crystals formed below $\mathrm{T}_{\mathrm{L}}$. The morphologies matched those observed in samples of AC2-03, AC2-05, and other glasses that were shown by SEM and/or $\mathrm{XRD}$ to be RES crystals.

Seven preliminary heat treatments were performed between $1198^{\circ} \mathrm{C}$ and $1274^{\circ} \mathrm{C}$ at approximately $50^{\circ} \mathrm{C}$ intervals. Abundant crystals were observed at $1248^{\circ} \mathrm{C}$, indicating that gross crystallization occurred at temperatures slightly below $\mathrm{T}_{\mathrm{L}}$. Samples at $1263^{\circ} \mathrm{C}, 1270^{\circ} \mathrm{C}, 1274^{\circ} \mathrm{C}$ appeared to be crystal free by OM. An additional sample was heat treated at $1249^{\circ} \mathrm{C}$ in Furnace \#8. This sample grossly crystallized.

Table 45.1. Heat-Treatment Summary for Determination of $T_{L}$ for AC2-45

\begin{tabular}{ccccccc}
\hline Crucible & Furnace & Date/Time IN & T $\left({ }^{\circ} \mathrm{C}\right)$ & Date/Time OUT & Observations & Comments \\
\hline 45 & 12 & $5: 00 \mathrm{pm} \mathrm{06/17}$ & 1260 & $3: 00 \mathrm{pm} \mathrm{06/18}$ & No crystals & $\mathrm{T}_{\mathrm{A}}$ \\
45 & 8 & $2: 00 \mathrm{pm} \mathrm{06/22}$ & 1249 & $12: 35 \mathrm{pm} \mathrm{06/23}$ & Crystals throughout & different furnace \\
45 & 12 & $8: 45 \mathrm{am} \mathrm{07/04}$ & 1255 & $8: 44 \mathrm{am} \mathrm{07/05}$ & Crystals & $\mathrm{T}_{\mathrm{C}}$ \\
\hline
\end{tabular}

\subsection{Viscosity}

Table 45.2 lists the measured $\eta-\mathrm{T}$ values for $\mathrm{AC} 2-45$ in chronological order. These data are shown on an Arrhenius plot $(\ln \eta$ vs. $1 / \mathrm{T})$ in Figure 45.1. A datum from Table 45.2, at $1236^{\circ} \mathrm{C}$, was taken at a $\mathrm{T}$ below $T_{\mathrm{L}}$ and was excluded from calculations. The excluded point was plotted as an open circle and listed in strike-through font. Equation (2) was fitted to the remaining data, shown as solid circles, to yield $\mathrm{E}$ and $\mathrm{F}$ values of -14.669 and $23967 \mathrm{~K}$, respectively. This fit, which accurately portrays the data, was then used to calculate a $\eta_{1350}$ value of $1.10 \mathrm{~Pa} \cdot \mathrm{s}$. 
Table 45.2. Viscosity-Temperature Data for AC2-45

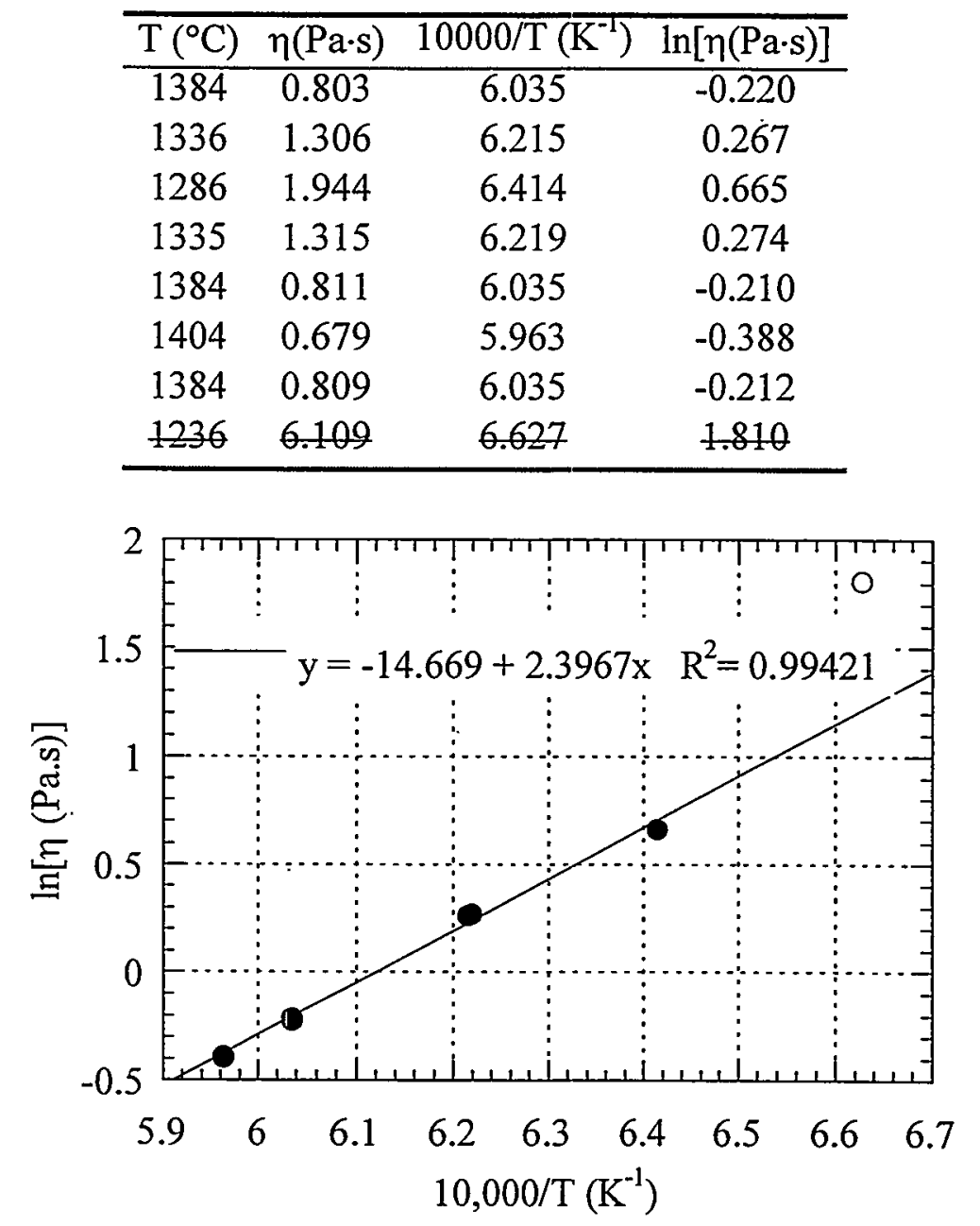

Figure 45.1. Measured ln Viscosity vs. 10000/T for AC2-45 


\subsection{AC2-46}

Glass AC2-46 is an interior point of the designed glass-composition region. This glass targets 60.2 mass percent $\mathrm{Ln}_{2} \mathrm{O}_{3}$. The ratios of frit components, $\mathrm{SiO}_{2}, \mathrm{Al}_{2} \mathrm{O}_{3}, \mathrm{~B}_{2} \mathrm{O}_{3}$, and $\mathrm{SrO}$, are the same as those in the baseline frit.

\subsection{Liquidus Temperature}

Table 46.1 summarizes the heat treatments performed on this glass. The $T_{L}$ of this glass was estimated at $1333^{\circ} \mathrm{C}$ using Furnace \#3. A sample heat treated at $1328^{\circ} \mathrm{C}$ contained crystals while a sample heat treated at $1335^{\circ} \mathrm{C}$ did not. RES crystals formed in samples of this glass heat treated at temperatures below $\mathrm{T}_{\mathrm{L}}$. These crystals were identified by the characteristic morphologies of the crystals formed below $T_{L}$. The morphologies matched those observed in samples of AC2-03, AC2-05, and other glasses that were shown by SEM and/or XRD to be RES crystals.

Five preliminary samples were heat treated at temperatures ranging from $1135^{\circ} \mathrm{C}$ to $1223^{\circ} \mathrm{C}$. Two additional samples were heat treated at $1320^{\circ} \mathrm{C}$ (Furnace \#12) and $1327^{\circ} \mathrm{C}$ (Furnace \#8); both contained crystals.

Table 46.1. Heat-Treatment Summary for Determination of $T_{L}$ for AC2-46

\begin{tabular}{ccccccc}
\hline Crucible & Furnace & Date/Time IN & $\mathrm{T}\left({ }^{\circ} \mathrm{C}\right)$ & Date/Time OUT & Observations & Comments \\
\hline 46 & 12 & $1: 35 \mathrm{pm} \mathrm{06/19}$ & 1320 & $2: 09 \mathrm{pm} \mathrm{06/20}$ & Crystals throughout & different furnace \\
46 & 8 & $4: 30 \mathrm{pm} \mathrm{06/23}$ & 1327 & $3: 00 \mathrm{pm} \mathrm{06/24}$ & Crystals & different furnace \\
46 & 3 & $1: 30 \mathrm{pm} \mathrm{06/26}$ & 1335 & $2: 52 \mathrm{pm} \mathrm{06/27}$ & No crystals & $\mathrm{T}_{\mathrm{A}}$ \\
46 & 3 & $3: 00 \mathrm{pm} \mathrm{07/14}$ & 1321 & $3: 05 \mathrm{pm} \mathrm{07/15}$ & Weird crystals & \\
46 & 3 & $3: 34 \mathrm{pm} \mathrm{07/16}$ & 1328 & $3: 44 \mathrm{pm} \mathrm{07/17}$ & Lots of crystals & $\mathrm{T}_{\mathrm{C}}$ \\
\hline
\end{tabular}

\subsection{Viscosity}

Table 46.2 lists the measured $\eta-T$ values for AC2-29 in chronological order. These data are shown on an Arrhenius plot $(\ln \eta$ vs. $1 / \mathrm{T})$ in Figure 46.1. Four data points from Table 46.2 were excluded from calculations. Three of these points, two at $1384^{\circ} \mathrm{C}$ and one at $1404^{\circ} \mathrm{C}$, had measured $\eta$ values below the instrument's range while the other, at $1326^{\circ} \mathrm{C}$, was taken at a $\mathrm{T}$ below $\mathrm{T}_{\mathrm{L}}$. The excluded data are plotted as open circles and listed in strike-through font. Equation (2) was fitted to the remaining data, shown as solid circles, to yield $\mathrm{E}$ and $\mathrm{F}$ values of 16.753 and $26832 \mathrm{~K}$, respectively. This fit, which accurately portrays the data, was then used to calculate a $\eta_{1350}$ value of $0.80 \mathrm{~Pa} \cdot \mathrm{s}$. 
Table 46.2. Viscosity-Temperature Data for AC2-46

\begin{tabular}{cccc}
\hline $\mathrm{T}\left({ }^{\circ} \mathrm{C}\right)$ & $\eta(\mathrm{Pa} \cdot \mathrm{s})$ & $10000 / \mathrm{T}\left(\mathrm{K}^{-1}\right)$ & $\ln [\eta(\mathrm{Pa} \cdot \mathrm{s})]$ \\
\hline 1384 & 0.533 & 6.035 & -0.628 \\
1404 & 0.421 & 5.963 & -0.866 \\
1384 & 0.540 & 6.035 & -0.616 \\
1366 & 0.685 & 6.101 & -0.378 \\
1346 & 0.833 & 6.177 & -0.182 \\
1326 & 1.414 & 6.254 & 0.346 \\
1385 & 0.564 & 6.031 & -0.572 \\
\hline
\end{tabular}

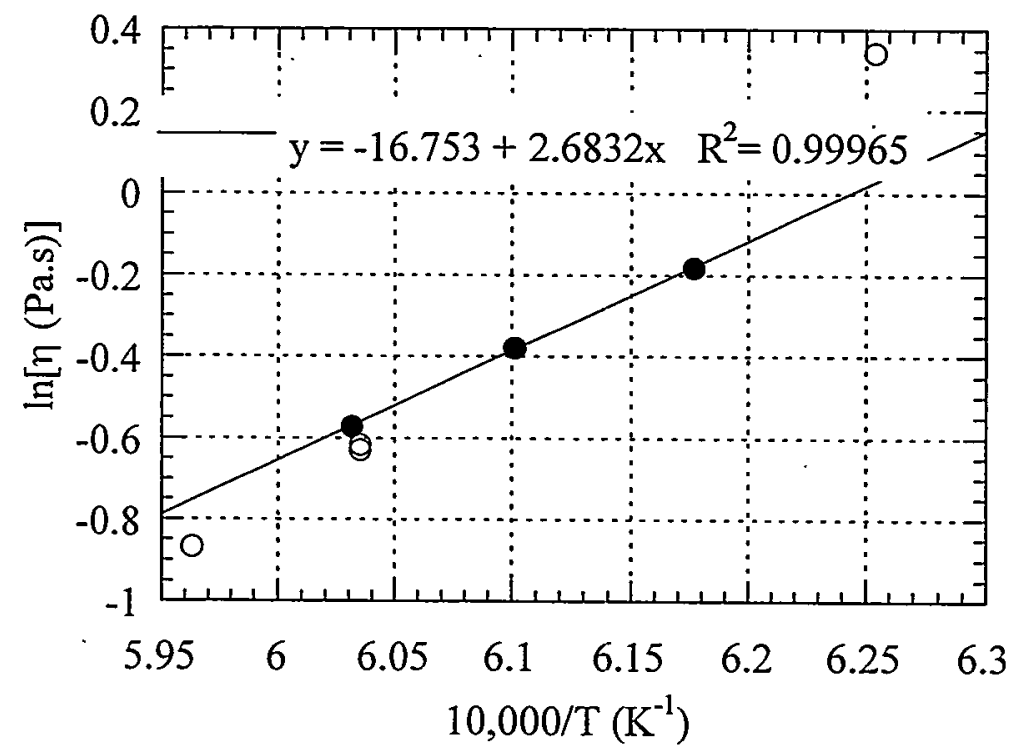

Figure 46.1. Measured ln Viscosity vs. 10000/T for AC2-46 


\subsection{AC2-47}

Glass $\mathrm{AC} 2-47$ is an interior point of the designed glass-composition region. This glass targets 56.4 mass percent $\mathrm{Ln}_{2} \mathrm{O}_{3}$ and is a duplicate of glass $\mathrm{AC} 2-33$. The ratios of frit components, $\mathrm{SiO}_{2}, \mathrm{Al}_{2} \mathrm{O}_{3}, \mathrm{~B}_{2} \mathrm{O}_{3}$, and $\mathrm{SrO}$, are the same as those in the baseline frit.

\subsection{Liquidus Temperature}

Table 47.1 summarizes the heat treatments performed on this glass. The $T_{L}$ of this glass was estimated at $1272^{\circ} \mathrm{C}$ using Furnace $\# 12$. A sample heat treated at $1265^{\circ} \mathrm{C}$ contained crystals while a sample heat treated at $1274^{\circ} \mathrm{C}$ did not. RES crystals formed in samples of this glass heat treated at temperatures below $T_{L}$. These crystals were identified by the characteristic morphologies of the crystals formed below $\mathrm{T}_{\mathrm{L}}$. The morphologies matched those observed in samples of AC2-03, AC2-05, and other glasses that were shown by SEM and/or XRD to be RES crystals. During the $1273^{\circ} \mathrm{C}$ (Furnace $\# 8$ ) and $1274^{\circ} \mathrm{C}$ heat treatments, small nodules or buds of glass formed at the upper edge of the $\mathrm{Pt} / \mathrm{Rh}$ box folds.

Six preliminary heat treatments were performed between $1212^{\circ} \mathrm{C}$ and $1278^{\circ} \mathrm{C}$ at approximately $20^{\circ} \mathrm{C}$ intervals. Abundant crystals were observed at $1240^{\circ} \mathrm{C}$ and $1258^{\circ} \mathrm{C}$. Samples at $1275^{\circ} \mathrm{C}$ and $1278^{\circ} \mathrm{C}$ appeared to be crystal free by $\mathrm{OM}$.

Table 47.1. Heat-Treatment Summary for Determination of $T_{L}$ for AC2-47

\begin{tabular}{ccccccc}
\hline Crucible & Furnace & Date/Time IN & $\mathrm{T}\left({ }^{\circ} \mathrm{C}\right)$ & Date/Time OUT & Observations & Comments \\
\hline 47 & 12 & $5: 00 \mathrm{pm} \mathrm{06/17}$ & 1260 & $3: 00 \mathrm{pm} \mathrm{06/18}$ & Crystals throughout & \\
47 & 8 & $3: 00 \mathrm{pm} \mathrm{06/25}$ & 1273 & $1: 25 \mathrm{pm} \mathrm{06/26}$ & No crystals & different furnace, Buds \\
47 & 12 & $2: 55 \mathrm{pm} \mathrm{06/27}$ & 1265 & $1: 00 \mathrm{pm} \mathrm{06/28}$ & Crystals throughout & $\mathrm{T}_{\mathrm{C}}$ \\
47 & 12 & $8: 50 \mathrm{am} \mathrm{07/05}$ & 1274 & $8: 51 \mathrm{am} \mathrm{07/06}$ & No crystals & $\mathrm{T}_{\mathrm{A}}$, Buds \\
\hline
\end{tabular}

\subsection{Viscosity}

Table 47.2 lists the measured $\eta-\mathrm{T}$ values for $\mathrm{AC} 2-47$ in chronological order. These data are shown on an Arrhenius plot $(\ln \eta$ vs. $1 / \mathrm{T})$ in Figure 47.1. A datum from Table 47.2, at $1236^{\circ} \mathrm{C}$, was taken at a $\mathrm{T}$ below $\mathrm{T}_{\mathrm{L}}$ and was excluded from calculations. The excluded point was plotted as an open circle and listed in strike-through font. Equation (2) was fitted to the remaining data, shown as solid circles, to yield $\mathrm{E}$ and $\mathrm{F}$ values of -14.938 and $24506 \mathrm{~K}$, respectively. This fit, which accurately portrays the data, was then used to calculate a $\eta_{1350}$ value of $1.17 \mathrm{~Pa} \cdot \mathrm{s}$. 
Table 47.2. Viscosity-Temperature Data for $\mathrm{AC} 2-47$

\begin{tabular}{cccc}
\hline $\mathrm{T}\left({ }^{\circ} \mathrm{C}\right)$ & $\eta(\mathrm{Pa} \cdot \mathrm{s})$ & $10000 / \mathrm{T}\left(\mathrm{K}^{-1}\right)$ & $\ln [\eta(\mathrm{Pa} \cdot \mathrm{s})]$ \\
\hline 1382 & 0.877 & 6.042 & -0.131 \\
1334 & 1.38 & 6.223 & 0.322 \\
1285 & 2.16 & 6.418 & 0.770 \\
1333 & 1.399 & 6.227 & 0.336 \\
1383 & 0.877 & 6.039 & -0.131 \\
1433 & 0.553 & 5.862 & -0.592 \\
1384 & 0.867 & 6.035 & -0.143 \\
1236 & 7.632 & 6.627 & 2.032 \\
\hline
\end{tabular}

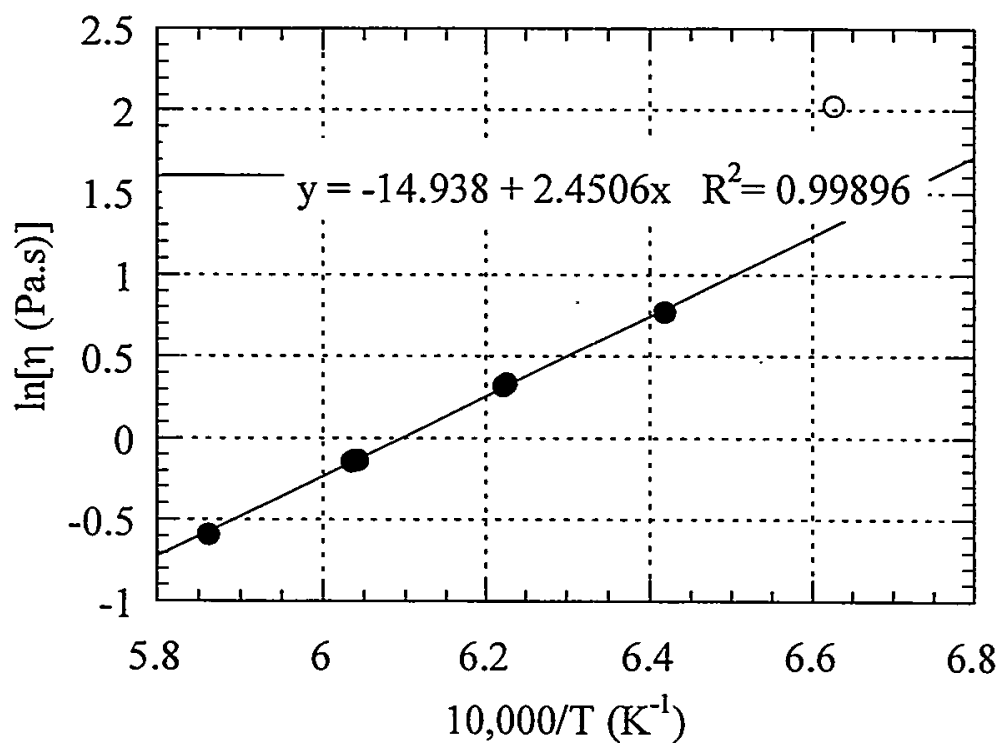

Figure 47.1. Measured ln Viscosity vs. $10000 / \mathrm{T}$ for $\mathrm{AC} 2-47$ 


\subsection{AC2-48}

Glass AC2-48 is an interior point of the designed glass-composition region. This glass targets 49.0 mass percent $\mathrm{Ln}_{2} \mathrm{O}_{3}$ and is a duplicate of glass $\mathrm{AC} 2-42$. The ratios of frit components, $\mathrm{SiO}_{2}, \mathrm{Al}_{2} \mathrm{O}_{3}, \mathrm{~B}_{2} \mathrm{O}_{3}$, and $\mathrm{SrO}$, are the same as those in the baseline frit.

\section{.48.1 Liquidus Temperature}

Table 48.1 summarizes the heat treatments performed on this glass. The $T_{L}$ of this glass was estimated at $1175^{\circ} \mathrm{C}$ using Furnace \#3. A sample heat treated at $1171^{\circ} \mathrm{C}$ contained crystals while a sample heat treated at $1179^{\circ} \mathrm{C}$ did not. RES crystals formed in samples of this glass heat treated at temperatures below $\mathrm{T}_{\mathrm{L}}$. These crystals were identified by the characteristic morphologies of the crystals formed below $\mathrm{T}_{\mathrm{L}}$. The morphologies matched those observed in samples of $\mathrm{AC2}-03, \mathrm{AC} 2-05$, and other glasses that were shown by SEM and/or XRD to be RES crystals.

Five preliminary heat treatments were performed between $1149^{\circ} \mathrm{C}$ and $1233^{\circ} \mathrm{C}$ at approximately $20^{\circ} \mathrm{C}$ intervals. Abundant crystals were observed at $1149^{\circ} \mathrm{C}$. Samples at $1212^{\circ} \mathrm{C}$ and $1220^{\circ} \mathrm{C}$ appeared to be crystal free by $\mathrm{OM}$. An additional sample, heat treated at $1192^{\circ} \mathrm{C}$ in Furnace \#12, did not contain crystals.

Table 48.1. Heat-Treatment Summary for Determination of $\mathrm{T}_{\mathrm{L}}$ for $\mathrm{AC} 2-48$

\begin{tabular}{ccccccc}
\hline Crucible & Furnace & Date/Time IN & $\mathrm{T}\left({ }^{\circ} \mathrm{C}\right)$ & Date/Time OUT & Observations & Comments \\
\hline 48 & 12 & $4: 15 \mathrm{pm} \mathrm{06/08}$ & 1192 & $2: 45 \mathrm{pm} \mathrm{06/09}$ & No crystals & different furnace \\
48 & 3 & $1: 05 \mathrm{pm} \mathrm{06/28}$ & 1185 & $11: 00 \mathrm{am} \mathrm{06/29}$ & No crystals & \\
48 & 3 & $9: 25 \mathrm{am} \mathrm{06/30}$ & 1179 & $9: 25 \mathrm{am} \mathrm{07/01}$ & No crystals & $\mathrm{T}_{\mathrm{A}}$ \\
48 & 3 & $1: 15 \mathrm{pm} \mathrm{07/10}$ & 1171 & $3: 45 \mathrm{pm} \mathrm{07/11}$ & Crystals throughout & $\mathrm{T}_{\mathrm{C}}$ \\
\hline
\end{tabular}

\subsection{Viscosity}

Table 48.2 lists the measured $\eta-T$ values for $A C 2-48$ in chronological order. These data are shown on an Arrhenius plot ( $\ln \eta$ vs. 1/T) in Figure 48.1. A datum from Table 48.2, at $1482^{\circ} \mathrm{C}$, had a measured $\eta$ value below the instrument's range and was excluded from calculations. The excluded point is plotted as an open circle and listed in strike-through font. Equation (2) was fitted to the remaining data, plotted as filled circles, to yield $\mathrm{E}$ and $\mathrm{F}$ values of -18.693 and $31393 \mathrm{~K}$, respectively. The data appear to be nonlinear. Therefore, a $\eta_{1350}$ value of $1.73 \mathrm{~Pa} \cdot \mathrm{s}$ was obtained by interpolation between the data points at $1334^{\circ} \mathrm{C}$ and $1382^{\circ} \mathrm{C}$ using Equation (2). 
Table 48.2. Viscosity-Temperature Data for AC2-48

\begin{tabular}{cccc}
\hline $\mathrm{T}\left({ }^{\circ} \mathrm{C}\right)$ & $\eta(\mathrm{Pa} \cdot \mathrm{s})$ & $10000 / \mathrm{T}\left(\mathrm{K}^{-1}\right)$ & $\ln [\eta(\mathrm{Pa} \cdot \mathrm{s})]$ \\
\hline 1382 & 1.364 & 6.042 & 0.310 \\
1334 & 1.960 & 6.223 & 0.673 \\
1284 & 3.860 & 6.423 & 1.351 \\
1334 & 1.957 & 6.223 & 0.671 \\
1383 & 1.362 & 6.039 & 0.309 \\
1433 & 0.888 & 5.862 & -0.119 \\
1482 & 0.540 & 5.698 & -0.616 \\
1383 & 1.357 & 6.039 & 0.305 \\
1235 & 8.268 & 6.631 & 2.112 \\
1186 & 20.143 & 6.854 & 3.003 \\
\hline
\end{tabular}

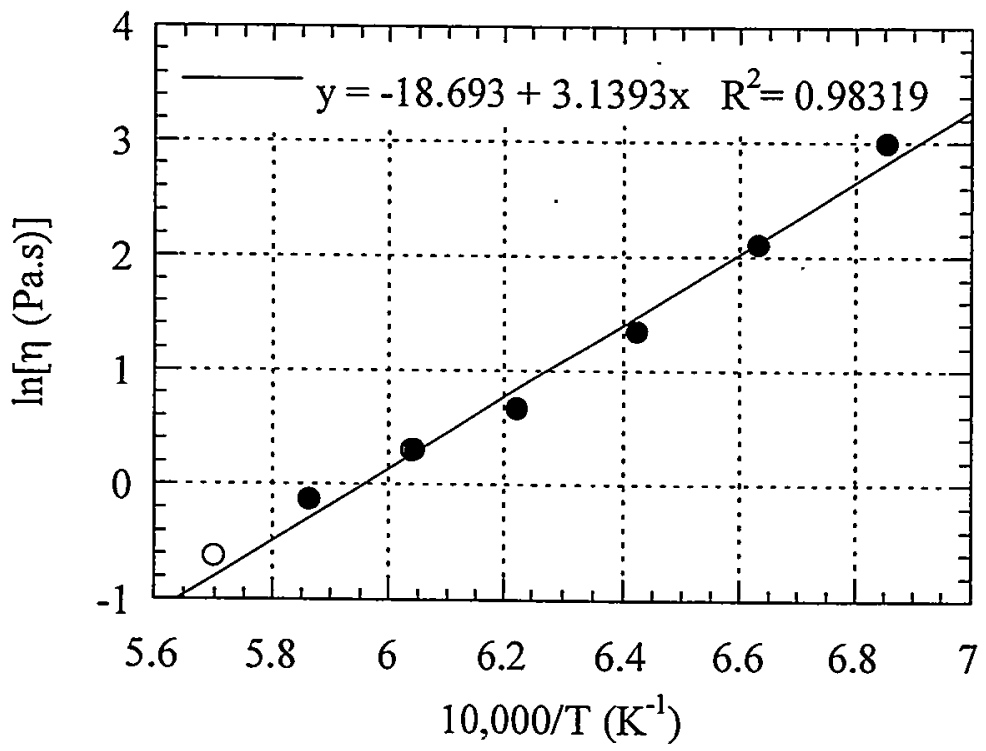

Figure 48.1. Measured ln Viscosity vs. 10000/T for AC2-48 


\subsection{AC2-49}

Glass AC2-49 is an interior point of the designed glass-composition region. This glass targets 52.7 mass percent $\mathrm{Ln}_{2} \mathrm{O}_{3}$ and is a duplicate of glass $\mathrm{AC2}-43$. The ratios of frit components, $\mathrm{SiO}_{2}, \mathrm{Al}_{2} \mathrm{O}_{3}, \mathrm{~B}_{2} \mathrm{O}_{3}$, and $\mathrm{SrO}$, are the same as those in the baseline frit.

\subsection{Liquidus Temperature}

Table 49.1 summarizes the heat treatments performed on this glass. The $T_{L}$ of this glass was estimated at $1220^{\circ} \mathrm{C}$ using Furnace \#12. A sample heat treated at $1219^{\circ} \mathrm{C}$ contained crystals while samples heat treated at $1226^{\circ} \mathrm{C}$ did not. RES crystals formed in samples of this glass heat treated at temperatures below $T_{L}$. These crystals were identified by the characteristic morphologies of the crystals formed below $T_{\mathrm{L}}$. The morphologies matched those observed in samples of AC2-03, AC2-05, and other glasses that were shown by SEM and/or XRD to be RES crystals.

Four preliminary samples were heat treated at temperatures ranging from $1198^{\circ} \mathrm{C}$ to $1251^{\circ} \mathrm{C}$. An additional sample, heat treated in Furnace $\# 3$ at $1242^{\circ} \mathrm{C}$, did not contain crystals.

Table 49.1. Heat-Treatment Summary for Determination of $T_{L}$ for AC2-49

\begin{tabular}{ccccccc}
\hline Crucible Furnace Date/Time IN & $\mathrm{T}\left({ }^{\circ} \mathrm{C}\right)$ & Date/Time OUT & Observations & Comments \\
\hline 49 & 3 & $4: 45 \mathrm{pm} \mathrm{06/08}$ & 1242 & $2: 45 \mathrm{pm} \mathrm{06/09}$ & No crystals & different furnace \\
49 & 12 & $1: 30 \mathrm{pm} \mathrm{06/26}$ & 1233 & $2: 51 \mathrm{pm} \mathrm{06/27}$ & No crystals & \\
49 & 12 & $2: 55 \mathrm{pm} \mathrm{07/03}$ & 1226 & $8: 41 \mathrm{am} \mathrm{07/04}$ & No crystals & $\mathrm{T}_{\mathrm{A}}$ \\
49 & 12 & $1: 15 \mathrm{pm} \mathrm{07/10}$ & 1219 & $3: 46 \mathrm{pm} \mathrm{07/11}$ & One crystal & $\mathrm{T}_{\mathrm{C}}$ \\
49 & 12 & $1: 45 \mathrm{pm} \mathrm{07/14}$ & 1210 & $3: 05 \mathrm{pm} \mathrm{07/15}$ & Crystals throughout & \\
\hline
\end{tabular}

\subsection{Viscosity}

Table 49.2 lists the measured $\eta-T$ values for $\mathrm{AC} 2-43$ in chronological order. These data are shown on an Arrhenius plot $(\ln \eta$ vs. $1 / \mathrm{T})$ in Figure 49.1. Two data points from Table 49.2 were excluded from calculations. One of these points, at $1483^{\circ} \mathrm{C}$, had a measured $\eta$ value below the instrument's range while the other, at $1186^{\circ} \mathrm{C}$, was taken at a $\mathrm{T}$ below $\mathrm{T}_{\mathrm{L}}$. The excluded data are plotted as open circles and listed in strike-through font. Equation (2) was fitted to the remaining data, plotted as filled circles, to yield $E$ and $F$ values of -16.762 and $27886 \mathrm{~K}$, respectively. The data appear to be nonlinear. Therefore, a $\eta_{1350}$ value of $1.46 \mathrm{~Pa} \cdot \mathrm{s}$ was obtained by interpolation between the data points at $1334^{\circ} \mathrm{C}$ and $1383^{\circ} \mathrm{C}$ using Equation (2). 
Table 49.2. Viscosity-Temperature Data for AC2-49

\begin{tabular}{cccc}
\hline $\mathrm{T}\left({ }^{\circ} \mathrm{C}\right)$ & $\eta(\mathrm{Pa} \cdot \mathrm{s})$ & $10000 / \mathrm{T}\left(\mathrm{K}^{-1}\right)$ & $\ln [\eta(\mathrm{Pa} \cdot \mathrm{s})]$ \\
\hline 1383 & 1.101 & 6.039 & 0.096 \\
1334 & 1.541 & 6.223 & 0.432 \\
1285 & 2.975 & 6.418 & 1.090 \\
1334 & 1.528 & 6.223 & 0.424 \\
1384 & 1.128 & 6.035 & 0.121 \\
1433 & 0.732 & 5.862 & -0.312 \\
1483 & 0.455 & 5.695 & -0.789 \\
1384 & 1.106 & 6.035 & 0.100 \\
1236 & 6.568 & 6.627 & 1.882 \\
1186 & 15.533 & 6.854 & 2.743 \\
\hline
\end{tabular}

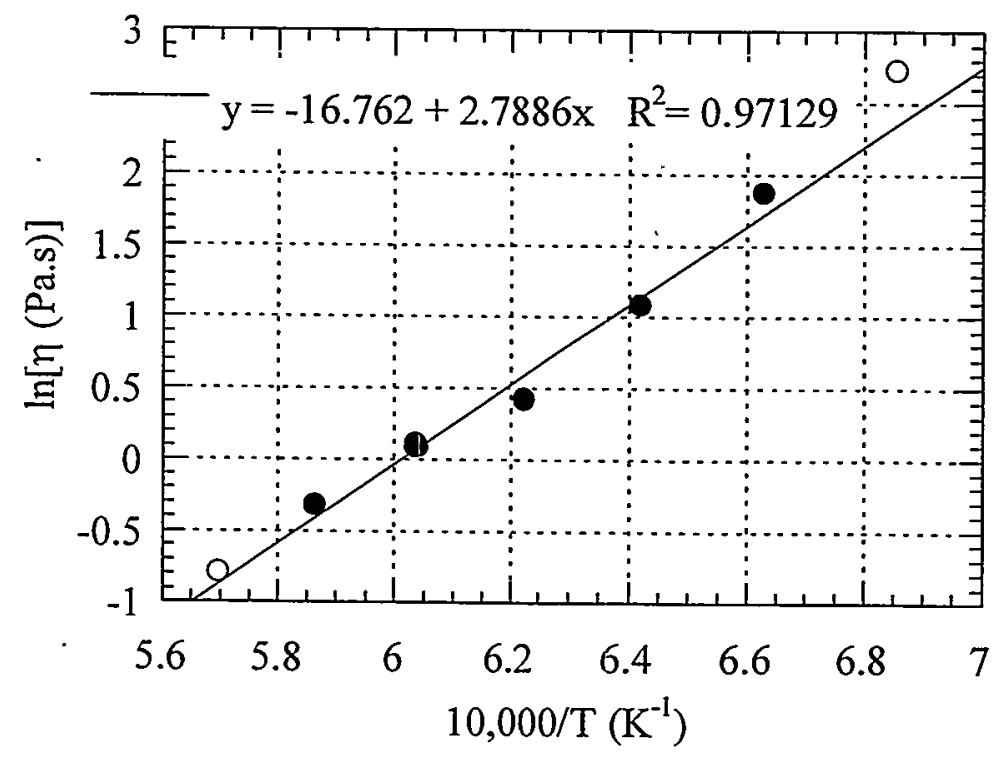

Figure 49.1. Measured ln Viscosity vs. 10000/T for AC2-49 


\section{$50.0 \quad$ AC2-50}

Glass $\mathrm{AC} 2-50$ is an interior point of the designed glass-composition region. This glass targets 56.4 mass percent $\mathrm{Ln}_{2} \mathrm{O}_{3}$ and is a duplicate of glass $\mathrm{AC} 2-33$ with a spike of minor components. The ratios of frit components, $\mathrm{SiO}_{2}, \mathrm{Al}_{2} \mathrm{O}_{3}, \mathrm{~B}_{2} \mathrm{O}_{3}$, and $\mathrm{SrO}$, are the same as those in the baseline frit.

\subsection{Liquidus Temperature}

Table 50.1 summarizes the heat treatments performed on this glass. The $T_{L}$ of this glass was estimated at $1272^{\circ} \mathrm{C}$ using Furnace $\# 12$. A sample heat treated at $1265^{\circ} \mathrm{C}$ contained crystals while samples heat treated at $1274^{\circ} \mathrm{C}$ did not. RES crystals formed in samples of this glass heat treated at temperatures below $T_{L}$. These crystals were identified by the characteristic morphologies of the crystals formed below $\mathrm{T}_{\mathrm{L}}$. The morphologies matched those observed in samples of AC2-03, AC2-05, and other glasses that were shown by SEM and/or XRD to be RES crystals. During the $1265^{\circ} \mathrm{C}, 1273^{\circ} \mathrm{C}$ (Furnace \#8), and $1274^{\circ} \mathrm{C}$ heat treatments, small nodules or buds of glass formed at the upper edge of the $\mathrm{Pt} / \mathrm{Rh}$ box folds.

Five preliminary heat treatments were performed between $1227^{\circ} \mathrm{C}$ and $1275^{\circ} \mathrm{C}$ at approximately $20^{\circ} \mathrm{C}$ intervals. Abundant crystals were observed at $1227^{\circ} \mathrm{C}$ and $1233^{\circ} \mathrm{C}$. The sample at $1275^{\circ} \mathrm{C}$ appeared to be crystal free by $\mathrm{OM}$.

Table 50.1. Heat-Treatment Summary for Determination of $T_{L}$ for AC2-50

\begin{tabular}{ccccccc}
\hline Crucible & Furnace & Date/Time IN & $\mathrm{T}\left({ }^{\circ} \mathrm{C}\right)$ & Date/Time OUT & Observations & Comments \\
\hline 50 & 12 & $5: 00 \mathrm{pm} \mathrm{06/17}$ & 1260 & $3: 00 \mathrm{pm} \mathrm{06/18}$ & Crystals throughout & \\
50 & 8 & $3: 00 \mathrm{pm} \mathrm{06/25}$ & 1273 & $1: 25 \mathrm{pm} \mathrm{06/26}$ & No crystals & different furnace, Buds \\
50 & 12 & $2: 55 \mathrm{pm} \mathrm{06/27}$ & 1265 & $1: 00 \mathrm{pm} \mathrm{06/28}$ & Crystals throughout & $\mathrm{T}_{\mathrm{C}}$, Buds \\
50 & 12 & $8: 50 \mathrm{am} \mathrm{07/05}$ & 1274 & $8: 51 \mathrm{am} \mathrm{07/06}$ & No crystals & $\mathrm{T}_{\mathrm{A}}$, Buds \\
\hline
\end{tabular}

\subsection{Viscosity}

Table 50.2 lists the measured $\eta-\mathrm{T}$ values for AC2-50 in chronological order. These data are shown on an Arrhenius plot ( $\ln \eta$ vs. 1/T) in Figure 50.1. Two data points from Table 50.2 were excluded from calculations. One of these points, at $1434^{\circ} \mathrm{C}$, had measured $\eta$ value below the instrument's range while the other, at $1236^{\circ} \mathrm{C}$, was taken at a $\mathrm{T}$ below $\mathrm{T}_{\mathrm{L}}$. The excluded data are plotted as open circles and listed in strike-through font. Equation (2) was fitted to the remaining data, shown as solid circles, to yield $\mathrm{E}$ and $\mathrm{F}$ values of -14.338 and $23449 \mathrm{~K}$, respectively. This fit, which accurately portrays the data, was then used to calculate a $\eta_{1350}$ value of $1.12 \mathrm{~Pa} \cdot \mathrm{s}$. 
Table 50.2. Viscosity-Temperature Data for $\mathrm{AC} 2-50$

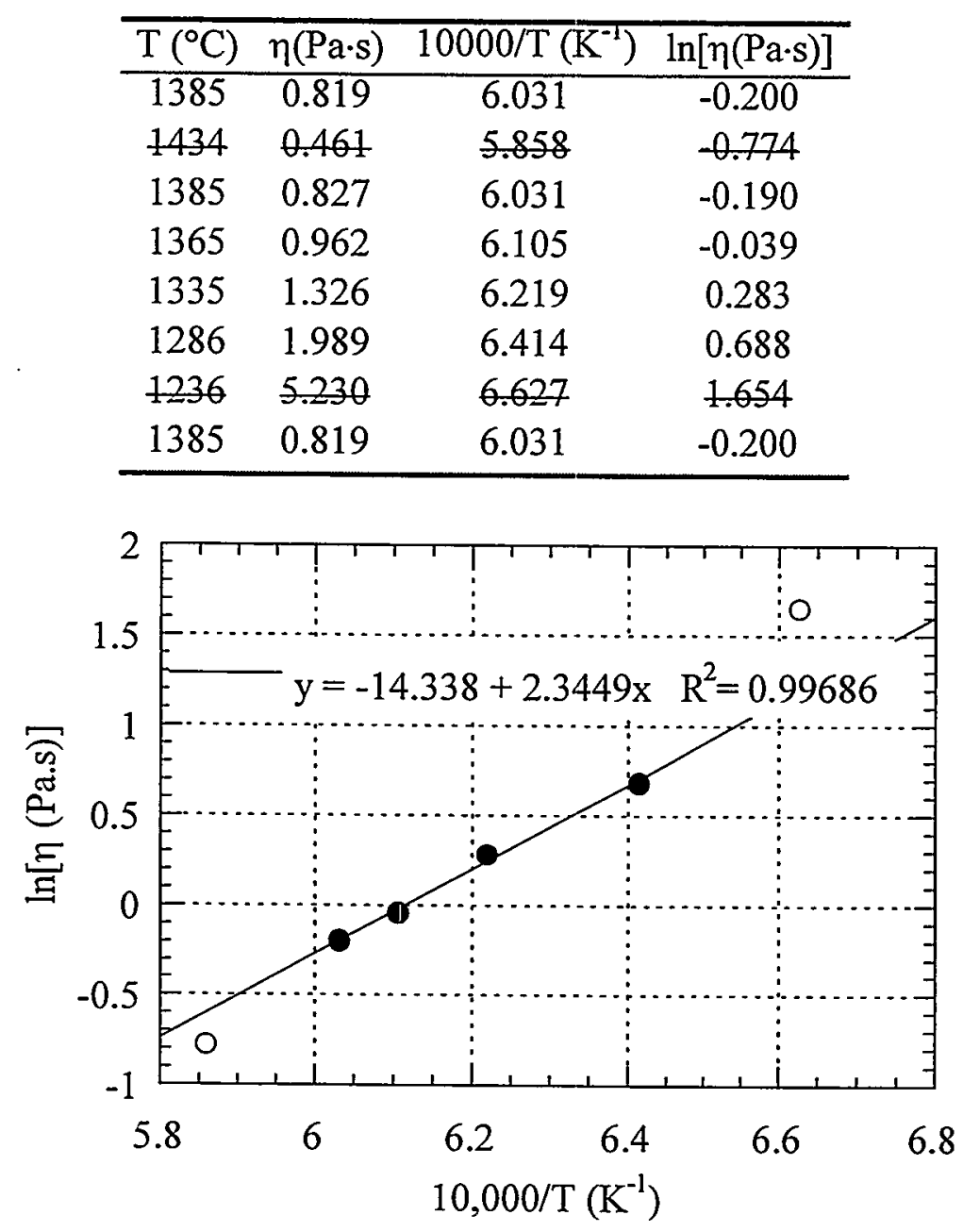

Figure 50.1. Measured ln Viscosity vs. 10000/T for $\mathrm{AC} 2-50$ 


\section{$51.0 \quad$ AC2-51}

Glass AC2-51 is an interior point of the designed glass-composition region. This glass targets 60.2 mass percent $\mathrm{Ln}_{2} \mathrm{O}_{3}$ and is a duplicate of glass $\mathrm{AC2}-38$ with a spike of minor components. The ratios of frit components, $\mathrm{SiO}_{2}, \mathrm{Al}_{2} \mathrm{O}_{3}, \mathrm{~B}_{2} \mathrm{O}_{3}$, and $\mathrm{SrO}$, are the same as those in the baseline frit.

\subsection{Liquidus Temperature}

Table 51.1 summarizes the heat treatments performed on this glass. The $T_{L}$ of this glass was estimated at $1305^{\circ} \mathrm{C}$ using Furnace \#3. A sample heat treated at $1300^{\circ} \mathrm{C}$ contained crystals while a sample heat treated at $1307^{\circ} \mathrm{C}$ did not. RES crystals formed in samples of this glass heat treated at temperatures below $\mathrm{T}_{\mathrm{L}}$. These crystals were identified by the characteristic morphologies of the crystals formed below $T_{L}$. The morphologies matched those observed in samples of AC2-03, AC2-05, and other glasses that were shown by SEM and/or XRD to be RES crystals.

Five preliminary heat treatments were performed between $1227^{\circ} \mathrm{C}$ and $1313^{\circ} \mathrm{C}$ at approximately $50^{\circ} \mathrm{C}$ intervals. Abundant crystals were observed at $1227^{\circ} \mathrm{C}$ and $1275^{\circ} \mathrm{C}$. The sample at $1313^{\circ} \mathrm{C}$ appeared to be crystal free by $\mathrm{OM}$. Additional samples, heat treated at $1306^{\circ} \mathrm{C}$ (Furnace \#8) and $1312^{\circ} \mathrm{C}$ (Furnace \#12), did not contain crystals.

Table 51.1. Heat-Treatment Summary for Determination of $T_{L}$ for $A C 2-51$

\begin{tabular}{ccccccc}
\hline Crucible & Furnace & Date/Time IN & T $\left({ }^{\circ} \mathrm{C}\right)$ & Date/Time OUT & Observations & Comments \\
\hline 51 & 3 & $1: 35 \mathrm{pm} \mathrm{06/19}$ & 1300 & $2: 09 \mathrm{pm} \mathrm{06/20}$ & Very crystalline & $\mathrm{T}_{\mathrm{C}}$ \\
51 & 12 & $3: 40 \mathrm{pm} \mathrm{06/21}$ & 1312 & $3: 30 \mathrm{pm} \mathrm{06/22}$ & No crystals & different furnace \\
51 & 8 & $11: 00 \mathrm{am} \mathrm{06/29}$ & 1306 & $9: 20 \mathrm{am} \mathrm{06/30}$ & No crystals & different furnace \\
51 & 3 & $1: 15 \mathrm{pm} \mathrm{07/08}$ & 1307 & $11: 15 \mathrm{am} \mathrm{07/09}$ & No crystals & $\mathrm{T}_{\mathrm{A}}$ \\
\hline
\end{tabular}

\subsection{Viscosity}

Table 51.2 lists the measured $\eta-\mathrm{T}$ values for AC2-51 in chronological order. These data are shown on an Arrhenius plot ( $\ln \eta$ vs. 1/T) in Figure 51.1. A datum from Table 51.2, at $1403^{\circ} \mathrm{C}$, had a measured $\eta$ value below the instrument's range and was excluded from calculations. The excluded point is shown as an open circle and listed in strike-through font. Equation (2) was fitted to the remaining data, shown as solid circles, to yield $E$ and $F$ values of 16.473 and $26651 \mathrm{~K}$, respectively. This fit, which accurately portrays the data, was then used to calculate a $\eta_{1350}$ value of $0.95 \mathrm{~Pa} \cdot \mathrm{s}$. 
Table 51.2. Viscosity-Temperature Data for $\mathrm{AC} 2-51$

\begin{tabular}{cccc}
\hline $\mathrm{T}\left({ }^{\circ} \mathrm{C}\right)$ & $\eta(\mathrm{Pa} \cdot \mathrm{s})$ & $10000 / \mathrm{T}\left(\mathrm{K}^{-1}\right)$ & $\ln [\eta(\mathrm{Pa} \cdot \mathrm{s})]$ \\
\hline 1383 & 0.672 & 6.039 & -0.397 \\
1403 & 0.548 & 5.967 & 0.601 \\
1384 & 0.675 & 6.035 & -0.393 \\
1365 & 0.830 & 6.105 & -0.186 \\
1345 & 1.009 & 6.180 & 0.009 \\
1325 & 1.218 & 6.258 & 0.198 \\
1305 & 1.510 & 6.337 & 0.412 \\
1384 & 0.680 & 6.035 & -0.385 \\
\hline
\end{tabular}

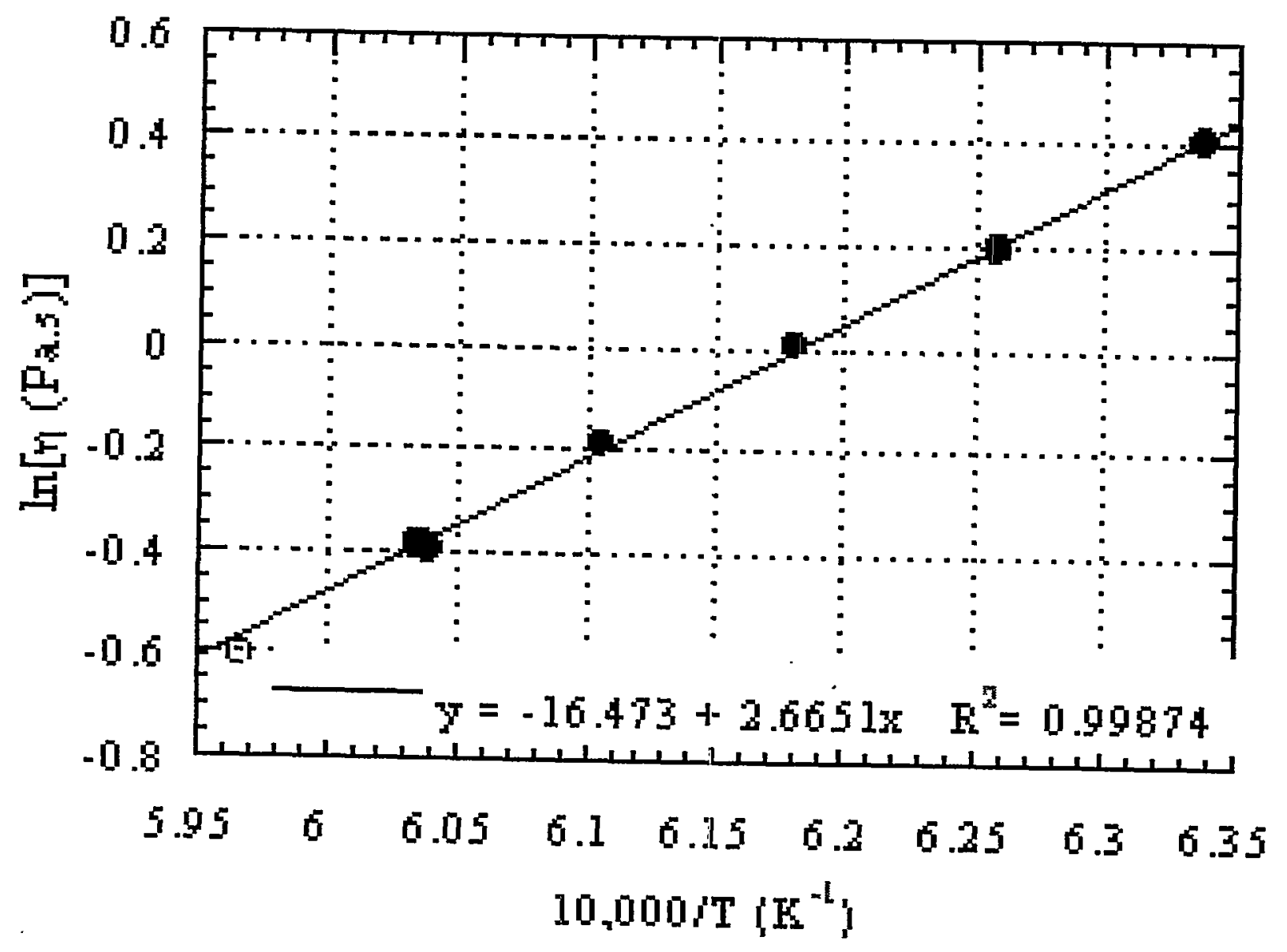

Figure 51.1. Measured ln Viscosity vs. 10000/T for AC2-51 


\section{$52.0 \quad$ AC2-52}

Glass AC2-52 is an interior point of the designed glass-composition region. This glass targets 49.0 mass percent $\mathrm{Ln}_{2} \mathrm{O}_{3}$ and is a duplicate of glass $\mathrm{AC} 2-42$ with a spike of minor components. The ratios of frit components, $\mathrm{SiO}_{2}, \mathrm{Al}_{2} \mathrm{O}_{3}, \mathrm{~B}_{2} \mathrm{O}_{3}$, and $\mathrm{SrO}$, are the same as those in the baseline frit.

\subsection{Liquidus Temperature}

Table 52.1 summarizes the heat treatments performed on this glass using Furnace \#3. The $\mathrm{T}_{\mathrm{L}}$ of this glass was estimated at $1153^{\circ} \mathrm{C}$ since a sample heat treated at $1150^{\circ} \mathrm{C}$ contained crystals while samples heat treated at $1158^{\circ} \mathrm{C}$ did not. RES crystals formed in samples of this glass heat treated at temperatures below $T_{L}$. These crystals were identified by the characteristic morphologies of the crystals formed below $T_{L}$. The morphologies matched those observed in samples of AC2-03, AC2-05, and other glasses that were shown by SEM and/or XRD to be RES crystals.

Five preliminary samples were heat treated at temperatures ranging from $1111^{\circ} \mathrm{C}$ to $1227^{\circ} \mathrm{C}$.

Table 52.1. Heat-Treatment Summary for Determination of $T_{L}$ for $A C 2-52$

\begin{tabular}{|c|c|c|c|c|c|c|}
\hline Crucible & Furnace & Date/Time IN & $\mathrm{T}\left({ }^{\circ} \mathrm{C}\right)$ & Date/Time OUT & Observations & Comments \\
\hline 52 & 3 & $2: 18 \mathrm{pm} 06 / 20$ & 1173 & $1: 00 \mathrm{pm} \mathrm{06/21}$ & No crystals & \\
\hline 52 & 3 & $2: 00 \mathrm{pm} 07 / 02$ & 1164 & $1: 55 \mathrm{pm} 07 / 03$ & No crystals & \\
\hline 52 & 3 & 2:30pm 07/07 & 1158 & $1: 10 \mathrm{pm} 07 / 08$ & No crystals & $\mathrm{T}_{\mathrm{A}}$ \\
\hline 52 & 3 & $4: 30 \mathrm{pm} 07 / 15$ & 1150 & $2: 37 \mathrm{pm} 07 / 16$ & Very crystalline & $\mathrm{T}_{\mathrm{C}}$ \\
\hline 52 & 3 & $2: 45 \mathrm{pm} 07 / 23$ & 1144 & $12: 45 \mathrm{pm} 07 / 24$ & Few crystals & \\
\hline
\end{tabular}

\subsection{Viscosity}

Table 52.2 lists the measured $\eta-\mathrm{T}$ values for $\mathrm{AC} 2-52$ in chronological order. These data are shown on an Arrhenius plot (ln $\eta$ vs. $1 / \mathrm{T}$ ) in Figure 52.1 . With a $\mathrm{T}_{\mathrm{L}}$ of $1153^{\circ} \mathrm{C}$, all the data in Table 52.2 are valid for calculations. Equation (2) was fitted to the remaining data, plotted as filled circles, to yield $E$ and $F$ values of -17.425 and $29700 \mathrm{~K}$, respectively. The data appear to be nonlinear. Therefore, a $\eta_{1350}$ value of $2.17 \mathrm{~Pa} \cdot \mathrm{s}$ was obtained by interpolation between the data points at $1333^{\circ} \mathrm{C}$ and $1382^{\circ} \mathrm{C}$ using Equation (2). 
Table 52.2. Viscosity-Temperature Data for $\mathrm{AC} 2-52$

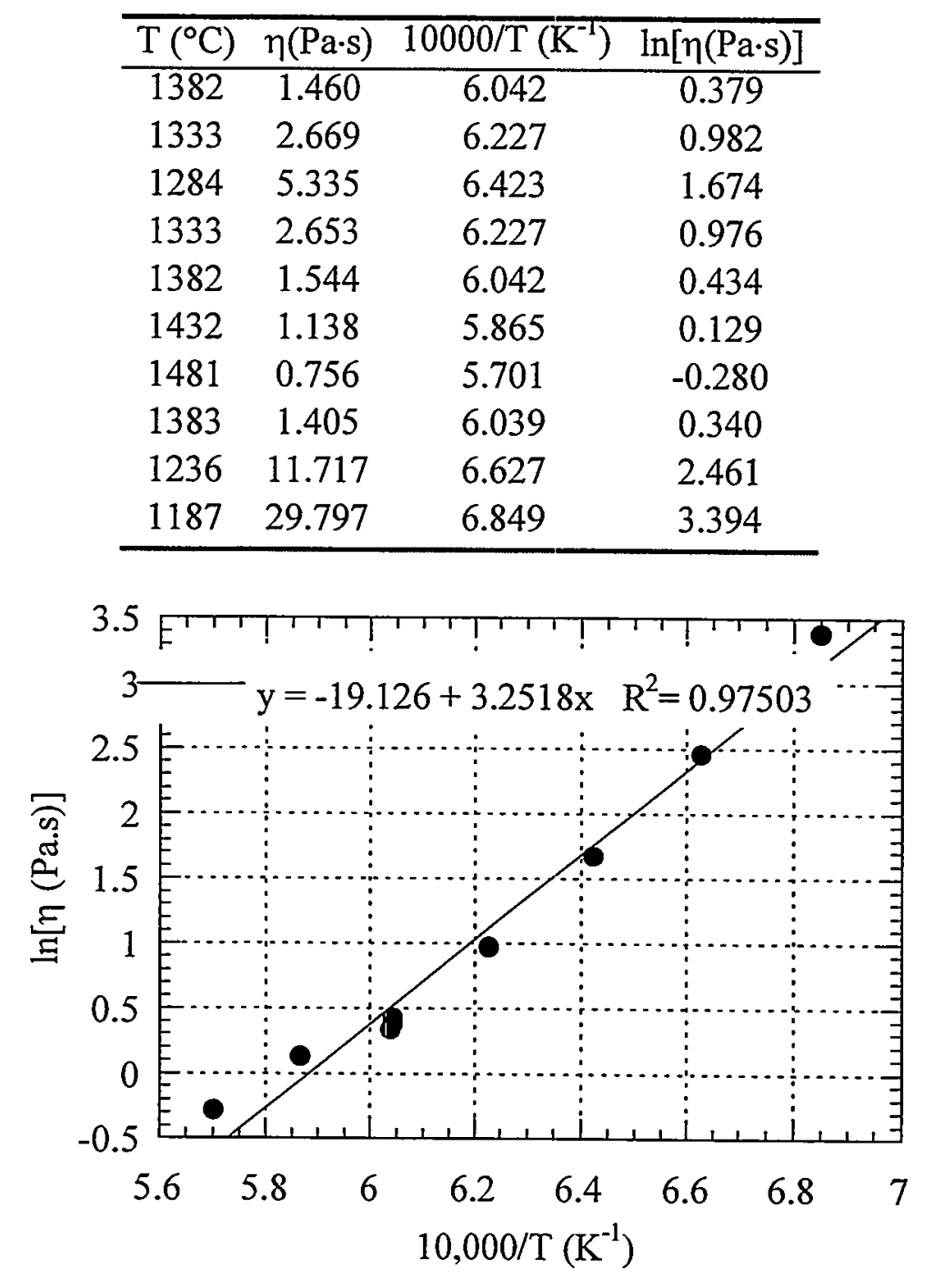

Figure 52.1. Measured ln Viscosity vs. 10000/T for AC2-52 


\subsection{AC2-53}

Glass AC2-53 is an interior point of the designed glass-composition region. This glass targets 52.7 mass percent $\mathrm{Ln}_{2} \mathrm{O}_{3}$ and is a duplicate of glass $\mathrm{AC2}-43$ with a spike of minor components. The ratios of frit components, $\mathrm{SiO}_{2}, \mathrm{Al}_{2} \mathrm{O}_{3}, \mathrm{~B}_{2} \mathrm{O}_{3}$, and $\mathrm{SrO}$, are the same as those in the baseline frit.

\subsection{Liquidus Temperature}

Table 53.1 summarizes the heat treatments performed on this glass using Furnace \#3. The $\mathrm{T}_{\mathrm{L}}$ of this glass was estimated at $1192^{\circ} \mathrm{C}$ since a sample heat treated at $1191^{\circ} \mathrm{C}$ contained crystals while a sample heat treated at $1197^{\circ} \mathrm{C}$ did not. RES crystals formed in samples of this glass heat treated at temperatures below $T_{L}$. These crystals were identified by the characteristic morphologies of the crystals formed below $T_{L}$. The morphologies matched those observed in samples of AC2-03, AC2-05, and other glasses that were shown by SEM and/or XRD to be RES crystals.

Five preliminary samples were heat treated at temperatures ranging from $1149^{\circ} \mathrm{C}$ to $1227^{\circ} \mathrm{C}$.

Table 53.1. Heat-Treatment Summary for Determination of $T_{L}$ for $A C 2-53$

\begin{tabular}{|c|c|c|c|c|c|c|}
\hline Crucible & Furnace & Date/Time IN & $\mathrm{T}\left({ }^{\circ} \mathrm{C}\right)$ & Date/Time OUT & Observations & Comments \\
\hline 53 & 3 & $2: 18 \mathrm{pm} \mathrm{06/20}$ & 1173 & $1: 00 \mathrm{pm} \mathrm{06/21}$ & Crystals throughout & \\
\hline 53 & 3 & $1: 05 \mathrm{pm} \mathrm{06/28}$ & 1185 & 11:00am 06/29 & Few crystals & \\
\hline 53 & 3 & 9:25am 06/30 & 1179 & $9: 25 \mathrm{am} 07 / 01$ & Crystals throughout & \\
\hline 53 & 3 & 3:30pm 07/12 & 1191 & $2: 45 \mathrm{pm} 07 / 13$ & Few crystals & $\mathrm{T}_{\mathrm{C}}$ \\
\hline 53 & 3 & $4: 36 \mathrm{pm} 07 / 18$ & 1197 & $2: 42 \mathrm{pm} \mathrm{07/19}$ & No crystals & $\mathrm{T}_{\mathrm{A}}$ \\
\hline
\end{tabular}

\subsection{Viscosity}

Table 53.2 lists the measured $\eta-T$ values for AC2-53 in chronological order. These data are shown on an Arrhenius plot ( $\ln \eta$ vs. 1/T) in Figure 53.1. A datum from Table 53.2, at $1187^{\circ} \mathrm{C}$, was taken at a $\mathrm{T}$ below $\mathrm{T}_{\mathrm{L}}$ and was excluded from calculations. The excluded point was plotted as an open circle and listed in strike-through font. Equation (2) was fitted to the remaining data, plotted as filled circles, to yield $E$ and $F$ values of -16.316 and $27609 \mathrm{~K}$, respectively. The data appear to be nonlinear. Therefore, a $\eta_{1350}$ value of $1.76 \mathrm{~Pa} \cdot \mathrm{s}$ was obtained by interpolation between the data points at $1334^{\circ} \mathrm{C}$ and $1383^{\circ} \mathrm{C}$ using Equation (2). 
Table 53.2. Viscosity-Temperature Data for $\mathrm{AC} 2-53$

\begin{tabular}{cccc}
\hline $\mathrm{T}\left({ }^{\circ} \mathrm{C}\right)$ & $\eta(\mathrm{Pa} \cdot \mathrm{s})$ & $10000 / \mathrm{T}\left(\mathrm{K}^{-1}\right)$ & $\ln [\eta(\mathrm{Pa} \cdot \mathrm{s})]$ \\
\hline 1383 & 1.381 & 6.039 & 0.323 \\
1334 & 1.973 & 6.223 & 0.679 \\
1285 & 4.110 & 6.418 & 1.413 \\
1334 & 1.976 & 6.223 & 0.681 \\
1383 & 1.426 & 6.039 & 0.355 \\
1433 & 0.933 & 5.862 & -0.069 \\
1482 & 0.637 & 5.698 & -0.452 \\
1384 & 1.397 & 6.035 & 0.335 \\
1237 & 8.800 & 6.623 & 2.175 \\
1187 & 21.597 & 6.849 & 3.073 \\
\hline
\end{tabular}

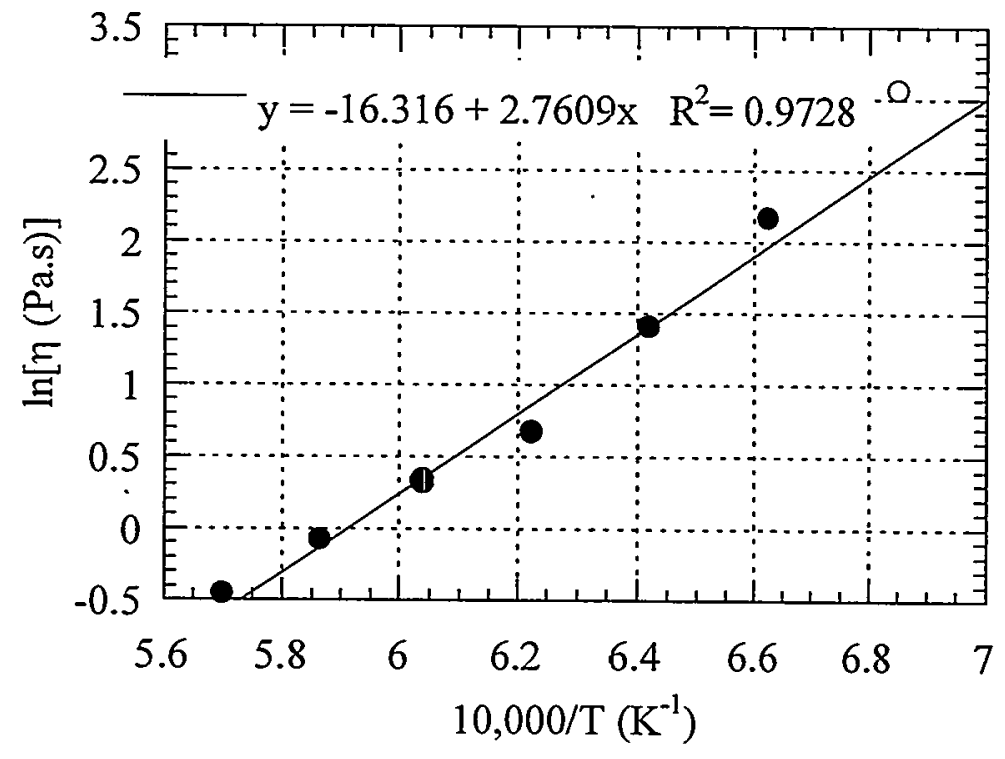

Figure 53.1. Measured ln Viscosity vs. 10000/T for AC2-53 


\section{$54.0 \quad \mathrm{AC} 2-54$}

Glass AC2-54 is an interior point of the designed glass-composition region. This glass targets 63.9 mass percent $\mathrm{Ln}_{2} \mathrm{O}_{3}$ and is a duplicate of glass $\mathrm{AC} 2-44$ with a spike of minor components. The ratios of frit components, $\mathrm{SiO}_{2}, \mathrm{Al}_{2} \mathrm{O}_{3}, \mathrm{~B}_{2} \mathrm{O}_{3}$, and $\mathrm{SrO}$, are the same as those in the baseline frit.

\subsection{Liquidus Temperature}

Table 54.1 summarizes the heat treatments performed on this glass using Furnace \#3. The $T_{L}$ of this glass was estimated at $1326^{\circ} \mathrm{C}$ since a sample heat treated at $1321^{\circ} \mathrm{C}$ contained crystals while a sample heat treated at $1328^{\circ} \mathrm{C}$ did not. RES crystals formed in samples of this glass heat treated at temperatures below $\mathrm{T}_{\mathrm{L}}$. The primary phase was identified by the characteristic morphologies of the crystals formed below $\mathrm{T}_{\mathrm{L}}$. The morphologies matched those observed in samples of AC2-03, AC2-05, and other glasses that were shown by SEM and/or $\mathrm{XRD}$ to be RES crystals. $1334^{\circ} \mathrm{C}$.

Five preliminary samples were heat treated at temperatures ranging from $1227^{\circ} \mathrm{C}$ to

Table 54.1. Heat-Treatment Summary for Determination of $\mathrm{T}_{\mathrm{L}}$ for AC2-54

\begin{tabular}{ccccccc}
\hline \multicolumn{2}{c}{ Crucible Furnace } & Date/Time IN & $\mathrm{T}\left({ }^{\circ} \mathrm{C}\right)$ & Date/Time OUT & Observations & Comments \\
\hline 54 & 3 & $1: 30 \mathrm{pm} \mathrm{06/26}$ & 1335 & $2: 52 \mathrm{pm} \mathrm{06/27}$ & No crystals & \\
54 & 3 & $11: 00 \mathrm{am} \mathrm{06/29}$ & 1314 & $9: 20 \mathrm{am} \mathrm{06/30}$ & Very crystalline & \\
54 & 3 & $3: 00 \mathrm{pm} \mathrm{07/14}$ & 1321 & $3: 05 \mathrm{pm} \mathrm{07/15}$ & Weird crystals & $\mathrm{T}_{\mathrm{C}}$, Buds \\
54 & 3 & $3: 34 \mathrm{pm} \mathrm{07/16}$ & 1328 & $3: 44 \mathrm{pm} \mathrm{07/17}$ & No crystals & $\mathrm{T}_{\mathrm{A}}$, Buds \\
\hline
\end{tabular}

\subsection{Viscosity}

Table 54.2 lists the measured $\eta$-T values for $\mathrm{AC} 2-54$ in chronological order. These data are shown on an Arrhenius plot ( $\ln \eta$ vs. 1/T) in Figure 54.1. A datum from Table 54.2, at $1404^{\circ} \mathrm{C}$, had a measured $\eta$ value below the instrument's range and was excluded from the calculations. The excluded point is shown as an open circle and listed in strike-through font. Equation (2) was fitted to the remaining data, shown as solid circles, to yield $\mathrm{E}$ and $\mathrm{F}$ values of 17.617 and $28349 \mathrm{~K}$, respectively. This fit, which accurately portrays the data, was then used to calculate a $\eta_{1350}$ value of $0.86 \mathrm{~Pa} \cdot \mathrm{s}$. 
Table 54.2. Viscosity-Temperature Data for $\mathrm{AC} 2-54$

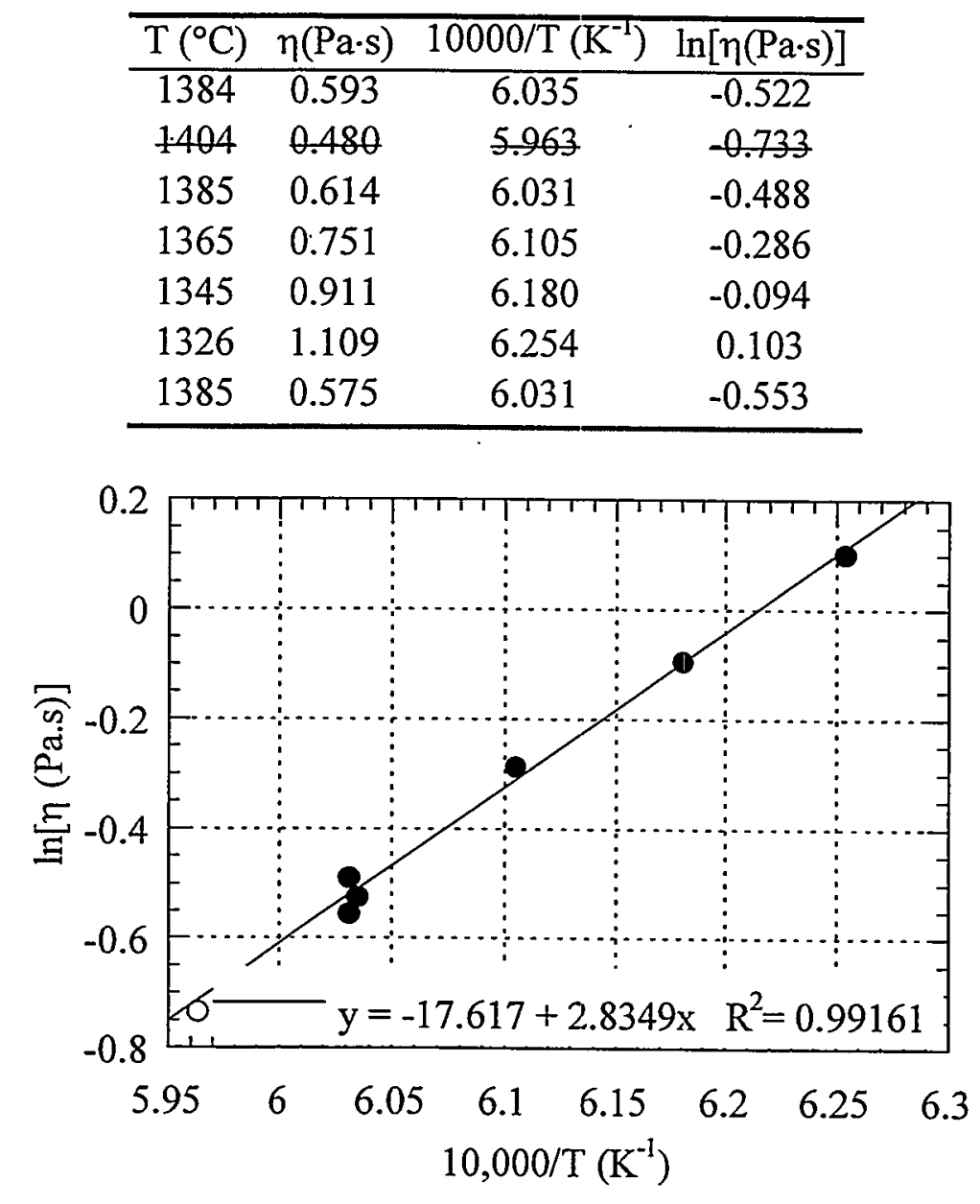

Figure 54.1. Measured ln Viscosity vs. 10000/T for $\mathrm{AC} 2-54$ 


\section{$55.0 \quad$ AC2-55}

Glass AC2-55 is an interior point of the designed glass-composition region. This glass targets 56.5 mass percent $\mathrm{Ln}_{2} \mathrm{O}_{3}$, with double the $\mathrm{Ce}_{2} \mathrm{O}_{3}$ as compared to the normal feed. The $\mathrm{Ce}_{2} \mathrm{O}_{3}$ doubling was achieved by replacing $\mathrm{Nd}_{2} \mathrm{O}_{3}$ in the glass. The ratios of frit components, $\mathrm{SiO}_{2}, \mathrm{Al}_{2} \mathrm{O}_{3}, \mathrm{~B}_{2} \mathrm{O}_{3}$, and $\mathrm{SrO}$, are the same as those in the baseline frit.

\subsection{Liquidus Temperature}

Table 55.1 summarizes the heat treatments performed on this glass. The $T_{L}$ of this glass was estimated at $1255^{\circ} \mathrm{C}$ using Furnace $\# 8$. A sample heat treated at $1249^{\circ} \mathrm{C}$ contained crystals while a sample heat treated at $1257^{\circ} \mathrm{C}$ did not. RES crystals formed in samples of this glass heat treated at temperatures below $T_{L}$. These crystals were identified by the characteristic morphologies of the crystals formed below $T_{L}$. The morphologies matched those observed in samples of AC2-03, AC2-05, and other glasses that were shown by SEM and/or XRD to be RES crystals.

Three preliminary samples were heat treated at temperatures ranging from $1226^{\circ} \mathrm{C}$ to $1251^{\circ} \mathrm{C}$. An additional sample was heat treated at $1242^{\circ} \mathrm{C}$ in Furnace \#3. This sample contained crystals.

Table 55.1. Heat-Treatment Summary for Determination of $T_{L}$ for $A C 2-55$

\begin{tabular}{|c|c|c|c|c|c|c|}
\hline Crucible & Furnace & $\overline{\text { Date/Time IN }}$ & $\mathrm{T}\left({ }^{\circ} \mathrm{C}\right)$ & Date/Time OUT & Observations & Comments \\
\hline 55 & 3 & $4: 45 \mathrm{pm} 06 / 08$ & 1242 & $2: 45 \mathrm{pm} 06 / 09$ & Lots of crystals & different furnace \\
\hline 55 & 8 & $2: 00 \mathrm{pm} 06 / 22$ & 1249 & $12: 35 \mathrm{pm} 06 / 23$ & Lots of crystals & $\mathrm{T}_{\mathrm{C}}$ \\
\hline 55 & 8 & 8:45am 07/04 & 1257 & 8:43am 07/05 & No crystals & $\mathrm{T}_{\mathrm{A}}$, Buds \\
\hline 55 & 8 & $4: 00 \mathrm{pm} 07 / 12$ & 1264 & $2: 45 \mathrm{pm} 07 / 13$ & No crystals & \\
\hline
\end{tabular}

\subsection{Viscosity}

Table 55.2 lists the measured $\eta$-T values for $\mathrm{AC} 2-55$ in chronological order. These data are shown on an Arrhenius plot ( $\ln \eta$ vs. 1/T) in Figure 55.1. Two data points from Table 55.2 were excluded from calculations. One of these points, at $1434^{\circ} \mathrm{C}$, had measured $\eta$ value below the instrument's range while the other, at $1237^{\circ} \mathrm{C}$, was taken at a $\mathrm{T}$ below $\mathrm{T}_{\mathrm{L}}$. The excluded data are plotted as open circles and listed in strike-through font. Equation (2) was fitted to the remaining data, plotted as filled circles, to yield $\mathrm{E}$ and $\mathrm{F}$ values of -5.474 and $8887 \mathrm{~K}$, respectively. The data appear to be highly nonlinear. Therefore, a $\eta_{1350}$ value of $1.14 \mathrm{~Pa} \cdot \mathrm{s}$ was obtained by interpolation between the data points at $1335^{\circ} \mathrm{C}$ and $1384^{\circ} \mathrm{C}$ using Equation (2). 
Table 55.2. Viscosity-Temperature Data for AC2-55

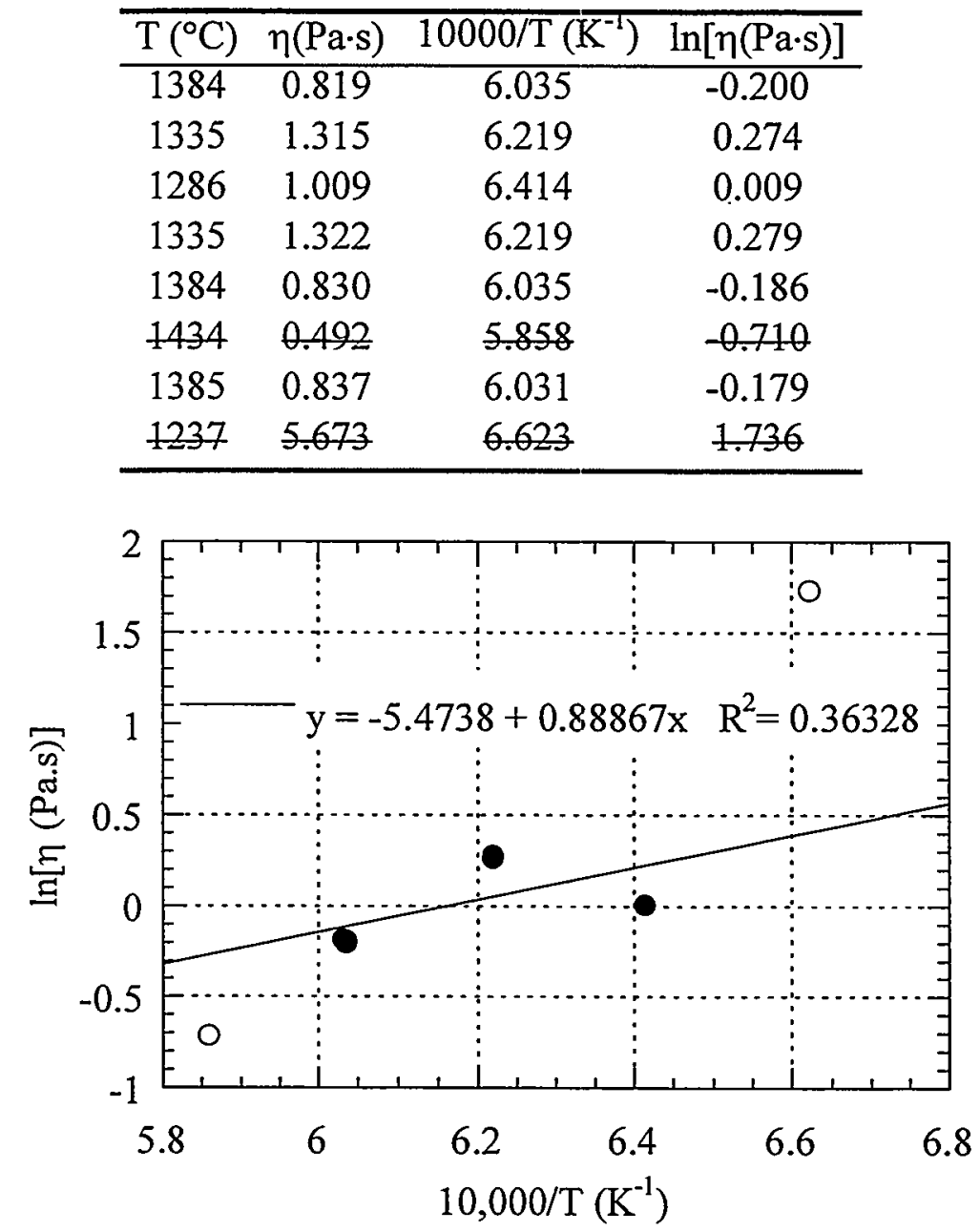

Figure 55.1. Measured ln Viscosity vs. 10000/T for AC2-55 